CONTRACTOR REPORT

SAND98-1714

Unlimited Release
MS 0619

OCT 261998

\title{
Database of Mechanical and Hydrological Properties of WIPP Anhydrite Derived from Laboratory-Scale Experiments
}

T. W. Pfeifle

RE/SPEC Inc.

P.O. Box 725

Rapid City, South Dakota 57709-0725

F. D. Hansen

Carlsbad Operations

Sandia National Laboratories

P.O. Box 5800

Albuquerque, New Mexico 87185-1395

Prepared by

Sandia National Laboratories

Albuquerque, New Mexico 87185 and Livermore, California 94550

Sandia is a multiprogram laboratory operated by Sandia Corporation, a Lockheed Martin Company, for the United States Department of Energy under Contract DE-AC04-94AL85000.

Approved for public release; distribution is unlimited.

Printed October 1998 
Issued by Sandia National Laboratories, operated for the United States Department of Energy by Sandia Corporation.

NOTICE: This report was prepared as an account of work sponsored by an agency of the United States Government. Neither the United States Government, nor any agency thereof, nor any of their employees, nor any of their contractors, subcontractors, or their employees, make any warranty, express or implied, or assume any legal liability or responsibility for the accuracy, completeness, or usefulness of any information, apparatus, product, or process disclosed, or represent that its use would not infringe privately owned rights. Reference herein to any specific commercial product, process, or service by trade name, trademark, manufacturer, or otherwise, does not necessarily constitute or imply its endorsement, recommendation, or favoring by the United States Government, any agency thereof, or any of their contractors or subcontractors. The views and opinions expressed herein do not necessarily state or reflect those of the United States Government, any agency thereof, or any of their contractors.

Printed in the United States of America. This report has been reproduced directly from the best available copy.

Available to DOE and DOE contractors from

Office of Scientific and Technical Information

P.O. Box 62

Oak Ridge, TN 37831

Prices available from (615) 576-8401, FTS 626-8401

Available to the public from

National Technical Information Service

U.S. Department of Commerce

5285 Port Royal Rd

Springfield, VA 22161

NTIS price codes

Printed copy: A03

Microfiche copy: A01

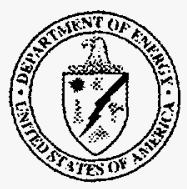




\section{DISCLAIMER}

Portions of this document may be illegible in electronic image products. Images are produced from the best available original document. 
SAND98-1714

Unlimited Release

Printed October 1998

\title{
Database of Mechanical and Hydrological Properties of WIPP Anhydrite
}

Derived from Laboratory-Scale Experiments

\author{
T.W. Pfeifle \\ RE/SPEC Inc. \\ P. O. Box 725 \\ Rapid City, SD 57709-0725 \\ F. D. Hansen \\ Carlsbad Operations \\ Sandia National Laboratories \\ P. O. Box 5800 \\ Albuquerque, NM 87185-1395
}

\begin{abstract}
The Department of Energy (DOE) has developed the Waste Isolation Pilot Plant (WIPP) for the purpose of demonstrating safe management, storage, and disposal of radioactive transuranic (TRU) waste generated by U.S. defense programs. The WIPP is located in southeastern New Mexico, and the underground facilities of the WIPP (i.e., experimental rooms, disposal rooms, etc.) are sited in the bedded salt of the Salado Formation at a depth of about 660 meters.

The DOE has authorized the continuance of scientific research and engineering analysis related to the performance of the WIPP repository. One area of additional research relates to characterization of the mechanical and hydrological properties of anhydrite interbeds within the Salado Formation. These anhydrite interbeds have been penetrated by the shafts that provide access to the underground facilities and also lie in close proximity to the proposed radioactive waste disposal rooms at the repository horizon. Properties of particular interest are mechanical strength, deformational behavior, and fluid transport properties such as permeability. These properties will be used in calculations/analyses of the mechanical and hydrological behavior of the anhydrite, in particular, and the shaft sealing system and disposal rooms, in general.
\end{abstract}


This page intentionally left blank 


\section{CONTENTS}

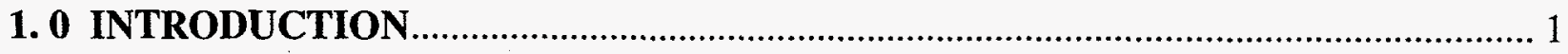

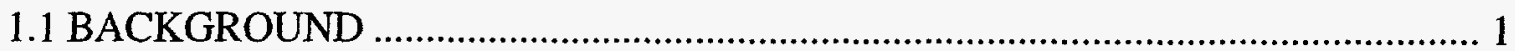

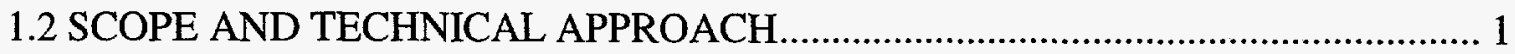

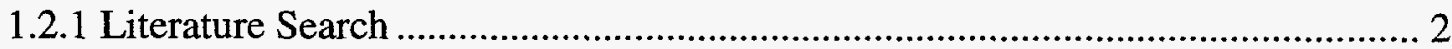

1.2.2 Supplemental Mechanical Properties Testing ...................................................... 2

1.2.3 Quality Assurance Requirements ................................................................. 3

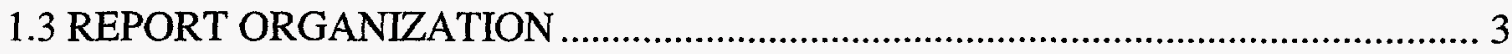

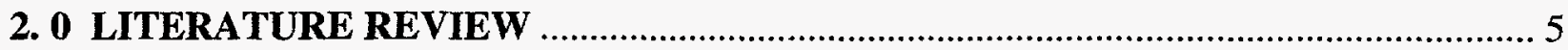

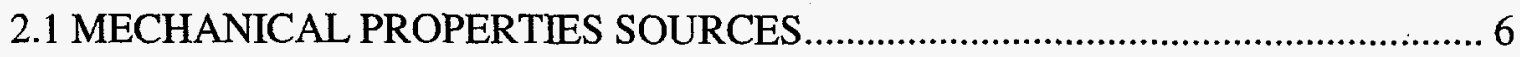

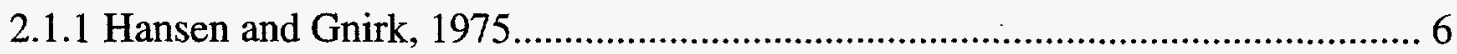

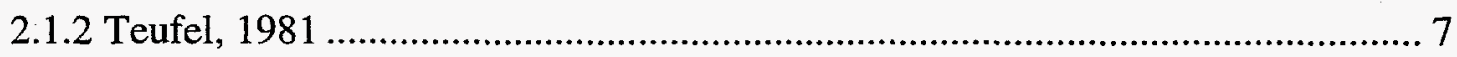

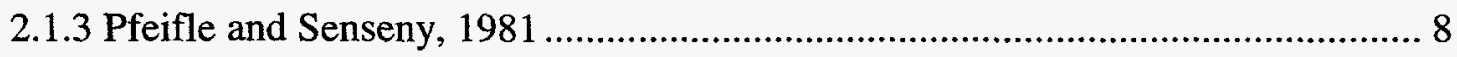

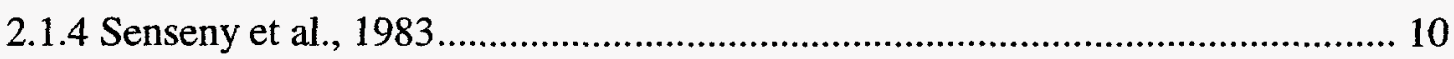

2.1.5 Unpublished Data Acquired Under Sandia Contract AA-2020 ........................ 11

2.2 SOURCES FOR HYDROLOGICAL PROPERTIES ............................................. 16

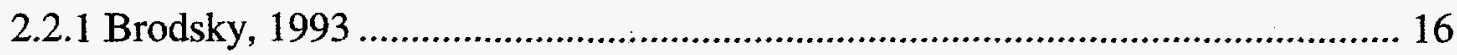

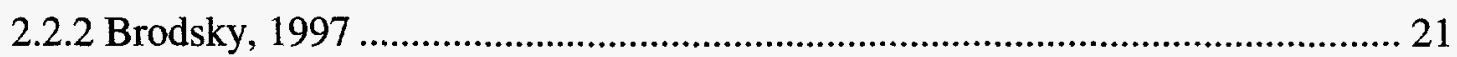

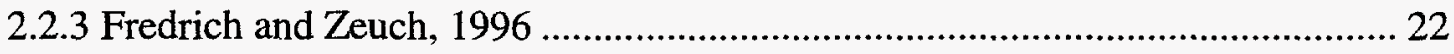

2.2.4 Howarth and Christian-Frear, 1997........................................................... 22

\section{0 SUPPLEMENTAL MECHANICAL PROPERTIES TESTING OF MARKER}

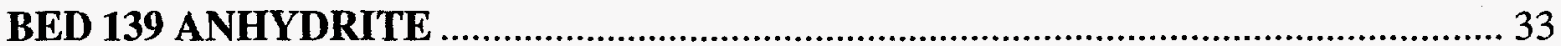

3.1 SAMPLE ACQUISITION AND SPECIMEN PREPARATION ………………......... 34

3.1.1 Sample Acquisition and Description................................................................ 34

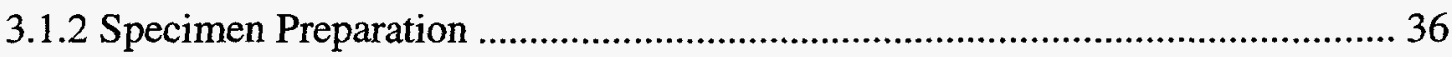

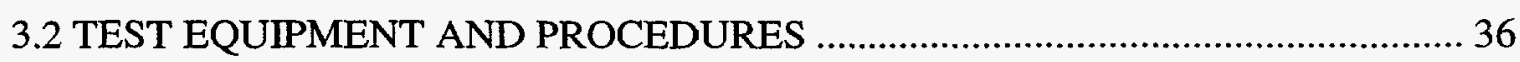

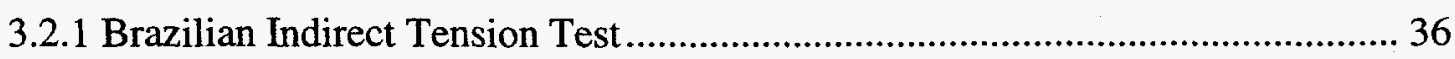

3.2.2 Quasi-Static Triaxial Compression Test ........................................................... 41

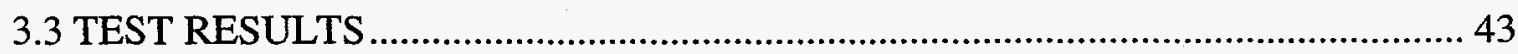

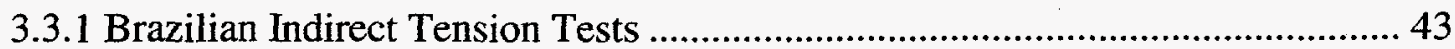

3.3.2 Quasi-Static Triaxial Compression Tests......................................................... 46 


\section{CONTENTS (Continued)}

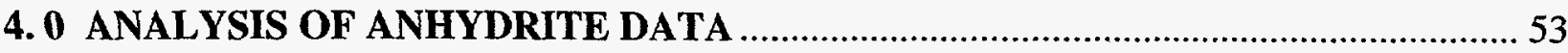

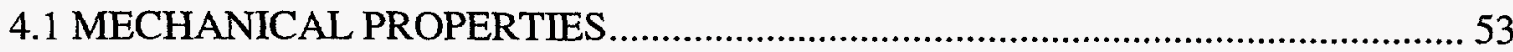

4.1.1 Brazilian Indirect Tensile Strength ................................................................ 53

4.1.2 Unconfined Compressive Strength .................................................................. 53

4.1.3 Confined Compressive Strength ...................................................................... 58

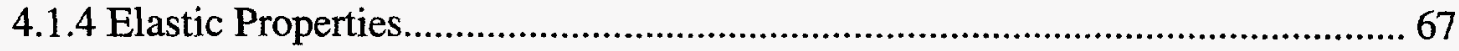

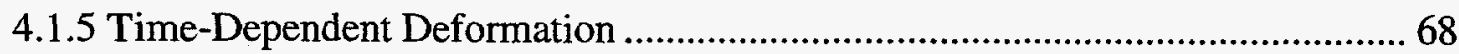

4.2 HYDROLOGICAL PROPERTIES AND PHYSICAL CHARACTERISTICS ......... 68

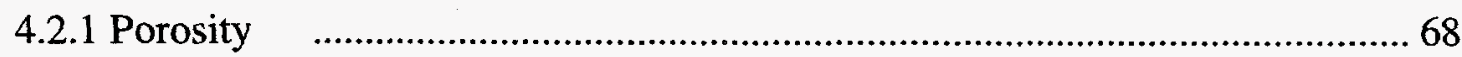

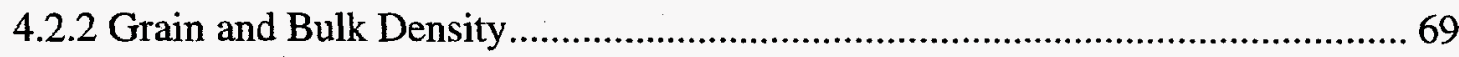

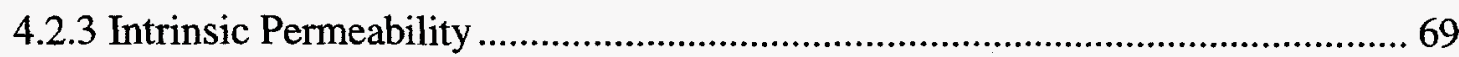

4.2.4 Threshold Pressure _................................................................................................ 69

4.2.5 Mineralogic Composition ............................................................................ 70

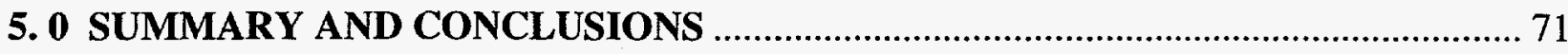

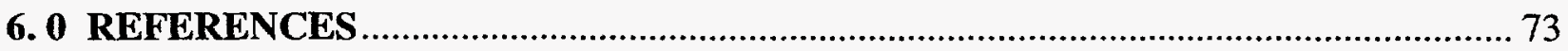

APPENDIX A: STRESS-STRAIN CURVES FOR UNCONFINED COMPRESSIVE STRENGTH TESTS OF WIPP ANHYDRITE ……….................................................. A-1

APPENDIX B: STRESS-STRAIN CURVES FOR TRIAXIAL COMPRESSIVE STRENGTH TESTS OF WIPP ANHYDRITE

APPENDIX C: STRESS-STRAIN CURVES FOR TRIAXIAL COMPRESSIVE STRENGTH TESTS OF WIPP ANHYDRITE

APPENDIX D: STRAIN-TIME CURVES FOR CONFINED CREEP TESTS OF WIPP ANHYDRITE.

APPENDIX E: LOAD-DISPLACEMENT CURVES FOR BRAZILIAN INDIRECT

TENSILE STRENGTH TESTS OF WIPP ANHYDRITE-SUPPLEMENTAL

TESTING

APPENDIX F: STRESS-STRAIN CURVES FOR TRIAXIAL COMPRESSIVE STRENGTH TESTS OF WIPP ANHYDRITE-

SUPPLEMENTAL TESTING 


\section{TABLES}

Table 2-1. Unconfined Strength and Elastic Property Data for WIPP Anhydrite at Room Temperature (After Hansen and Gnirk [1975])...................................... 8

Table 2-2. Brazilian Indirect Tensile Strength for WIPP Anhydrite (After Hansen and Gnirk [1975])

Table 2-3. Unconfined and Confined Strength Data for WIPP Anhydrite at Room Temperature (After Teufel [1981]) 10

Table 2-4. Elastic Properties for WIPP Anhydrite (After Teufel [1981]) …............................. 11

Table 2-5. Confined Strength Data for WIPP Anhydrite at Temperatures of $25^{\circ} \mathrm{C}$ and $100^{\circ} \mathrm{C}$ (After Pfeifle and Senseny [1981]) ................................................. 12

Table 2-6. Elastic Properties for WIPP Anhydrite (After Pfeifle and Senseny [1981]) ......... 13

Table 2-7. Unconfined and Confined Strength Data for WIPP Anhydrite - SNL Contract AA-2020............................................................ 15

Table 2-8. Elastic Properties for WIPP Anhydrite - Sandia Contract AA-2020 ................. 17

Table 2-9. Compressive Strength Data for WIPP Anhydrite as Determined From Constant Mean Stress Compression Tests - Sandia Contract AA-2020............. 19

Table 2-10. Minimum Creep Rates for WIPP Anhydrite - Sandia Contract AA-2020......... 20

Table 2-11. Summary of X-Ray Diffraction Analyses for Marker Bed 139 Anhydrite (After Fredrich and Zeuch [1996])

Table 2-12. Summary of Petrographic Microscopy for Marker Bed 139 Anhydrite (After Fredrich and Zeuch [1996]).

Table 2-13. Summary of Hydrological Properties for WIPP Marker Bed 139

Anhydrite as Determined by Core Laboratories (After Howarth and Christian-Frear [1997]).

Table 2-14. Summary of Hydrological Properties for Wipp Marker Bed 139 Anhydrite as

Determined by RE/SPEC Inc. (After Howarth and Christian-Frear [1997])........ 30

Table 2-15. Summary of Hydrological Properties for WIPP Marker Bed 139 Anhydrite as Determined by Terra Tek Inc. (After Howarth and Christian-Frear [1997])........ 31

Table 3-1. Supplemental Test Matrix for Marker Bed 139 Anhydrite $^{(a)}$................................. 34

Table 3-2. Dimensions, Mass, and Bulk Density of Marker Bed 139 Anhydrite Specimens Recovered From Field Core TV10-3 ……......................... 37

Table 3-3. Dimensions, Mass, and Bulk Density of Marker Bed 139 Anhydrite Specimens Recovered From Field Core MX05-12 ……...................... 38

Table 3-4. Summary of Results From Brazilian Indirect Tension Tests of Marker Bed 139 Anhydrite - Supplemental Testing ............................................ 45

Table 3-5. Summary of Results for Triaxial Compression Test of Marker Bed 139, Field Core TV10-3 - Supplemental Test Matrix. 50

Table 3-6. Summary of Results for Triaxial Compression Tests of Marker Bed 139, Field Core MX05-12 - Supplemental Test Matrix 


\section{TABLES (Continued)}

Table 4-1. Summary of All Indirect Tensile Strength Data for WIPP Anhydrite ...................54

Table 4-2. Summary of All Unconfined Compressive Strength Data for WIPP Anhydrite... 56

Table 4-3. Yield, Failure, and Residual Stress States for WIPP Anhydrite ...........................59

Table 4-4. Elastic Properties of WIPP Anhydrite Determined From Triaxial

Compression Tests

Table 4-5. Summary of Mineralogic Analyses of WIPP Marker Bed 139 Anhydrite.............. 70

\section{FIGURES}

Figure 3-1. Photographs of Marker Bed Anhydrite Field Cores: Block TV10-3

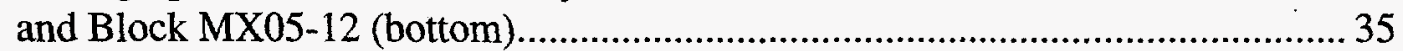

Figure 3-2. Schematic Diagram of Four-Column Universal Test System.............................. 39

Figure 3-3. Schematic of Instrumented Indirect Tension Test Specimen...............................40

Figure 3-4. Schematic of Stiff Test System. ..................................................................... 42

Figure 3-5. Compressive Line Load Versus Compressive and Tensile Displacements for a Typical Brazilian Indirect Tension Test on Marker Bed 139 Anhydrite. ..... 44

Figure 3-6. Tensile and Compressive Displacement Ratio Versus Tensile and Compressive Modulus Ratio for Brazilian Indirect Tension Test Configuration........................ 47

Figure 3-7. Stress Difference Versus Axial and Radial Strains for a Typical Triaxial Compression Test on a Horizontally Oriented Anhydrite Test Specimen.............48

Figure 4-1. Effect of Specimen Size on Unconfined Strength of Salado Formation Anhydrite.

Figure 4-2. $\quad \mathbf{J}_{2}{ }^{1 / 2}$ Versus $I_{1}$ for Yield Stress States for WIPP Anhydrite From the Salado and Castile Formations.

Figure 4-3. $\quad \mathbf{J}_{2}{ }^{1 / 2}$ Versus $I_{1}$ for Failure Stress States for WIPP Anhydrite From the Castile Formation.

Figure 4-4. $\quad \mathbf{J}_{2}{ }^{1 / 2}$ Versus $I_{1}$ for Failure Stress States for WIPP Anhydrite From the Salado Formation (Except for Marker Bed 139 From the MX05-12 Core).

Figure 4-5. $\quad J_{2}{ }^{1 / 2}$ Versus $I_{1}$ for Failure States for WIPP Anhydrite From the MX05-12 Core and for Residual Stress States for WIPP Anhydrite From the TV10-3 Core. 


\subsection{INTRODUCTION}

\subsection{BACKGROUND}

The Department of Energy (DOE) has developed the Waste Isolation Pilot Plant (WIPP) for the purpose of demonstrating safe management, storage, and disposal of radioactive transuranic (TRU) waste generated by defense programs of the U.S. Government. The WIPP is located in southeastern New Mexico, and the underground facilities of the WIPP (i.e., experimental rooms, disposal rooms, etc.) are sited in the bedded salt of the Salado Formation at a depth of about 660 meters.

Before disposal of radioactive waste can begin at the WIPP, the U.S. Environmental Protection Agency (EPA) must certify that the WIPP facility will comply with EPA's radioactive waste disposal regulations (40 CFR Part 191) (U.S. Environmental Protection Agency, 1985). To that end, DOE prepared a Compliance Certification Application (CCA) (U.S. Department of Energy, 1996) that documents the steps taken to ensure compliance of the WIPP with these standards and submitted the CCA to the EPA in September 1996 for their review and approval. On October 30, 1997, the EPA approved the proposed CCA subject to several conditions. Following a 120-day public comment period, the EPA certified that the WIPP facility complies with regulations.

In response to questions raised by the EPA in their review of the CCA and those posed by stakeholders during the public comment period, DOE has authorized the continuance of scientific research and engineering analysis related to the performance of the WIPP repository. One area of additional research relates to the characterization of the mechanical and hydrological properties of anhydrite interbeds within the Salado Formation. These anhydrite interbeds have been penetrated by the shafts that provide access to the underground facilities and also lie in close proximity to the proposed radioactive waste disposal rooms planned at the repository horizon. Properties of particular interest are mechanical strength, deformational behavior, and fluid transport properties such as permeability. It is anticipated that these properties will be used in calculations/analyses of the mechanical and hydrological behavior of the anhydrite, in particular, and the shaft sealing system and disposal rooms, in general.

\subsection{SCOPE AND TECHNICAL APPROACH}

Sandia National Laboratories (SNL) is leading an effort to assemble a database of both mechanical and hydrological properties for WIPP anhydrite. The effort requires both a literature search to identify existing relevant anhydrite data and supplemental laboratory testing of anhydrite recovered from Marker Bed 139, an anhydrite stringer approximately 0.4 to 1.25 meters thick located within the Salado Formation approximately 1 meter below the planned repository interval. This report presents the results of the literature search and laboratory testing and documents the contents of the anhydrite database. 


\subsubsection{Literature Search}

Early studies of WIPP anhydrite concentrated primarily on the characterization of the mechanical properties of the anhydrite. For example, Hansen and Gnirk (1975) performed indirect tensile strength and unconfined compressive strength tests on Salado and Castile Formation anhydrite recovered from WIPP Boreholes AEC 7 and AEC 8. Later, in parallel studies conducted by Teufel (1981) and Pfeifle and Senseny (1981), confined triaxial compressive strength data were acquired at confining pressures ranging from 0 to $20 \mathrm{MPa}$ and temperatures of $25^{\circ} \mathrm{C}$ and $100^{\circ} \mathrm{C}$. All of the testing conducted by Teufel (1981) utilized anhydrite cores recovered from WIPP Borehole ERDA 9 at depths corresponding to anhydrite stringers or interbeds within the Salado Formation. Pfeifle and Senseny (1981) tested Salado and Castile Formation anhydrite cores recovered from WIPP Boreholes AEC 7, AEC 8, and AEC 9. The most recent mechanical properties testing of anhydrite was conducted by RE/SPEC Inc., Rapid City, South Dakota, under contract to SNL. The experiments performed in this study included: (1) indirect tension tests, (2) standard unconfined and triaxial compression tests, (3) constant mean stress tests conducted under conditions of either triaxial compression or triaxial extension, and (4) constant stress creep tests. All of these tests utilized cores recovered from Marker Bed 139. Data from the tests have been previously documented only in informal reports and are, therefore, presented in this report for the first time. In addition to strength, elastic properties, such as Young's modulus $E$ and Poisson's ratio $v$, were also reported in each of the previous studies.

Because of recent interest in the fluid flow characteristics of the Salado Formation in general and the anhydrite marker beds in particular, other experimental studies have focused on the hydrological behavior of WIPP anhydrite. Brodsky $(1993 ; 1997)$ conducted tests on specimens prepared from field cores recovered from Marker Bed 139 to acquire data for intrinsic permeability, porosity, and grain and bulk density. Fredrich and Zeuch (1996) documented the mineralogy of Marker Bed 139 by synthesizing the petrographic and X-ray powder diffraction studies performed by three independent commercial laboratories (including Brodsky [1993; 1997]) and also presented observations on pore structure (e.g., penetrative microporosity, discrete microfractures, etc.) of the Marker Bed 139 anhydrite. A comprehensive study was conducted by Howarth and Christian-Frear (1997) to acquire data for three groups of core samples from Marker Bed 139. The study was designed to: (1) generate WIPP anhydrite-specific porosity and single-phase permeability values; (2) provide information needed to design test equipment and implement planned tests to measure two-phase flow properties including threshold pressure, capillary pressure, and relative permeability; and (3) evaluate the suitability of using analog correlations for the Salado Formation to assess the long-term performance of the WIPP.

\subsubsection{Supplemental Mechanical Properties Testing}

The mechanical properties data identified in the literature search were supplemented by performing a total of 32 indirect tensile strength and triaxial compressive strength tests on anhydrite specimens prepared from large-diameter (approximately 1 meter in diameter) field cores recovered from two intervals within Marker Bed 139. These field cores were subcored to produce cylindrical test specimens oriented so that their central axes were aligned either normal to or parallel with bedding. Sixteen tests were performed on specimens from each core interval, including eight triaxial compression tests and eight Brazilian indirect tension tests. 
Of the eight triaxial compression tests, four were performed on specimens oriented vertically (central axis normal to bedding) and four were performed on specimens oriented horizontally (central axis parallel with bedding). Loading in the tests was conducted at constant confining pressure in axial strain control at a strain rate of $1 \times 10^{-5} \mathrm{~s}^{-1}$. The nominal confining pressure in the tests was either $0,5,10$, or $15 \mathrm{MPa}$. Loading continued until a peak axial stress was observed. Periodically during the test, loading was suspended temporarily so that an unload/reload cycle could be performed. Data from the unload/reload cycles were subsequently used to calculate elastic moduli, Young's modulus $E$ and Poisson's ratio v. Extensometers were mounted directly on the specimen to measure both the axial and radial deformations. In the tests performed on horizontally oriented specimens, the radial deformations were measured both normal to and parallel with bedding.

Of the eight Brazilian indirect tension tests, six were performed on specimens oriented horizontally, while only two were performed on specimens oriented vertically. Compressional loading across the diameter of the Brazilian indirect tension specimens was conducted in stroke control at a rate of $2.5 \times 10^{-3}$ millimeters per second. Loading continued until a peak compressional load was observed or a vertical fracture developed parallel to the line load. Tensile deformations normal to the line load were measured using a clip gage mounted directly on the specimen at its midheight. The compressional deformations parallel to the line load were measured using a linear variable differential transformer (LVDT) mounted between the upper and lower end platens of the testing machine. The output of the LVDT was corrected to account for nonspecimen deformations (i.e., deformations of the end platens and interfaces).

\subsubsection{Quality Assurance Requirements}

All of the work performed in this study was subject to the quality assurance requirements documented in RE/SPEC's Quality Assurance Project Plan (QAPP), QAPP-9, entitled Quality Assurance Project Plan Rock Mechanics Analysis Support for Sandia National Laboratories (RE/SPEC Inc., 1998). This plan was approved by SNL and is considered to be equivalent to applicable requirements in the DOE CAO-94-1012, Rev. 1 (U.S. Department of Energy, 1996), the American Society of Mechanical Engineers (ASME) NQA-1-1994 edition (American Society of Mechanical Engineers, 1994), ASME NQA-3-1989 edition (American Society of Mechanical Engineers, 1990), and DOE Order 5700.6C (U.S. Department of Energy, 1991).

\subsection{REPORT ORGANIZATION}

This report summarizes the mechanical and hydrological properties data for WIPP anhydrite derived from the literature search and the supplemental testing.

In addition to this introduction, the report is organized into five chapters and six appendices. Chapter 2.0 provides a summary of the anhydrite data identified in the literature search. Results from the supplemental mechanical properties testing of Marker Bed 139, including a discussion of sample acquisition and test procedures, are presented in Chapter 3.0. Chapter 4.0 presents analyses of all mechanical properties data and is followed by Chapter 5.0, which provides a summary and conclusions. The report concludes with a list of cited references in Chapter 6.0 and six appendices. Appendices A, B, C, and D provide supporting information (i.e., stress-strain and 
strain-time plots) for data acquired from the literature search. Appendices $E$ and $F$ provide, respectively, plots of indirect tension and triaxial compression data acquired from the supplemental mechanical properties testing conducted in this study. 


\subsection{LITERATURE REVIEW}

A literature search was performed to identify sources of mechanical and hydrological property data for anhydrite within the lithologic units of the WIPP. Sources searched included papers published in the open technical literature, reports prepared by Sandia staff and subcontractors, and any unpublished data developed under Sandia contracts. The search was limited to data derived from laboratory-scale experiments.

Sources identified in the literature containing mechanical properties data for WIPP anhydrite included the following:

Hansen, F. D. and P. F. Gnirk, 1975. Design Aspects of the Alpha Repository: III. Uniaxial Quasi-Static and Creep Properties of the Site Rock, Technical Memorandum Report RSI-0029, prepared by RE/SPEC Inc., Rapid City, SD, for Holifield National Laboratory, Oak Ridge, TN.

Teufel, L. W., 1981. Mechanical Properties of Anhydrite and Polyhalite in QuasiStatic Triaxial Compression, SAND81-0858, prepared by Sandia National Laboratories, Albuquerque, NM.

Pfeifle, T. W. and P. E. Senseny, 1981. Elastic-Plastic Deformation of Anhydrite and Polyhalite as Determined From Quasi-Static Triaxial Compression Tests, SAND817063, prepared by RE/SPEC Inc., Rapid City, SD, for Sandia National Laboratories, Albuquerque, NM.

Senseny, P. E., A. F. Fossum, and T. W. Pfeifle, 1983. "Non-Associative Constitutive Laws for Low Porosity Rocks," International Journal for Numerical and Analytical Methods in Geomechanics, Vol. 7, pp. 101-115.

Sandia Contract AA-2020 (Unpublished). Data acquired by RE/SPEC Inc., Rapid City, SD, under Sandia National Laboratories Contract AA-2020, March 18, 1992, through June 30, 1995.

A brief description of the experimental procedures and test specimens used in these studies is presented below in Section 2.1 along with a tabulation of the test results.

Sources identified in the literature containing hydrological data for WIPP anhydrite included the following:

Brodsky, N. S., 1993. Porosity and Gas Permeability Measurements on Marker Bed 139 Anhydrite From the Waste Isolation Pilot Plant, RSI-0484, prepared by RE/SPEC Inc., Rapid City, SD, for Sandia National Laboratories, Albuquerque, NM.

Brodsky, N. S., 1997. Laboratory Measurements of Fluid Transport Properties for Marker Bed 139 Anhydrite From the Waste Isolation Pilot Plant, RSI-0491, prepared by RE/SPEC Inc., Rapid City, SD, for Sandia National Laboratories, Albuquerque, NM. 
Fredrich, J. T. and D. H. Zeuch, 1996. Petrographic and X-Ray Diffraction Analyses of Selected Samples From Marker Bed 139 at the Waste Isolation Pilot Plant, SAND95-1240, prepared by Sandia National Laboratories, Albuquerque, NM.

Howarth, S. M. and T. Christian-Frear, 1997. Porosity, Single-Phase Permeability, and Capillary Pressure Data From Preliminary Laboratory Experiments on Selected Samples From Marker Bed 139 at the Waste Isolation Pilot Plant, Volume I of 3: Main Report, Appendix A, SAND94-0472/1, prepared by Sandia National Laboratories, Albuquerque, NM.

Howarth, S. M. and T. Christian-Frear, 1997. Porosity, Single-Phase Permeability, and Capillary Pressure Data From Preliminary Laboratory Experiments on Selected Samples From Marker Bed 139 at the Waste Isolation Pilot Plant, Volume 2 of 3: Appendix B, SAND94-0472/2, prepared by Sandia National Laboratories, Albuquerque, NM.

Howarth, S. M. and T. Christian-Frear, 1997. Porosity, Single-Phase Permeability, and Capillary Pressure Data From Preliminary Laboratory Experiments on Selected Samples From Marker Bed 139 at the Waste Isolation Pilot Plant, Volume 3 of 3: Appendices $C, D, E$, and $F$, SAND94-0472/3, prepared by Sandia National Laboratories, Albuquerque, NM.

A brief description of the experimental procedures and test samples used in these studies is also presented below in Section 2.2, along with a tabulation of the test results.

\subsection{MECHANICAL PROPERTIES SOURCES}

\subsubsection{Hansen and Gnirk, 1975}

Hansen and Gnirk (1975) reported mechanical properties data for anhydrite acquired from laboratory tests on cores recovered from the AEC 7 and AEC 8 boreholes drilled at the WIPP site. The cores for the testing were provided by Holifield National Laboratories (currently Oak Ridge National Laboratory) and were nominally 100 millimeters in diameter. Cores were recovered from nominal depths of 624 and 778 meters within the Salado Formation and from depths of 902, 917, 920, 1,018, 1,032, 1,104, and 1,176 meters within the Castile Formation.

The mechanical properties data reported in the study included: (1) tensile strength, (2) unconfined compressive strength, (3) Young's modulus, and (4) Poisson's ratio. Tensile strength was determined for 17 specimens using the Brazilian splitting tensile strength procedure. The unconfined compressive strength, Young's modulus, and Poisson's ratio were evaluated from eight specimens and were all determined from a single type of test; i.e., the uniaxial compressive strength test. Test specimens were solid cylinders having a nominal diameter of either 100 millimeters or 50 millimeters. The length-to-diameter ratio (L:D) was between $0.5: 1$ to $1: 1$ for the tensile strength specimens and was 2:1 for the compressive strength specimens. The orientation of the specimens with respect to bedding was not given; however, because the specimens were prepared from borehole core that was nominally 100 millimeters in diameter, it was assumed that the central axis of all specimens was aligned normal to bedding. In addition to 
the mechanical properties data, specimen density as determined from density logs of the boreholes was also reported.

The protocol used in the compressive strength test was to load the test specimen in a cyclic manner. In the first two cycles, the axial load was increased to about $35 \mathrm{MPa}$ and then reduced to zero. In the third cycle, the specimen was loaded to failure. The nominal loading rate during the three cycles was $5 \mathrm{MPa} /$ minute, and the temperature during each test was ambient room temperature (about $24^{\circ} \mathrm{C}$ ). The unconfined compressive strength was defined as the ultimate axial stress at failure. The elastic moduli; i.e., Young's modulus and Poisson's ratio, were evaluated from the stress-strain data acquired during the third cycle over the range in axial stress corresponding to 25 to 75 percent of the ultimate strength. Strains were measured using two pair of diametrically opposed strain gages glued to each specimen at midheight. One pair was aligned parallel to the central axis of the specimen to measure axial strain while the other pair was mounted perpendicular to the central axis to measure radial strain.

Stress-strain plots for each of the unconfined compressive strength tests conducted by Hansen and Gnirk (1975) are provided in Appendix A. Tables 2-1 and 2-2 summarize the unconfined compressive strength (including estimates of the elastic properties) and indirect tensile strength results, respectively.

\subsubsection{Teufel, 1981}

Teufel (1981) reported mechanical properties data for anhydrite acquired from laboratory tests on cores recovered from the ERDA 9 borehole drilled at the WIPP site. The cores for the testing were recovered from a depth interval of 767 to 768 meters within the Salado Formation.

The mechanical properties data reported in the study included: (1) unconfined and confined compressive strength both for yield and failure, (2) Young's modulus, (3) Poisson's ratio, (4) bulk modulus, and (5) shear modulus. These properties were evaluated from ten specimens and all were determined from a single type of test; i.e., the confined triaxial compressive strength test. Test specimens were solid cylinders having a nominal diameter of 36.8 millimeters and a nominal length of 76.2 millimeters. The specimens were oriented so that their central axes were aligned normal to bedding.

The tests were performed at room temperature and at confining pressures of either $0,5,10$, or 20 MPa. Axial load was applied in axial strain rate control at a rate of $2.1 \times 10^{-4} / \mathrm{second}$. During each test, axial deformation was measured using two diametrically opposed LVDTs mounted over the length of the specimen. Lateral disk gages were used to measure radial deformations across a single diameter in some tests and across two orthogonal diameters in other tests. The use of two lateral disk gages on a single specimen provided data for use in evaluating the inplane (parallel to bedding) isotropy of the anhydrite. Plots of stress difference versus axial strain, stress difference versus radial strain, stress difference versus volumetric strain, and stress difference versus principal strain difference were developed to aid in the interpretation of the data. An example of stress difference versus axial strain plots is presented in Appendix B; however, stress-strain curves for all tests were not provided by Teufel (1981) so only these examples are included in this review. 
Table 2-1. Unconfined Strength and Elastic Property Data for WIPP Anhydrite at Room Temperature (After Hansen and Gnirk [1975])

\begin{tabular}{|c|c|c|c|c|}
\hline \multirow{2}{*}{$\begin{array}{c}\text { Specimen } \\
\text { I. D. }\end{array}$} & $\begin{array}{c}\text { Recovery } \\
\text { Location/Depth (m) }\end{array}$ & $\begin{array}{c}\text { Stress Difference at } \\
\text { Failure } \\
(\mathbf{M P a})\end{array}$ & \multicolumn{2}{|c|}{ Elastic Properties $^{\text {(b) }}$} \\
\cline { 3 - 5 } & E & (GPa) & v \\
\hline $8 / 2049(100)$ & AEC 8/624.5 & 44.5 & 47.4 & 0.33 \\
\hline $8 / 2553(100)$ & AEC 8/778.2 & 51.7 & 75.2 & 0.34 \\
\hline $8 / 3007(100)$ & AEC 8/916.5 & 96.0 & 64.5 & 0.39 \\
\hline $8 / 3008(50)$ & AEC 8/916.8 & 95.5 & 67.0 & 0.30 \\
\hline $8 / 3019(100)$ & AEC 8/920.2 & 96.0 & 68.2 & 0.35 \\
\hline $7 / 3339(100)$ & AEC 7/1017.7 & 73.9 & 56.3 & 0.35 \\
\hline $7 / 3387(50)$ & AEC 7/1032.4 & 74.0 & 74.4 & 0.36 \\
\hline $7 / 3624(100)$ & AEC 7/1104.6 & 105.8 & 87.6 & 0.39 \\
\hline
\end{tabular}

(a) Value in parentheses represents the nominal specimen diameter in millimeters.

(b) Young's modulus, $E$, and Poisson's ratio, v, were determined over the stress difference interval corresponding to 25 to 75 percent of the ultimate strength.

The ultimate (or failure) strength of each specimen was defined as the peak stress difference measured during the test. The yield strength was defined as the stress difference that corresponded to the initiation of inelastic strain. The initiation of inelastic straining was defined as the stress difference at which the specimen exhibited rapidly increasing dilation as determined from the stress difference versus volumetric strain curve. The elastic properties were determined from the slopes of the stress difference versus strain (or strain difference) curves over the interval of stress difference ranging from test initiation to the point of dilatancy. The values of $G$ and $K$ reported by Teufel (1981) were measured directly rather than derived from $E$ and v.

Tables 2-3 and 2-4 summarize, respectively, the yield and ultimate compressive strength data and the elastic properties data for anhydrite from this study.

\subsubsection{Pfeifle and Senseny, 1981}

In a parallel effort, Pfeifle and Senseny (1981) supplemented the mechanical properties database developed by Teufel (1981) for WIPP anhydrite. Pfeifle and Senseny (1981) performed triaxial compression tests on anhydrite cores recovered primarily from the AEC 7 borehole; however, some testing was also performed on cores from the AEC 8 and ERDA 9 boreholes. The cores used in the testing from the AEC 7 borehole were recovered from the Castile Formation at a depth of 1,019 meters, while the cores from the AEC 8 and ERDA 9 boreholes were recovered from the Salado Formation at depths of 531 meters (near the McNutt potash zone) and 677 meters, respectively. The cores from AEC 7 and AEC 8 were recovered in the spring of 1974, and the cores from ERDA 9 were recovered in the spring of 1976. 
Table 2-2. Brazilian Indirect Tensile Strength for WIPP Anhydrite (After Hansen and Gnirk [1975])

\begin{tabular}{|c|c|c|c|}
\hline Specimen I.D. & $\begin{array}{c}\text { Recovery } \\
\text { Location/Depth }(\mathrm{m})\end{array}$ & $\begin{array}{c}\text { Nominal } \\
\text { Specimen } \\
\text { Diameter }(\mathbf{m m})\end{array}$ & $\begin{array}{c}\text { Tensile } \\
\text { Strength, } \mathrm{T}_{\mathrm{o}} \\
\text { (MPa) }\end{array}$ \\
\hline $8 / 2552$ & AEC $8 / 777.8$ & 100 & 3.9 \\
\hline $7 / 2957(1)$ & AEC 7/901.3 & 50 & 9.8 \\
\hline $7 / 2957(2)$ & $\mathrm{AEC} 7 / 901.3$ & 50 & 5.0 \\
\hline $7 / 2957(3)$ & $\mathrm{AEC} 7 / 901.3$ & 50 & 4.3 \\
\hline $7 / 2957(4)$ & AEC 7/901.3 & 100 & 6.5 \\
\hline $7 / 2959$ & AEC 7/901.9 & 100 & 6.6 \\
\hline $7 / 2960$ & $\mathrm{AEC} 7 / 902.2$ & 100 & 6.6 \\
\hline $8 / 3009$ & AEC 8/917.1 & 50 & 7.5 \\
\hline $8 / 3019$ & AEC 8/920.2 & 100 & 5.4 \\
\hline $7 / 3340$ & AEC $7 / 1018.0$ & 100 & 3.9 \\
\hline $7 / 3388$ & AEC $7 / 1032.7$ & 100 & 5.9 \\
\hline $7 / 3389$ & AEC $7 / 1033.0$ & 100 & 3.6 \\
\hline $7 / 3623(1)$ & AEC $7 / 1104.3$ & 100 & 4.8 \\
\hline $7 / 3623(2)$ & AEC 7/1104.3 & 100 & 7.1 \\
\hline $7 / 3858(1)$ & AEC $7 / 1175.9$ & 100 & 4.2 \\
\hline $7 / 3858(2)$ & AEC $7 / 1175.9$ & 100 & 5.2 \\
\hline $7 / 3859$ & AEC $7 / 1176.2$ & 100 & 5.3 \\
\hline
\end{tabular}

The mechanical properties data reported in the study included: (1) confined compressive strength both for yield and failure, (2) Young's modulus, (3) Poisson's ratio, and (4) bulk modulus. These properties were evaluated from 20 specimens and all were determined from a single type of test; i.e., the confined triaxial compressive strength test. The test specimens were solid cylinders having a nominal diameter of 38 millimeters and a nominal length of 90 millimeters and were oriented so that their central axes were aligned normal to bedding.

Ten tests each were performed at room temperature and at $100^{\circ} \mathrm{C}$, and the confining pressure in each test was either $1,5,10$, or $20 \mathrm{MPa}$. Axial load was applied in axial stress control at a stress rate of $5.75 \times 10^{-2} \mathrm{MPa} /$ second. During each test, axial deformation was measured using two diametrically opposed LVDTs mounted over the length of the specimen. Radial deformations were inferred from the volume of the confining pressure fluid either injected into or withdrawn from the pressure vessel at constant confining pressure. Plots of stress difference versus axial strain, stress difference versus radial strain, and stress difference versus volumetric strain were developed to aid 
Table 2-3. Unconfined and Confined Strength Data for WIPP Anhydrite at Room Temperature (After Teufel [1981])

\begin{tabular}{|l|c|c|c|c|}
\hline Specimen 1.D. & \multicolumn{1}{|c|}{$\begin{array}{c}\text { Recovery } \\
\text { Location/Depth (m) }\end{array}$} & $\begin{array}{c}\text { Confining } \\
\text { Pressure (MPa) }\end{array}$ & $\begin{array}{c}\text { Stress } \\
\text { Difference at } \\
\text { Yield (MPa) }\end{array}$ & $\begin{array}{c}\text { Stress } \\
\text { Difference at } \\
\text { Failure (MPa) }\end{array}$ \\
\hline UAN 1 (37) & ERDA 9/767.5 & 0 & 94 & 117 \\
\hline UAN 2 (37) & ERDA 9/767.5 & 0 & 91 & 118 \\
\hline UAN 3 (37) & ERDA 9/767.5 & 0 & 93 & 120 \\
\hline AN 3 (37) & ERDA 9/767.5 & 5 & 102 & 136 \\
\hline AN 8 (37) & ERDA 9/767.5 & 5 & 107 & 140 \\
\hline AN 19 (37) & ERDA 9/767.5 & 5 & 114 & 153 \\
\hline AN 2 (37) & ERDA 9/767.5 & 10 & 108 & 150 \\
\hline AN 27 (37) & ERDA 9/767.5 & 10 & 133 & 179 \\
\hline AN 4 (37) & ERDA 9/767.5 & 20 & 129 & 174 \\
\hline AN 14 (37) & ERDA 9/767.5 & 20 & & 133 \\
\hline
\end{tabular}

(a) Value in parentheses represents the nominal specimen diameter in millimeters.

in the interpretation of the data. These plots are provided in Appendix $\mathrm{C}$. The definitions for yield and ultimate strengths were identical to those reported by Teufel (1981). Similarly, the elastic properties were determined from the slopes of the stress difference versus strain curves over the interval of stress ranging from test initiation to the point of dilatancy.

The triaxial compressive strength and elastic properties data acquired by Pfeifle and Senseny (1981) are summarized in Tables 2-5 and 2-6, respectively. Parameters in the Mohr-Coulomb and MisesSchleicher failure and yield criteria were determined both for room temperature and $100^{\circ} \mathrm{C}$ data. These criteria were then incorporated into two simple constitutive laws appropriate for elasticplastic deformation up to peak load. Both laws accounted for mean stress dependence of yield hardening between yield and peak strength and nonassociative plastic straining. The two yield criteria were matched at axisymmetric compression and relationships among the constitutive parameters were developed.

\subsubsection{Senseny et al., 1983}

The experimental work performed by Pfeifle and Senseny (1981) was summarized in a technical paper prepared by Senseny et al. (1983). The paper provides a complete description of the two constitutive laws developed for WIPP anhydrite, including a discussion of the method used to evaluate the constitutive parameters. No new mechanical properties data for anhydrite were reported in this paper. 
Table 2-4. Elastic Properties for WIPP Anhydrite (After Teufel [1981])

\begin{tabular}{|c|c|c|c|c|c|}
\hline \multirow{2}{*}{$\begin{array}{c}\text { Specimen } \\
\text { I.D. }^{\text {(a) }}\end{array}$} & \multirow{2}{*}{$\begin{array}{c}\text { Recovery } \\
\text { Location/Depth (m) }\end{array}$} & \multicolumn{4}{|c|}{ Elastic Properties $^{(\mathbf{b})}$} \\
\hline & & $\mathbf{E}(\mathbf{G P a})$ & $v$ & $\mathbf{K}(\mathbf{G P a})$ & $\mathbf{G}(\mathbf{G P a})$ \\
\hline UAN1 $(37,0)$ & ERDA $9 / 767.5$ & 74.8 & 0.35 & 76.2 & 26.2 \\
\hline UAN2 $(37,0)$ & ERDA 97767.5 & 72.2 & 0.39 & 68.1 & 22.7 \\
\hline $\operatorname{UAN} 3(37,0)$ & ERDA $9 / 767.5$ & 73.1 & 0.37 & 73.6 & 23.8 \\
\hline AN3 $(37,5)$ & ERDA $9 / 767.5$ & 75.4 & 0.33 & 83.1 & 28.8 \\
\hline AN8 $(37,5)$ & ERDA $9 / 767.5$ & 72.3 & 0.32 & 74.2 & 27.5 \\
\hline AN19 $(37,5)$ & ERDA $9 / 767.5$ & 74.1 & 0.35 & 77.1 & 25.9 \\
\hline AN2 $(37,10)$ & ERDA $9 / 767.5$ & 78.9 & 0.31 & 82.3 & 30.4 \\
\hline AN27 $(37,10)$ & ERDA $9 / 767.5$ & 75.4 & 0.35 & 73.4 & 24.4 \\
\hline AN4 $(37,20)$ & ERDA $9 / 767.5$ & 76.0 & 0.37 & 75.1 & 26.7 \\
\hline AN14 $(37,20)$ & ERDA 9/767.5 & 78.8 & 0.34 & 81.8 & 29.6 \\
\hline
\end{tabular}

(a) Values in parentheses represent the nominal specimen diameter in millimeters and the test confining pressure in MPa, respectively.

(b) Elastic properties, Young's modulus, $E$; Poisson's ratio, $v$; bulk modulus, $K$; and shear modulus, $G$, are determined over the stress difference interval ranging from test initiation to the point of dilatancy.

\subsubsection{Unpublished Data Acquired Under Sandia Contract AA-2020}

During March 1992 through June 1995, mechanical properties tests on specimens of anhydrite were performed by RE/SPEC under Sandia Contract AA-2020. The test specimens were prepared from two 1-meter-diameter cores recovered from Marker Bed 139 of the Salado Formation. The cores were obtained from boreholes drilled in the floor of the WIPP Experimental Rooms T and M and are identified as TV10-3 and MX05-12. The approximate recovery depth of both cores was 660 meters. Core TV10-3 was recovered in November 1985, while Core MX05-12 was recovered in February 1992.

The objectives of the testing were to acquire data for: (1) tensile strength, (2) unconfined and confined compressive strength, (3) elastic properties (i.e., Young's modulus and Poisson's ratio), and (4) creep behavior. Tensile strength was determined for 15 specimens prepared from the TV10-3 block and 6 specimens prepared from the MX05-12 block using the Brazilian indirect tension test method. The confined compressive strength and elastic properties were evaluated from 23 triaxial compression tests, while the creep behavior of the anhydrite was determined from 3 multi-stage triaxial compression constant stress creep tests. The 23 triaxial compression tests comprised 8 standard constant confining pressure tests and 15 constant mean stress tests conducted in a manner to induce either triaxial compression or triaxial extension stress states in the test specimens. 
Table 2-5. Confined Strength Data for WIPP Anhydrite at Temperatures of $25^{\circ} \mathrm{C}$ and $100^{\circ} \mathrm{C}$ (After Pfeifle and Senseny [1981])

\begin{tabular}{|c|c|c|c|c|}
\hline $\begin{array}{l}\text { Specimen } \\
\text { I.D. }\end{array}$ & $\begin{array}{c}\text { Recovery } \\
\text { Location/Depth (m) }\end{array}$ & $\begin{array}{l}\text { Confining } \\
\text { Pressure } \\
\text { (MPa) }\end{array}$ & $\begin{array}{l}\text { Stress } \\
\text { Difference at } \\
\text { Yield (MPa) }\end{array}$ & $\begin{array}{c}\text { Stress } \\
\text { Difference at } \\
\text { Failure (MPa) }\end{array}$ \\
\hline \multicolumn{5}{|c|}{ Temperature $=25^{\circ} \mathrm{C}$} \\
\hline SLA/80/10C/1 (38) & AEC 7/1019 & 1 & 55 & 74 \\
\hline SLA/80/10B/2 (38) & $\mathrm{AEC} 7 / 1019$ & 1 & 24 & 75 \\
\hline SLA/80/10A/1 (38) & AEC $7 / 1019$ & 5 & 76 & 95 \\
\hline SLA/80/7B/2 (38) & ERDA 9/677 & 5 & 92 & 126 \\
\hline SLA/80/10D/3 (38) & AEC $7 / 1019$ & 5 & 62 & 96 \\
\hline SLA/80/10C/3 (38) & AEC 7/1019 & 10 & 59 & 113 \\
\hline SLA/80/10B/3 (38) & AEC 7/1019 & 10 & 66 & 105 \\
\hline SLA/80/10A/3 (38) & AEC 7/1019 & 20 & 93 & 142 \\
\hline SLA/80/10D/2 (38) & $\mathrm{AEC} 7 / 1019$ & 20 & 90 & 135 \\
\hline SLA/80/9B/1 (38) & AEC 8/531 & 20 & 86 & 187 \\
\hline \multicolumn{5}{|c|}{ Temperature $=100^{\circ} \mathrm{C}$} \\
\hline SLA/80/10C/2 (38) & $\mathrm{AEC} 7 / 1019$ & 1 & 21 & 68 \\
\hline SLA/80/10B/1 (38) & AEC 7/1019 & 1 & 14 & 75 \\
\hline SLA/80/10D/4 (38) & AEC 7/1019 & 5 & 59 & 89 \\
\hline SLA/80/10A/2 (38) & AEC 7/1019 & 5 & 10 & 89 \\
\hline SLA/80/9B/3 (38) & $\mathrm{AEC} \mathrm{8/531}$ & 5 & 48 & 123 \\
\hline SLA/80/10C/4 (38) & AEC 7/1019 & 10 & 97 & 105 \\
\hline SLA/80/10B/4 (38) & AEC 7/1019 & 10 & 90 & 96 \\
\hline SLA/80/10D/1 (38) & AEC 7/1019 & 20 & 88 & 131 \\
\hline SLA/80/7B/4 (38) & ERDA 9/677 & 20 & 121 & 155 \\
\hline SLA/80/10A/4 (38) & AEC 7/1019 & 20 & 69 & 120 \\
\hline
\end{tabular}

(a) Value in parentheses represents the nominal specimen diameter in millimeters. 
Table 2-6. Elastic Properties for WIPP Anhydrite (After Pfeifle and Senseny [1981])

\begin{tabular}{|c|c|c|c|c|}
\hline \multirow{2}{*}{$\begin{array}{l}\text { Specimen } \\
\text { I.D. }^{(a)}\end{array}$} & \multirow{2}{*}{$\begin{array}{c}\text { Recovery } \\
\text { Location/Depth (m) }\end{array}$} & \multicolumn{3}{|c|}{ Elastic Properties $^{(\mathbf{b})}$} \\
\hline & & $\begin{array}{c}\mathbf{E} \\
(\mathbf{G P a})\end{array}$ & $v$ & $\underset{(\mathbf{G P a})}{\mathbf{K}}$ \\
\hline \multicolumn{5}{|c|}{ Temperature $=25^{\circ} \mathrm{C}$} \\
\hline SLA/80/10C/1 $(38,1)$ & AEC 7/1019 & 55 & 0.44 & 74 \\
\hline SLA/80/10B/2 $(38,1)$ & AEC 7/1019 & 45 & 0.48 & 40 \\
\hline SLA/80/10A/1 $(38,5)$ & AEC 7/1019 & 53 & 0.46 & - \\
\hline SLA $/ 80 / 7 B / 2(38,5)$ & ERDA 9/677 & 59 & 0.42 & 85 \\
\hline SLA/80/10D/3 $(38,5)$ & AEC $7 / 1019$ & 66 & 0.40 & 107 \\
\hline SLA $/ 80 / 10 C / 3(38,10)$ & AEC 7/1019 & 62 & 0.31 & 92 \\
\hline $\operatorname{SLA} / 80 / 10 B / 3(38,10)$ & AEC 7/1019 & 54 & 0.30 & 45 \\
\hline SLA/80/10A/3 $(38,20)$ & AEC 7/1019 & 63 & 0.37 & 74 \\
\hline SLA/80/10D/2 $(38,20)$ & AEC $7 / 1019$ & 73 & 0.43 & 76 \\
\hline SLA/80/9B/1 $(38,20)$ & AEC $8 / 531$ & 60 & 0.37 & 84 \\
\hline \multicolumn{5}{|c|}{ Temperature $=100^{\circ} \mathrm{C}$} \\
\hline SLA/80/10C/2 $(38,1)$ & AEC $7 / 1019$ & 31 & 0.45 & 43 \\
\hline SLA/80/10B/1 $(38,1)$ & AEC $7 / 1019$ & 14 & 0.43 & 6 \\
\hline SLA/80/10D/4 $(38,5)$ & AEC 7/1019 & 41 & 0.32 & 35 \\
\hline SLA/80/10A/2 $(38,5)$ & AEC 7/1019 & 34 & 0.28 & 19 \\
\hline SLA/80/9B/3 $(38,5)$ & AEC $8 / 531$ & 41 & 0.36 & 47 \\
\hline $\operatorname{SLA} / 80 / 10 C / 4(38,10)$ & AEC 7/1019 & 44 & 0.21 & 23 \\
\hline SLA/80/10B/4 $(38,10)$ & AEC $7 / 1019$ & 43 & 0.18 & 22 \\
\hline SLA/80/10D/1 $(38,20)$ & AEC $7 / 1019$ & 57 & 0.34 & 50 \\
\hline SLA/80/7B/4 $(38,20)$ & ERDA $9 / 677$ & 50 & 0.26 & 37 \\
\hline SLA/80/10A/4 $(38,20)$ & AEC 7/1019 & 56 & - & 23 \\
\hline
\end{tabular}

(a) Values in parentheses represent the nominal specimen diameter in millimeters and the test confining pressure in $\mathrm{MPa}$, respectively.

(b) Elastic properties, Young's modulus, $E$; Poisson's ratio, $v$, and bulk modulus, $K$, were determined over the stress difference interval ranging from test initiation to the point of dilatancy. 
Cylindrical specimens were used in the Brazilian indirect tensile strength tests, the constant confining pressure compressive strength tests, the constant mean stress compressive strength tests, and the creep tests. Dog-bone-shaped specimens were used for the constant mean stress extension tests. The cylindrical specimens had a nominal diameter of either 54 millimeters or 100 millimeters. All 100-millimeter-diameter specimens were used for the creep tests and had an L:D of $2: 1$. The tensile strength specimens had a nominal L:D of $0.5: 1$, while the compressive strength specimens had a nominal L:D of 2:1. The dog-bone specimens were fabricated with a central region having a reduced diameter of 43 millimeters and an end region having an enlarged diameter of 54 millimeters. All specimens were oriented so their central axes were aligned normal to bedding.

The triaxial compression tests were conducted using three different loading paths as follows:

1. Application of axial stress while simultaneously maintaining a constant confining pressure (standard triaxial compression (STC) test).

2. Application of axial stress while simultaneously decreasing the confining pressure at a rate that ensures the mean stress is held constant (constant mean stress compression (CMS-C) test).

3. Application of radial stress while simultaneously reducing the axial stress at a rate that ensures the mean stress is held constant (constant mean stress extension (CMS-E) test).

All test were performed at a temperature of $20^{\circ} \mathrm{C}$. Other details of the three loading paths are given on the next page.

\subsubsection{Standard Triaxial Compression Tests}

The nominal confining pressures investigated in the STC tests were $0,5,10$, and $20 \mathrm{MPa}$. Axial load was applied in axial strain control at a rate of either $1 \times 10^{-6} \mathrm{~s}^{-1}$ or $8 \times 10^{-6} \mathrm{~s}^{-1}$, depending upon whether the specimen was unconfined (radial stress of zero) or confined, respectively. During each test, axial deformation was measured using a 50-millimeter-gage length axial extensometer mounted directly on the specimen at its midheight, while radial deformation was measured using a circumferential extensometer mounted between the ends of a chain that wrapped around the specimen at its midheight. The circumferential extensometer measured the change in chord length between the ends of the chain so during data reduction, its output was corrected to permit calculation of radial strain. During each test, several unload/reload cycles were performed. The unload/reload data acquired below 80 percent of the unload stress were used to calculate elastic moduli. All specimens were eventually loaded to failure and the confined strength was defined as the ultimate or maximum stress difference (axial stress minus confining pressure) sustained by the specimen during loading. In four of the tests conducted on specimens from the TV10-3 core, loading continued beyond ultimate strength to estimate values for residual strength; i.e., the stress difference the specimen could maintain after failure. Plots of stress difference versus axial strain and stress difference versus radial strain were developed to aid in the interpretation of the data and are provided in Appendix D. Tables 2-7 and 2-8 provide, respectively, strength and elastic properties determined in the standard triaxial compression tests. 


\subsubsection{Constant Mean Stress Compression Tests}

The CMS-C tests were performed at nominal mean stresses of 25, 30, 40, and $50 \mathrm{MPa}$. During each test, loading was controlled by decreasing the radial stress at a rate of $0.02 \mathrm{MPa} / \mathrm{second}$, while simultaneously increasing the axial stress at twice this rate to maintain constant mean stress. Loading continued until either the specimen failed or the radial stress reached zero (the test configuration would not allow the application of tensile radial stresses). Axial and radial deformations were measured using the axial and circumferential extensometers described above. Because these transducers were mounted directly on the specimen, they were subjected to changes in confining pressure as the radial stress was dropped. The outputs of both extensometers were calibrated to account for pressure-induced zero shifts. Plots of hydrostatic stress versus volumetric strain, stress difference versus strain difference, and stress difference versus volumetric strain were developed to aid in the interpretation of the data. These plots are also provided in Appendix D. Table 2-9 provides a summary of the strength data for the CMS-C tests. Elastic properties determined in the CMS-C tests are provided in Table 2-8. Bulk and shear moduli were determined from the slopes of the hydrostatic stress-volumetric strain curves and stress difference-strain difference curves, respectively.

\subsubsection{Constant Mean Stress Extension Tests}

The CMS-E tests were performed at the same nominal mean stresses used in the CMS-C tests; i.e., $25,30,40$ and $50 \mathrm{MPa}$. In these tests, however, loading was controlled by increasing the radial stress at a rate of $0.02 \mathrm{MPa}$ /second, while simultaneously decreasing the axial stress at twice this rate to again maintain constant mean stress. Loading continued until the specimen failed. Axial and radial strains were measured using strain gages glued to the reduced section of the specimen at

Table 2-7. Unconfined and Confined Strength Data for WIPP Anhydrite - SNL Contract AA-2020

\begin{tabular}{|c|c|c|c|c|}
\hline $\begin{array}{l}\text { Specimen } \\
\text { I.D. }\end{array}$ & $\begin{array}{c}\text { Recovery } \\
\text { Location/Depth (m) }\end{array}$ & $\begin{array}{c}\text { Confining } \\
\text { Pressure } \\
\text { (MPa) }\end{array}$ & $\begin{array}{c}\text { Stress } \\
\text { Difference } \\
\text { at Failure } \\
\text { (MPa) }\end{array}$ & $\begin{array}{c}\text { Residual } \\
\text { Stress } \\
\text { Difference } \\
(\mathbf{M P a})\end{array}$ \\
\hline TV10-3-1/13/3 (54) & Room T/655 & 0.0 & 63.3 & 25.0 \\
\hline TV10-3-1/14/3 (54) & Room T/655 & 5.3 & 96.9 & 65.0 \\
\hline TV10-3-1/15-2 (54) & Room T/655 & 10.5 & 175.4 & 88.0 \\
\hline TV10-3-1/18-3(54) & Room T/655 & 20.7 & 163.4 & 116.0 \\
\hline MX05-12-6-1-2/12-1 (54) & Room M/655 & 0.0 & 31.6 & N/A \\
\hline MX05-12-6-1-2/20-2 (54) & Room M/655 & 0.0 & 35.2 & N/A \\
\hline MX05-12-6-1-2/2-2 (54) & Room M/655 & 10.4 & 69.7 & N/A \\
\hline MX05-12-6-1-2/7-3 (54) & Room M/655 & 20.8 & 87.2 & N/A \\
\hline
\end{tabular}

(a) Value in parentheses represents the nominal specimen diameter in millimeters. 
its midheight. In five of the six CMS-E tests, the failure plane was located outside of the straingaged section of the specimen and often occurred either through or near the enlarged end of the dog-bone. These failures were attributed to a possible alignment problem between the specimen and loading platens used to apply the axial stress. No extensional data are reported because of this anomalous behavior.

\subsubsection{Constant Stress Triaxial Compression Creep Tests}

Three triaxial compression constant stress creep tests were performed on the Marker Bed 139 anhydrite specimens recovered from the TV10-3 core. The temperature in all three tests was $25^{\circ} \mathrm{C}$, while the confining pressure was either 5,10 , or $15 \mathrm{MPa}$. The tests were designed to be performed in stages. During the first stage, the stress difference was specified to be $75 \mathrm{MPa}$; however, the first test conducted at this stress difference and a confining pressure of $5 \mathrm{MPa}$ resulted in failure of the specimen during the load application. Therefore, in the second and third tests (conducted at confining pressures of 10 and $15 \mathrm{MPa}$ ), the stress difference specified for the initial stage was 50 MPa. In subsequent stages, the stress difference was increased to $75 \mathrm{MPa}$ and then to $100 \mathrm{MPa}$. During each stage of each test, axial deformation was measured using two diametrically opposed LVDTs mounted on the piston outside the pressure vessel that applied the axial load and advanced into the pressure vessel as the specimen deformed. These deformations were corrected to account for deformations of the loading piston during changes in axial stress. Radial deformations were inferred from the volume of the confining pressure fluid either injected into or withdrawn from the pressure vessel to maintain the constant confining pressure condition. Radial deformations were used to correct the axial force on the specimen so the axial stress, and therefore, the axial stress difference, remained constant throughout the test. Plots of axial and radial strain versus time were developed to aid in the interpretation of the data. These plots are also provided in Appendix D.

Minimum strain rates were determined for each stage of creep and are summarized in Table 2-10, along with test conditions and durations. As shown, the creep behavior of WIPP anhydrite is quite variable. For example, at a stress difference of $75 \mathrm{MPa}$ and a temperature of $25^{\circ} \mathrm{C}$, the minimum strain rate in one test was about $2 \times 10^{-6} \mathrm{~s}^{-1}$, while in another test, the minimum rate was less than $5 \times 10^{-11} \mathrm{~s}^{-1}$. In another example, a stress difference of $75 \mathrm{MPa}$ induced creep rupture in one specimen, while it induced very low strain rates $\left(<5 \times 10^{-11} \mathrm{~s}^{-1}\right)$ in another. The variability can probably be attributed to heterogeneous mineralogy, but quantitative mineralogical analyses of the specimens were not performed. It is likely that halite may be the primary impurity of the test specimens and its mechanical response is vastly different from anhydrite.

\subsection{SOURCES FOR HYDROLOGICAL PROPERTIES}

\subsubsection{Brodsky, 1993}

Brodsky (1993) reported hydrologic properties data acquired from laboratory-scale tests performed on cores recovered from Marker Bed 139. The cores for the testing were recovered from two holes, P3X10 and P3X11, drilled from the floor of one of the experimental rooms (i.e., Room 3). The horizontal distance between the two boreholes was 0.61 meter. 
Table 2-8. Elastic Properties for WIPP Anhydrite - Sandia Contract AA-2020

(Page 1 of 3)

\begin{tabular}{|c|c|c|c|c|c|}
\hline \multirow{2}{*}{$\begin{array}{l}\text { Specimen } \\
\text { I.D. }^{(\mathbf{a})}\end{array}$} & \multirow{2}{*}{$\begin{array}{c}\text { Recovery } \\
\text { Location/Depth } \\
\text { (m) }\end{array}$} & \multicolumn{4}{|c|}{ Elastic Properties $^{(b)}$} \\
\hline & & $\begin{array}{c}\mathbf{E} \\
(\mathbf{G P a})\end{array}$ & $v$ & $\begin{array}{c}\mathbf{K} \\
(\mathbf{G P a})\end{array}$ & $\underset{(\mathbf{G P a})}{\mathbf{G}}$ \\
\hline \multicolumn{6}{|c|}{ Constant Confining Pressure Tests; Temperature $=20^{\circ} \mathrm{C}$} \\
\hline $\begin{array}{l}\text { TV10-3-1/13-3 }(54,0) \text { Initial } \\
\text { Loading U/R Cycle } 1\end{array}$ & Room T/655 & $\begin{array}{l}40.7 \\
29.5\end{array}$ & 0.37 & - & - \\
\hline $\begin{array}{l}\text { TV10-3-1/14-3 }(54,5.3) \quad \text { Initial } \\
\text { Loading U/R Cycle } 1 \\
\text { U/R Cycle } 2 \\
\text { U/R Cycle } 3 \\
\text { U/R Cycle } 4 \\
\text { U/R Cycle } 5 \\
\text { U/R Cycle } 6 \\
\text { U/R Cycle } 7\end{array}$ & Room T/655 & $\begin{array}{l}47.9 \\
59.7 \\
53.9 \\
45.0 \\
38.2 \\
35.4 \\
33.6 \\
31.6\end{array}$ & $\begin{array}{l}0.20 \\
0.20 \\
0.23 \\
0.34 \\
0.45 \\
0.50 \\
\overline{0.47}\end{array}$ & $\begin{array}{l}- \\
- \\
- \\
- \\
- \\
-\end{array}$ & $\begin{array}{l}- \\
- \\
- \\
- \\
-\end{array}$ \\
\hline $\begin{array}{c}\text { TV10-3-1/15-2 }(54,10.5) \\
\text { Initial Loading } \\
\text { U/R Cycle } 1 \\
\text { U/R Cycle } 2 \\
\end{array}$ & Room T/655 & $\begin{array}{l}57.4 \\
63.0 \\
39.2 \\
\end{array}$ & $\begin{array}{l}0.21 \\
0.21 \\
0.28 \\
\end{array}$ & - & $\begin{array}{l}- \\
-\end{array}$ \\
\hline $\begin{array}{c}\text { TV10-3-1/18-3 }(54,20.7) \\
\text { Initial Loading } \\
\text { U/R Cycle } 1 \\
\text { U/R Cycle } 2 \\
\text { U/R Cycle } 3 \\
\end{array}$ & Room T/655 & $\begin{array}{l}51.2 \\
59.8 \\
52.6 \\
53.0\end{array}$ & $\begin{array}{l}0.19 \\
0.20 \\
0.24 \\
0.24\end{array}$ & $\begin{array}{l}- \\
- \\
-\end{array}$ & $\begin{array}{l}- \\
- \\
-\end{array}$ \\
\hline $\begin{array}{c}\text { MX05-12-6-2/12-1 }(54,0) \\
\text { Initial Loading } \\
\text { U/R Cycle } 1 \\
\text { U/R Cycle } 2 \\
\text { U/R Cycle } 3\end{array}$ & Room M/655 & $\begin{array}{r}5.6 \\
17.4 \\
21.0 \\
22.0\end{array}$ & $\begin{array}{l}0.28 \\
0.11 \\
0.21 \\
0.27\end{array}$ & $\begin{array}{l}- \\
- \\
-\end{array}$ & $\begin{array}{l}- \\
- \\
-\end{array}$ \\
\hline $\begin{array}{c}\text { MX05-12-6-1-2/20-2 }(54,0) \\
\text { Initial Loading } \\
\text { U/R Cycle } 1 \\
\text { U/R Cycle } 2\end{array}$ & Room M/655 & $\begin{array}{r}6.7 \\
22.1 \\
26.8\end{array}$ & $\frac{0.18}{0.48}$ & - & - \\
\hline
\end{tabular}

(a) Values in parentheses represent the nominal specimen diameter in millimeters and the test confining pressure in $\mathrm{MPa}$, respectively.

(b) Elastic properties determined from unload/reload (U/R) cycles. 
Table 2-8. Elastic Properties for WIPP Anhydrite — Sandia Contract AA-2020 (Page 2 of 3)

\begin{tabular}{|c|c|c|c|c|c|}
\hline \multirow{2}{*}{$\begin{array}{l}\text { Specimen } \\
\text { I.D. }^{\text {(a) }}\end{array}$} & \multirow{2}{*}{$\begin{array}{c}\text { Recovery } \\
\text { Location/Depth } \\
\text { (m) }\end{array}$} & \multicolumn{4}{|c|}{ Elastic Properties ${ }^{(b)}$} \\
\hline & & $\begin{array}{c}\mathbf{E} \\
(\mathbf{G P a})\end{array}$ & $\mathbf{v}$ & $\begin{array}{c}K \\
(\mathbf{G P a})\end{array}$ & $\begin{array}{c}\mathbf{G} \\
(\mathbf{G P a})\end{array}$ \\
\hline \multicolumn{6}{|c|}{ Constant Confining Pressure Tests; Temperature $=20^{\circ} \mathrm{C}$} \\
\hline $\begin{array}{l}\text { MX05-12-6-1-2/2-2 }(54,10.4) \\
\text { Initial Loading } \\
\text { U/R Cycle } 1 \\
\text { U/R Cycle } 2 \\
\text { U/R Cycle } 3 \\
\text { U/R Cycle } 4 \\
\text { U/R Cycle } 5 \\
\text { U/R Cycle } 6 \\
\text { U/R Cycle } 7 \\
\text { U/R Cycle } 8 \\
\text { U/R Cycle } 9 \\
\text { U/R Cycle } 10 \\
\text { U/R Cycle } 11 \\
\text { U/R Cycle } 12 \\
\text { U/R Cycle } 13 \\
\text { U/R Cycle } 14\end{array}$ & Room M/655 & $\begin{array}{l}10.9 \\
33.9 \\
35.7 \\
36.6 \\
36.7 \\
36.4 \\
35.2 \\
34.6 \\
33.7 \\
32.7 \\
31.9 \\
31.0 \\
30.3 \\
29.8 \\
29.2\end{array}$ & $\begin{array}{l}0.17 \\
0.17 \\
0.20 \\
0.22 \\
0.23 \\
0.24 \\
0.25 \\
0.25 \\
0.25 \\
0.26 \\
0.25 \\
0.25 \\
0.25 \\
0.24 \\
0.23\end{array}$ & $\begin{array}{l}- \\
- \\
- \\
- \\
- \\
- \\
- \\
- \\
- \\
- \\
-\end{array}$ & $\begin{array}{l}- \\
- \\
- \\
- \\
- \\
- \\
- \\
- \\
- \\
- \\
-\end{array}$ \\
\hline $\begin{array}{c}\text { MX05-12-6-1-2/7-3 }(54,20.8) \\
\text { Initial Loading } \\
\text { U/R Cycle } 1 \\
\text { U/R Cycle } 2 \\
\text { U/R Cycle } 3 \\
\text { U/R Cycle } 4\end{array}$ & Room M/655 & $\begin{array}{r}7.6 \\
38.7 \\
34.7 \\
32.4 \\
31.2\end{array}$ & $\begin{array}{l}- \\
0.40 \\
0.42 \\
0.44 \\
0.44\end{array}$ & $\begin{array}{l}- \\
- \\
-\end{array}$ & $\begin{array}{l}- \\
- \\
-\end{array}$ \\
\hline \multicolumn{6}{|c|}{ Constant Mean Stress Tests; Temperature $=20^{\circ} \mathrm{C}$} \\
\hline MX05-12-6-1-2/11-1 $(54,26.2)$ & Room M/655 & - & - & 51.8 & 4.8 \\
\hline MX05-12-6-1-2/14-3 $(54,31.1)$ & Room M/655 & - & - & 43.0 & 3.2 \\
\hline MX05-12-6-1-2/8-2 $(54,41.1)$ & Room M/655 & - & - & 35.4 & 4.5 \\
\hline
\end{tabular}

(a) Values in parentheses represent the nominal specimen diameter in millimeters and the test confining pressure or mean stress in $\mathrm{MPa}$, respectively.

(b) In constant confining pressure tests, elastic properties determined from unload/reload (U/R) cycles. In constant mean stress tests, bulk modulus determined from hydrostatic loading, while shear modulus determined using data from load initiation to 60 percent of the peak stress difference. 
Table 2-8. Elastic Properties for WIPP Anhydrite - Sandia Contract AA-2020 (Page 3 of 3)

\begin{tabular}{|c|c|c|c|c|c|}
\hline \multirow[b]{2}{*}{$\begin{array}{l}\text { Specimen } \\
\text { I.D. }^{(a)}\end{array}$} & \multirow{2}{*}{$\begin{array}{c}\text { Recovery } \\
\text { Location/Depth } \\
\text { (m) }\end{array}$} & \multicolumn{4}{|c|}{ Elastic Properties ${ }^{(b)}$} \\
\hline & & $\begin{array}{c}\mathbf{E} \\
(\mathrm{GPa})\end{array}$ & $v$ & $\begin{array}{c}\mathbf{K} \\
(\mathbf{G P a})\end{array}$ & $\begin{array}{c}\mathbf{G} \\
\text { (GPa) }\end{array}$ \\
\hline \multicolumn{6}{|c|}{ Constant Mean Stress Tests; Temperature $=20^{\circ} \mathrm{C}$} \\
\hline TV10-3-1/8-3 $(54,51)$ & Room T/655 & - & - & 49.8 & 26.8 \\
\hline TV10-3-1/7-3 $(54,50)$ & Room T/655 & - & - & 40.5 & 26.6 \\
\hline TV10-3-1/6-3 $(54,41.1)$ & Room T/655 & - & - & 67.2 & 27.5 \\
\hline TV10-3-1/5-3 $(54,41)$ & Room T/655 & - & - & 50.6 & 33.1 \\
\hline TV10-3-1/4-3 $(54,31.1)$ & Room T/655 & - & - & 56.7 & 27.7 \\
\hline TV10-3-1/3-3 $(54,31.1)$ & Room T/655 & 一 & - & 55.2 & 29.8 \\
\hline
\end{tabular}

(a) Values in parentheses represent the nominal specimen diameter in millimeters and the test mean stress in $\mathrm{MPa}$, respectively.

(b) Bulk modulus determined from hydrostatic loading. Shear modulus determined using data from load initiation to 60 percent of the peak stress difference.

Table 2-9. Compressive Strength Data for WIPP Anhydrite as Determined From Constant Mean Stress Compression Tests - Sandia Contract AA-2020

\begin{tabular}{|c|c|c|c|}
\hline $\begin{array}{c}\text { Specimen } \\
\text { I.D. }\end{array}$ & $\begin{array}{c}\text { Recovery } \\
\text { Location/Depth } \\
(\mathbf{m})\end{array}$ & $\begin{array}{c}\text { Mean Stress } \\
\text { at Failure } \\
(\mathbf{M P a})\end{array}$ & $\begin{array}{c}\text { Stress } \\
\text { Difference } \\
\text { at Failure } \\
(\mathrm{MPa})\end{array}$ \\
\hline \multicolumn{4}{|c|}{ RE/SPEC Inc.; Temperature $=20^{\circ} \mathrm{C}$} \\
\hline TV10-3-1/8-3 (54) & Room T/655 & 51.0 & 122.6 \\
\hline TV10-3-1/7/3 (54) & Room T/655 & 50.0 & 136.9 \\
\hline TV10-3-1/6-3 (54) & Room T/655 & 41.1 & 100.7 \\
\hline TV10-3-1/5-3 (54) & Room T/655 & 41.0 & 112.9 \\
\hline TV10-3-1/4-3 (54) & Room T/655 & 31.1 & 88.0 \\
\hline TV10-3-1/3-3 (54) & Room T/655 & (b) & (b) \\
\hline $\mathrm{MX05-12-6-1-2/11-1(54)}$ & Room M/655 & 26.2 & 27.8 \\
\hline $\mathrm{MX05-12-6-1-2/14-3(54)}$ & Room M/655 & 31.1 & 46.0 \\
\hline MX05-12-6-1-2/8-2 (54) & Room M/655 & 41.1 & 58.2 \\
\hline
\end{tabular}

(a) Value in parentheses represents the nominal specimen diameter in millimeters.

(b) No failure was observed for this specimen. 
Table 2-10. Minimum Creep Rates for WIPP Anhydrite - Sandia Contract AA-2020

\begin{tabular}{||c|c|c|c|c|}
\hline \multirow{2}{*}{$\begin{array}{c}\text { Specimen } \\
\text { I.D. }\end{array}$} & $\begin{array}{c}\text { Confining } \\
\text { Pressure } \\
(\mathbf{M P a})\end{array}$ & $\begin{array}{c}\text { Stress } \\
\text { Difference } \\
(\mathbf{M P a})\end{array}$ & $\begin{array}{c}\text { Test } \\
\text { Duration } \\
(\text { days })\end{array}$ & $\begin{array}{c}\text { Minimum } \\
\text { Strain Rate } \\
\left(\mathbf{s}^{-1}\right)\end{array}$ \\
\hline \multirow{3}{*}{ TV10-3-2/3-1 } & 15 & 50 & 14 & $<5 \times 10^{-11}$ \\
\cline { 2 - 5 } & 15 & 75 & 14 & $<5 \times 10^{-11}$ \\
\cline { 2 - 5 } & 15 & 100 & 85 & $<5 \times 10^{-11}$ \\
\hline \multirow{2}{*}{ TV10-3-4/1-1 } & 10 & 50 & 13 & $1.7 \times 10^{-9}$ \\
\cline { 2 - 6 } & 10 & 75 & 1 & $2.2 \times 10^{-6}$ \\
\hline
\end{tabular}

(a) Test temperature of $25^{\circ} \mathrm{C}$.

The data reported in the study included: (1) Klinkenberg-corrected intrinsic permeability, (2) porosity, (3) grain density, and (4) bulk density. Permeability was evaluated from three specimens prepared from cores recovered from the top, middle, and lower portions of Marker Bed 139. Porosity and grain and bulk densities were determined from two samples taken from the opposite ends of each of the three permeability specimens for a total of six samples.

The permeability specimens were prepared in a manner that produced 100 -millimeter-diameter by 100-millimeter-long solid cylinders with their central axes oriented parallel with bedding. Before any permeability testing was performed, each specimen was dried to constant mass at a temperature of $60^{\circ} \mathrm{C}$ and a relative humidity of 45 percent. Each specimen was placed in a flexible-wall permeameter and subjected to a series of confining pressures starting with $2 \mathrm{MPa}$ and then stepping up to $6 \mathrm{MPa}$ and $10 \mathrm{MPa}$. The permeant used in the tests was nitrogen gas. At each confining pressure, flow measurements were made at inlet pore fluid pressures of $1.0 \mathrm{MPa}, 0.7 \mathrm{MPa}$, and 0.4 $\mathrm{MPa}$. The pore pressure at the outlet was maintained at $0.1 \mathrm{MPa}$ (atmospheric) for all tests. Three separate steady-state flow measurements were made at each combination of confining pressure and inlet pore pressure, so a total of 81 measurements was made for each specimen. Gas flow was measured using a manometer system. The data from the 81 measurements were used to assess variability of the flow measurement system, to check for laminar flow, and to correct for gas slippage (i.e., the Klinkenberg effect).

The specimens used in the porosity and density determinations were prepared in a manner similar to that used for the permeability specimens except they were nominally 39 millimeters in diameter by 12 millimeters in length. Direct grain volume measurements were made using a small volume helium porosimeter. Then, grain density was calculated for each specimen using the dry specimen mass and the grain volume measurements. The bulk volume of each specimen was determined using Archimedes' principle of buoyancy. In this method, the specimen is submerged in mercury and the mass of the displaced mercury is measured. Bulk volume is calculated from the mass of the displaced mercury and its density. Bulk density is calculated from the dry specimen mass and the 
bulk volume. Porosity is calculated from the grain volume and bulk volume determinations and represents the interconnected or effective porosity rather than the total porosity.

Howarth and Christian-Frear (1997) summarized the work of Brodsky (1993), as well as other researchers. This summary is included in Section 2.2.4.

\subsubsection{Brodsky, 1997}

The hydrologic data presented in the interim report prepared by Brodsky (1993) were summarized and supplemented with additional data acquired by Brodsky (1997). The supplemental data included the characterization of the mineralogy of the cores from Boreholes P3X10 and P3X11, the assessment of coring-induced damage during specimen preparation, and the measurement of total porosity and brine permeability.

Mineralogy was determined using petrographic microscopy and X-ray diffraction techniques. Nine specimens were analyzed using both techniques for a total of eighteen analyses. The petrographic microscopy was performed using thin sections (25-millimeter slides) viewed under polarized light at $100 \times$ magnification. The slides were scanned along traverse lines with stops or point counts along the traverses. A total of 180 point counts was made per slide. Because the method provided areal element fractions, composition was reported in terms of volume percentages. The X-ray diffraction analyses were performed on finely ground, homogenized samples using the Reference Intensity Method (RM). Composition determined from this technique was reported in terms of weight percentages.

The effect of coring-induced damage was assessed in a three-step process. In the first step, two anhydrite specimens were cored from the original Marker Bed 139 field cores using a standard rock core barrel. One specimen was prepared using a rotational speed of 1,300 revolution per minute (rpm) and a feed rate of approximately 0.15 millimeter per second, while the second was prepared using a speed of $1,000 \mathrm{rpm}$ and a feed rate of about 0.075 millimeter per second. In the second step, the two specimens were vacuum-impregnated with epoxy containing a fluorescent rhodamine$B$ dye and after the epoxy had dried, the specimens were sawed in half lengthwise (parallel to the core axis and parallel to bedding). In the final step, one-half of each specimen was mounted in a petrographic microscope and examined at a magnification of $200 \times$. Three lines parallel to the specimen axis were defined, and these lines were traversed by translating the moving stage of the microscope relative to a fixed vernier scale. The three parallel lines were located coincident with the central axis of the specimen and at positions 0.5 millimeter from each edge. The cross hair of the microscope was translated along each line and the locations of all cracks intersected by the cross hair were recorded. The results of this analysis indicated that crack densities along the edges of both specimens were higher than at the center, but that the difference in crack populations between the specimens was not statistically significant.

Three specimens were used to assess total porosity. The procedure used for this determination was American Society for Testing and Materials (ASTM) D854-83 entitled Standard Test Method for Specific Gravity of Soils (American Society for Testing and Materials, 1983). In this method, the specimens are ground until all particles pass a 0.425 -millimeter sieve. These particles are then submerged in a fluid of known density and the mass of the displaced fluid is determined. The 
volume of the particles is calculated from the mass of the displaced fluid and its density. The total porosity is calculated as the difference between the original specimen volume before crushing and the volume of the particles after grinding divided by the original specimen volume.

The three anhydrite specimens used by Brodsky (1993) for the measurement of nitrogen gas permeabilities were saturated with brine and retested to measure their respective steady-state brine permeabilities. The brine-permeability tests were performed using the same flexible-wall permeameter described above and identical confining pressures and pore pressure gradients used by Brodsky (1993) in the gas permeability measurements. It was noted in these tests that the brine caused some dissolution of the test specimens, so the measured brine permeabilities may be biased; i.e., the measured permeability was too high because of the dissolution.

Howarth and Christian-Frear (1997) summarized the work of Brodsky (1997), as well as other researchers. This summary is included in Section 2.2.4.

\subsubsection{Fredrich and Zeuch, 1996}

Fredrich and Zeuch (1996) synthesized the petrographic and X-ray powder diffraction studies performed on Marker Bed 139 core samples by three independent commercial laboratories. This synthesis incorporated the work of Brodsky (1997) on cores from Boreholes P3X10 and P3X11 as well as additional analyses performed on samples recovered from four other boreholes; i.e., Boreholes E1X07, E1X08, E1X10, and E1X11. These four boreholes were drilled from the floor of WIPP Experimental Room E140. Fredrich and Zeuch (1996) also presented observations on the pore structure of the marker bed (e.g., penetrative microporosity, discrete microfractures, etc.).

Twenty-three X-ray diffraction analyses and twenty petrographic microscopy modal analyses were summarized by Fredrich and Zeuch (1996). Although some differences in technique were reported among the participating commercial laboratories, the general procedures presented above for X-ray diffraction and petrographic microscopy were followed. For example, the size fraction used in the $\mathrm{X}$-ray diffraction analyses varied from less than 15 micrometers to about 45 micrometers, and the number of point counts in the modal analyses varied from 180 to 300 . Modal analyses were performed on three mutually perpendicular thin sections prepared from each location sampled for Cores E1X07, E1X08, P3X10, and P3X11, while only one or two sections were prepared from each location sampled for Cores E1X10 and E1X11. The three mutually perpendicular sections comprised one section oriented nominally parallel to bedding and two sections oriented perpendicular to bedding.

Tables 2-11 and 2-12 summarize, respectively, the X-ray diffraction analyses and petrographic microscopy reported by Fredrich and Zeuch (1996).

\subsubsection{Howarth and Christian-Frear, 1997}

Howarth and Christian-Frear (1997) reported hydrologic data from three groups of core samples from Marker Bed 139. The data were acquired from laboratory experiments designed to (1) generate WIPP-specific porosity and single-phase permeability values; (2) provide information needed to design test equipment and implement planned tests to measure two-phase flow properties 
including threshold pressure, capillary pressure, and relative permeability; and (3) evaluate the suitability of using analog correlations for the Salado Formation to assess the long-term performance of the WIPP. Howarth and Christian-Frear (1997) provided a description of the borehole core samples, the core preparation techniques, sample size, testing procedures, test conditions, and the results of porosity and single-phase permeability tests performed at three laboratories: RE/SPEC (Rapid City, South Dakota); Terra Tek Inc. (Salt Lake City, Utah); and Core Laboratories - Special Core Analysis Laboratory (Carrollton, Texas) for Rock Physics Associates. In addition, data were presented for the only WIPP-specific, two-phase flow testing that has been performed to date. Tables 2-13, 2-14, and 2-15 summarize, respectively, the hydrologic properties for anhydrite measured by Core Laboratories, RE/SPEC Inc., and Terra Tek Inc.

All of the data presented by Howarth and Christian-Frear (1997) were obtained from tests performed on specimens prepared from anhydrite cores recovered from the six boreholes identified above; i.e., E1X07, E1X08, E1X10, E1X11, P3X10, and P3X11. The porosity and single-phase permeability data include the data reported by Brodsky $(1993 ; 1997)$ and Fredrich and Zeuch (1996). In general, the test procedures followed those presented by these investigators. The capillary pressure tests were performed on 12 cores from Core Laboratories' set of 25-millimeterdiameter specimens.

The capillary pressure tests were performed using high-speed centrifuge and mercury injection techniques. In the high-speed centrifuge technique, the specimen is first saturated with a liquid; in this case, decane, and then placed on a semipermeable membrane inside the centrifuge. The centrifuge is set at a low rotational speed and the specimen is spun, causing fluid to be expelled. The volume of this fluid is measured with time, and when this volume reaches a constant value, the rotational speed of the centrifuge is increased and the process is repeated. The force produced by the centrifuge at the middle of the specimen is determined from the rotational speed and converted to a capillary pressure. The saturation of the specimen at this pressure is calculated from the expelled fluid knowing the original porosity of the specimen. The capillary pressure curve during drainage can then be constructed from this pressure-saturation data. Pressures up to $3.45 \mathrm{MPa}$ were induced during the testing. In the mercury injection technique, a dry specimen is submerged in a chamber containing mercury and then evacuated. Volumes of mercury are then incrementally forced into the specimen under different pressures. The volume of mercury injected at each pressure is used to construct the capillary pressure curve during imbibition or saturation. Injection pressures ranged from 0 to $345 \mathrm{MPa}$. Because air-decane and air-mercury systems were used instead of an air-brine system, the data acquired from the two methods had to be converted to represent an air-brine system. 
Table 2-11. Summary of X-Ray Diffraction Analyses for Marker Bed 139 Anhydrite (After Fredrich and Zeuch [1996])

\begin{tabular}{|c|c|c|c|c|c|c|}
\hline \multirow{2}{*}{$\begin{array}{l}\text { Core } \\
\text { I.D. }\end{array}$} & \multirow{2}{*}{$\begin{array}{l}\text { Depth } \\
\text { Interval } \\
\text { (ft) }\end{array}$} & \multicolumn{5}{|c|}{ Composition (weight percent) } \\
\hline & & Anhydrite & Halite & Polyhalite & Carbonate & Other \\
\hline \multirow{3}{*}{ E1X07 } & $4.00-4.14$ & 7 & 23 & 28 & 42 & trace \\
\hline & $5.00-5.14$ & 62 & 38 & - & - & - \\
\hline & $5.73-5.87$ & 81 & 19 & - & - & - \\
\hline \multirow{3}{*}{ E1X08 } & $4.00-4.14$ & 70 & 30 & trace & - & - \\
\hline & $4.86-5.00$ & 32 & 68 & - & - & - \\
\hline & $5.71-5.85$ & 98 & 2 & - & - & - \\
\hline \multirow{6}{*}{ E1X10 } & 4.50 & 80 & 20 & - & trace & trace \\
\hline & 5.00 & 73 & 26 & - & 1 & trace \\
\hline & 5.25 & 77 & 23 & - & trace & trace \\
\hline & 5.50 & 92 & 7 & 一 & 1 & trace \\
\hline & 5.75 & 94 & 4 & - & 2 & trace \\
\hline & 6.25 & 96 & trace & - & 4 & trace \\
\hline \multirow{5}{*}{ E1X11 } & 4.50 & 54 & 46 & - & trace & trace \\
\hline & 4.75 & 68 & 32 & - & trace & - \\
\hline & 5.00 & 66 & 30 & - & 4 & trace \\
\hline & 5.25 & 61 & 36 & - & 3 & trace \\
\hline & 5.75 & 92 & 8 & - & trace & trace \\
\hline \multirow{2}{*}{ P3X10 } & $5.15-5.39$ & 47 & 52 & - & 1 & - \\
\hline & $5.53-5.87$ & 50 & 44 & 5 & 1 & - \\
\hline \multirow{4}{*}{ P3X11 } & $5.33-5.67$ & 12 & 7 & 80 & 1 & - \\
\hline & $5.84-6.04$ & 60 & 11 & 27 & 2 & - \\
\hline & $6.88-7.22$ & 57 & 38 & - & 5 & - \\
\hline & $7.55-7.72$ & 72 & 28 & - & - & - \\
\hline
\end{tabular}




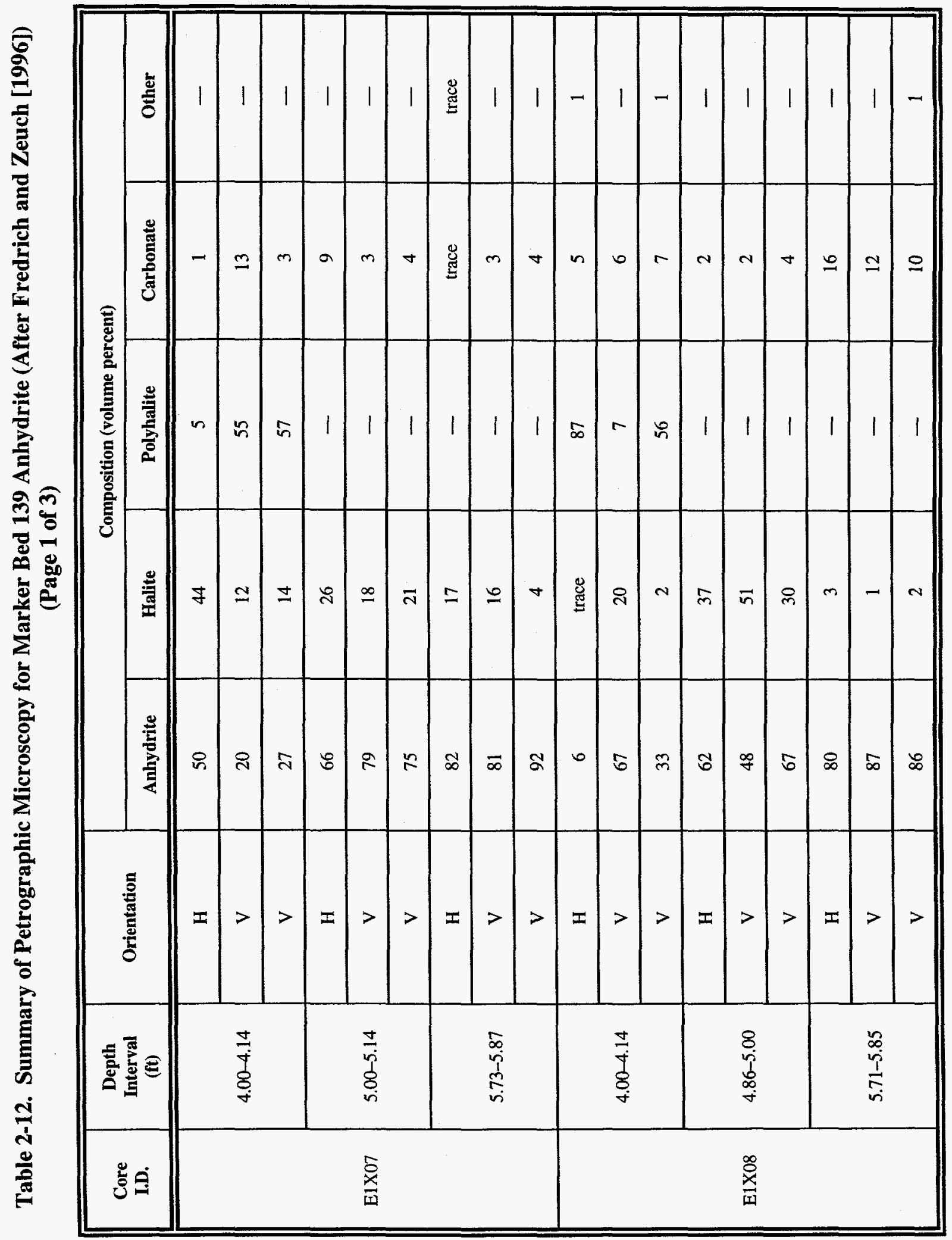




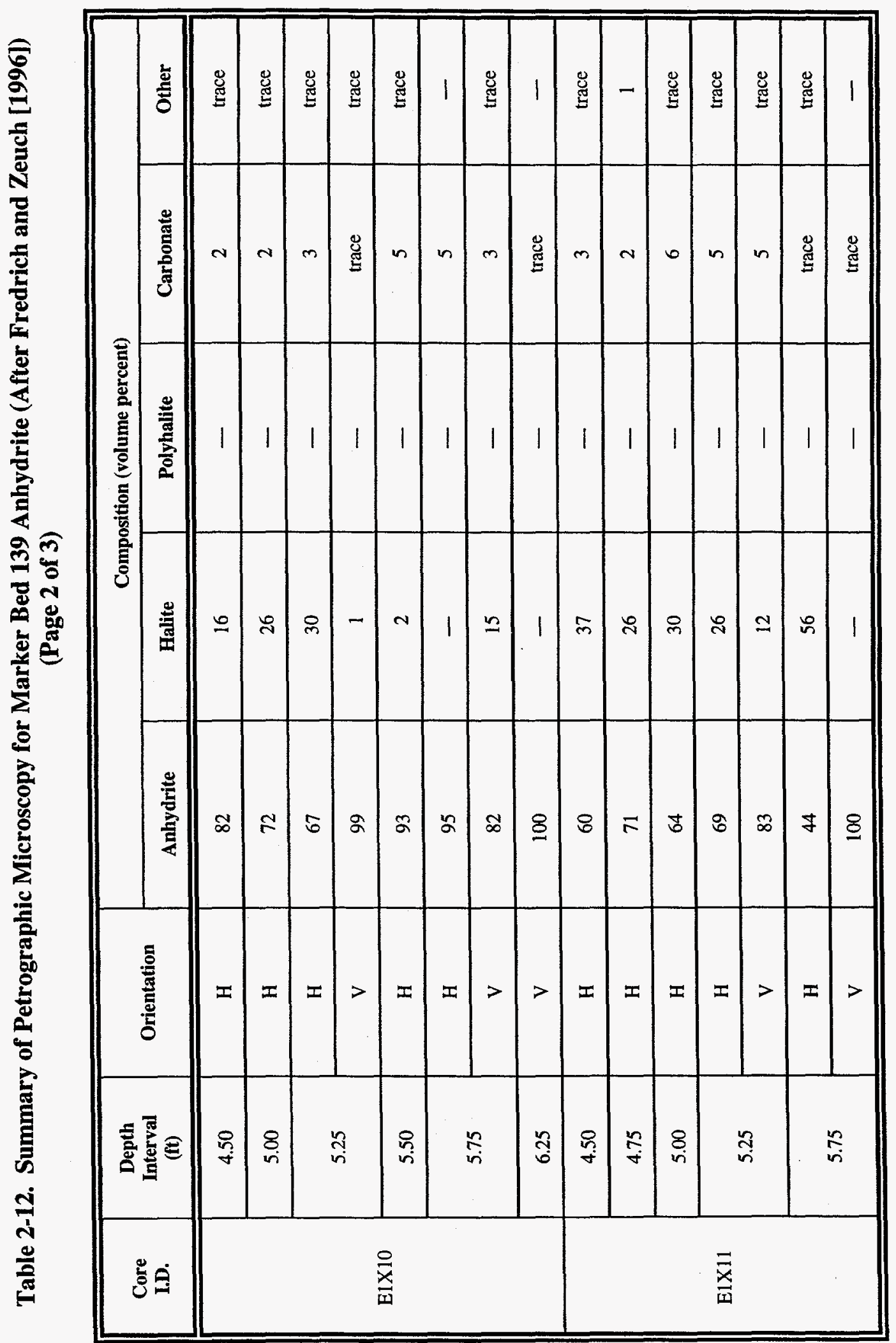




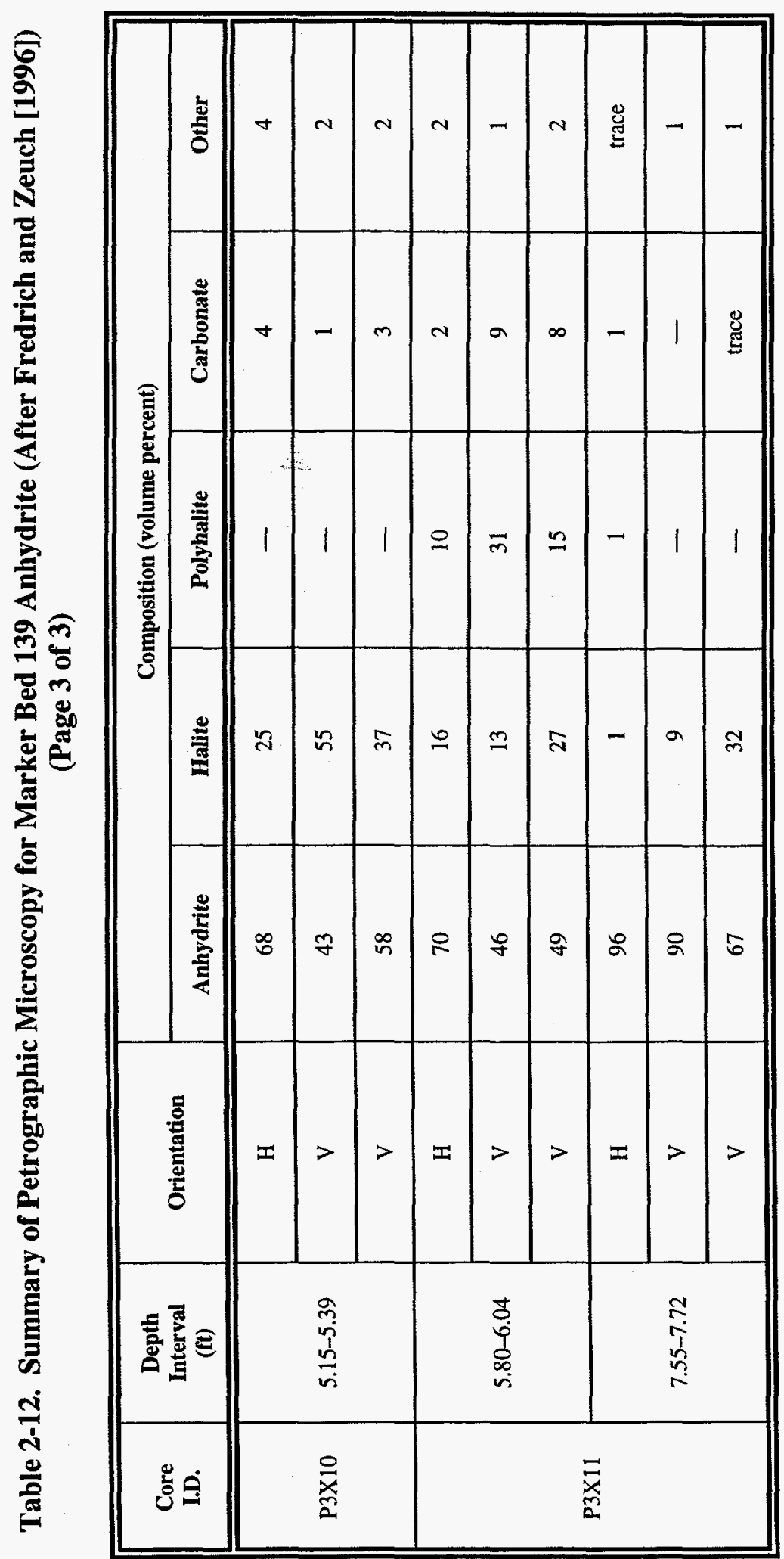




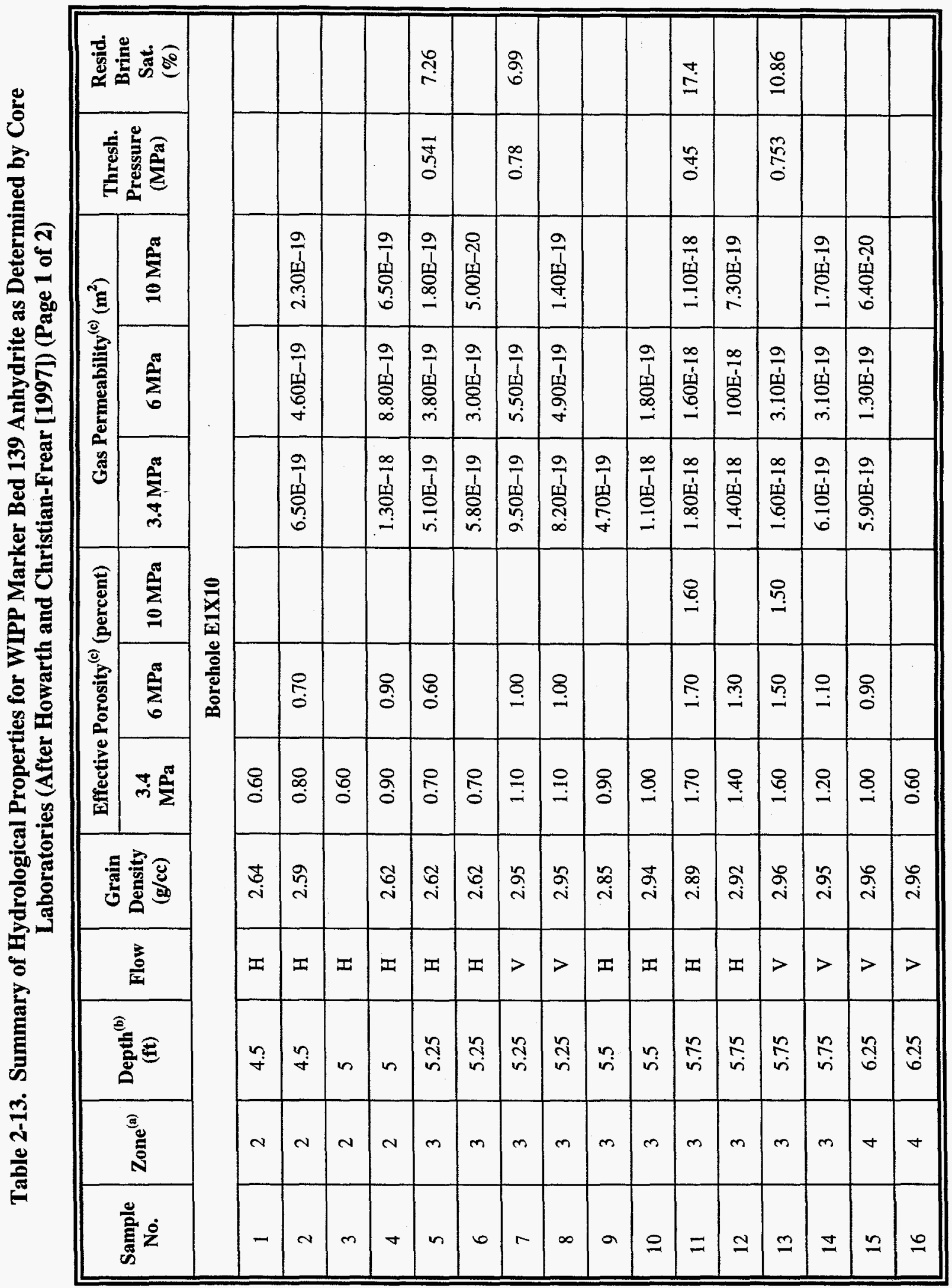




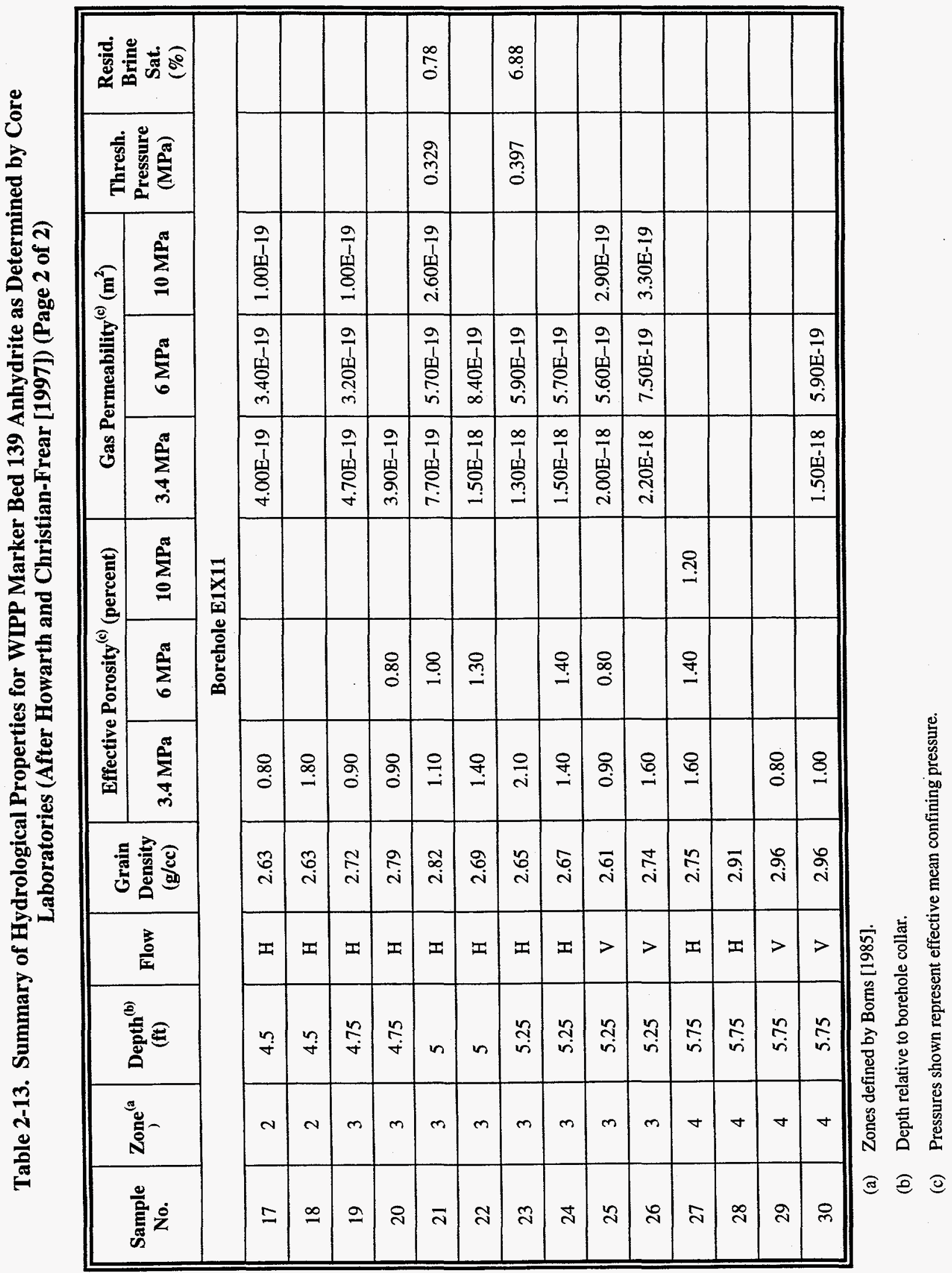




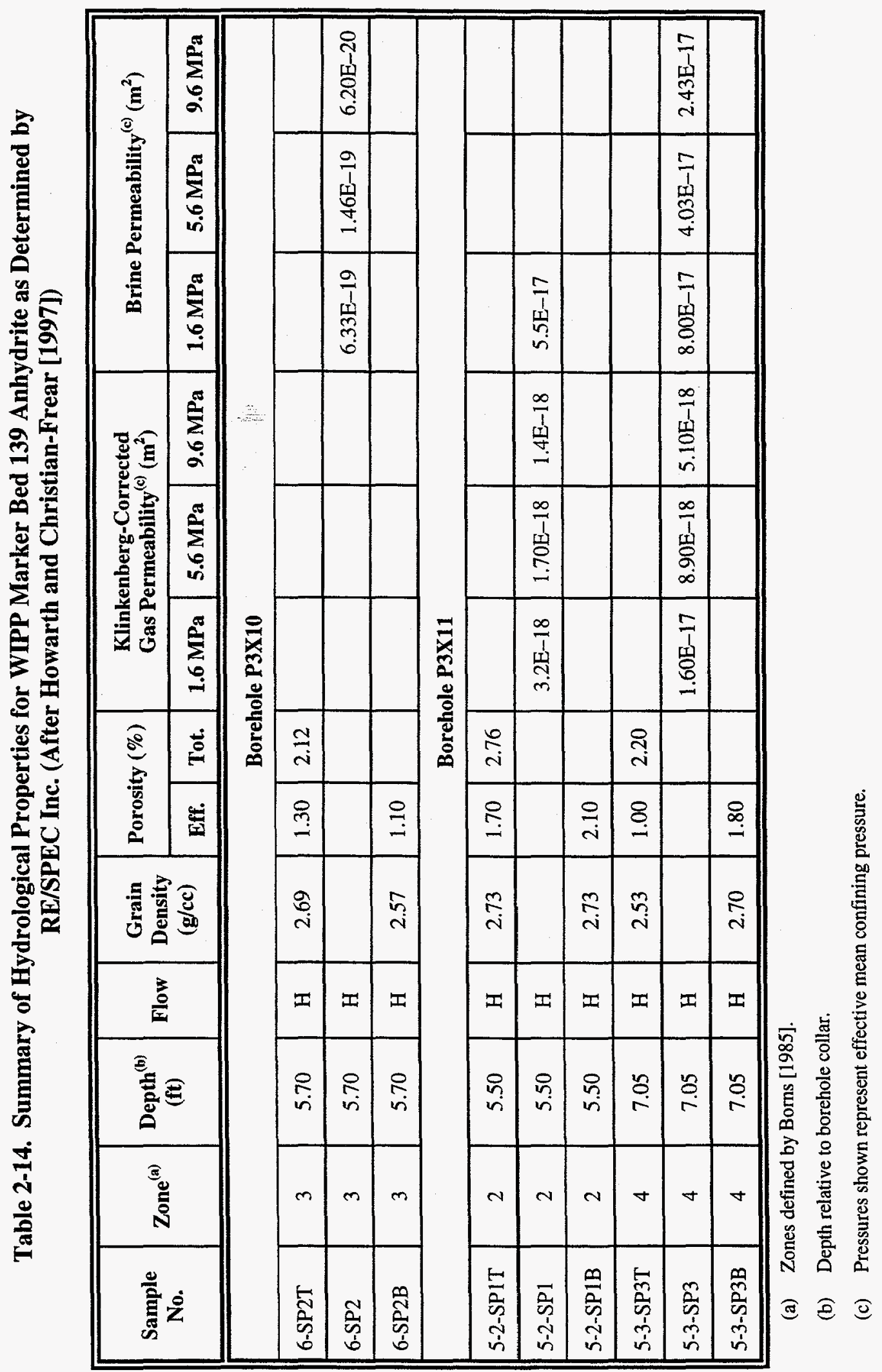




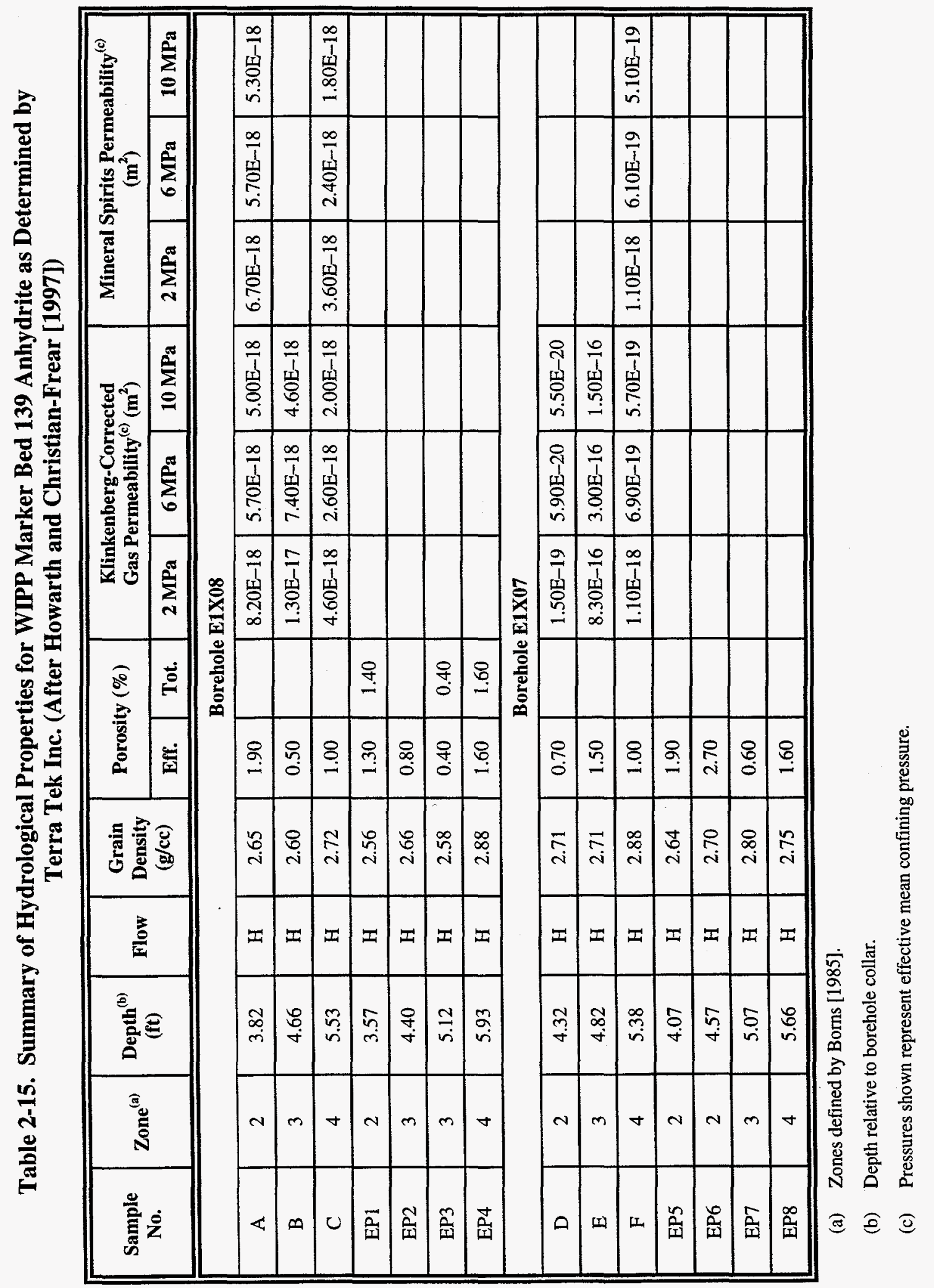


This page intentionally left blank 


\section{0 SUPPLEMENTAL MECHANICAL PROPERTIES TESTING OF MARKER BED 139 ANHYDRITE}

Analyses associated with the Compliance Certification Application (CCA) included several different considerations of anhydrite fracture. Generally, these analyses considered events such as brine disposal in the oil field and the possibility of fracture propagating out of a pressurized repository. In the first case, concern was expressed during public comment on the CCA that brine disposal at depth could hydraulically link to the WIPP site. The transport stratigraphic horizon was assumed to be anhydrite stringers. Similarly, fractures emanating from the WIPP facility itself were assumed to propagate along anhydrite beds, particularly Marker Bed 139, which lies 1 meter below the floor. Open discussion of these calculations as they were implemented in the CCA led to a suggestion that additional, more detailed analyses of anhydrite fracture might be warranted. To this end, an initial task was to ensure complete mechanical characterization of anhydrite properties, particularly site-specific stratigraphy. This document completes the assembly of anhydrite properties.

The database documented in Chapter 2.0 provides substantial information of the mechanical behavior of WIPP anhydrite, particularly in terms of compressive strength and compressive elastic moduli. While this assembly represents an enormous amount of pertinent information, we found certain types of experimental data to be lacking. In view of the analyses likely to be undertaken to further examine the fracture processes, the database was found lacking in tensile properties, especially those parallel to bedding. For example, all the data acquired to date and summarized in Chapter 2.0 were derived from specimens oriented perpendicular to bedding. Further, no data were available on tensile moduli of anhydrite. To address these deficiencies in the database, a test matrix comprising 32 additional tests on Marker Bed 139 anhydrite was designed to assess anisotropy of strength and deformation.

The supplemental test matrix is shown in Table 3-1. Sixteen tests are identified for each of two different layers or horizons within Marker Bed 139. The tests include: standard triaxial compressive strength tests conducted on vertically and horizontally oriented specimens at nominal confining pressures of $0,5,10$, and $15 \mathrm{MPa}$; and Brazilian indirect tensile strength tests also conducted on vertically and horizontally oriented specimens. In addition, the horizontally oriented tensile strength specimens are loaded in a manner to promote fracture either perpendicular or parallel to bedding.

This chapter presents descriptions of the sample acquisition/specimen preparation process, the test equipment and procedures, and the results of the supplemental testing on Marker Bed 139. 
Table 3-1. Supplemental Test Matrix for Marker Bed 139 Anhydrite $^{(a)}$

\begin{tabular}{|c|c|c|c|}
\hline \multirow{2}{*}{$\begin{array}{c}\text { Specimen } \\
\text { Orientation }^{(b)}\end{array}$} & \multicolumn{3}{|c|}{ Test Type $^{(c)}$} \\
\hline & $\begin{array}{c}\text { Confining Pressure } \\
(\mathbf{M P a})\end{array}$ & $\begin{array}{c}\text { Triaxial } \\
\text { Compression }\end{array}$ & $\begin{array}{c}\text { Brazilian } \\
\text { Indirect Tension }\end{array}$ \\
\hline Horizontal & 0 & $\mathrm{X}$ & - \\
\hline Horizontal & 5 & $X$ & - \\
\hline Horizontal & 10 & $\mathrm{X}$ & - \\
\hline Horizontal & 15 & $\mathrm{X}$ & - \\
\hline Vertical & 0 & $\mathrm{X}$ & - \\
\hline Vertical & 5 & $\mathrm{X}$ & - \\
\hline Vertical & 10 & $\mathrm{X}$ & - \\
\hline Vertical & 15 & $\mathrm{X}$ & - \\
\hline Horizontal & N/A & - & $\mathrm{XXXXXX}^{(\mathrm{d})}$ \\
\hline Vertical & N/A & - & $X X$ \\
\hline
\end{tabular}

(a) Matrix shown is performed on specimens recovered from two horizons.

(b) The central axes of the horizontal and vertical specimens are oriented parallel with and perpendicular to bedding, respectively.

(c) An " $\mathrm{X}$ " indicates one test.

(d) Three specimens will be loaded to promote fracture parallel with bedding and three will be loaded to promote fracture perpendicular to bedding.

\subsection{Sample Acquisition and Specimen Preparation}

\subsubsection{Sample Acquisition and Description}

The 32 tests described above were performed on specimens prepared from two 1-meter-diameter anhydrite field cores recovered from the floors in Rooms $\mathrm{T}$ and $\mathrm{M}$ of the WIPP underground workings. Portions of these cores were used previously for the testing performed under Sandia Contract AA-2020. Core TV10-3 was recovered from a construction hole drilled in Room T in November 1985 and delivered to RE/SPEC in three pieces on October 24, 1991. Core MX05-12 was recovered from Room M nearly 7 years later in February 1992 and delivered to RE/SPEC in six pieces on March 12, 1992. Five of the pieces were too thin for testing purposes and were discarded.

Figure 3-1 presents photographs of the two field cores. Because of their large size, the field cores were dry-cut into smaller blocks using an ordinary masonry saw equipped with a diamondimpregnated blade. The blocks cut from Core MX05-12 were obtained from the middle portion of the core. 
RSI-325-98-126
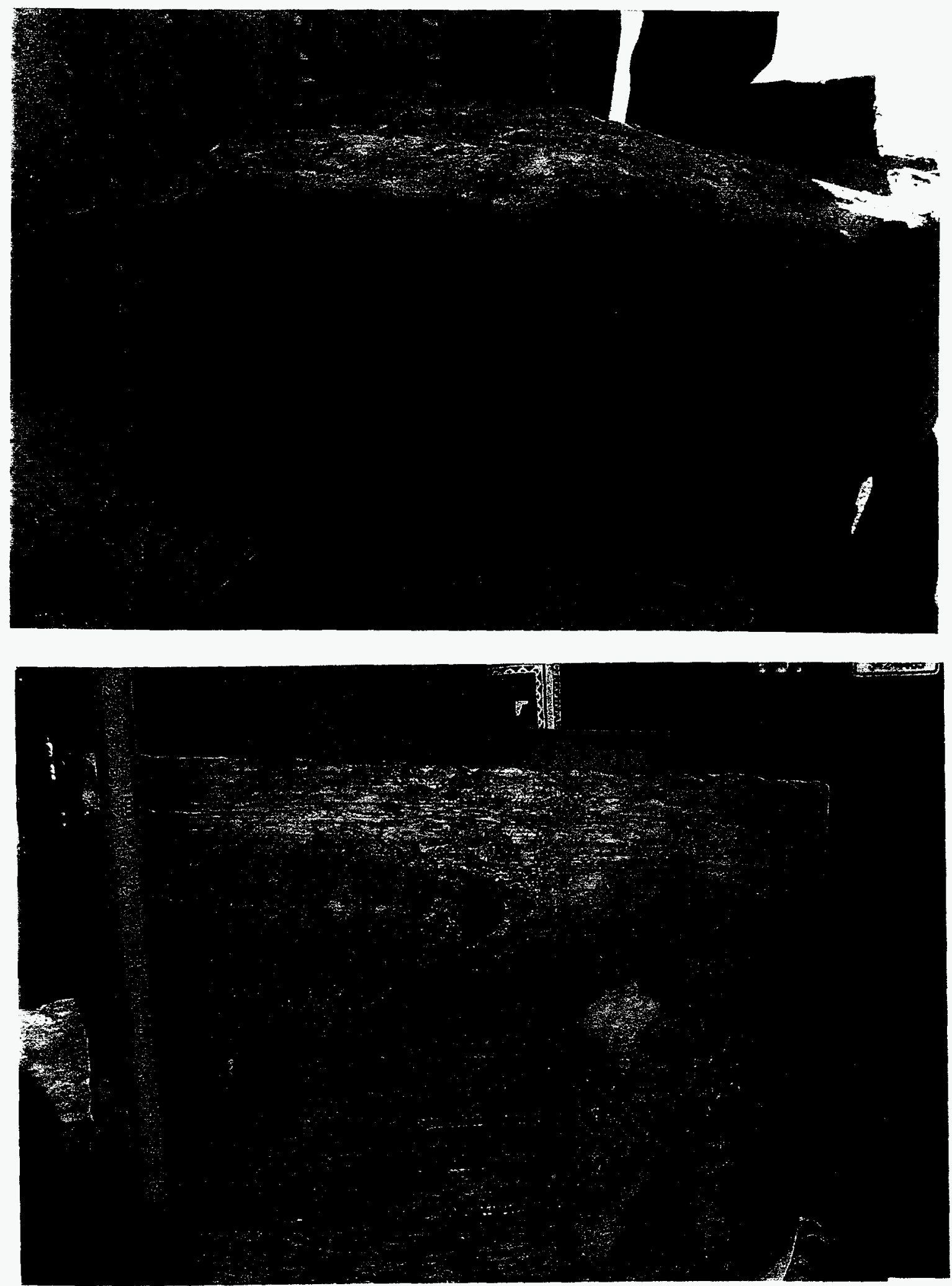

Figure 3-1. Photographs of Marker Bed Anhydrite Field Cores: Block TV10-3 (top) and Block MX05-12 (bottom). 


\subsubsection{Specimen Preparation}

Each of the blocks removed from the field cores was mounted in a vertical milling machine equipped with a standard core barrel having a nominal diameter of either 100 millimeters or 54 millimeters. The blocks were then subcored using compressed air both to remove cuttings and to cool the core barrel. The recovery of vertically oriented subcores was particularly difficult because of separation along preexisting fractures and planes of weakness aligned subparallel to bedding. Subcores recovered successfully from the field cores were cut to approximate length using a rock cutting saw to produce rough specimens that had length-to-diameter (L:D) ratios of either $2: 1$ or $0.5: 1$. The ends of the rough specimens were finished flat and parallel in a surface grinder.

After each specimen was finished within acceptable tolerances for flatness and parallelism, it was assigned a unique identification number for tracking purposes. A typical specimen identification number is as follows:

TV $10-3 / 4 / 3-2 / 1 \mathrm{H}$

where:

$$
\begin{aligned}
\text { TV10-3 } & =\text { field core number } \\
4 / 3-2 / 1 & =\text { number assigned by } \mathrm{RE} / \mathrm{SPEC} \\
\mathrm{H} & =\text { specimen orientation }(\mathrm{H}=\text { horizontal; } \mathrm{V}=\text { vertical })
\end{aligned}
$$

In addition to the assignment of unique identification numbers, the dimensions and mass of each specimen were accurately measured using micrometers and a scale, respectively. Tables 3-2 and 3-3 provide the specimen identification numbers for each of the specimens used in the supplemental testing as well as specimen dimensions, mass, and bulk density. Bulk density is determined from the ratio of the specimen mass and volume assuming right-circular geometry for each specimen.

The nominal diameter of the specimens with a L:D of 2:1 was 54 millimeters. These specimens were used in the quasi-static triaxial compressive strength tests. The nominal diameter of the specimens with a L:D of $0.5: 1$ was 100 millimeters. These specimens were used in the indirect tensile strength tests.

\subsection{Test Equipment and Procedures}

\subsubsection{Brazilian Indirect Tension Test}

All of the Brazilian indirect tension tests were performed in an MTS Corporation Universal Test System (UTS). The UTS is a computer-controlled, closed-loop servohydraulic system that comprises: (1) a four-column load frame as shown schematically in Figure 3-2, (2) a Digital Equipment Corporation (DEC) LSI-11/73 microprocessor, and (3) a control console. 
Table 3-2. Dimensions, Mass, and Bulk Density of Marker Bed 139 Anhydrite Specimens Recovered From Field Core TV10-3

\begin{tabular}{|c|c|c|c|c|}
\hline \multirow{2}{*}{$\begin{array}{l}\text { Specimen } \\
\text { I.D. }\end{array}$} & \multicolumn{2}{|c|}{ Specimen Dimensions } & \multirow{2}{*}{$\begin{array}{l}\text { Specimen } \\
\text { Mass } \\
\text { (g) }\end{array}$} & \multirow{2}{*}{$\begin{array}{c}\text { Specimen } \\
\text { Bulk Density } \\
\left(\mathrm{kg} / \mathrm{m}^{3}\right)\end{array}$} \\
\hline & $\begin{array}{c}\text { Length } \\
\text { (mm) }\end{array}$ & $\begin{array}{c}\text { Diameter } \\
\text { (mm) }\end{array}$ & & \\
\hline TV10-3/4/2-1/5H & 54.58 & 101.75 & $1,204.44$ & 2,710 \\
\hline TV10-3/4/3-7/1H & 51.28 & 102.41 & $1,174.16$ & 2,780 \\
\hline TV10-3/4/2-1/2H & 52.68 & 101.61 & $1,196.28$ & 2,800 \\
\hline TV10-3/4/2-1/4H & 52.88 & 101.69 & $1,193.70$ & 2,780 \\
\hline TV10-3/4/2-1/3H & 54.20 & 101.65 & $1,240.06$ & 2,820 \\
\hline TV10-3/4/3-7/2H & 51.54 & 102.46 & $1,174.72$ & 2,760 \\
\hline TV10-3/4/1-6/1V & 51.79 & 98.90 & $1,039.70$ & 2,610 \\
\hline TV10-3/4/1-6/2V & 55.08 & 98.90 & $1,156.64$ & 2,730 \\
\hline TV10-3/4/1-3/2V & 109.27 & 54.52 & 680.48 & 2,670 \\
\hline TV10-3/4/1-1/2V & 109.28 & 54.51 & 669.76 & 2,640 \\
\hline TV10-3/4/3-11/2V & 109.65 & 54.60 & 708.50 & 2,760 \\
\hline TV10-3/4/3-12/2V & 109.63 & 54.58 & 703.59 & 2,740 \\
\hline TV10-3/4/3-2/1H & 109.40 & 54.55 & 704.93 & 2,760 \\
\hline TV10-3/4/3-8/1H & 108.61 & 53.99 & 684.54 & 2,750 \\
\hline TV10-3/4/3-9/1H & 109.50 & 54.60 & 712.60 & 2,780 \\
\hline TV10-3/4/3-10/1H & 109.51 & 54.60 & 691.40 & 2,700 \\
\hline
\end{tabular}

The load frame, as well as the hydraulic actuator located in the base of the load frame, is rated for a compressive force of $1 \mathrm{MN}$. The crosshead of the frame is adjustable so that specimens with varying geometry can be accommodated with a single test system. The test frame and actuator are linked to the microprocessor via an interface control console. The control console houses all signal conditioning for the instrumentation, feedback and valve driver modules for the hydraulics, and digital panel meters for display of force and compressive and tensile displacements. The DEC LSI$11 / 73$ microprocessor provides data acquisition and programmable control of the test system using the MTS BASIC programming language.

Instrumentation used in the tension tests included a clip gage, a load cell, and an LVDT. The clip gage was mounted between two aluminum platens glued to the face of the test specimen, as shown in Figure 3-3, and measured the tensile displacements in a direction normal to the applied compressive line load. The effective gage length for the clip gage was 8.9 millimeters. A load cell was mounted directly on the adjustable crosshead of the load frame and measured the compressive line force applied to the test specimen. The LVDT was mounted between the 
Table 3-3. Dimensions, Mass, and Bulk Density of Marker Bed 139 Anhydrite Specimens Recovered From Field Core MX05-12

\begin{tabular}{|c|c|c|c|c|}
\hline \multirow{2}{*}{$\begin{array}{l}\text { Specimen } \\
\text { I.D. }\end{array}$} & \multicolumn{2}{|c|}{ Specimen Dimensions } & \multirow{2}{*}{$\begin{array}{l}\text { Specimen } \\
\text { Mass } \\
\text { (g) }\end{array}$} & \multirow{2}{*}{$\begin{array}{c}\text { Specimen } \\
\text { Bulk Density } \\
\left(\mathrm{kg} / \mathrm{m}^{\mathbf{3}}\right)\end{array}$} \\
\hline & $\begin{array}{c}\text { Length } \\
\text { (mm) }\end{array}$ & $\begin{array}{c}\text { Diameter } \\
(\mathbf{m m})\end{array}$ & & \\
\hline MX05-12-6-3/2-1/1H & 53.69 & 102.35 & $1,147.08$ & 2,600 \\
\hline $\mathrm{MX05}-12-6-3 / 2-2 / 1 \mathrm{H}$ & 52.17 & 102.43 & $1,096.98$ & 2,550 \\
\hline MX05-12-6-3/2-3/1H & 53.58 & 102.52 & $1,187.26$ & 2,680 \\
\hline MX05-12-6-3/2-1/2H & 52.80 & 102.69 & $1,172.48$ & 2,680 \\
\hline MX05-12-6-3/2-2/2H & 55.33 & 102.45 & $1,181.74$ & 2,590 \\
\hline MX05-12-6-3/2-3/2H & 53.57 & 102.39 & $1,128.98$ & 2,560 \\
\hline MX05-12-6-3/2-9/4V & 55.60 & 102.88 & $1,240.46$ & 2,680 \\
\hline $\mathrm{MX05}-12-6-3 / 2-2 / 2 \mathrm{~V}$ & 57.88 & 102.59 & $1,232.58$ & 2,580 \\
\hline MX05-12-6-3/2-11/1V & 106.47 & 52.89 & 606.04 & 2,590 \\
\hline MX05-12-6-3/2-12/1V & 103.55 & 51.66 & 592.07 & 2,730 \\
\hline MX05-12-6-3/2-13/1V & 103.54 & 51.64 & 581.22 & 2,680 \\
\hline MX05-12-6-3/2-15/2V & 109.50 & 54.57 & 671.44 & 2,620 \\
\hline MX05-12-6-3/2-4/1H & 109.09 & 54.59 & 669.81 & 2,620 \\
\hline MX05-12-6-3/2-5/1H & 109.39 & 54.58 & 660.79 & 2,580 \\
\hline MX05-12-6-3/2-6/1H & 109.39 & 54.59 & 654.17 & 2,560 \\
\hline MX05-12-6-3/2-7/1H & 109.26 & 54.59 & 660.78 & 2,580 \\
\hline
\end{tabular}

spherical seat of the load cell and the hydraulic actuator and measured compressive displacements in a direction parallel with the compressive line load. The displacements measured by the LVDT included specimen displacements as well as nonspecimen displacements attributable to the compression of the spherical seat, the metal loading platens, and cardboard strips placed in the specimen/load platen interfaces to aid in load distribution. The compressive displacements measured by the LVDT were corrected during data reduction to account for the nonspecimen displacements, using calibration factors determined from system calibrations made using an instrumented aluminum specimen with known elastic properties.

The Brazilian indirect tension tests were initiated by placing an instrumented specimen (shown in Figure 3-3) into the load frame (shown in Figure 3-2) and manually applying a small compressive preload across the specimen diameter. The test system control code for the test was then executed by the system operator and the microprocessor assumed control of the loading of the test specimen up to peak load and also acquired data from the load cell, LVDT, and clip gage. Loading was accomplished in stroke-rate control using the output of the LVDT for feedback. The nominal displacement rate specified for each test was $2.5 \times 10^{-3}$ millimeter/second. 


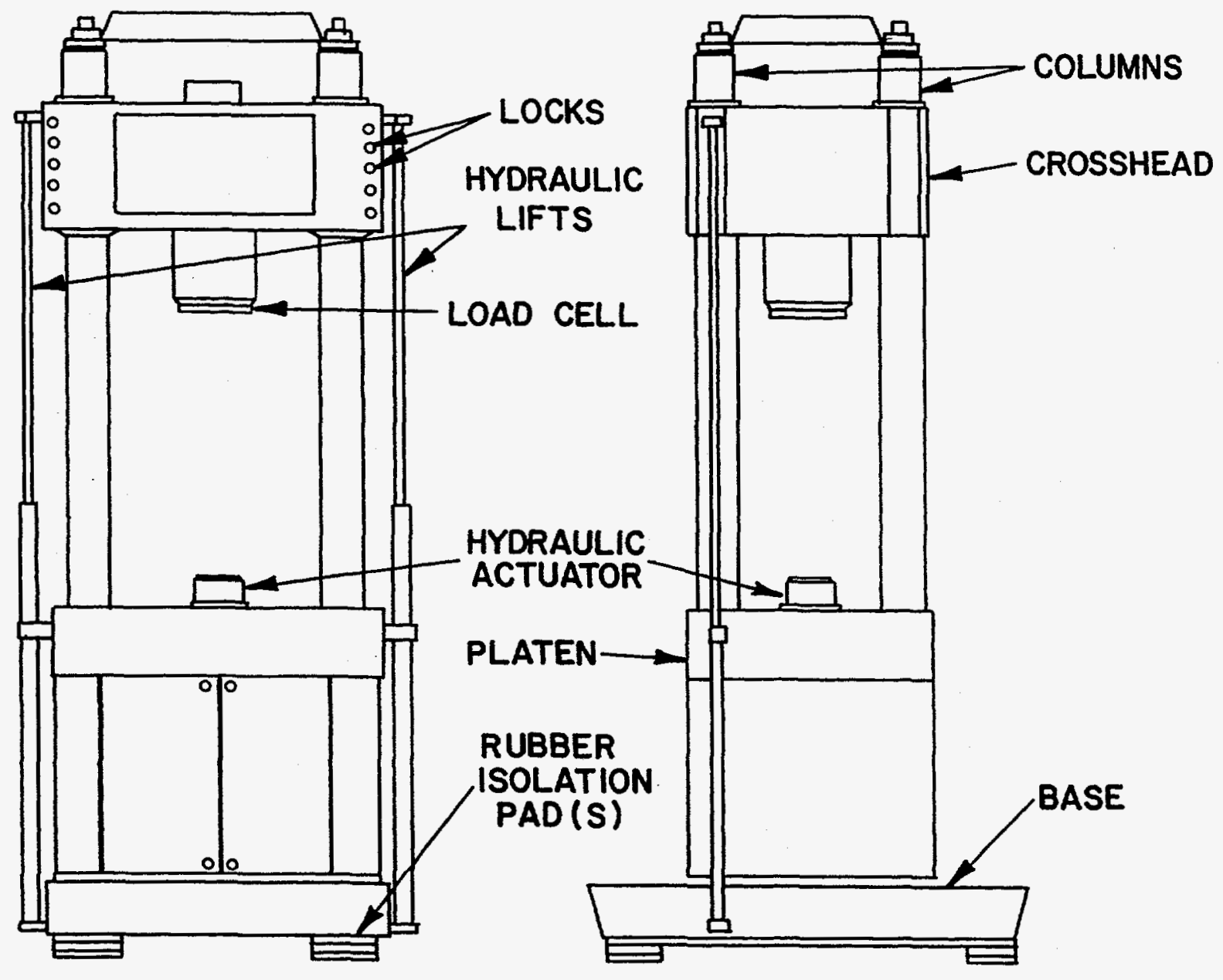

Figure 3-2. Schematic Diagram of Four-Column Universal Test System. 


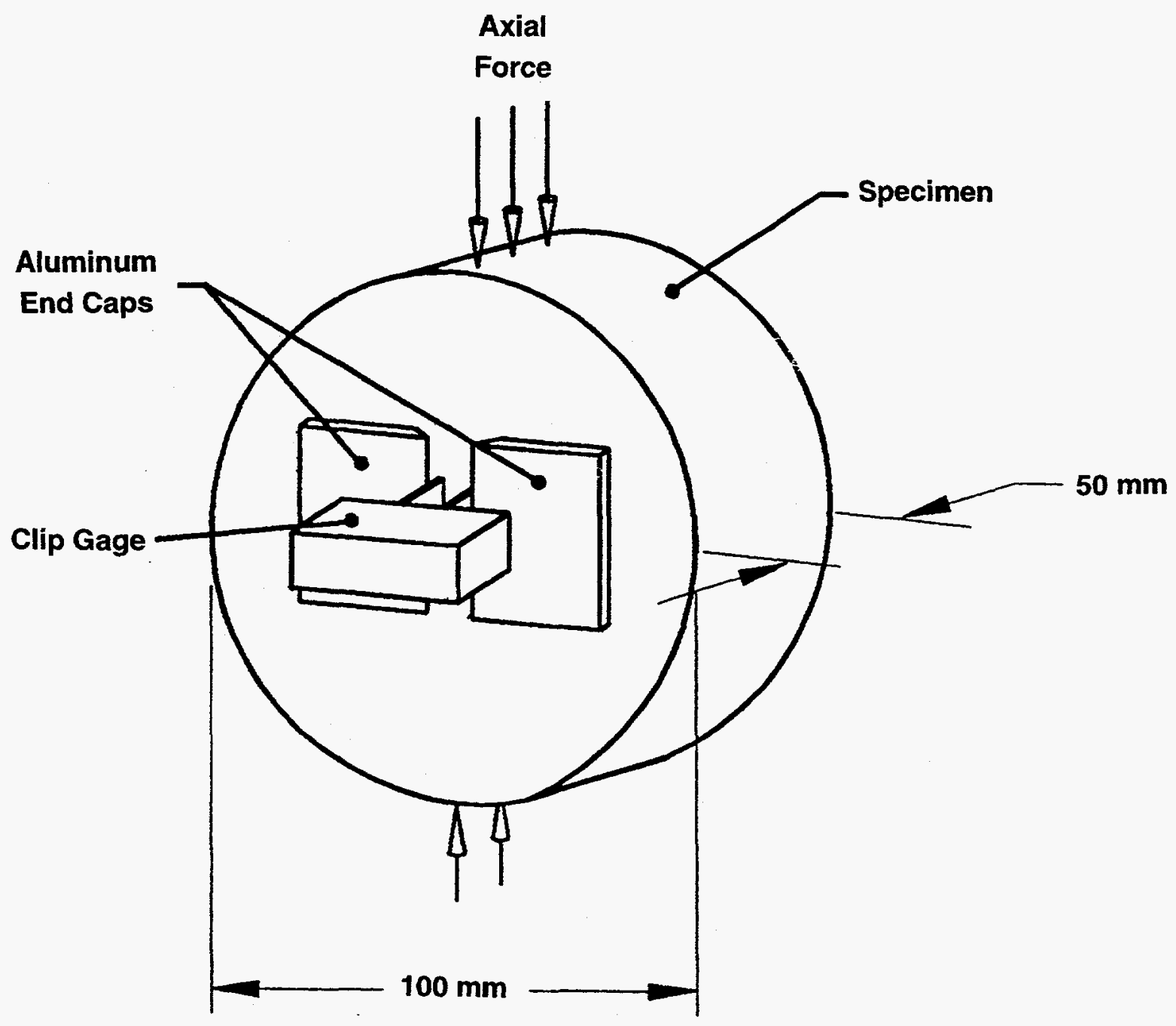

Figure 3-3. Schematic of Instrumented Indirect Tension Test Specimen. 


\subsubsection{Quasi-Static Triaxial Compression Test}

All of the quasi-static triaxial compression tests were performed in an MTS Corporation Stiff Test System (STS). As with the UTS, the STS is a computer-controlled, closed-loop servohydraulic system that comprises: (1) a horse-shoe-shaped load frame, as shown schematically in Figure 3-4; (2) a Digital Equipment Corporation (DEC) LSI-11/23 microprocessor; and (3) a control console.

The load frame, as well as the hydraulic cylinder located in the base of the load frame, is rated for a compressive force of $5 \mathrm{MN}$. In contrast to the UTS, the STS load frame is equipped with a pressure vessel to apply confining pressures up to $140 \mathrm{MPa}$. The test frame and actuator are linked to the microprocessor via an interface control console. The control console houses all signal conditioning for the instrumentation; feedback and valve driver modules for the hydraulics; and digital panel meters for display of force, confining pressure, and axial and radial specimen deformations. The DEC LSI-11/23 microprocessor provides for data acquisition and programmable control of the test system using the MTS BASIC programming language.

Each test specimen used in the triaxial compression tests was mounted between two metal platens and covered by a flexible sleeve or jacket sealed to the platens with lock wire. The jacket was 0.25 millimeter thick and protected the specimen from the confining pressure fluid (i.e., silicone oil). Two deformation extensometers were mounted directly on the test specimen at its midheight. Axial deformations were measured by an axial extensometer having an initial gage length of 50 millimeters. Radial deformations were measured by a diametral extensometer comprising a ring with four strain-gaged sensing arms located at the quarter points of the ring. The ring was placed over the test specimen and the ends of the sensing arms (which extend up from the ring) were positioned at the midheight of the specimen. The four sensing arms provide measures of radial deformation across two orthogonal diameters. When used with horizontally oriented specimens, one pair of sensing arms was aligned parallel with bedding while the other pair was aligned perpendicular to bedding.

The instrumented specimen was placed inside the pressure vessel and a small axial preload was applied manually to the specimen to seat all the interfaces. Then, the annulus between the specimen and pressure vessel wall was filled with silicone oil. The test system control code for the test was initiated by the system operator, at which point, the specimen was hydrostatically loaded at a rate of $0.02 \mathrm{MPa} / \mathrm{second}$. When the hydrostatic stress reached the confining pressure level specified for the test, the control code maintained the confining pressure at the specified level and executed an axial loading ramp to apply a stress difference (axial stress minus confining pressure) to the specimen. Axial loading was performed in strain rate control at an axial strain rate of $1 \times 10^{-5} \mathrm{~s}^{-1}$. Periodically, the axial load ramp was suspended and an unload/reload cycle was performed to acquire data for estimation of elastic properties. This sequence of loading ramps and unload/reload cycles continued until a peak axial stress was observed, at which time, the specimen was unloaded to complete the test. 


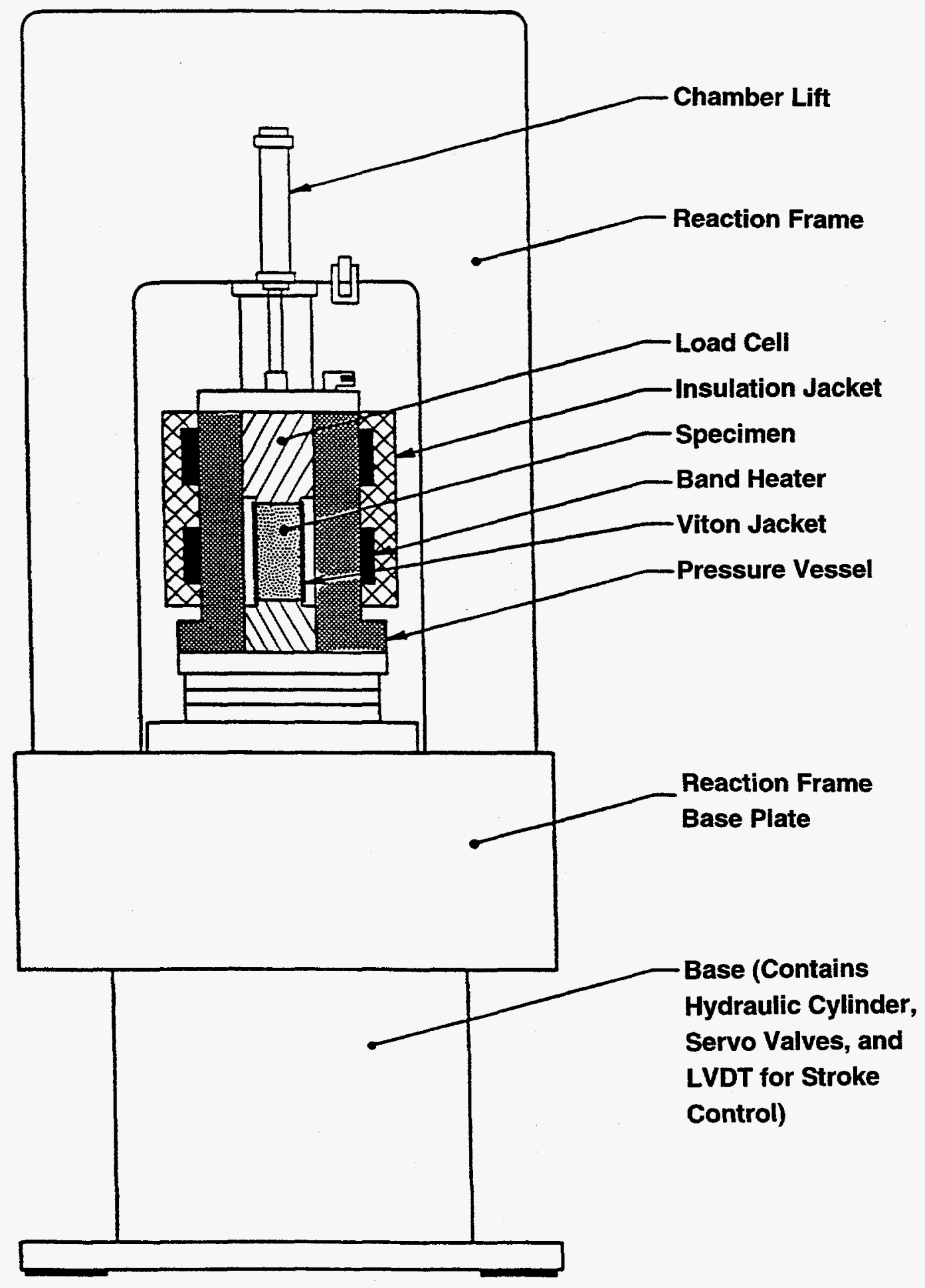

Figure 3-4. Schematic of Stiff Test System. 


\subsection{Test results}

\subsubsection{Brazilian Indirect Tension Tests}

A total of 16 Brazilian indirect tension tests was performed in the supplemental testing program, including 8 each on specimens from Field Cores TV10-3 and MX05-12, respectively. Twelve of the tension tests were performed on horizontally oriented specimens. Of these twelve, six were loaded to promote fracture parallel with bedding and six were loaded to promote fracture perpendicular to bedding. The other four tests were performed on vertically oriented specimens.

The compressional line load is plotted both as a function of compressive displacement parallel to the line load and tensile displacement perpendicular to the line load in Figure 3-5 for a typical indirect tension test. The compressional load versus displacement curve shows substantial nonlinearity at low loads but then becomes much more linear at higher loads. Although the compressional displacements have been corrected to account for nonspecimen deformations, the correction factors were established to be linear in the applied load so that the slope of the loaddisplacement curve would match the theoretical slope of the load-displacement curve for the calibration material; i.e., aluminum. Therefore, the nonlinearity in the curve at low loads is attributed to nonlinear compressive displacements of the cardboard placed in the specimen/platen interfaces. The linear portion of the curve at higher loads represents the true response of the anhydrite under this loading configuration. The compressive load versus tensile displacement curve shown in Figure 3-5 is quite linear up to the point at which failure occurs. Load-displacement curves for all tests are shown in Appendix E.

The Brazilian tensile strength test is termed an indirect test method for tensile strength because a compressive, diametral line load is applied over the length of a cylindrical specimen which, in turn, induces a tensile stress at the center of the specimen. As the compressive line load increases, so does the tensile stress. When the tensile stress exceeds the tensile strength of the specimen, a tensile fracture develops and extends along a line parallel to the applied load. The tensile stress, $T_{0}$, is then calculated in units of $\mathrm{MPa}$ according to:

$$
T_{0}=\frac{2 P}{\pi D L}
$$

where:

$$
\begin{aligned}
& P=\text { compressive line load at failure }, \mathrm{MN} \\
& D=\text { specimen diameter, meters } \\
& L=\text { specimen length, meters }
\end{aligned}
$$

Table 3-4 presents the tensile strength for each of the 16 Marker Bed 139 anhydrite specimens tested under the supplemental testing program. The tensile strengths for the specimens from Field Core TV10-3 range from 2.3 MPa to $7.7 \mathrm{MPa}$. The average tensile strength of vertically oriented specimens from this core appears to be slightly higher than the average tensile strength 


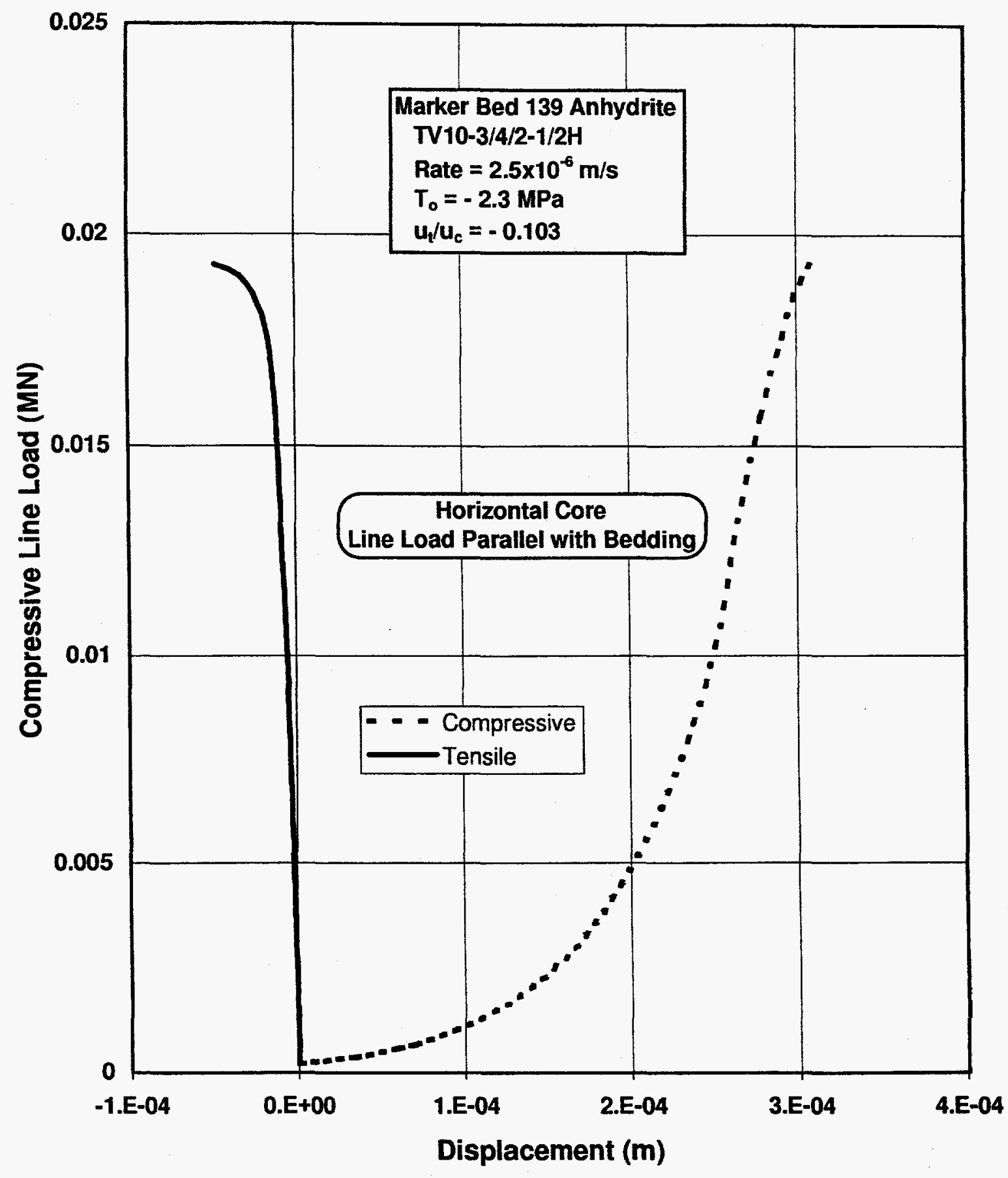

Figure 3-5. Compressive Line Load Versus Compressive and Tensile Displacements for a Typical Brazilian Indirect Tension Test on Marker Bed 139 Anhydrite. 
Table 3-4. Summary of Results From Brazilian Indirect Tension Tests of Marker Bed 139 Anhydrite - Supplemental Testing

\begin{tabular}{|c|c|c|c|c|}
\hline $\begin{array}{l}\text { Specimen } \\
\text { I.D. }\end{array}$ & $\begin{array}{c}\text { Line } \\
\text { Load } \\
\text { Direction }^{(a)}\end{array}$ & $\begin{array}{c}\text { Tensile } \\
\text { Strength } \\
\text { (MPa) }\end{array}$ & $\begin{array}{c}\text { Displacement } \\
\text { Ratio } \\
\boldsymbol{u}_{t} / \boldsymbol{u}_{\boldsymbol{c}}\end{array}$ & $\begin{array}{c}\text { Modulus } \\
\text { Ratio } \\
E_{t} / E_{c}^{(b)}\end{array}$ \\
\hline TV $10-3 / 4 / 2-1 / 5 \mathrm{H}$ & Parallel & 4.6 & -0.017 & 0.13 \\
\hline TV $10-3 / 4 / 3-7 / 1 \mathrm{H}$ & Parallel & 4.6 & -0.006 & - \\
\hline TV $10-3 / 4 / 2-1 / 2 \mathrm{H}$ & Parallel & 2.3 & -0.103 & - \\
\hline \multicolumn{2}{|c|}{ Mean \pm Standard Deviation } & $3.8 \pm 1.3$ & & - \\
\hline TV10-3/4/2-1/4H & Perpendicular & 4.6 & N/A & - \\
\hline TV10-3/4/2-1/3H & Perpendicular & 2.8 & -0.024 & 0.53 \\
\hline TV10-3/4/3-7/2H & Perpendicular & 4.0 & -0.005 & 一 \\
\hline \multicolumn{2}{|c|}{ Mean \pm Standard Deviation } & $3.8 \pm 0.9$ & & \\
\hline TV $10-3 / 4 / 1-6 / 1 \mathrm{~V}$ & $\mathrm{~N} / \mathrm{A}$ & 4.9 & -0.022 & 0.41 \\
\hline TV10-3/4/1-6/2V & N/A & 7.7 & -0.011 & - \\
\hline \multicolumn{2}{|c|}{ Mean } & 6.3 & & \\
\hline MX05-12-6-3/2-1/2H & Parallel & 1.9 & -0.370 & - \\
\hline $\mathrm{MX} 05-12-6-3 / 2-2 / 1 \mathrm{H}$ & Parallel & 3.2 & -0.024 & 0.53 \\
\hline 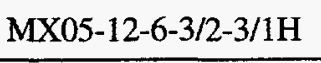 & Parallel & 2.6 & -0.048 & - \\
\hline \multicolumn{2}{|c|}{ Mean \pm Standard Deviation } & $2.6 \pm 0.7$ & & \\
\hline 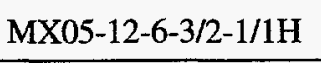 & Perpendicular & 4.4 & -0.023 & 0.47 \\
\hline 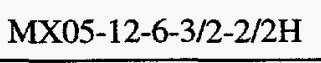 & Perpendicular & 2.2 & -0.021 & 0.35 \\
\hline 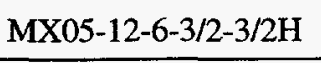 & Perpendicular & 3.7 & -0.490 & 一 \\
\hline \multicolumn{2}{|c|}{ Mean \pm Standard Deviation } & $3.4 \pm 1.1$ & & \\
\hline 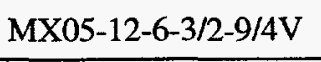 & N/A & 4.7 & -0.010 & - \\
\hline $\mathrm{MX05-12-6-3/2-2/2 \textrm {V }}$ & N/A & 4.0 & -0.017 & 0.13 \\
\hline \multicolumn{2}{|c|}{ Mean } & 4.4 & & \\
\hline
\end{tabular}

(a) Indicates direction with respect to bedding.

(b) Assumes a Poisson's ratio of 0.35 .

of the horizontally oriented specimens, and there appears to be no anisotropy in tensile strength based on the results of the horizontally oriented specimens. The tensile strengths for the specimens from Field Core MX05-12 range from 1.9 MPa to 4.7 MPa. The average tensile strength of vertically oriented specimens from this second core also appears to be slightly higher than the average strength of the horizontally oriented specimens, and there appears to be weak 
anisotropy in tensile strength based on the results of the horizontally oriented specimens. When the test results from the two field cores are compared, the average tensile strength for the specimens from Core TV10-3 is higher than the average tensile strength of the specimens from Core MX05-12.

The compressive load versus compressive and tensile displacement curves were used to estimate values of Young's modulus under tensile stress states. The method utilized was to assume, initially, that the compressive and tensile Young's moduli were different and then to perform a linear-elastic finite element analysis of the indirect tension test configuration using the program SPECTROM-32, Version 4.10 (Callahan, 1998). In this analysis, tensile and compressive displacements, $u_{t}$ and $u_{c}$, were calculated at positions corresponding to the gage lengths of the instrumentation used during actual testing. The ratio of these displacements, $u_{t} / u_{c}$, were plotted against the ratio of the tensile and compressive elastic moduli, $E_{t} / E_{c}$, in the form of a nomograph as shown in Figure 3-6. The analysis was performed at Poisson's ratio, v, values of 0.20 to 0.40 , assuming the tensile and compressive values of Poisson's ratio are equal and the line load is distributed over the arc length subtended by a central angle of $14^{\circ}$. The experimental value of the displacement ratio was determined for each test from the slopes of the compressive load versus compressive and tensile displacement curves and then compared to the curves in Figure 3-6 to obtain the experimental ratio for Young's modulus. Because the tensile displacements in the indirect tension tests were extremely small, the experimental displacement ratio, $u_{t} / u_{c}$, proved to be quite variable, as shown in Table 3-4. Therefore, modulus ratios were determined only for those displacement ratios that plotted within the nomograph shown in Figure 3-6. Assuming a Poisson's ratio of 0.35 , the modulus ratio, as shown in Table 3-4, varies from 0.13 to 0.53 with an average of 0.36 ; however, because of the variability in $u_{t} / u_{c}$, this average is highly speculative.

\subsubsection{Quasi-Static Triaxial Compression Tests}

A total of 16 quasi-static triaxial compression tests was performed in the supplemental testing program, including 8 each on specimens from Field Cores TV10-3 and MX05-12, respectively. Eight of the tests were performed on horizontally oriented specimens, while eight were performed on vertically oriented specimens. In addition to confined compressive strength, the data acquired from the tests were used to estimate elastic moduli including Young's modulus, $E$, and Poisson's ratio, $v$.

Figure 3-7 presents stress difference versus strain curves for a typical test on a horizontally oriented test specimen. Similar curves are presented for each of the 16 triaxial compression tests in Appendix F. All tests exhibited some level of nonlinearity in the stress-strain behavior upon initial loading with the degree of nonlinearity most likely dependent on the level of halite impurities in the test specimen. As shown in Figure 3-7, unload/reload cycles were performed throughout each test to obtain data for estimating elastic moduli. As discussed above, radial strain was measured with a diametral extensometer equipped with four sensing arms that contacted the specimen across two orthogonal diameters. One set of sensing arms was mounted so it measured radial deformation normal to bedding ("Radial Strain - 1"), while the other set measured radial deformation parallel with bedding ("Radial Strain - 2"). In tests performed on vertically oriented specimens, the position of the diametral extensometer on the specimen was arbitrary. 


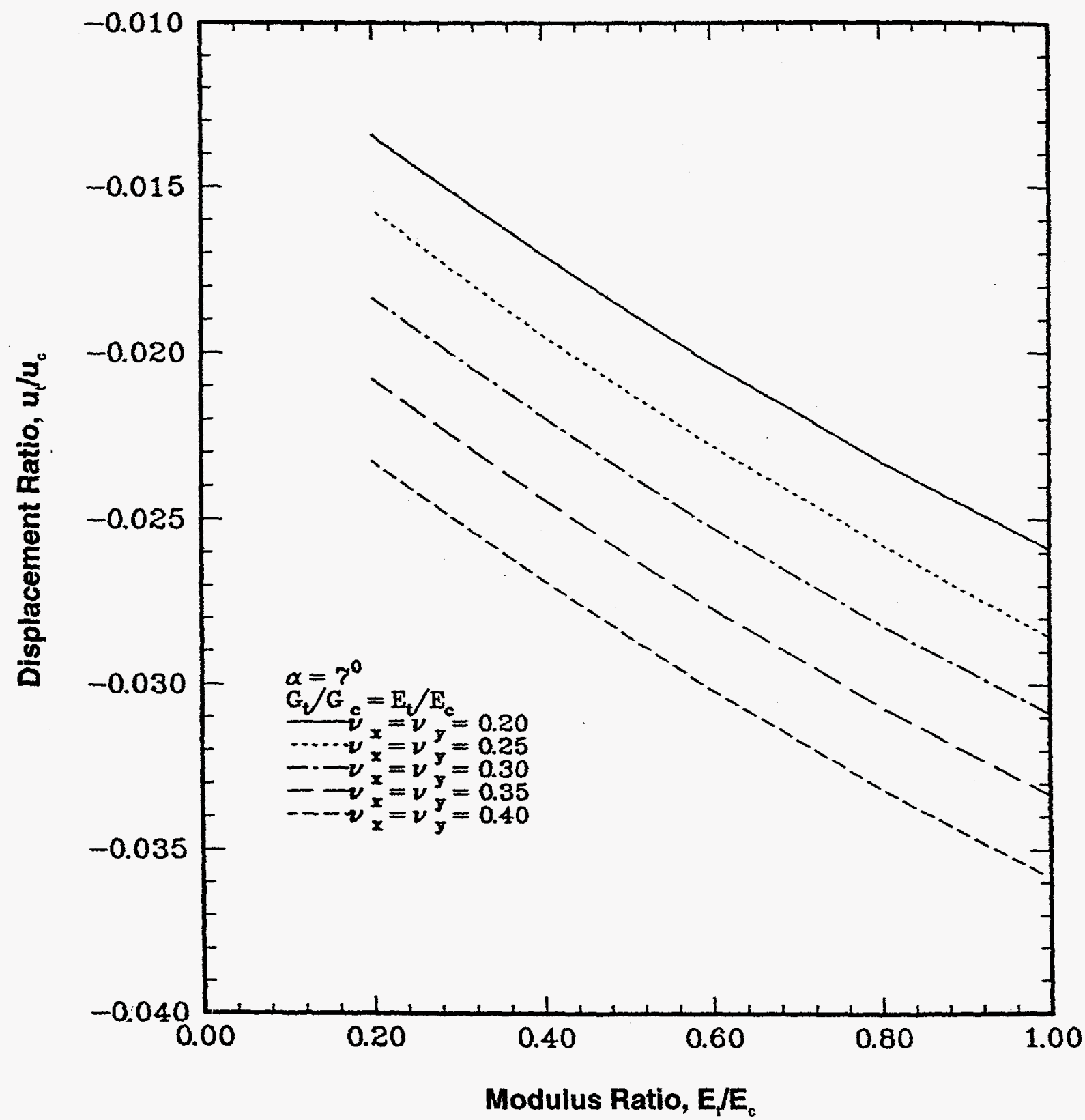

Figure 3-6. Tensile and Compressive Displacement Ratio Versus Tensile and Compressive Modulus Ratio for Brazilian Indirect Tension Test Configuration. 


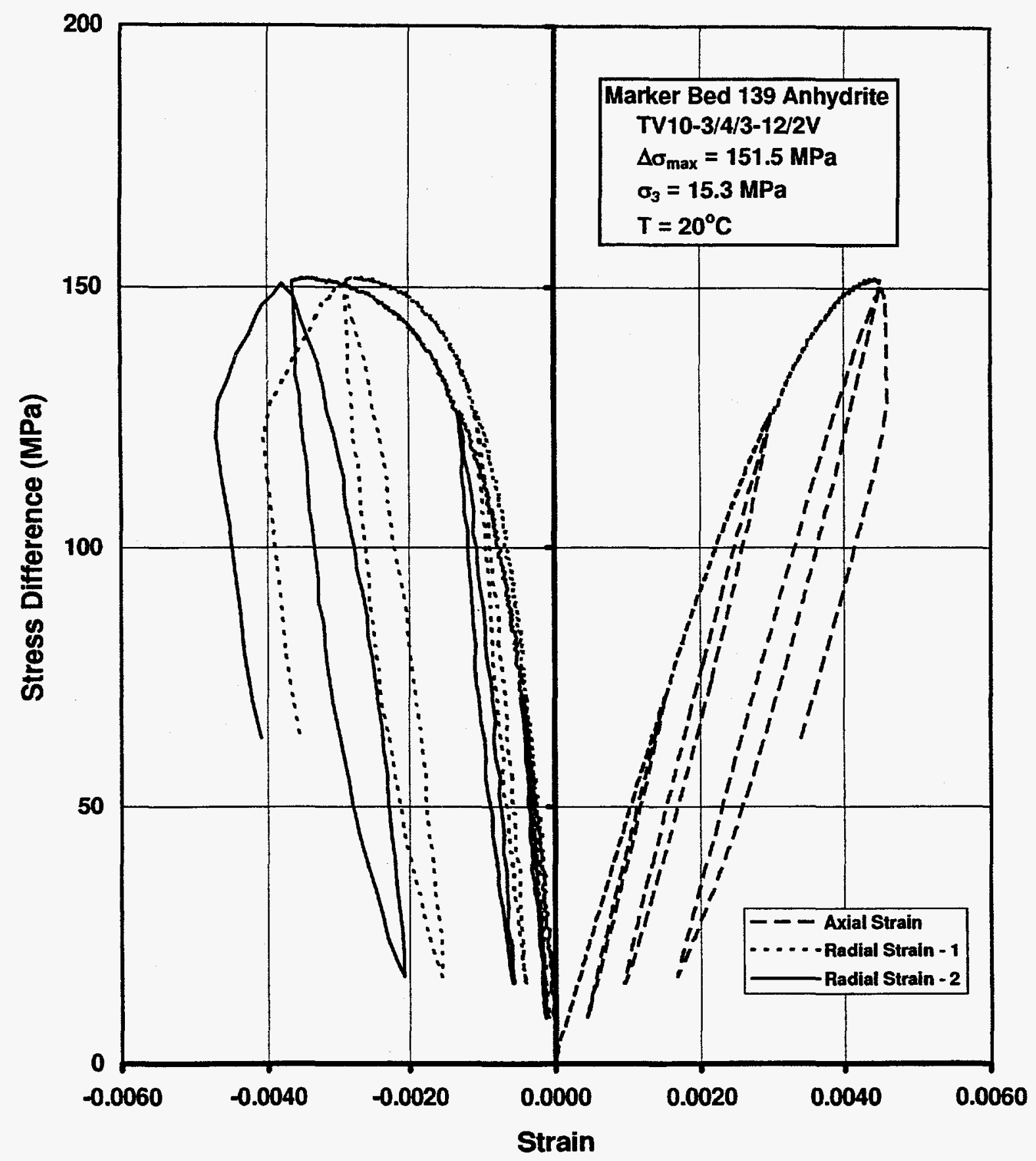

Figure 3-7. Stress Difference Versus Axial and Radial Strains for a Typical Triaxial Compression Test on a Horizontally Oriented Anhydrite Test Specimen. 
The stress difference at failure in each test was defined as the peak or ultimate stress difference attained during the test. Estimates of Young's modulus, $E$, were calculated from the data acquired both during initial loading and from the unload/reload cycles using:

$$
E=\frac{\Delta \sigma_{i}-\Delta \sigma_{0}}{\Delta \varepsilon_{1}}
$$

where the numerator of Equation 3-2 represents the change in stress difference during either initial loading or the unload/reload cycle, and $\Delta \varepsilon_{1}$ is the corresponding change in the axial strain. The right-hand side of Equation 3-2 represents the slope of either the initial loading stress-strain curve or the unload/reload stress-strain curve. This slope was determined from a least-squares fit to the data acquired either between 20 and 60 percent of the first unload stress for the initial loading portion of the stress-strain curve or below 80 percent of the unload stress difference for the unload/reload portions of the stress-strain curve. Two estimates of Poisson's ratio, $v$, were determined for each unload/reload cycle using:

$$
v=-\frac{\Delta \varepsilon_{3}}{\Delta \varepsilon_{1}}
$$

where $\Delta \varepsilon_{3}$ and $\Delta \varepsilon_{1}$ are the changes in radial strain and axial strain, respectively, measured either during initial loading or the unload/reload cycle. As with the estimation of Young's modulus, Poisson's ratio was estimated from fits of Equation 3-3 to the data acquired either between 20 to 60 percent of the first unload stress for the initial loading portion of the stress-strain curve or below 80 percent of the unload stress difference for the unload/reload portions of the stress-strain curve. Tables 3-5 and 3-6 summarize, by specimen identification number, the results of the quasi-static triaxial compression tests performed on the Marker Bed 139 anhydrite under the supplemental testing programs. The results include specimen orientation, confining pressure, stress difference at failure, and elastic constants, $E$ and $v$. As expected, the stress difference at failure increases with confining pressure except for the highest confining pressure tests conducted on specimens from Field Core TV10-3. This anomalous result is attributed to specimen-to-specimen variability such as impurities, planes of weakness, etc. Values of Young's modulus determined from initial loading data are lower than the values determined from unload/reload data. This difference may be attributed to a component of inelastic strain measured during initial loading, but absent during unload/reload cycles.

At equivalent confining pressures, the strengths of the specimens recovered from Field Core TV10-3 are higher than the strengths of the specimens recovered from Field Core MX05-12, particularly at high confining pressure. Also, when comparing the strengths of horizontally and vertically oriented specimens, there is little evidence of strength anisotropy. Estimates of Young's modulus for the specimens recovered from Field Core TV10-3 are significantly higher than the estimates for the specimens recovered from Field Core MX05-12. In contrast, the value of Poisson's ratio for the specimens from the two field cores is similar. Neither Young's modulus nor Poisson's ratio appear to be affected by confining pressure or by the level of induced deformation. 
Table 3-5. Summary of Results for Triaxial Compression Test of Marker Bed 139, Field Core TV10-3 - Supplemental Test Matrix

\begin{tabular}{|c|c|c|c|c|c|c|}
\hline \multirow{3}{*}{$\begin{array}{l}\text { Specimen } \\
\text { I.D. }^{(a)}\end{array}$} & \multicolumn{4}{|c|}{ Elastic Constants } & \multirow{3}{*}{$\begin{array}{c}\text { Confining } \\
\text { Pressure } \\
\text { (MPa) }\end{array}$} & \multirow{3}{*}{$\begin{array}{c}\text { Peak } \\
\text { Stress } \\
\text { Difference } \\
\text { (MPa) }\end{array}$} \\
\hline & \multirow{2}{*}{$\begin{array}{l}\text { U/R } \\
\text { Cycle }\end{array}$} & \multirow{2}{*}{$\begin{array}{l}\text { Young's } \\
\text { Modulus, } E \\
\text { (GPa) }\end{array}$} & \multicolumn{2}{|c|}{$\begin{array}{c}\text { Poisson's Ratio, } \\
v^{(\mathbf{b})}\end{array}$} & & \\
\hline & & & $\mathbf{1}$ & 2 & & \\
\hline TV10-3/4/1-3/2V & $\begin{array}{c}\text { Initial } \\
1\end{array}$ & $\begin{array}{l}33.5 \\
48.2\end{array}$ & $\begin{array}{l}0.22 \\
-\end{array}$ & $\begin{array}{c}0.23 \\
-\end{array}$ & 0.0 & 52.7 \\
\hline TV10-3/4/1-1/2V & $\begin{array}{c}\text { Initial } \\
1 \\
2 \\
3 \\
4\end{array}$ & $\begin{array}{l}26.2 \\
43.7 \\
43.0 \\
40.0 \\
37.6\end{array}$ & $\begin{array}{l}0.31 \\
0.27 \\
0.28 \\
0.28 \\
0.31\end{array}$ & $\begin{array}{l}0.32 \\
0.27 \\
0.28 \\
0.29 \\
0.35\end{array}$ & 5.3 & 65.2 \\
\hline TV10-3/4/3-11/2V & $\begin{array}{c}\text { Initial } \\
1 \\
2\end{array}$ & $\begin{array}{l}49.7 \\
54.8 \\
53.6\end{array}$ & $\begin{array}{l}0.28 \\
0.29 \\
0.30\end{array}$ & $\begin{array}{l}0.23 \\
0.28 \\
0.29\end{array}$ & 10.3 & 173.2 \\
\hline TV10-3/4/3-12/2V & $\begin{array}{c}\text { Initial } \\
1 \\
2 \\
\end{array}$ & $\begin{array}{l}47.0 \\
56.5 \\
52.7 \\
\end{array}$ & $\begin{array}{l}0.25 \\
0.26 \\
0.32\end{array}$ & $\begin{array}{l}0.28 \\
0.28 \\
0.36\end{array}$ & 15.3 & 151.5 \\
\hline TV $10-3 / 4 / 3-2 / 1 \mathrm{H}$ & $\begin{array}{c}\text { Initial } \\
1\end{array}$ & - & $\overline{0.21}$ & $\overline{0.19}$ & 0.0 & 82.2 \\
\hline TV10-3/4/3-8/1H & $\begin{array}{c}\text { Initial } \\
1 \\
2 \\
\end{array}$ & $\begin{array}{l}69.5 \\
71.6 \\
52.4 \\
\end{array}$ & $\begin{array}{l}0.29 \\
0.32 \\
0.40\end{array}$ & $\begin{array}{l}0.30 \\
0.31 \\
0.32\end{array}$ & 5.1 & 156.5 \\
\hline TV10-3/4/3-9/1H & $\begin{array}{c}\text { Initial } \\
1 \\
2 \\
\end{array}$ & $\begin{array}{l}75.8 \\
74.9 \\
60.2 \\
\end{array}$ & $\begin{array}{l}0.30 \\
0.30 \\
0.34 \\
\end{array}$ & $\begin{array}{l}0.29 \\
0.26 \\
0.32\end{array}$ & 10.3 & 178.8 \\
\hline TV10-3/4/3-10/1H & $\begin{array}{c}\text { Initial } \\
1 \\
2 \\
3\end{array}$ & $\begin{array}{l}62.0 \\
64.0 \\
54.3 \\
46.3\end{array}$ & $\begin{array}{l}0.27 \\
0.28 \\
0.32 \\
0.39\end{array}$ & $\begin{array}{l}0.37 \\
0.27 \\
0.32 \\
0.34\end{array}$ & 15.3 & 157.0 \\
\hline
\end{tabular}

(a) The last character in the specimen identification number indicates the orientation of the test specimen; i.e., "V" implies the central axis is vertical (normal to bedding) and " $\mathrm{H}$ " implies the central axis is horizontal (parallel with bedding).

(b) For tests performed on horizontally oriented specimens, Poisson's ratio No. 1 is for radial deformations normal to bedding, while No. 2 is for radial deformations parallel with bedding. For calculated values of Poisson's ratio greater than 0.5 or less than 0 , no entry is given in the table. 
Table 3-6. Summary of Results for Triaxial Compression Tests of Marker Bed 139, Field Core MX05-12 — Supplemental Test Matrix

\begin{tabular}{|c|c|c|c|c|c|c|}
\hline \multirow{3}{*}{$\begin{array}{l}\text { Specimen } \\
\text { I.D. }^{(a)}\end{array}$} & \multicolumn{4}{|c|}{ Elastic Constants } & \multirow{3}{*}{$\begin{array}{c}\text { Confining } \\
\text { Pressure } \\
\text { (MPa) }\end{array}$} & \multirow{3}{*}{$\begin{array}{c}\text { Peak } \\
\text { Stress } \\
\text { Difference } \\
\text { (MPa) }\end{array}$} \\
\hline & \multirow{2}{*}{$\begin{array}{c}\text { U/R } \\
\text { Cycle }\end{array}$} & \multirow{2}{*}{$\begin{array}{l}\text { Young's } \\
\text { Modulus, } E \\
\text { (GPa) }\end{array}$} & \multicolumn{2}{|c|}{$\begin{array}{l}\text { Poisson's } \\
\text { Ratio, }^{\text {(b) }} \\
\end{array}$} & & \\
\hline & & & 1 & 2 & & \\
\hline MX05-12-6-3/2-11/1V & $\begin{array}{c}\text { Initial } \\
1 \\
2 \\
3 \\
4 \\
5 \\
6\end{array}$ & $\begin{array}{r}7.9 \\
22.0 \\
24.9 \\
25.5 \\
25.9 \\
24.6 \\
25.0\end{array}$ & $\begin{array}{c}- \\
- \\
0.31 \\
0.17 \\
0.45 \\
0.45 \\
-\end{array}$ & $\begin{array}{l}0.07 \\
- \\
0.19 \\
0.09 \\
0.25 \\
0.25 \\
0.28\end{array}$ & 0.0 & 35.6 \\
\hline $\mathrm{MX} 05-12-6-3 / 2-12 / 1 \mathrm{~V}$ & $\begin{array}{c}\text { Initial } \\
1\end{array}$ & $\begin{array}{l}14.9 \\
32.6\end{array}$ & $\begin{array}{l}0.38 \\
0.46\end{array}$ & $\begin{array}{l}0.38 \\
0.35\end{array}$ & 5.3 & 62.9 \\
\hline $\mathrm{MX} 05-12-6-3 / 2-13 / 1 \mathrm{~V}$ & $\begin{array}{c}\text { Initial } \\
1 \\
2\end{array}$ & $\begin{array}{r}8.7 \\
30.2 \\
25.4\end{array}$ & $\begin{array}{l}0.42 \\
0.14 \\
0.40\end{array}$ & $\begin{array}{l}-\overline{0.19} \\
0.39\end{array}$ & 10.3 & 69.1 \\
\hline MX05-12-6-3/2-15/2V & $\begin{array}{c}\text { Initial } \\
\mathbf{1} \\
2 \\
3\end{array}$ & $\begin{array}{r}7.8 \\
35.7 \\
32.6 \\
30.6\end{array}$ & $\begin{array}{l}0.35 \\
0.31 \\
0.37 \\
0.37\end{array}$ & $\begin{array}{l}0.28 \\
0.30 \\
0.32 \\
0.35\end{array}$ & 15.3 & 73.7 \\
\hline $\mathrm{MX05}-12-6-3 / 2-4 / 1 \mathrm{H}$ & $\begin{array}{c}\text { Initial } \\
1\end{array}$ & $\begin{array}{l}23.3 \\
32.2\end{array}$ & $\begin{array}{l}0.31 \\
0.49\end{array}$ & $\begin{array}{l}0.26 \\
0.34\end{array}$ & 0.0 & 43.7 \\
\hline MX05-12-6-3/2-5/1H & $\begin{array}{c}\text { Initial } \\
1 \\
2 \\
3 \\
4 \\
\end{array}$ & $\begin{array}{l}22.1 \\
32.3 \\
27.5 \\
25.4 \\
24.4 \\
\end{array}$ & $\begin{array}{l}-\overline{0.24} \\
- \\
0.45 \\
-\end{array}$ & $\begin{array}{l}- \\
0.27 \\
0.40 \\
0.38 \\
0.50 \\
\end{array}$ & 5.3 & 52.7 \\
\hline MX05-12-6-3/2-6/1H & $\begin{array}{c}\text { Initial } \\
1 \\
2 \\
3\end{array}$ & $\begin{array}{l}12.6 \\
29.8 \\
26.3 \\
25.3\end{array}$ & $\begin{array}{c}0.39 \\
0.43 \\
- \\
0.40\end{array}$ & $\begin{array}{l}0.44 \\
0.34 \\
0.48 \\
0.33\end{array}$ & 10.1 & 63.3 \\
\hline MX05-12-6-3/2-7/1H & $\begin{array}{c}\text { Initial } \\
1 \\
2\end{array}$ & $\begin{array}{l}14.4 \\
28.5 \\
26.0\end{array}$ & - & $\begin{array}{l}-\overline{0.47} \\
0.47\end{array}$ & 15.2 & 68.6 \\
\hline
\end{tabular}

(a) The last character in the specimen identification number indicates the orientation of the test specimen, i.e., "V" implies the central axis is vertical (normal to bedding) and " $\mathrm{H}$ " implies the central axis is horizontal (parallel with bedding).

(b) For tests performed on horizontally oriented specimens, Poisson's ratio No. 1 is for radial deformations normal to bedding, while No. 2 is for radial deformations parallel with bedding. For calculated values of Poisson's ratio greater than 0.5 or less than 0 , no entry is given in the table. 
This page intentionally left blank 


\subsection{ANALYSIS OF ANHYDRITE DATA}

\subsection{Mechanical Properties}

\subsubsection{Brazilian Indirect Tensile Strength}

A total of 54 Brazilian indirect tension tests is included in the database and comprise 38 tests and 16 tests, respectively, on anhydrite specimens prepared from Salado Formation and Castile Formation cores. Data are available for two nominal specimen diameters; i.e., 50 millimeters and 100 millimeters. Data are also available for two specimen orientations; i.e., horizontal and vertical, which correspond approximately to parallel and perpendicular orientations of the central axes of the test specimens with respect to bedding. Table 4-1 summarizes the results of the Brazilian indirect tensile strength of anhydrite recovered from the Salado and Castile Formations and includes mean values and standard deviations for subsets of the database for comparative purposes.

Considering all data, the mean tensile strength of the Castile anhydrite is slightly higher than the mean tensile strength of the Salado anhydrite; i.e., 5.7 MPa compared to 4.8 MPa. This difference is attributed primarily to the lower strengths of the test specimens recovered from the MX05-12 core. Tensile strength has a weak dependence on specimen size with smaller specimens having higher mean strengths. Also, on average, the tensile strength of horizontally oriented specimens is lower than for vertically oriented specimens. In general, however, the statistical effect of variables such as recovery location and specimen size and orientation on indirect tensile strength is weak because of the variability of the test results as indicated by the relatively large values of standard deviation for the different subsets of the database.

\subsubsection{Unconfined Compressive Strength}

A total of 18 unconfined compression tests is included in the database and comprise 12 tests and 6 tests, respectively, on anhydrite specimens prepared from Salado Formation and Castile Formation cores. Data are available for three nominal specimen diameters; i.e., 37, 50, and 100 millimeters. Data are also available for two specimen orientations; i.e., horizontal and vertical, which correspond approximately to parallel and perpendicular orientations of the central axes of the test specimens with respect to bedding. Table 4-2 summarizes the results of the unconfined compressive strengths of anhydrite recovered from the Salado and Castile Formations and includes mean values and standard deviations for subsets of the database for comparative purposes.

For identical specimen size and orientation, the results summarized in Table 4-2 show that the mean unconfined compressive strength of Salado Formation anhydrite from the MX05-12 core is significantly lower than the mean strength of the Salado Formation anhydrite from the TV10-3 core. In contrast, the mean unconfined compressive strength of the Salado Formation anhydrite from the TV10-3 core is significantly lower than the mean compressive strength of the Castile Formation anhydrite. The data also show that the unconfined compressive strength of the Salado 
Table 4-1. Summary of All Indirect Tensile Strength Data for WIPP Anhydrite (Page 1 of 2)

\begin{tabular}{|c|c|c|c|c|}
\hline \multirow{2}{*}{$\begin{array}{l}\text { Specimen } \\
\text { I.D. }\end{array}$} & \multirow{2}{*}{$\begin{array}{c}\text { Specimen } \\
\text { Diameter } \\
\quad(\mathbf{m m})\end{array}$} & \multicolumn{3}{|c|}{ Tensile Strength (MPa) } \\
\hline & & $\begin{array}{c}\text { Test } \\
\text { Estimate }^{(a)}\end{array}$ & Mean & $\begin{array}{l}\text { Standard } \\
\text { Deviation }\end{array}$ \\
\hline \multicolumn{5}{|c|}{ Salado Formation Anhydrite } \\
\hline TV10-3-1/1-2 & 54 & $5.1(\mathrm{~V})$ & \multirow{15}{*}{5.9} & \multirow{15}{*}{1.7} \\
\hline TV $10-3-1 / 2-2$ & 54 & $2.0(\mathrm{~V})$ & & \\
\hline TV10-3-1/3-2 & 54 & $6.1(\mathrm{~V})$ & & \\
\hline TV10-3-1/4-2 & 54 & $6.5(V)$ & & \\
\hline TV10-3-1/5-2 & 54 & $5.2(\mathrm{~V})$ & & \\
\hline TV10-3-1/6-2 & 54 & $4.6(V)$ & & \\
\hline TV10-3-1/7-2 & 54 & $2.6(\mathrm{~V})$ & & \\
\hline TV10-3-1/8-2 & 54 & $6.7(V)$ & & \\
\hline TV10-3-1/9-2 & 54 & $8.1(\mathrm{~V})$ & & \\
\hline TV10-3-1/10-2 & 54 & $7.4(\mathrm{~V})$ & & \\
\hline TV10-3-1/11-2 & 54 & $6.8(\mathrm{~V})$ & & \\
\hline TV10-3-1/13-2 & 54 & $7.1(\mathrm{~V})$ & & \\
\hline TV10-3-1/14-2 & 54 & $6.1(\mathrm{~V})$ & & \\
\hline TV10-3-1/14-4 & 54 & $6.8(V)$ & & \\
\hline TV10-3-1/18-2 & 54 & $7.5(V)$ & & \\
\hline MX05-12-6-1-2/7-1 & 54 & $4.4(V)$ & \multirow{6}{*}{4.9} & \multirow{6}{*}{1.4} \\
\hline MX05-12-6-1-2/8-3 & 54 & $4.3(\mathrm{~V})$ & & \\
\hline MX05-12-6-1-2/11-3 & 54 & $3.5(\mathrm{~V})$ & & \\
\hline MX05-12-6-1-2/12-3 & 54 & $3.9(\mathrm{~V})$ & & \\
\hline MX05-12-6-1-2/14-2 & 54 & $5.8(V)$ & & \\
\hline MX05-12-6-1-2/20-1 & 54 & $7.2(\mathrm{~V})$ & & \\
\hline $8 / 2552$ & 100 & $3.9(\mathrm{~V})$ & \multirow{3}{*}{5.5} & \multirow{3}{*}{2.0} \\
\hline TV10-3/4/1-6/1V & 100 & $4.9(\mathrm{~V})$ & & \\
\hline TV10-3/4/1-6/2V & 100 & $7.7(\mathrm{~V})$ & & \\
\hline $\mathrm{MX05-12-6-3/2-9/4V}$ & 100 & $4.7(\mathrm{~V})$ & \multirow{2}{*}{4.4} & \multirow{2}{*}{ - } \\
\hline $\mathrm{MX} 05-12-6-3 / 2-2 / 2 \mathrm{~V}$ & 100 & $4.0(\mathrm{~V})$ & & \\
\hline TV10-3/4/2-1/5H & 100 & $4.6(\mathrm{HP})$ & \multirow{3}{*}{3.8} & \multirow{3}{*}{1.3} \\
\hline TV10-3/4/3-7/1H & 100 & $4.6(\mathrm{HP})$ & & \\
\hline TV10-3/4/2-1/2H & 100 & $2.3(\mathrm{HP})$ & & \\
\hline
\end{tabular}


Table 4-1. Summary of All Indirect Tensile Strength Data for WIPP Anhydrite (Page 2 of 2)

\begin{tabular}{|c|c|c|c|c|}
\hline \multirow{2}{*}{$\begin{array}{c}\text { Specimen } \\
\text { I.D. }\end{array}$} & \multirow{2}{*}{$\begin{array}{c}\text { Specimen } \\
\text { Diameter } \\
(\mathbf{m m})\end{array}$} & \multicolumn{3}{|c|}{ Tensile Strength (MPa) } \\
\hline & & $\begin{array}{c}\text { Test } \\
\text { Estimate }^{(\mathfrak{a})}\end{array}$ & Mean & $\begin{array}{l}\text { Standard } \\
\text { Deviation }\end{array}$ \\
\hline \multicolumn{5}{|c|}{ Salado Formation Anhydrite } \\
\hline TV10-3/4/2-1/4H & 100 & $4.6(\mathrm{HN})$ & \multirow{3}{*}{3.8} & \multirow{3}{*}{0.9} \\
\hline TV10-3/4/2-1/3H & 100 & $2.8(\mathrm{HN})$ & & \\
\hline TV10-3/4/2-7/2H & 100 & $4.0(\mathrm{HN})$ & & \\
\hline $\mathrm{MX} 05-12-6-3 / 2-1 / 2 \mathrm{H}$ & 100 & $1.9(\mathrm{HP})$ & \multirow{3}{*}{2.6} & \multirow{3}{*}{0.7} \\
\hline MX05-12-6-3/2-2/1H & 100 & $3.2(\mathrm{HP})$ & & \\
\hline MX05-12-6-3/2-3/1H & 100 & $2.6(\mathrm{HP})$ & & \\
\hline MX05-12-6-3/2-1/1H & 100 & $4.4(\mathrm{HN})$ & \multirow{3}{*}{3.4} & \multirow{3}{*}{1.1} \\
\hline 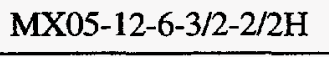 & 100 & $2.2(\mathrm{HN})$ & & \\
\hline MX05-12-6-3/2-3/2H & 100 & $3.7(\mathrm{HN})$ & & \\
\hline \multicolumn{3}{|c|}{ All Salado Formation Data } & 4.8 & 1.8 \\
\hline \multicolumn{5}{|c|}{ Castile Formation Anhydrite } \\
\hline $7 / 2957(1)$ & 50 & $9.8(\mathrm{~V})$ & \multirow{4}{*}{6.7} & \multirow{4}{*}{2.5} \\
\hline $7 / 2957(2)$ & 50 & $5.0(\mathrm{~V})$ & & \\
\hline $7 / 2957(3)$ & 50 & $4.3(\mathrm{~V})$ & & \\
\hline $8 / 3009$ & 50 & $7.5(\mathrm{~V})$ & & \\
\hline $7 / 2957(4)$ & 100 & $6.5(V)$ & 5.4 & 1.2 \\
\hline $7 / 2959$ & 100 & $6.6(V)$ & & \\
\hline $7 / 2960$ & 100 & $6.6(V)$ & & \\
\hline $8 / 3019$ & 100 & $5.4(\mathrm{~V})$ & & \\
\hline $7 / 3340$ & 100 & $3.9(\mathrm{~V})$ & & \\
\hline $7 / 3388$ & 100 & $5.9(V)$ & & \\
\hline $7 / 3389$ & 100 & $3.6(V)$ & & \\
\hline $7 / 3623(1)$ & 100 & $4.8(V)$ & & \\
\hline $7 / 3623(2)$ & 100 & $7.1(\mathrm{~V})$ & & \\
\hline $7 / 3858(1)$ & 100 & $4.2(\mathrm{~V})$ & & \\
\hline $7 / 3858(2)$ & 100 & $5.2(\mathrm{~V})$ & & \\
\hline $7 / 3859$ & 100 & $5.3(\mathrm{~V})$ & & \\
\hline & ormation D & & 5.7 & 1.6 \\
\hline
\end{tabular}

(a) Values in parentheses indicate specimen orientation $-\mathrm{V}=$ vertical; $\mathrm{HN}=$ horizontal with line load normal to bedding; $\mathrm{HP}=$ horizontal with line load parallel with bedding. 
Table 4-2. Summary of All Unconfined Compressive Strength Data for WIPP Anhydrite

\begin{tabular}{|c|c|c|c|c|}
\hline \multirow[b]{2}{*}{$\begin{array}{l}\text { Specimen } \\
\text { I.D. }\end{array}$} & \multirow{2}{*}{$\begin{array}{l}\text { Specimen } \\
\text { Diameter } \\
(\mathrm{mm})\end{array}$} & \multicolumn{3}{|c|}{ Unconfined Compressive Strength (MPa) } \\
\hline & & $\begin{array}{c}\text { Test } \\
\text { Estimate }^{(\mathbf{a})}\end{array}$ & Mean & $\begin{array}{l}\text { Standard } \\
\text { Deviation }\end{array}$ \\
\hline \multicolumn{5}{|c|}{ Salado Formation Anhydrite } \\
\hline UAN1 & 37 & $117(\mathrm{~V})$ & \multirow{3}{*}{118.3} & \multirow{3}{*}{1.5} \\
\hline UAN2 & 37 & $118(\mathrm{~V})$ & & \\
\hline UAN3 & 37 & $120(\mathrm{~V})$ & & \\
\hline TV10-3-1/13-3 & 54 & $63.3(V)$ & \multirow{2}{*}{58.0} & \multirow{2}{*}{ N/A } \\
\hline TV $10-3 / 4 / 1-3 / 2 \mathrm{~V}$ & 54 & $52.7(\mathrm{~V})$ & & \\
\hline TV10-3/4/3-2/1H & 54 & $82.2(\mathrm{H})$ & N/A & N/A \\
\hline MX05-12-6-1-2/12-1 & 54 & $31.6(V)$ & \multirow{3}{*}{34.1} & \multirow{3}{*}{2.2} \\
\hline MX05-12-6-1-2/20-2 & 54 & $35.2(\mathrm{~V})$ & & \\
\hline 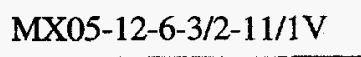 & 54 & $35.6(\mathrm{~V})$ & & \\
\hline MX05-12-6-3/2-4/1H & 54 & $43.7(\mathrm{H})$ & N/A & N/A \\
\hline $8 / 2049$ & 100 & $44.5(\mathrm{~V})$ & \multirow{2}{*}{48.1} & \multirow{2}{*}{$\mathrm{N} / \mathrm{A}$} \\
\hline $8 / 2553$ & 100 & $51.7(\mathrm{~V})$ & & \\
\hline \multicolumn{5}{|c|}{ Castile Formation Anhydrite } \\
\hline $8 / 3008$ & 50 & 95.5 & \multirow{2}{*}{84.8} & \multirow{2}{*}{$\mathrm{N} / \mathrm{A}$} \\
\hline $7 / 3387$ & 50 & 74.0 & & \\
\hline $8 / 3007$ & 100 & 96.0 & \multirow{4}{*}{92.9} & \multirow{4}{*}{13.5} \\
\hline $8 / 3019$ & 100 & 96.0 & & \\
\hline $7 / 3339$ & 100 & 73.9 & & \\
\hline $7 / 3624$ & 100 & 105.8 & & \\
\hline
\end{tabular}

(a) Values in parentheses indicate specimen orientation, $\mathrm{V}=$ vertical; $\mathrm{H}=$ horizontal.

Formation anhydrite in the horizontal direction (parallel with bedding) is higher than for the vertical direction (perpendicular to bedding) for both the TV10-3 and the MX05-12 cores; however, only two of the twelve tests included in the database were performed on horizontally oriented specimens.

Specimen size clearly affects the unconfined compressive strength, as shown in Figure 4-1 for anhydrite from the TV10-3 core. Higher strength correlates with smaller specimen diameter, particularly at specimen diameters below about 55 millimeters. The decrease in strength with increase in specimen dimension is common for many materials because larger specimens have a greater probability of possessing a flaw or nucleation site for fracture initiation. 


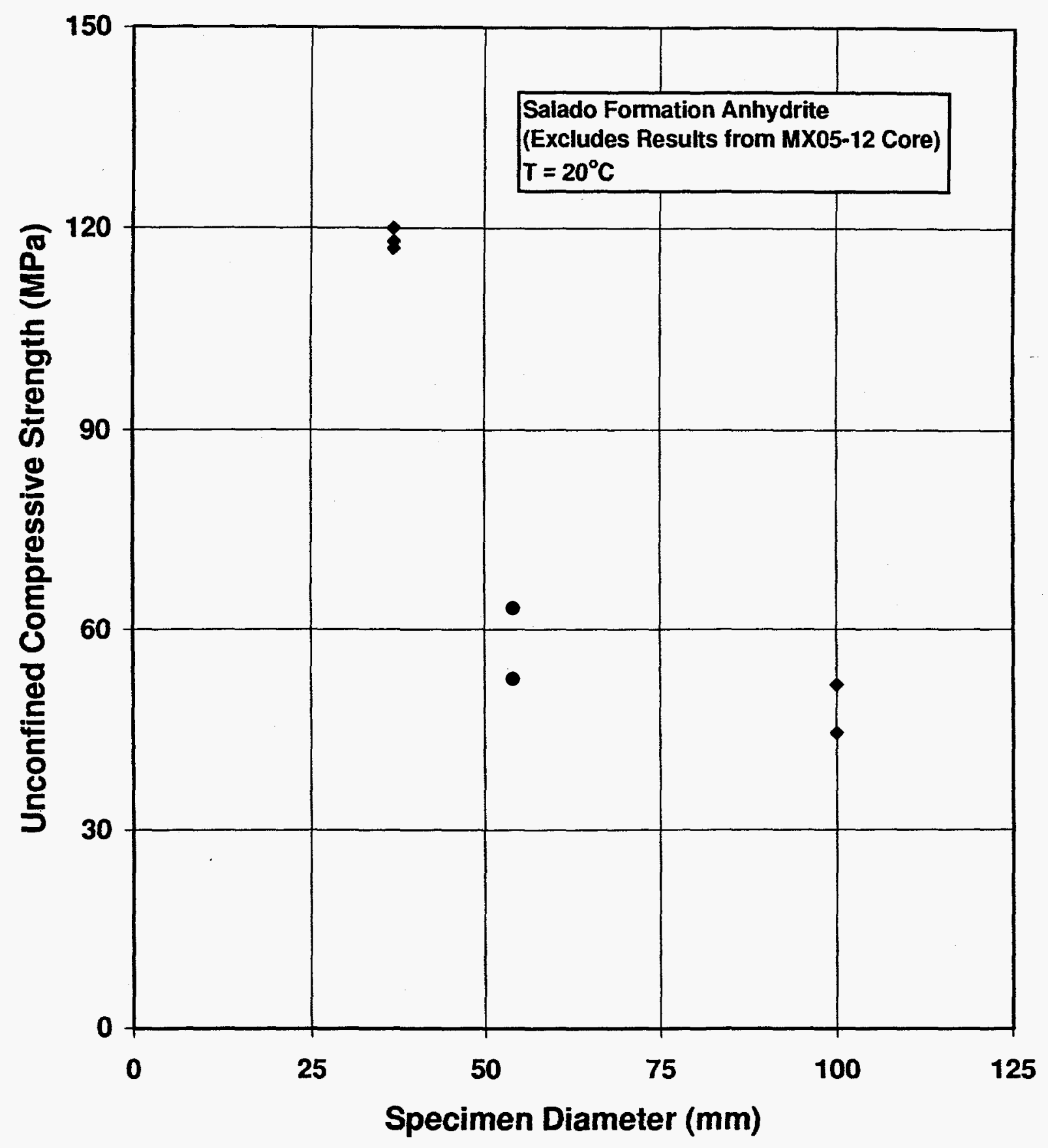

Figure 4-1. Effect of Specimen Size on Unconfined Strength of Salado Formation Anhydrite. 


\subsubsection{Confined Compressive Strength}

The confined compressive strength database comprises 70 triaxial compression test results, including the 18 unconfined compressive strength tests described above. Of this total, 48 and 22 test results, respectively, are available for Salado Formation and Castile Formation cores. Data are available for two nominal test temperatures; i.e., $20^{\circ} \mathrm{C}$ and $100^{\circ} \mathrm{C}$, as well as the same three nominal diameters and two specimen orientations described for the unconfined compression test database.

The confined triaxial compressive strength database for WIPP anhydrite was acquired from two types of tests, as discussed in Chapter 2.0. The tests are the standard triaxial compression (STC) test and the constant mean stress (CMS) compression test. In the STC test, the confining pressure is maintained constant, while the axial stress increases, thereby inducing a stress difference. In the CMS test, the stress difference is induced by increasing the axial stress and simultaneously decreasing the confining pressure at a rate that maintains the mean stress (average of the three principal stresses) constant. Triaxial compressive strength test data of this type are often interpreted

using stress invariants. Two stress invariants typically used are the first invariant of the Cauchy stress tensor, $I_{1}$, and the second invariant of the deviatoric tensor, $J_{2}{ }^{1 / 2}$. For the triaxial compression test configuration, these stress invariants may be defined in terms of the minor principal stress (i.e., the radial stress or confining pressure), $\sigma_{3}$, and the major principal stress (or axial stress), $\sigma_{1}$ as follows:

$$
\begin{aligned}
& I_{1}=\sigma_{1}+2 \sigma_{3}=3 \sigma_{\mathrm{m}} \\
& \sqrt{J_{2}}=\frac{\sigma_{1}-\sigma_{3}}{\sqrt{3}}=\frac{\Delta \sigma}{\sqrt{3}}
\end{aligned}
$$

where $\sigma_{\mathrm{m}}$ and $\Delta \sigma$ are the mean stress and stress difference, respectively. As shown in these equations, the first invariant of the stress tensor represents the mean stress imposed during the test, while the second invariant of the deviatoric stress tensor represents the stress difference or shear stress imposed during the test. These stress invariants have been calculated for yield, failure, and residual stress states using the data presented in Chapters 3.0 and 4.0 for Salado and Castile Formation anhydrite and are summarized below under separate headings.

\subsubsection{Yield Strength}

Teufel (1981) and Pfeifle and Senseny (1981) reported yield strength for a total of 30 triaxial compression tests on anhydrite from the Salado and Castile Formations. The stress invariants for these yield stress states are summarized in Table 4-3 and plotted in Figure 4-2 for nominal temperatures of $25^{\circ} \mathrm{C}$ and $100^{\circ} \mathrm{C}$. The yield strength for the Salado anhydrite is slightly higher than the yield strength of the Castile anhydrite. Also, the yield strength for both Salado and Castile anhydrite is lower at the higher temperature. 
Table 4-3. Yield, Failure, and Residual Stress States for WIPP Anhydrite (Page 1 of 3)

\begin{tabular}{|c|c|c|c|c|c|c|}
\hline \multirow{2}{*}{$\begin{array}{l}\text { Specimen } \\
\text { I.D. }\end{array}$} & \multicolumn{2}{|c|}{$\begin{array}{c}\text { Yield Stress } \\
(\mathrm{MPa})\end{array}$} & \multicolumn{2}{|c|}{$\begin{array}{c}\text { Failure Stress } \\
(\mathbf{M P a})\end{array}$} & \multicolumn{2}{|c|}{$\begin{array}{c}\text { Residual Stress } \\
\text { (MPa) }\end{array}$} \\
\hline & $I_{1}$ & $J_{2}^{1 / 2}$ & $I_{1}$ & $J_{2}^{1 / 2}$ & $I_{1}$ & $J_{2}^{1 / 2}$ \\
\hline \multicolumn{7}{|c|}{ Castille Formation; Standard Triaxial Compression; $\mathrm{T}=20 \& 25^{\circ} \mathrm{C}$; Vertical Orientation } \\
\hline $8 / 3007$ & - & - & 96.0 & 55.4 & - & 一 \\
\hline $8 / 3008$ & - & - & 95.5 & 55.1 & - & - \\
\hline $8 / 3019$ & - & - & 96.0 & 55.4 & - & - \\
\hline $7 / 3339$ & - & - & 73.9 & 42.7 & - & - \\
\hline $7 / 3387$ & - & - & 74.0 & 42.7 & - & - \\
\hline $7 / 3624$ & - & - & 105.8 & 61.1 & - & - \\
\hline SLA/80/10C/1 & 58.0 & 31.8 & 77.0 & 42.7 & - & - \\
\hline SLA $/ 80 / 10 B / 2$ & 27.0 & 13.9 & 78.0 & 43.3 & - & 一 \\
\hline SLA/80/10A/1 & 91.0 & 43.9 & 110.0 & 54.8 & - & - \\
\hline SLA $/ 80 / 10 D / 3$ & 77.0 & 35.7 & 111.0 & 55.4 & - & - \\
\hline $\mathrm{SLA} / 80 / 10 \mathrm{C} / 3$ & 89.0 & 34.1 & 143.0 & 65.2 & - & - \\
\hline SLA $/ 80 / 10 B / 3$ & 96.0 & 38.1 & 135.0 & 60.6 & - & - \\
\hline SLA $/ 80 / 10 A / 3$ & 153.0 & 53.7 & 202.0 & 82.0 & - & - \\
\hline SLA/80/10D/2 & 150.0 & 52.0 & 195.0 & 77.9 & - & - \\
\hline \multicolumn{7}{|c|}{ Castille Formation; Standard Triaxial Compression; $\mathrm{T}=100^{\circ} \mathrm{C}$; Vertical Orientation } \\
\hline $\mathrm{SLA} / 80 / 10 \mathrm{C} / 2$ & 24.0 & 12.1 & 71.0 & 39.3 & - & - \\
\hline SLA/80/10B/1 & 17.0 & 8.1 & 78.0 & 43.3 & 一 & - \\
\hline SLA/80/10D/4 & 74.0 & 34.1 & 104.0 & 51.4 & - & - \\
\hline SLA $/ 80 / 10 \mathrm{~A} / 2$ & 25.0 & 5.8 & 104.0 & 51.4 & - & - \\
\hline SLA/80/10C/4 & 127.0 & 56.0 & 135.0 & 60.6 & - & - \\
\hline SLA $/ 80 / 10 B / 4$ & 120.0 & 52.0 & 126.0 & 55.4 & - & - \\
\hline SLA/80/10D/1 & 148.0 & 50.8 & 191.0 & 75.6 & - & - \\
\hline SLA $/ 80 / 10 A / 4$ & 129.0 & 39.8 & 180.0 & 69.3 & - & - \\
\hline
\end{tabular}


Table 4-3. Yield, Failure, and Residual Stress States for WIPP Anhydrite (Page 2 of 3)

\begin{tabular}{|c|c|c|c|c|c|c|}
\hline \multirow{2}{*}{$\begin{array}{l}\text { Specimen } \\
\text { I.D. }\end{array}$} & \multicolumn{2}{|c|}{$\begin{array}{l}\text { Yield Stress } \\
\quad(\mathrm{MPa})\end{array}$} & \multicolumn{2}{|c|}{$\begin{array}{l}\text { Failure Stress } \\
\qquad(\mathrm{MPa})\end{array}$} & \multicolumn{2}{|c|}{$\begin{array}{l}\text { Residual Stress } \\
\text { (MPa) }\end{array}$} \\
\hline & $I_{I}$ & $J_{2}^{1 / 2}$ & $I_{I}$ & $J_{2}^{1 / 2}$ & $I_{1}$ & $J_{2}^{1 / 2}$ \\
\hline \multicolumn{7}{|c|}{$\begin{array}{c}\text { Salado Formation (Except for MX05-12 Core); Standard Triaxial Compression; } \mathrm{T}=20^{\circ} \mathrm{C} \text {; Vertical } \\
\text { Orientation }\end{array}$} \\
\hline $8 / 2049$ & - & - & 44.5 & 25.7 & - & - \\
\hline $8 / 2553$ & - & - & 51.7 & 29.8 & - & - \\
\hline UAN1 & 94.0 & 54.3 & 117.0 & 67.5 & - & - \\
\hline UAN2 & 91.0 & 52.5 & 118.0 & 68.1 & - & - \\
\hline UAN3 & 93.0 & 53.7 & 120.0 & 69.3 & - & - \\
\hline AN3 & 117.0 & 58.9 & 151.0 & 78.5 & - & - \\
\hline AN8 & 122.0 & 61.8 & 155.0 & 80.8 & - & — \\
\hline AN19 & 116.0 & 58.3 & 148.0 & 76.8 & - & 一 \\
\hline $\mathrm{AN} 2$ & 144.0 & 65.8 & 183.0 & 88.3 & - & - \\
\hline $\mathrm{A} 27$ & 138.0 & 62.4 & 180.0 & 88.6 & - & - \\
\hline AN4 & 193.0 & 76.8 & 239.0 & 103.3 & - & - \\
\hline AN14 & 189.0 & 74.5 & 234.0 & 100.5 & - & - \\
\hline SLA/80/7B/2 & 107.0 & 53.1 & 141.0 & 72.7 & - & 一 \\
\hline SLA/80/9B/1 & 146.0 & 49.7 & 247.0 & 108.0 & - & - \\
\hline TV $10-3-1 / 13 / 3$ & - & - & 63.3 & 36.5 & 25.0 & 14.4 \\
\hline TV10-3-1/14/3 & 一 & - & 112.8 & 55.9 & 80.9 & 37.5 \\
\hline TV10-3-1/15-2 & - & - & 206.9 & 101.3 & 119.5 & 50.8 \\
\hline TV10-3-1/18-3 & - & - & 225.5 & 94.3 & 178.1 & 67.0 \\
\hline $\mathrm{TV} 10-3 / 4 / 1-3 / 2 \mathrm{~V}$ & - & 一 & 52.7 & 30.4 & - & 一 \\
\hline TV10-3/4/1-1/2V & - & - & 81.1 & 37.6 & - & - \\
\hline TV10-3/4/1-11/2V & 一 & - & 204.1 & 100.0 & - & - \\
\hline TV10-3/4/1-12/2V & - & - & 197.4 & 87.5 & - & - \\
\hline \multicolumn{7}{|c|}{$\begin{array}{c}\text { Salado Formation (Except for MX05-12 Core); Standard Triaxial Compression; } \mathrm{T}=20^{\circ} \mathrm{C} ; \text { Horizontal } \\
\text { Orientation }\end{array}$} \\
\hline TV10-3/4/3-2/1H & - & - & 82.2 & 47.5 & - & - \\
\hline TV $10-3 / 4 / 3-8 / 1 \mathrm{H}$ & - & 二 & 171.8 & 90.4 & - & - \\
\hline TV10-3/4/3-9/1H & 一 & 一 & 209.7 & 103.2 & 一 & - \\
\hline TV $10-3 / 4 / 3-10 / 1 \mathrm{H}$ & - & - & 202.9 & 90.6 & - & - \\
\hline
\end{tabular}


Table 4-3. Yield, Failure, and Residual Stress States for WIPP Anhydrite (Page 3 of 3)

\begin{tabular}{|c|c|c|c|c|c|c|}
\hline \multirow{2}{*}{$\begin{array}{l}\text { Specimen } \\
\text { I.D. }\end{array}$} & \multicolumn{2}{|c|}{$\begin{array}{l}\text { Yield Stress } \\
(\mathrm{MPa})\end{array}$} & \multicolumn{2}{|c|}{$\begin{array}{l}\text { Failure Stress } \\
(\mathrm{MPa})\end{array}$} & \multicolumn{2}{|c|}{$\begin{array}{l}\text { Residual Stress } \\
(\mathrm{MPa})\end{array}$} \\
\hline & $I_{1}$ & $J_{2}^{1 / 2}$ & $I_{1}$ & $J_{2}^{1 / 2}$ & $\boldsymbol{I}_{1}$ & $J_{2}^{1 / 2}$ \\
\hline \multicolumn{7}{|c|}{ Salado Formation (Except for MX05 12 Core); Constant Mean Stress; $T=20^{\circ} \mathrm{C}$; Vertical Orientation } \\
\hline TV10-3-1/8-3 & - & - & 153.0 & 70.8 & - & - \\
\hline TV10-3-1/7/3 & - & - & 150.0 & 79.0 & - & - \\
\hline TV10-3-1/6-3 & - & - & 123.3 & 58.2 & - & - \\
\hline TV10-3-1/5/3 & - & - & 123.0 & 65.2 & - & - \\
\hline TV10-3-1/4-3 & - & - & 93.3 & 50.8 & - & - \\
\hline \multicolumn{7}{|c|}{$\begin{array}{c}\text { Salado Formation (Except for MX05-12 Core); Standard Triaxial Compression; } \mathrm{T}=100^{\circ} \mathrm{C} \text {; Vertical } \\
\text { Orientation }\end{array}$} \\
\hline SLAV80/9B/3 & 63.0 & 27.7 & 138.0 & 71.1 & - & - \\
\hline SLA/80/7B/4 & 181.0 & 69.9 & 215.0 & 89.5 & - & - \\
\hline \multicolumn{7}{|c|}{$\begin{array}{l}\text { Salado Formation - MX05-12 Core Only; Standard Triaxial Compression; } T=20^{\circ} \mathrm{C} \text {; Vertical } \\
\text { Orientation }\end{array}$} \\
\hline MX05-12-6-1-2/12-1 & - & - & 31.6 & 18.2 & - & - \\
\hline $\mathrm{MX} 05-12-6-1-2 / 20-2$ & 一 & - & 35.2 & 20.3 & - & - \\
\hline $\mathrm{MX} 05-12-6-1-2 / 2-2$ & - & - & 100.9 & 40.2 & 一 & - \\
\hline MX05-12-6-1-2/7-3 & - & - & 149.6 & 50.3 & - & - \\
\hline $\mathrm{MX} 05-12-6-3 / 2-11 / 1 \mathrm{~V}$ & - & - & 35.6 & 20.6 & - & - \\
\hline $\mathrm{MX} 05-12-6-3 / 2-12 / 1 \mathrm{~V}$ & - & - & 78.8 & 36.3 & - & - \\
\hline MX05-12-6-3/2-13/1V & - & - & 100.0 & 39.9 & - & - \\
\hline $\mathrm{MX} 05-12-6-3 / 2-15 / 2 \mathrm{~V}$ & - & - & 119.6 & 42.6 & 二 & 一 \\
\hline \multicolumn{7}{|c|}{$\begin{array}{c}\text { Salado Formation - MX05-12 Core Only; } \begin{array}{l}\text { Standard Triaxial Compression; } \mathrm{T}=20^{\circ} \mathrm{C} \text {; Horizontal } \\
\text { Orientation }\end{array}\end{array}$} \\
\hline MX05-12-6-3/2-4/1H & - & - & 43.7 & 25.2 & 一 & - \\
\hline MX05-12-6-3/2-5/1H & - & 一 & 68.6 & 30.4 & 一 & - \\
\hline MX05-12-6-3/2-6/1H & - & - & 93.6 & 36.5 & - & - \\
\hline MX05-12-6-3/2-7/1H & - & - & 114.2 & 39.6 & 二 & - \\
\hline \multicolumn{7}{|c|}{ Salado Formation - MX05-12 Core Only; Constant Mean Stress; $\mathrm{T}=20^{\circ} \mathrm{C}$; Vertical Orientation } \\
\hline MX05-12-6-1-2/11-1 & - & - & 78.6 & 16.0 & - & - \\
\hline MX05-12-6-1-2/14-3 & - & - & 93.3 & 26.5 & - & - \\
\hline MX05-12-6-1-2/8-2 & - & - & 123.3 & 33.6 & - & 一 \\
\hline
\end{tabular}




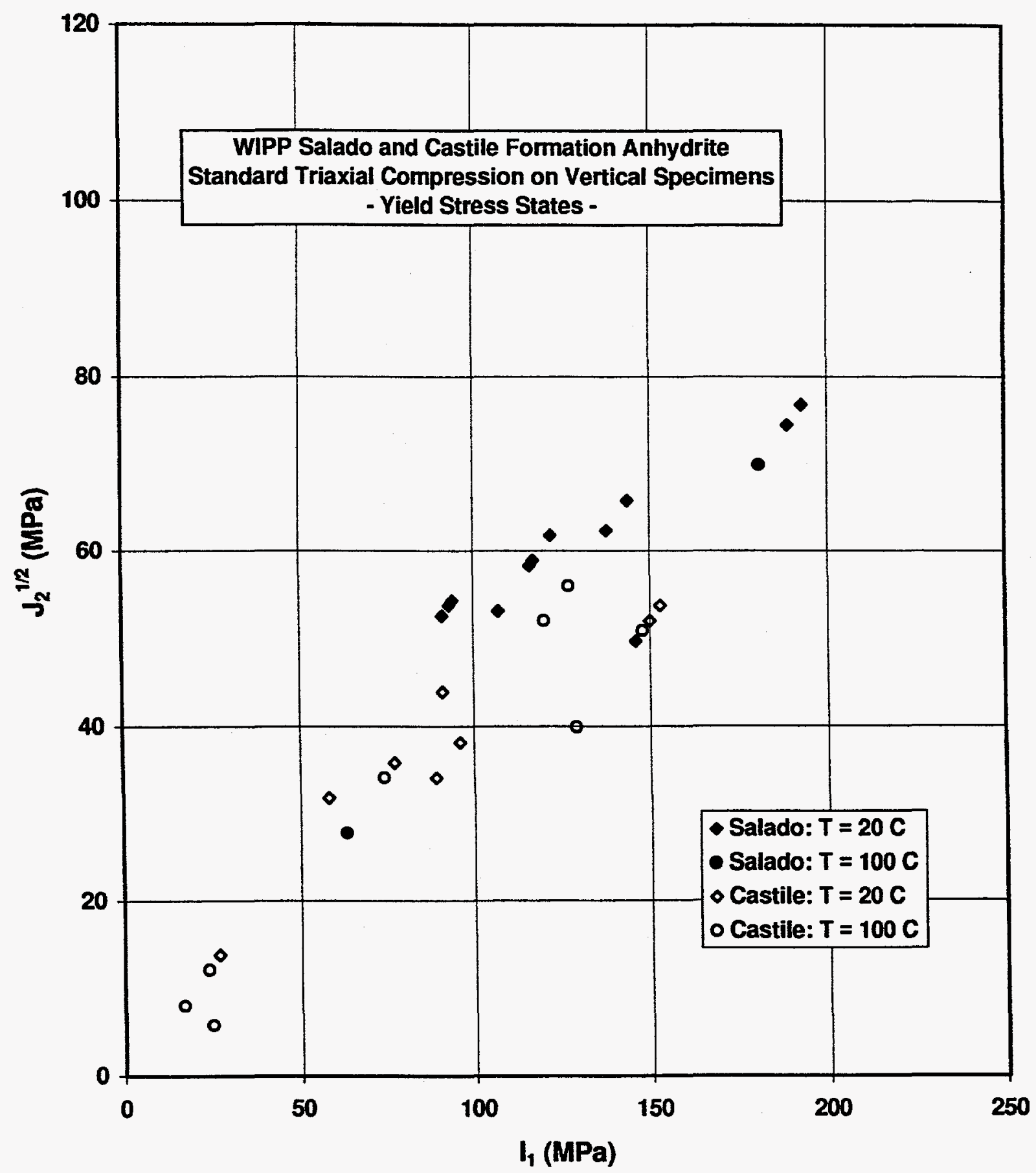

Figure 4-2. $\mathrm{J}_{2}{ }^{1 / 2}$ Versus $\mathrm{I}_{1}$ for Yield Stress States for WIPP Anhydrite From the Salado and Castile Formations. 


\subsubsection{Failure Strength}

Failure strength was estimated from the data acquired in all 70 triaxial compression tests included in the database. The stress invariants for these failure states are also summarized in Table 4-3 for both Castile and Salado Formation anhydrite.

The stress invariants for the failure stress states of the Castile anhydrite are shown in Figure 4-3 for nominal temperatures of $25^{\circ} \mathrm{C}$ and $100^{\circ} \mathrm{C}$. Temperature has only a small affect on the failure strength with the higher temperature corresponding to the lower strength. All failure data were acquired from the STC test.

Figure 4-4 plots the stress invariants for the failure stress states of the Salado Formation anhydrite for nominal temperatures of $25^{\circ} \mathrm{C}$ and $100^{\circ} \mathrm{C}$ as well as for horizontally and vertically oriented test specimens. These data were acquired both from the STC test and the CMS test. Data from the MX05-12 core are treated separately below so are not included in Figure 4-4. The data plotted in Figure 4-4 show little variability even though the test method, test temperature, and specimen size and orientation varied among the tests. Comparisons between the failure strength data for the Castile anhydrite and the Salado anhydrite (i.e., Figure 4-3 versus Figure 4-4) suggest that the Salado anhydrite is slightly stronger than the Castile anhydrite, particularly at higher mean stresses.

The failure strength data for horizontally and vertically oriented specimens of Salado anhydrite recovered from the MX05-12 core are presented in Figure 4-5 for a nominal temperature of $20^{\circ} \mathrm{C}$. These data were also acquired from the STC and the CMS tests. With the exception of the CMS data, the failure strengths of the Salado anhydrite from the MX05-12 core exhibit little variability. The failure strengths determined from the CMS tests are significantly lower than the strengths determined from the STC tests. The anhydrite recovered from the MX05-12 core is treated separately in this analysis of the data because its failure strength is much lower than the failure strengths of other anhydrite recovered from the Salado Formation, including the TV10-3 core recovered from Marker Bed 139.

A possible explanation for the lower strengths of the MX05-12 anhydrite may be found in the historical core recovery records summarized in Chapter 2.0. As described, both the MX05-12 core and the TV10-3 core were recovered from Marker Bed 139; however, the MX05-12 core was not recovered until nearly 7 years after the TV10-3 core was recovered. During this time, it is speculated that the creep deformations of the salt around the WIPP underground openings may have induced sufficient load on the marker bed to cause damage. Additional supporting evidence for this assumption is provided from an analysis of the residual strength of the anhydrite and the elastic moduli. As shown previously in Figure 3-1, the lithology of the MX05-12 is visibly different from the lithology of the other Salado anhydrites which may also contribute to the measure difference in strength. 


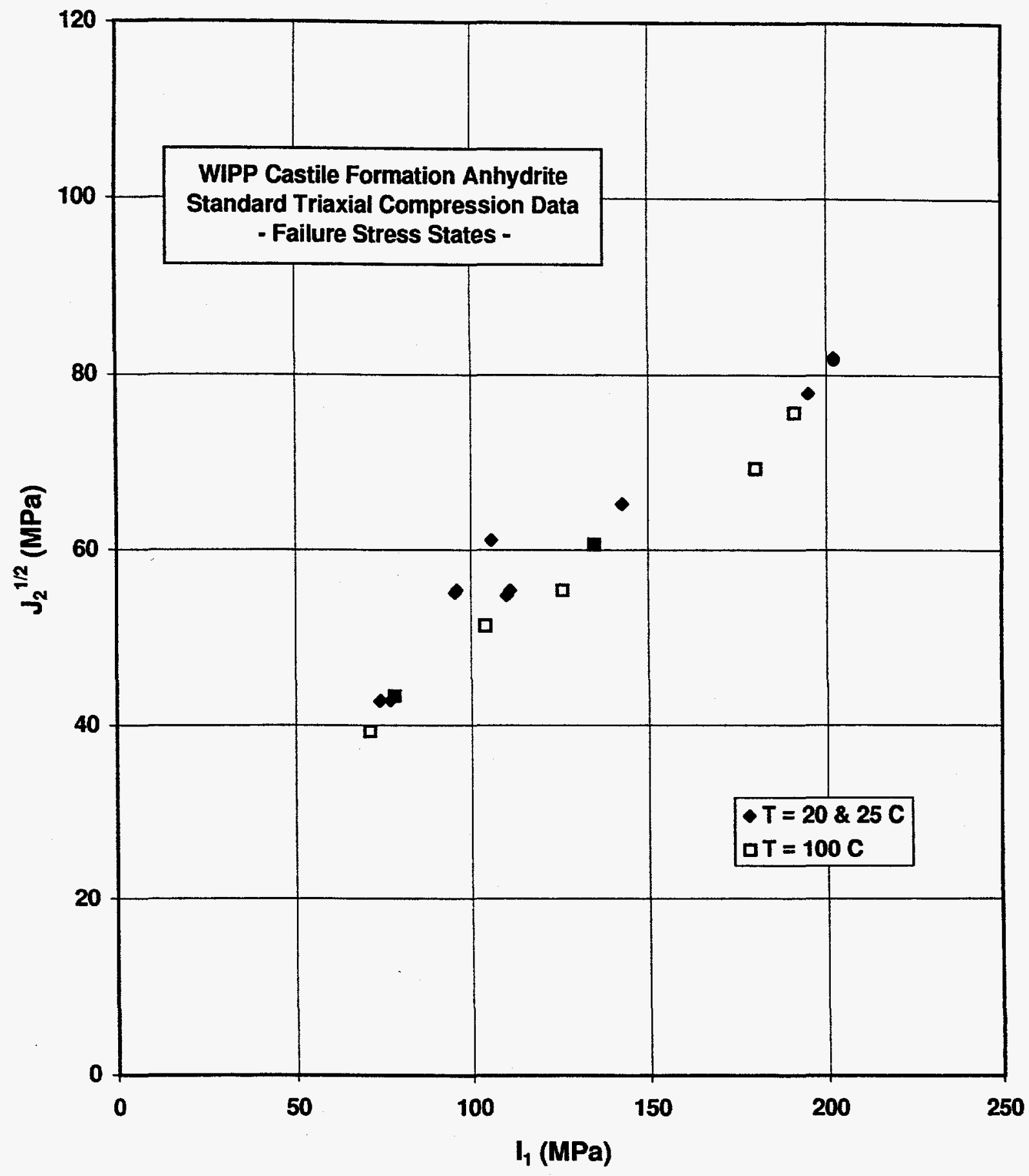

Figure 4-3. $J_{2}^{1 / 2}$ Versus $I_{1}$ for Failure Stress States for WIPP Anhydrite From the Castile Formation. 


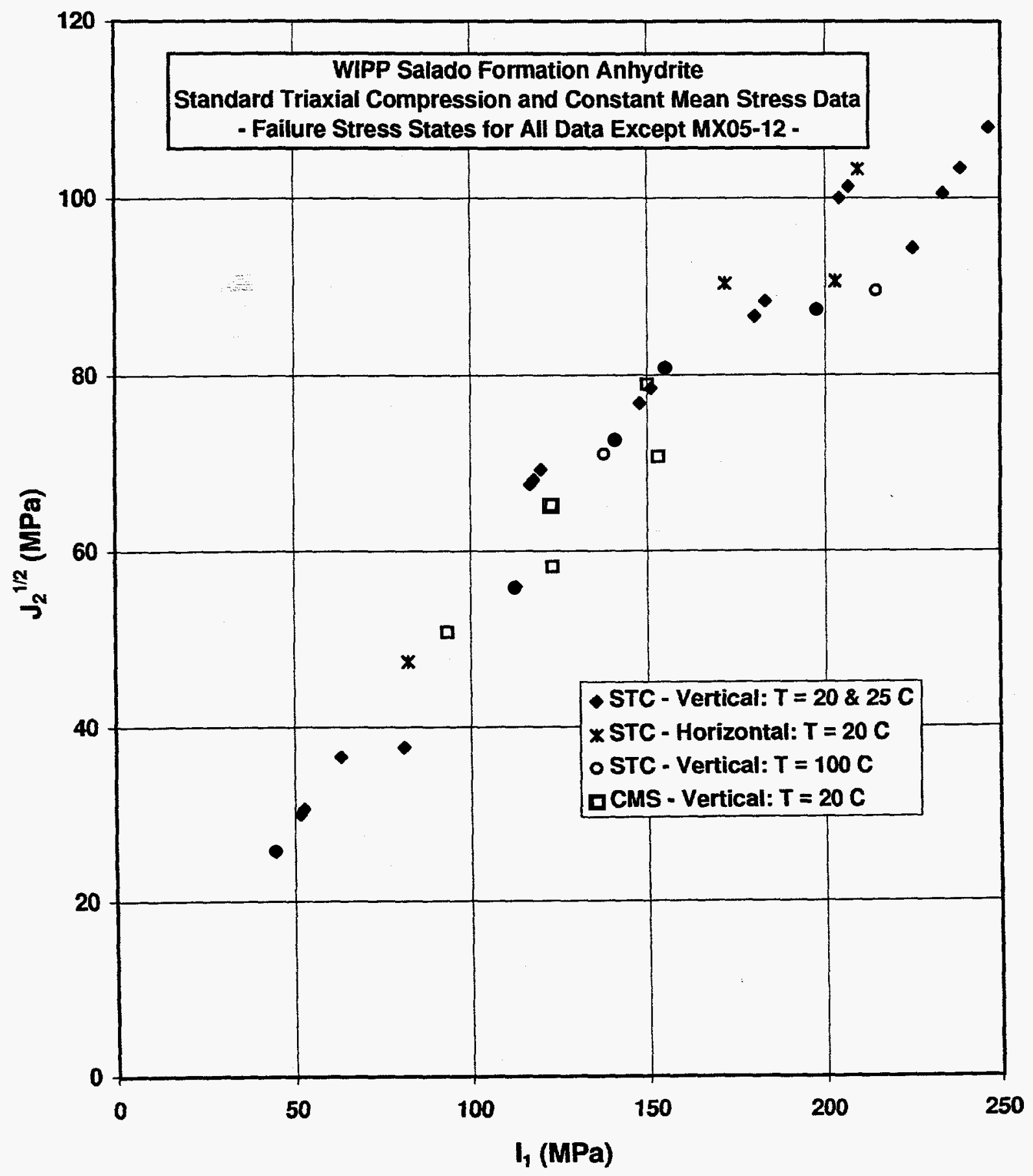

Figure 4-4. $\mathrm{J}_{2}{ }^{1 / 2}$ Versus $I_{1}$ for Failure Stress States for WIPP Anhydrite From the Salado Formation (Except for Marker Bed 139 From the MX05-12 Core). 


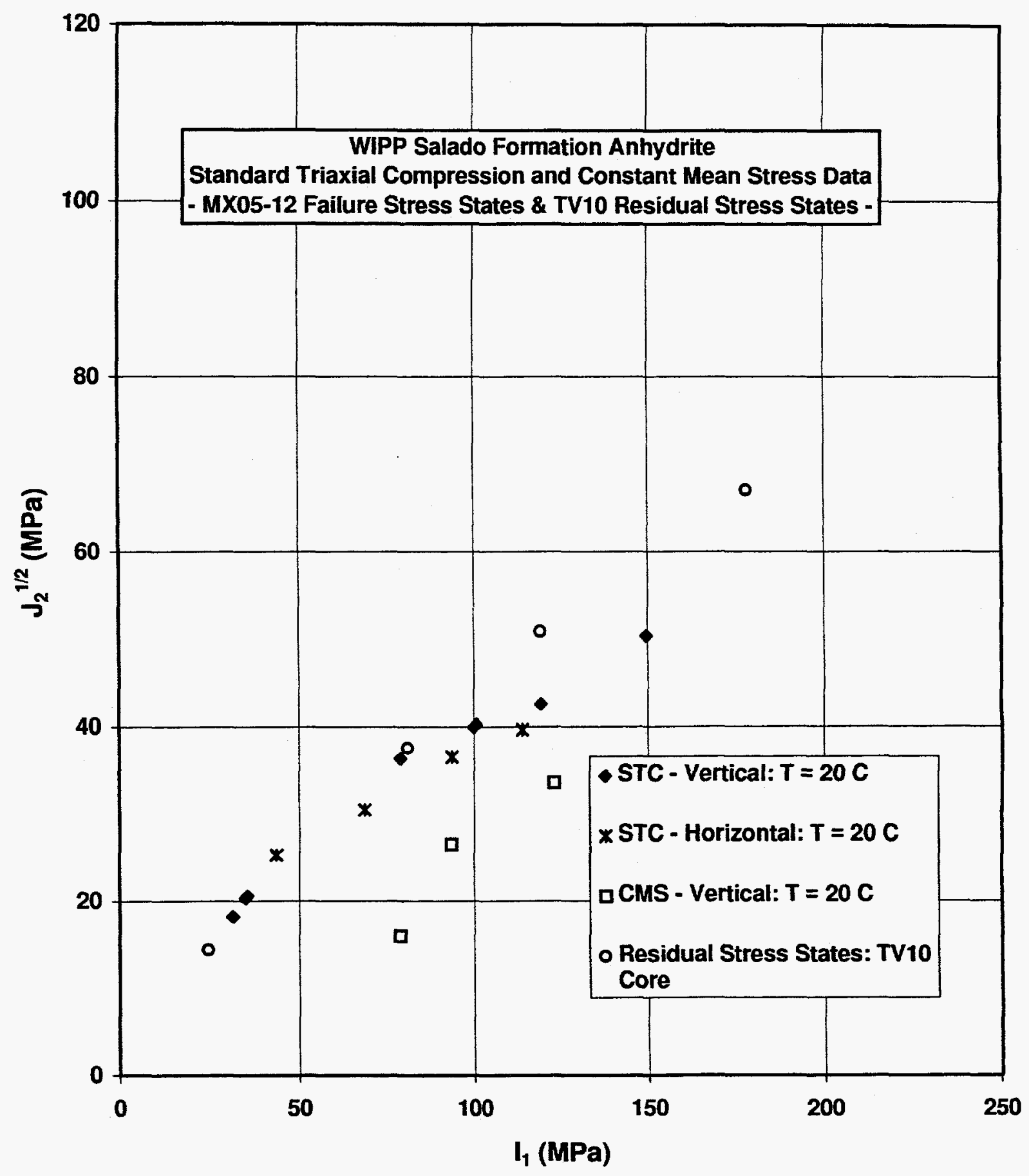

Figure 4-5. $J_{2}{ }^{1 / 2}$ Versus $I_{1}$ for Failure States for WIPP Anhydrite From the MX05-12 Core and for Residual Stress States for WIPP Anhydrite From the TV10-3 Core. 


\subsubsection{Residual Strength}

In four of the triaxial compression tests conducted on anhydrite from the TV10 core under Sandia Contract AA-2020, loading continued beyond peak strength to obtain an estimate of the residual strength of the Salado anhydrite. The stress invariants for these four tests are also summarized in Table 4-3 and are plotted in Figure 4-5 for comparison with the failure strength data for Salado anhydrite recovered from the MX05-12 core. As shown in Figure 4-5, the residual strengths of the TV10-3 core are comparable to the failure strengths of the MX05-12 core, providing additional evidence that the anhydrite from which the MX05-12 core was obtained may have been damaged before it was recovered from the floor of Room $\mathrm{M}$.

\subsubsection{Elastic Properties}

Elastic properties for WIPP anhydrite were determined for all triaxial compression tests included in the database. In addition, estimates of the tensile Young's modulus were determined from the indirect tension tests performed in the supplemental testing program. Table 4-4 summarizes the elastic properties data included in the database. As shown, the results from tests on Salado anhydrite from the MX05-12 core are treated separately.

Table 4-4. Elastic Properties of WIPP Anhydrite Determined From Triaxial Compression Tests

\begin{tabular}{|c|c|c|c|c|}
\hline \multirow{2}{*}{ Formation } & \multicolumn{2}{|c|}{ Young's Modulus $^{(\mathrm{a})}$ (GPa) } & \multicolumn{2}{|c|}{ Poisson's Ratio } \\
\hline & Mean & $\begin{array}{l}\text { Standard } \\
\text { Deviation }\end{array}$ & Mean & $\begin{array}{l}\text { Standard } \\
\text { Deviation }\end{array}$ \\
\hline $\begin{array}{l}\text { Castile } \\
\text { Vertical, } T=20^{\circ} \mathrm{C} \\
\text { Vertical, } T=100^{\circ} \mathrm{C}\end{array}$ & $\begin{array}{l}63.5 \\
40.0\end{array}$ & $\begin{array}{l}10.7 \\
14.0\end{array}$ & $\begin{array}{l}0.38 \\
0.32\end{array}$ & $\begin{array}{l}0.06 \\
0.10\end{array}$ \\
\hline $\begin{array}{l}\text { Salado (Except MX05-12) } \\
\text { Vertical, } \mathrm{T}=20^{\circ} \mathrm{C} \\
\text { Vertical, } \mathrm{T}=100^{\circ} \mathrm{C} \\
\text { Horizontal, } \mathrm{T}=20^{\circ} \mathrm{C}\end{array}$ & $\begin{array}{l}64.0 \\
45.5 \\
54.8\end{array}$ & $\begin{array}{r}13.4 \\
6.4 \\
11.6\end{array}$ & $\begin{array}{l}0.32 \\
0.31 \\
0.27\end{array}$ & $\begin{array}{l}0.06 \\
0.07 \\
0.05\end{array}$ \\
\hline $\begin{array}{l}\text { Salado (MX05-12 Only) } \\
\text { Vertical, } \mathrm{T}=20^{\circ} \mathrm{C} \\
\text { Horizontal, } \mathrm{T}=20^{\circ} \mathrm{C}\end{array}$ & $\begin{array}{l}29.0 \\
30.7\end{array}$ & $\begin{array}{l}7.6 \\
1.9\end{array}$ & $\begin{array}{l}0.26 \\
0.36\end{array}$ & $\begin{array}{l}0.12 \\
0.09\end{array}$ \\
\hline
\end{tabular}

(a) Values of tensile Young's moduli estimated from indirect tension tests are approximately 35 to 40 percent of the values of compressive Young's moduli.

Young's modulus for vertically oriented specimens tested in compression at a temperature of $20^{\circ} \mathrm{C}$ is approximately $64 \mathrm{GPa}$ for both the Castile and Salado anhydrite. This value decreases to about 40 to $45 \mathrm{GPa}$ when the temperature is elevated to $100^{\circ} \mathrm{C}$. For horizontally oriented specimens of Salado anhydrite, Young's modulus is approximately $55 \mathrm{GPa}$. The values of Young's modulus reported in Table 4-4 were determined from the initial unload/reload cycle of each test; however as discussed previously, values of Young's modulus were also determined from subsequent unload/reload cycles after considerable deformation had occurred. In these subsequent 
cycles, Young's modulus continuously decreased, and in some cases, the values were as low as 30 $\mathrm{GPa}$, comparable to the values measured for Salado anhydrite from the MX05-12 core. Poisson's ratio for both the Castile and Salado anhydrite was about 0.30 to 0.35 and was not affected by temperature, specimen orientation, or induced deformation.

Estimates of Young's modulus were also made from the Brazilian indirect tension tests. As described in Chapter 3.0, the method used to estimate these values required simulations of the indirect tension test configuration using the finite element program SPECTROM-32. In this analysis, the tensile and compressive displacements were calculated at positions corresponding to the gage lengths of the instrumentation used during the actual testing. Assuming linear elastic response with different elastic and compressive moduli, a nomograph was developed between ratios of the tensile and compressive displacements and the tensile and compressive moduli assuming that Poisson's ratio was isotropic. Because the tensile displacements measured in the actual tests were quite small, the displacement ratio proved to be quite variable. However, the elastic modulus ratio could be determined from some tests and the mean value of this ratio was approximately 0.35 to 0.40 , which implies that the tensile Young's modulus of anhydrite is about 35 to 40 percent of the compressive modulus.

The elastic properties of Salado anhydrite from the MX05-12 core are treated separately in this discussion because of the difference between these values and those determined from other anhydrite cores. In general, the mean value of Young's modulus for Salado anhydrite from the MX05-12 core is about $30 \mathrm{GPa}$, which is about one-half the value determined for other anhydrite cores. This lower value of Young's modulus supports the assumption that the MX05-12 core was damaged before testing was performed or that lithology effects are present. The value of Poisson's ratio for the MX05-12 does not appear to be affected by the assumed damage and ranges from 0.26 to 0.36 .

\subsubsection{Time-Dependent Deformation}

Creep deformations of Salado anhydrite were measured in two multi-stage triaxial compression constant stress creep tests. In these tests, the confining pressure was either 5,10 , or $15 \mathrm{MPa}$, and the stress difference was either 50,75 , or $100 \mathrm{MPa}$. Deformation rates during the tests were highly variable, ranging from less than $5 \times 10^{-11} \mathrm{~s}^{-1}$ to more than $2 \times 10^{-6} \mathrm{~s}^{-1}$. The variability was attributed to variations in halite content of the test specimens.

\subsection{HYDROLOGICAL PROPERTIES AND PHYSICAL CHARACTERISTICS}

Hydrological properties and physical characteristics of the Salado anhydrite are included in the database. These properties and characteristics have been determined exclusively from tests of Marker Bed 139 and are summarized below.

\subsubsection{Porosity}

The effective porosity of Marker Bed 139 anhydrite, as measured from 49 specimens, ranged from 0.4 to 2.7 percent with a mean value of 1.20 percent and a standard deviation of 0.50 percent. 
Based on six tests, the total porosity of the anhydrite ranges from 0.4 to 2.76 percent with a mean and standard deviation of 1.75 percent and 0.82 percent, respectively.

\subsubsection{Grain and Bulk Density}

A total of 49 measurements of grain density was made on specimens of Marker Bed 139 anhydrite. The range in grain density was 2.53 to $2.96 \mathrm{~g} / \mathrm{cm}^{3}$ with a mean and standard deviation of 2.75 $\mathrm{g} / \mathrm{cm}^{3}$ and $0.15 \mathrm{~g} / \mathrm{cm}^{3}$, respectively. The theoretical grain density of pure anhydrite is 2.94 (Hurlbut, 1971). The difference between this theoretical value and the measured value is attributed to the presence of impurities including halite, polyhalite, and carbonaceous material.

Brodsky (1997) determined bulk density of six anhydrite specimens recovered from the P3X10 and P3X11 field cores. The mean and standard deviation for these measurements are $2.62 \mathrm{~g} / \mathrm{cm}^{3}$ and $0.07 \mathrm{~g} / \mathrm{cm}^{3}$, respectively. Bulk density was also determined for the 32 test specimens prepared for the supplemental testing program, including 16 measurements on specimens from each of the two field cores, TV10-3 and MX05-12. The mean and standard deviation of the bulk density measurements on specimens from the TV10-3 core are $2.74 \mathrm{~g} / \mathrm{cm}^{3}$ and $0.06 \mathrm{~g} / \mathrm{cm}^{3}$, respectively. The mean and standard deviation of the bulk density measurements on specimens from the MX0512 core are

$2.62 \mathrm{~g} / \mathrm{cm}^{3}$ and $0.06 \mathrm{~g} / \mathrm{cm}^{3}$, respectively. The lower values of bulk density for the MX05-12, $\mathrm{P} 3 \mathrm{X} 10$, and P3X11 cores may be a result of higher porosity contents or differences in specimen composition. Higher porosity levels could be a result of microfracture-induced damaged.

\subsubsection{Intrinsic Permeability}

Gas permeability ranged from a minimum of $5.0 \times 10^{-20} \mathrm{~m}^{2}$ at $10 \mathrm{MPa}$ net effective stress (confining pressure minus mean pore pressure) to a maximum of $8.3 \times 10^{-16} \mathrm{~m}^{2}$ at $2 \mathrm{MPa}$ net effective stress. For all specimens, permeability decreased as net effective stress was increased. Differences between vertical and horizontal permeability were within experimental error bounds. The relationship between effective porosity and gas permeability was linear; however, insufficient total-porosity data were available to define a relationship between total porosity and gas permeability. No trend exists between gas permeability and grain density, nor gas permeability and threshold pressure resulting from mercury injection capillary pressure tests.

The magnitude and range of intrinsic permeability results determined from gas permeability measurements and nonreactive liquid (odorless mineral spirits) permeability measurements were comparable. Intrinsic permeabilities determined using simulated Marker Bed 139 brine were about an order of magnitude higher than the intrinsic permeabilities measured using gas and this difference was attributed to the dissolution of the specimens when the brine was used.

\subsubsection{Threshold Pressure}

Air-brine threshold pressures determined from mercury injection test results ranged from 0.33 to $0.78 \mathrm{MPa}$. The mean value for the threshold pressure was $0.54 \mathrm{MPa}$ and its standard deviation was $0.19 \mathrm{MPa}$. The residual liquid saturation for these threshold pressures ranged from 0.8 to 17.4 percent. 


\subsubsection{Mineralogic Composition}

The mineralogic composition of Marker Bed 139 anhydrite has been characterized in several studies to support laboratory investigations of hydrologic properties and to facilitate correlation of transport properties with composition. Marker Bed 139 composition was determined both by X-ray diffraction and petrographic microscopy analyses.

Fredrich and Zeuch (1996) presented results for 23 X-ray diffraction analyses and 42 petrographic microscopy analyses of Marker Bed 139. In these analyses, the mean anhydrite content was about 65 percent by weight. Major impurities included halite ( 20 to 25 percent), polyhalite ( 7 to 8 percent), and carbonate ( 4 percent). Table $4-5$ summarizes these results and provides means and standard deviations for each mineralogic component.

Table 4-5. Summary of Mineralogic Analyses of WIPP Marker Bed 139 Anhydrite

\begin{tabular}{|c|c|c|}
\hline $\begin{array}{c}\text { Mineral } \\
\text { Type }\end{array}$ & Mean & $\begin{array}{l}\text { Standard } \\
\text { Deviation }\end{array}$ \\
\hline \multicolumn{3}{|c|}{ X-Ray Diffraction ( 23 analyses) } \\
\hline Anhydrite & 65.3 & 24.5 \\
\hline Halite & 25.7 & 17.5 \\
\hline Polyhalite & 6.1 & 17.9 \\
\hline Carbonate & 2.9 & 8.7 \\
\hline \multicolumn{3}{|c|}{ Petrographic Microscopy (42 analyses) } \\
\hline Anhydrite & 68.5 & 22.2 \\
\hline Halite & 19.3 & 15.8 \\
\hline Polyhalite & 7.7 & 19.7 \\
\hline Carbonate & 4.1 & 3.8 \\
\hline
\end{tabular}




\section{0 SUMMARY AND CONCLUSIONS}

This report compiles a comprehensive database of mechanical properties of WIPP-specific anhydrite. As a compendium of laboratory results, data contained herein should be sufficient basis for analyses of fracture propagation or other arising issues pertaining to mechanical response of anhydrite rocks. We have not attempted to perform structural analyses of any kind here, but rather to provide sufficient documentation that analysts have at their disposal sufficient quality data to perform a wide range of possible analyses.

Impetus for compiling anhydrite experimental data also derives from a project need to preserve such information. Although the EPA has favorably ruled that the WIPP site meets requirements of 40 CFR 194, the certification process will be repeated at least every 5 years. In the interim periods, it is likely that analyses of various scenarios will be pursued. This report provides a resource of anhydrite data that can be accessed and readily referenced should any future analysis require such data.

The compilation of data in this report summarizes previously published technical reports, unpublished experimental results, and new experimental results. The new experiments looked at possible compressive and tensile strength anisotropy within Marker Bed 139, as well as certain tensile elastic responses. These particular tests were added to existing results because of stakeholder's interest in hypothetical anhydrite fracture propagation events. The survey of existing literature focused on formal reports prepared by Sandia and its contractors, progress reports prepared under Sandia contracts, and technical papers and articles available in the open literature. The scope of the supplemental testing program was developed after an initial review of the existing literature. The test matrix for the supplemental testing was designed to support perceived deficiencies and possible future use of such data. The supplemental testing included 32 mechanical properties tests performed on horizontally and vertically oriented test specimens. Results obtained included: (1) unconfined and confined compressive strength; (2) Brazilian indirect tensile strength; and (3) elastic tensile and compressive moduli; i.e., Young's modulus, $E$, and Poisson's ratio, $v$.

The combined database contains mechanical and hydrological properties as well as physical characteristics of the anhydrite. Specifically, the database includes:

- Brazilian indirect tensile strength tests of anhydrite from the Salado and Castile Formations.

- Unconfined and confined compressive strength tests of anhydrite from the Salado and Castile Formations.

- Elastic properties from all unconfined and confined compressive strength tests of anhydrite from the Salado and Castile Formations as well as from indirect tensile strength tests of Marker Bed 139 conducted in the supplemental test program.

- Porosity and grain and bulk densities of Marker Bed 139 anhydrite. 
- Intrinsic permeability of Marker Bed 139 anhydrite conducted using gas, brịne, and mineral spirits permeants.

- Air-brine threshold pressures and residual liquid saturation of Marker Bed 139 anhydrite.

- Mineralogic composition of Marker Bed 139 anhydrite from quantitative X-ray diffraction analyses and petrographic microscopy.

In general, the mechanical and hydrological properties of the WIPP anhydrite were consistent among tests. However, a consistent difference in "anhydrite" properties was discovered during the assembly of the database. In particular, the values of tensile strength, compressive strength, and Young's modulus determined from specimens prepared from the MX05-12 field core recovered from Marker Bed 139 were consistently lower than for all other anhydrite test specimens. The cause for the difference could be attributed to compositional difference or attributed to preexisting damage in the field core. The damage was most likely induced by salt creep around the underground workings of the WIPP before the core was recovered from the marker bed. In the realm of geomechanics characterization, these ranges of material properties are to be expected. Proper analysis of structural problems must allow for such variability in material properties. 


\subsection{REFERENCES}

American Society for Testing and Materials, 1983. "Standard Test Method for Specific Gravity of Soils," Annual Book of ASTM Standards, Standard D854-83, Vol. 4.08, Philadelphia, PA.

American Society of Mechanical Engineers, 1990. Quality Assurance Program Requirements for the Collection of Scientific and Technical Information for Site Characterization of High-Level Nuclear Waste Repositories, ASME NQA-3-1989 Edition, The American Society of Mechanical Engineers, New York, NY, March.

American Society of Mechanical Engineers, 1994. Quality Assurance Requirements for Nuclear Facility Applications, ASME NQA-1-1994 Edition, The American Society of Mechanical Engineers, New York, NY, July.

Borns, D. J., 1985. A Study of Drill Core From a Systematic Array, SAND85-0023, prepared by Sandia National Laboratories, Albuquerque, NM.

Brodsky, N. S., 1993. Porosity and Gas Permeability Measurements on Marker Bed 139 Anhydrite From the Waste Isolation Pilot Plant, RSI-0484, prepared by RE/SPEC Inc., Rapid City, SD, for Sandia National Laboratories, Albuquerque, NM.

Brodsky, N. S., 1997. Laboratory Measurements of Fluid Transport Properties for Marker Bed 139 Anhydrite From the Waste Isolation Pilot Plant, RSI-0491, prepared by RE/SPEC Inc., Rapid City, SD, for Sandia National Laboratories, Albuquerque, NM.

Callahan, G. D., 1998. Documentation of SPECTROM-32 Theoretical Enhancements, Code Structure Changes, and Input Changes to Include Version 4.10, RSI(RCO)-326/2-98/V0410, prepared by RE/SPEC Inc., Rapid City, SD, February 20.

Fredrich, J. T. and D. H. Zeuch, 1996. Petrographic and X-Ray Diffraction Analyses of Selected Samples From Marker Bed 139 at the Waste Isolation Pilot Plant, SAND95-1240, prepared by Sandia National Laboratories, Albuquerque, NM.

Hansen, F. D. and P. F. Gnirk, 1975. Design Aspects of the Alpha Repository: III. Uniaxial QuasiStatic and Creep Properties of the Site Rock, Technical Memorandum Report RSI-0029, prepared by RE/SPEC Inc., Rapid City, SD, for Holifield National Laboratory, Oak Ridge, TN.

Howarth, S. M. and T. Christian-Frear, 1997. Porosity, Single-Phase Permeability, and Capillary Pressure Data From Preliminary Laboratory Experiments on Selected Samples From Marker Bed 139 at the Waste Isolation Pilot Plant, SAND94-0472/1/2/3, prepared by Sandia National Laboratories, Albuquerque, NM.

Hurlbut, 1971. Dana's Manual of Mineralogy, John Wiley \& Sons, New York, NY. 
Pfeifle, T. W. and P. E. Senseny, 1981. Elastic-Plastic Deformation of Anhydrite and Polyhalite as Determined From Quasi-Static Triaxial Compression Tests, SAND81-7063, prepared by RE/SPEC Inc., Rapid City, SD, for Sandia National Laboratories, Albuquerque, NM.

RE/SPEC Inc., 1998. Quality Assurance Project Plan Rock Mechanics Analysis Support for Sandia National Laboratories, RSI QAPP-09, Rev. 4, WPO \#49077, prepared by RE/SPEC Inc., Rapid City, SD, for Sandia National Laboratories, Albuquerque, NM.

Senseny, P. E., A. F. Fossum, and T. W. Pfeifle, 1983. "Non-Associative Constitutive Laws for Low Porosity Rocks," WPO \#42579, International Journal for Numerical and Analytical Methods in Geomechanics, Vol. 7, pp. 101-115.

Teufel, L. W., 1981. Mechanical Properties of Anhydrite and Polyhalite in Quasi-Static Triaxial Compression, SAND81-0858, WPO \#27447, prepared by Sandia National Laboratories, Albuquerque, NM.

U.S. Department of Energy, 1991. Quality Assurance, DOE Order 5700.6C, U.S. Department of Energy, Office of Nuclear Energy and Office of Environment, Safety, and Health, Washington, DC, August.

U.S. Department of Energy, 1996. Title 40 CFR Part 191 Compliance Certification Application for the Waste Isolation Pilot Plant, DOE/CAO-1996-2184, prepared by Carlsbad Area Office, United States Department of Energy, Carlsbad, NM.

U.S. Environmental Protection Agency, 1985. Environmental Standards for the Management and Disposal of Spent Nuclear Fuel, High-Level and Transuranic Radioactive Waste; Final Rule, 40 CFR Part 191, 50 Federal Registrar, 38066-38089, WPO \#39132. 


\section{APPENDIX A}

SUPPORTING INFORMATION FOR

HANSEN AND GNIRK, 1975

STRESS-STRAIN CURVES FOR UNCONFINED

COMPRESSIVE STRENGTH TESTS

OF WIPP ANHYDRITE 


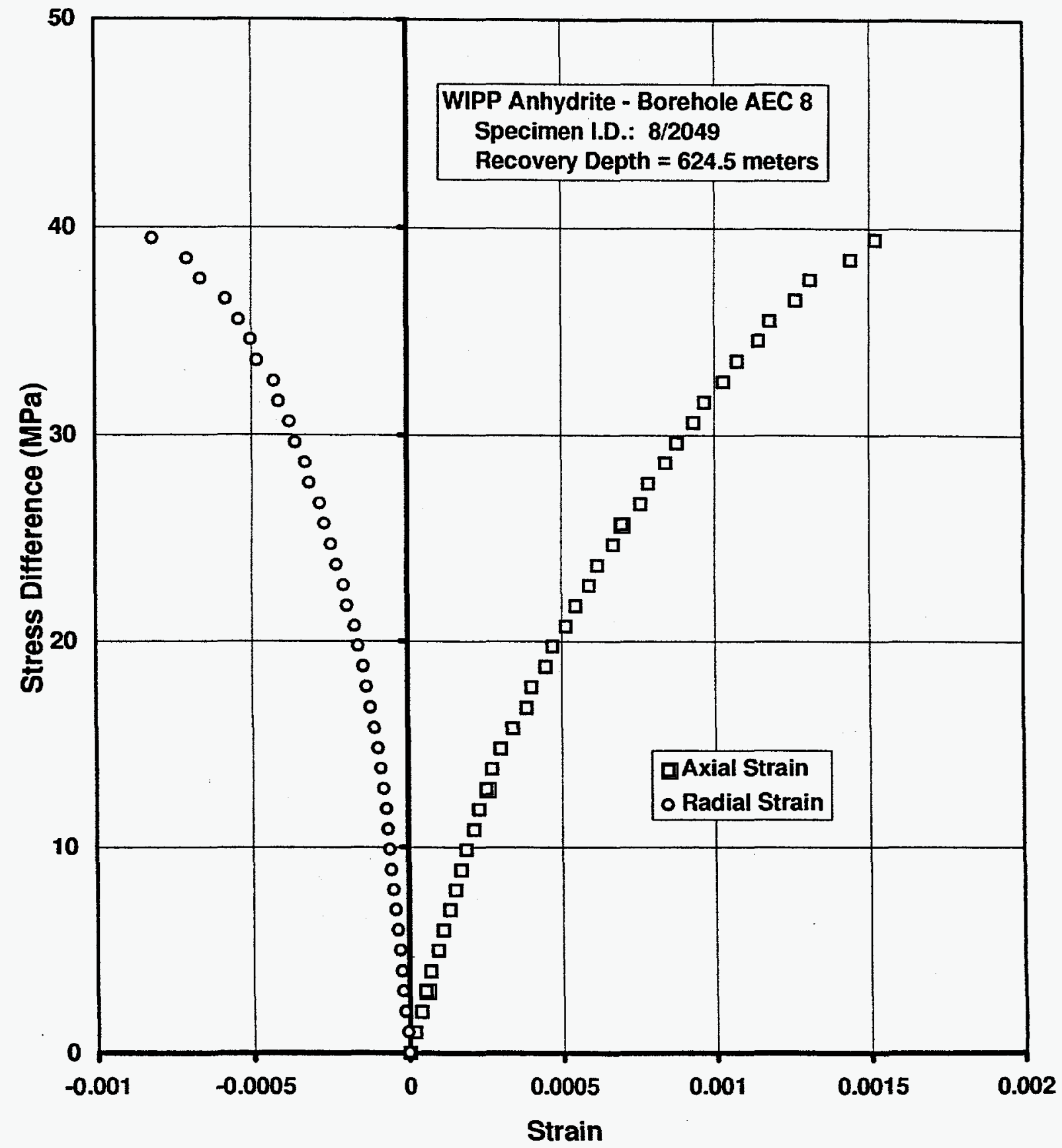

Figure A-1. Stress Difference Versus Axial and Radial Strain for an Unconfined Compression Test on WIPP Anhydrite, Specimen 8/2049. 


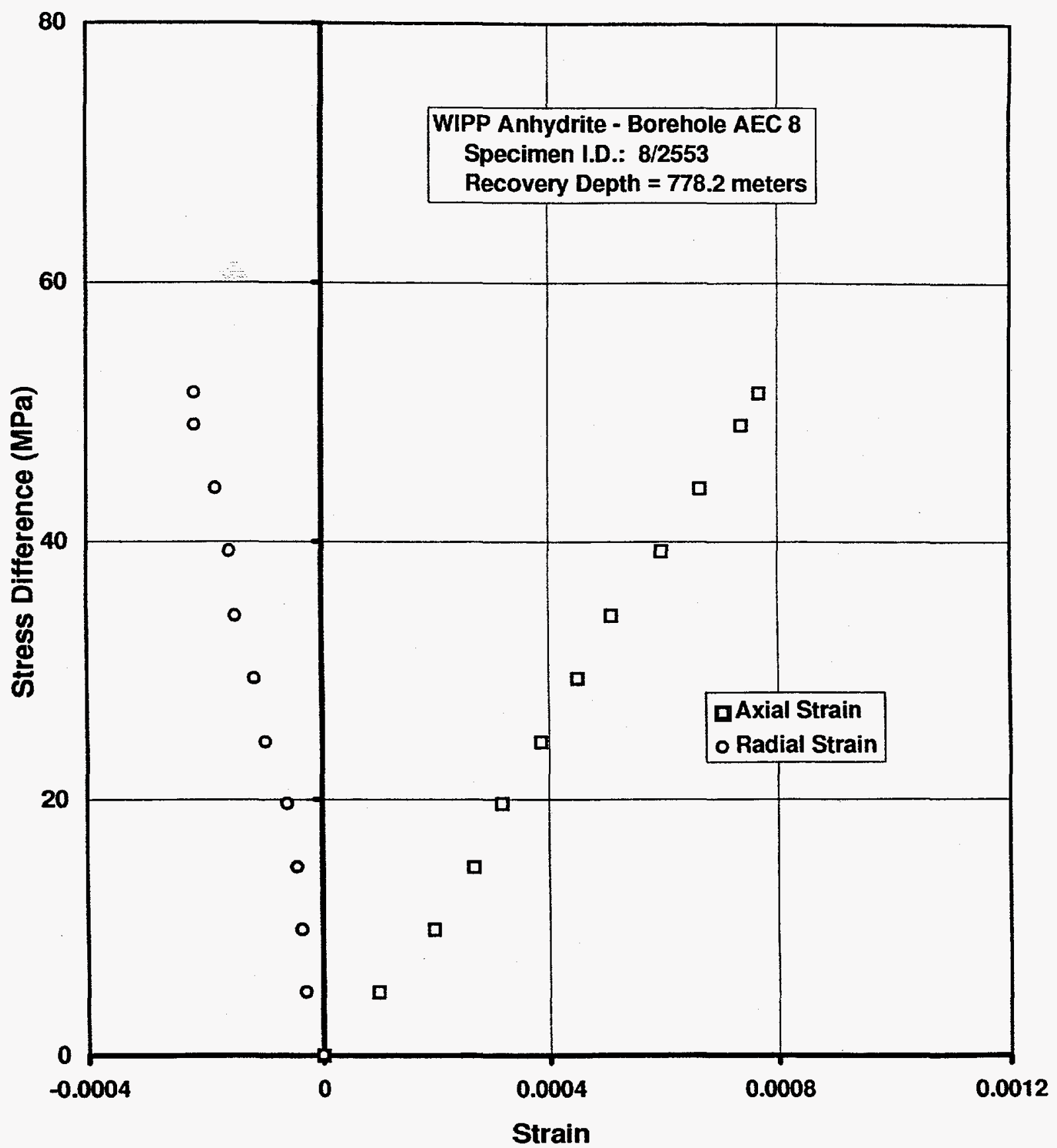

Figure A-2. Stress Difference Versus Axial and Radial Strain for an Unconfined Compression Test on WIPP Anhydrite, Specimen 8/2553. 


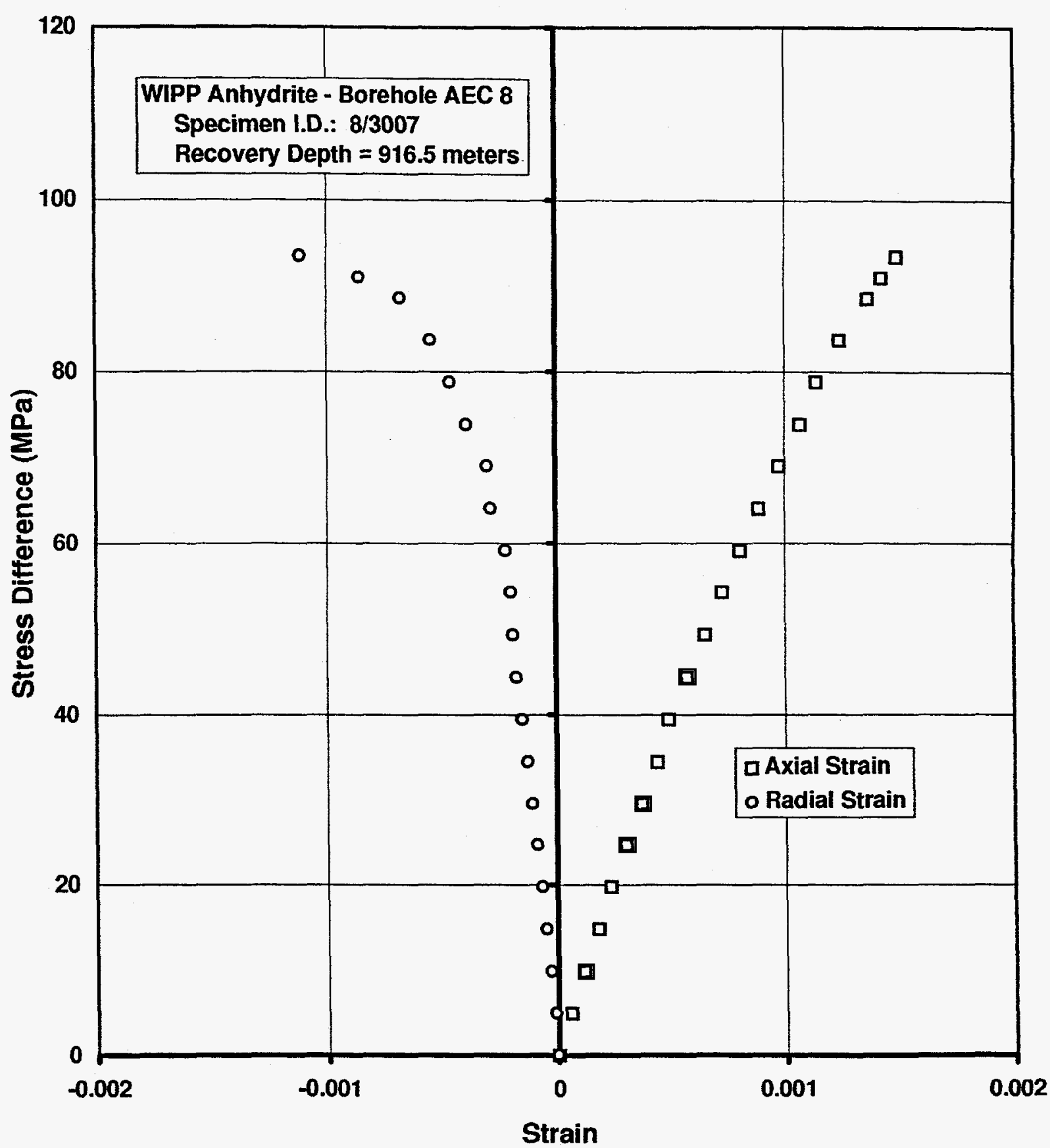

Figure A-3. Stress Difference Versus Axial and Radial Strain for an Unconfined Compression Test on WIPP Anhydrite, Specimen 8/3007. 


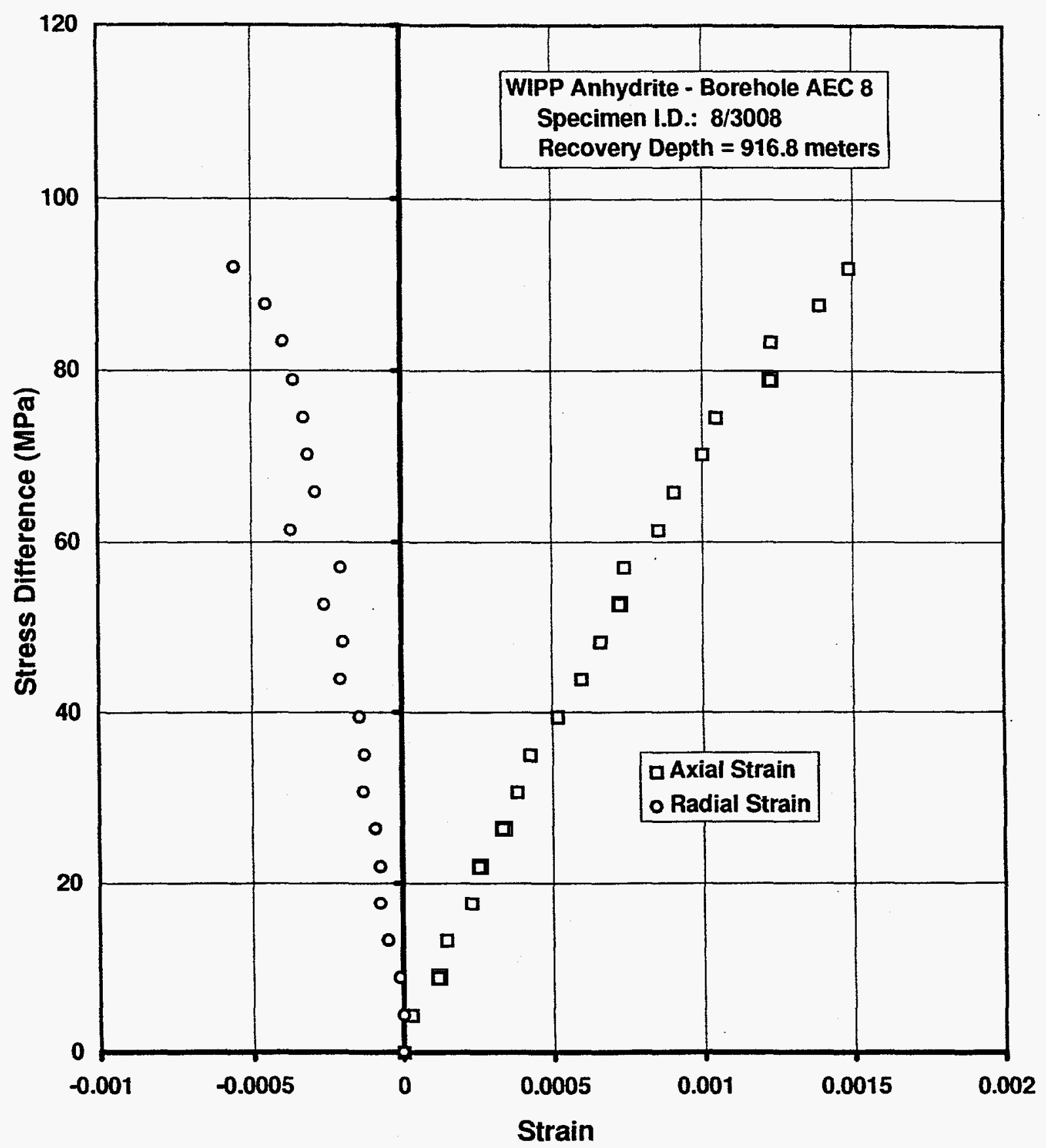

Figure A-4. Stress Difference Versus Axial and Radial Strain for an Unconfined Compression Test on WIPP Anhydrite, Specimen 8/3008. 


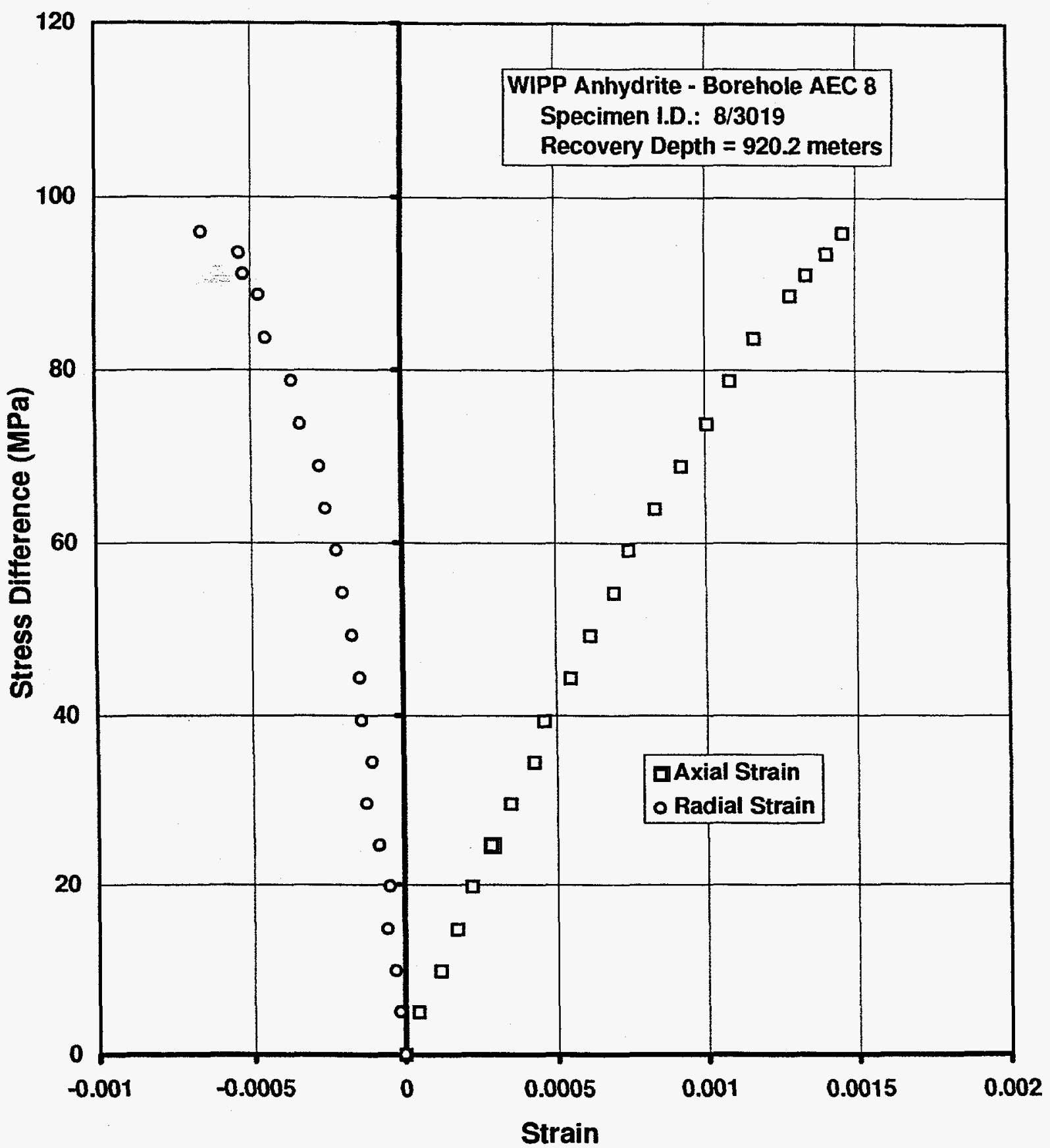

Figure A-5. Stress Difference Versus Axial and Radial Strain for an Unconfined Compression Test on WIPP Anhydrite, Specimen 8/3019. 
RSI-325-98-008

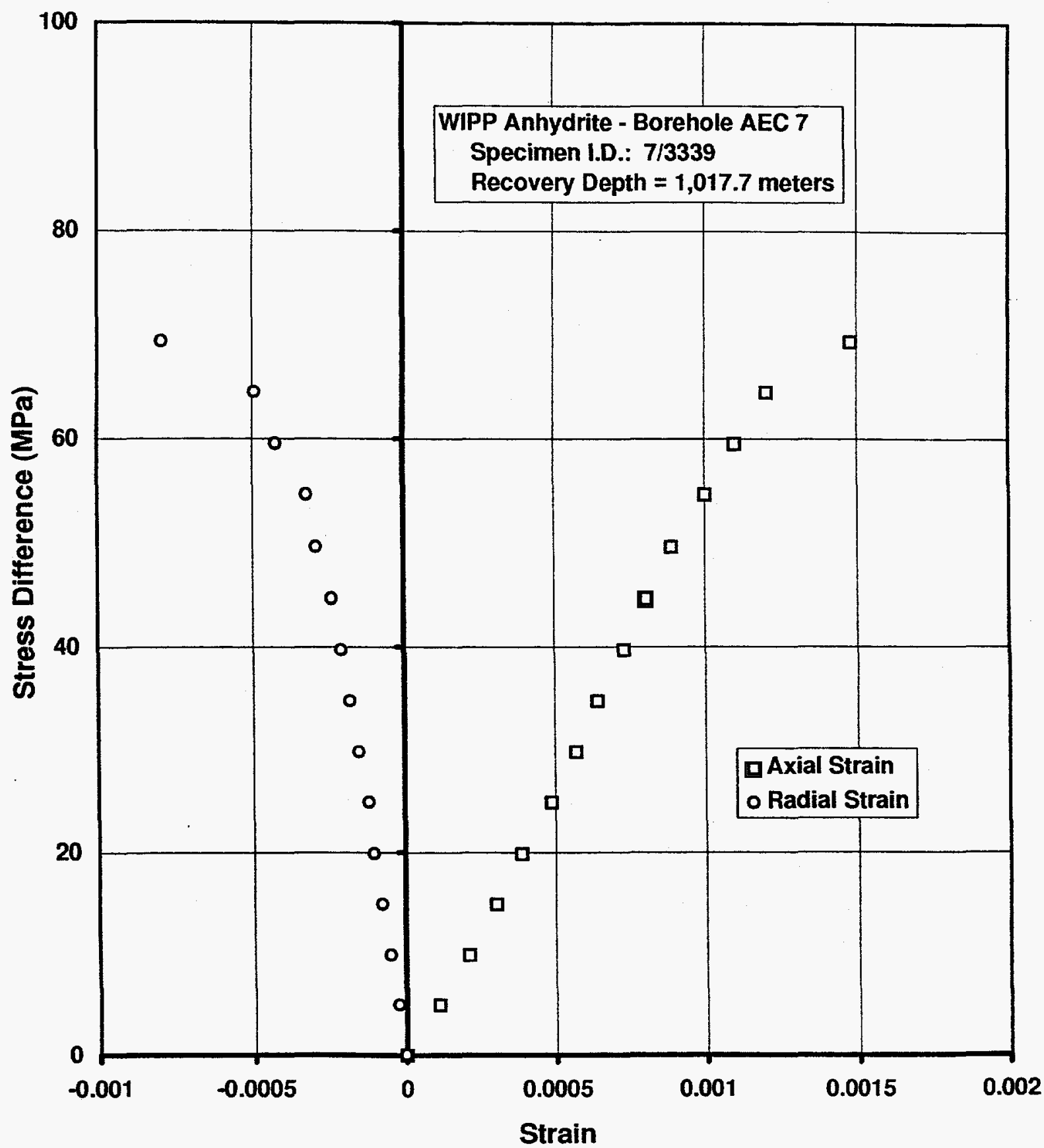

Figure A-6. Stress Difference Versus Axial and Radial Strain for an Unconfined Compression Test on WIPP Anhydrite, Specimen 7/3339. 
RSI-325-98-009

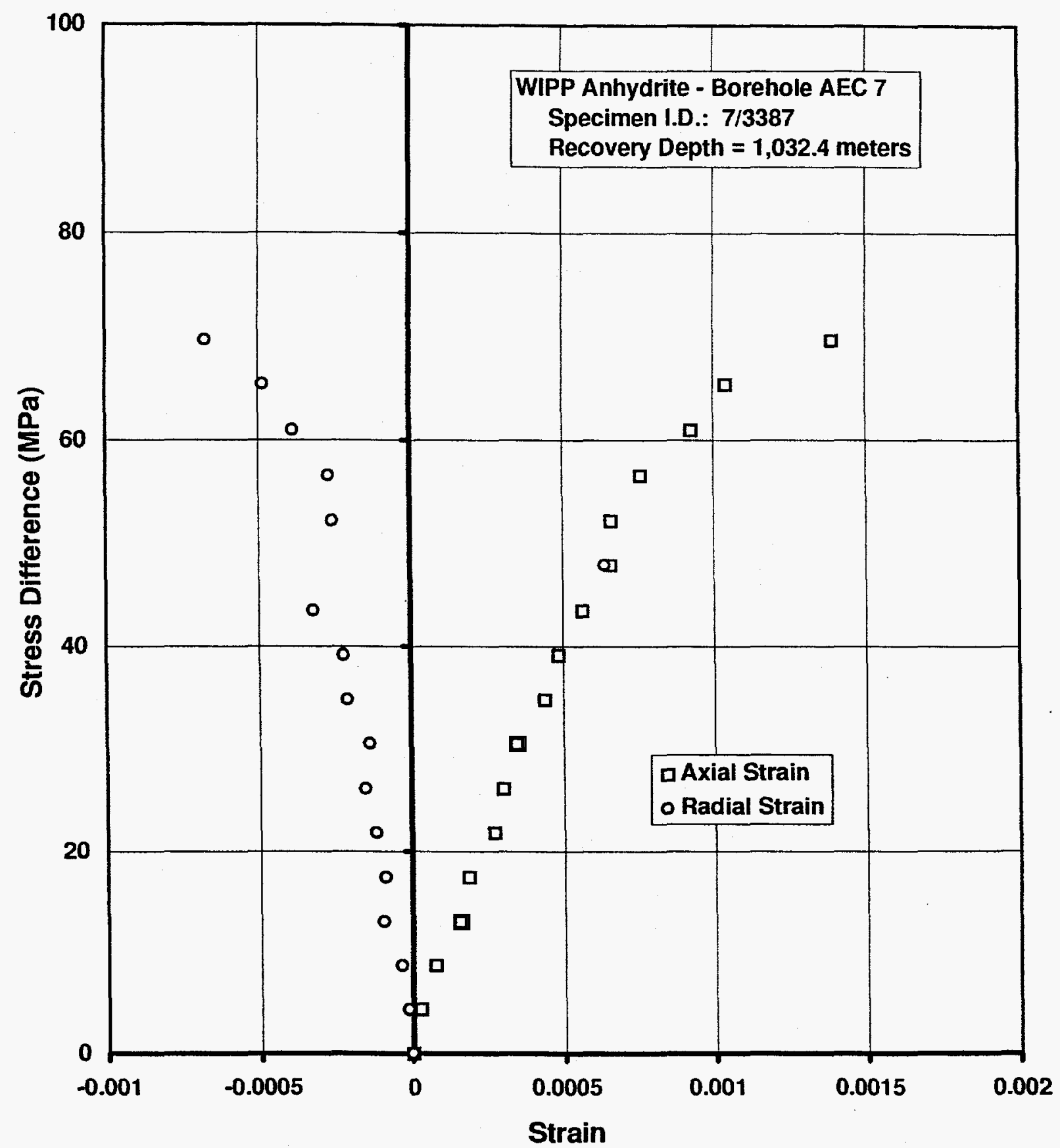

Figure A-7. Stress Difference Versus Axial and Radial Strain for an Unconfined Compression Test on WIPP Anhydrite, Specimen 7/3387. 


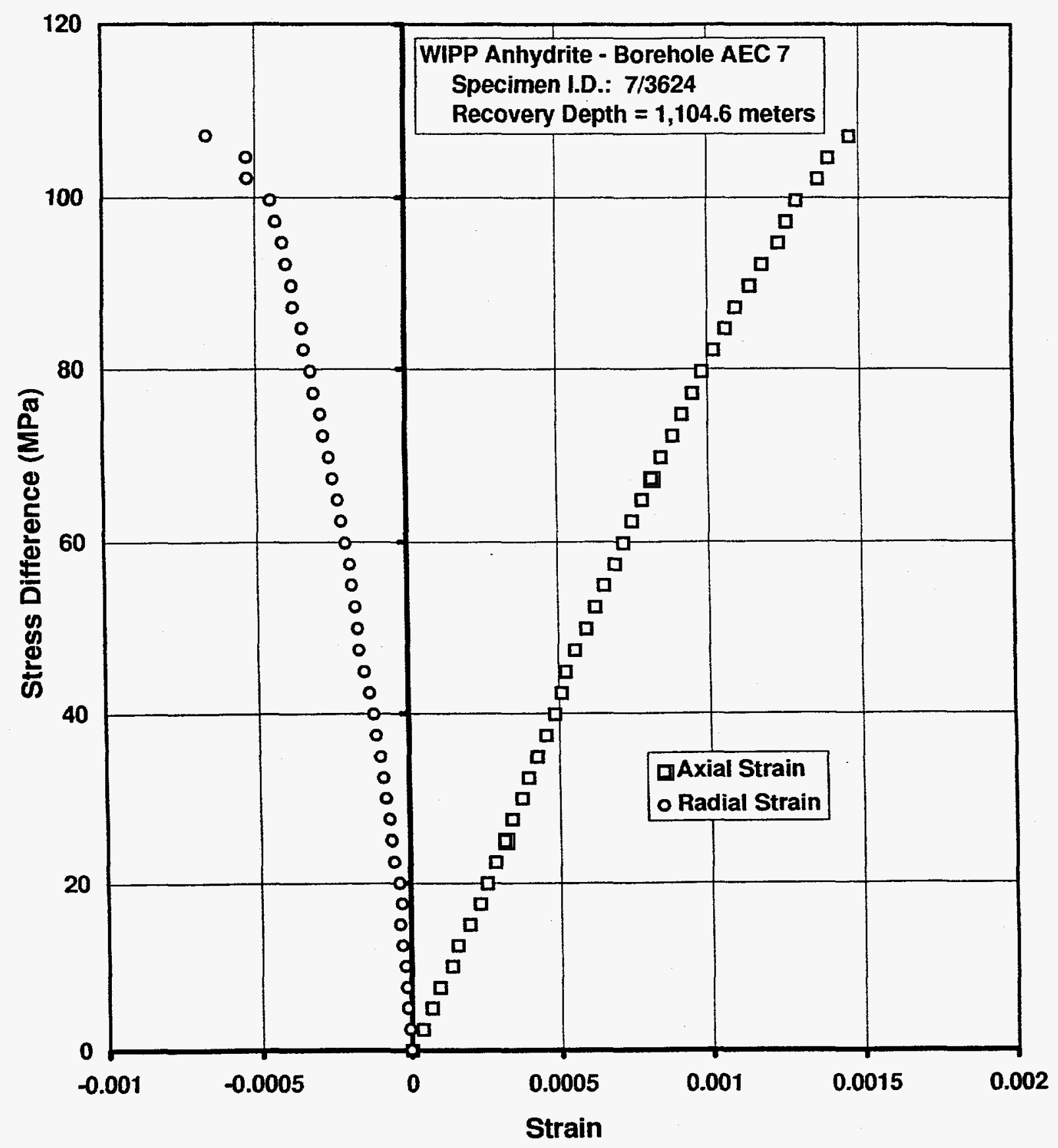

Figure A-8. Stress Difference Versus Axial and Radial Strain for an Unconfined Compression Test on WIPP Anhydrite, Specimen 7/3624. 
This page intentionally left blank

A-10 
APPENDIX B

SUPPORTING INFORMATION FOR

TEUFEL, 1981

STRESS-STRAIN CURVES FOR TRIAXIAL

COMPRESSIVE STRENGTH TESTS

OF WIPP ANHYDRITE

B-1 
RSI-325-98-011

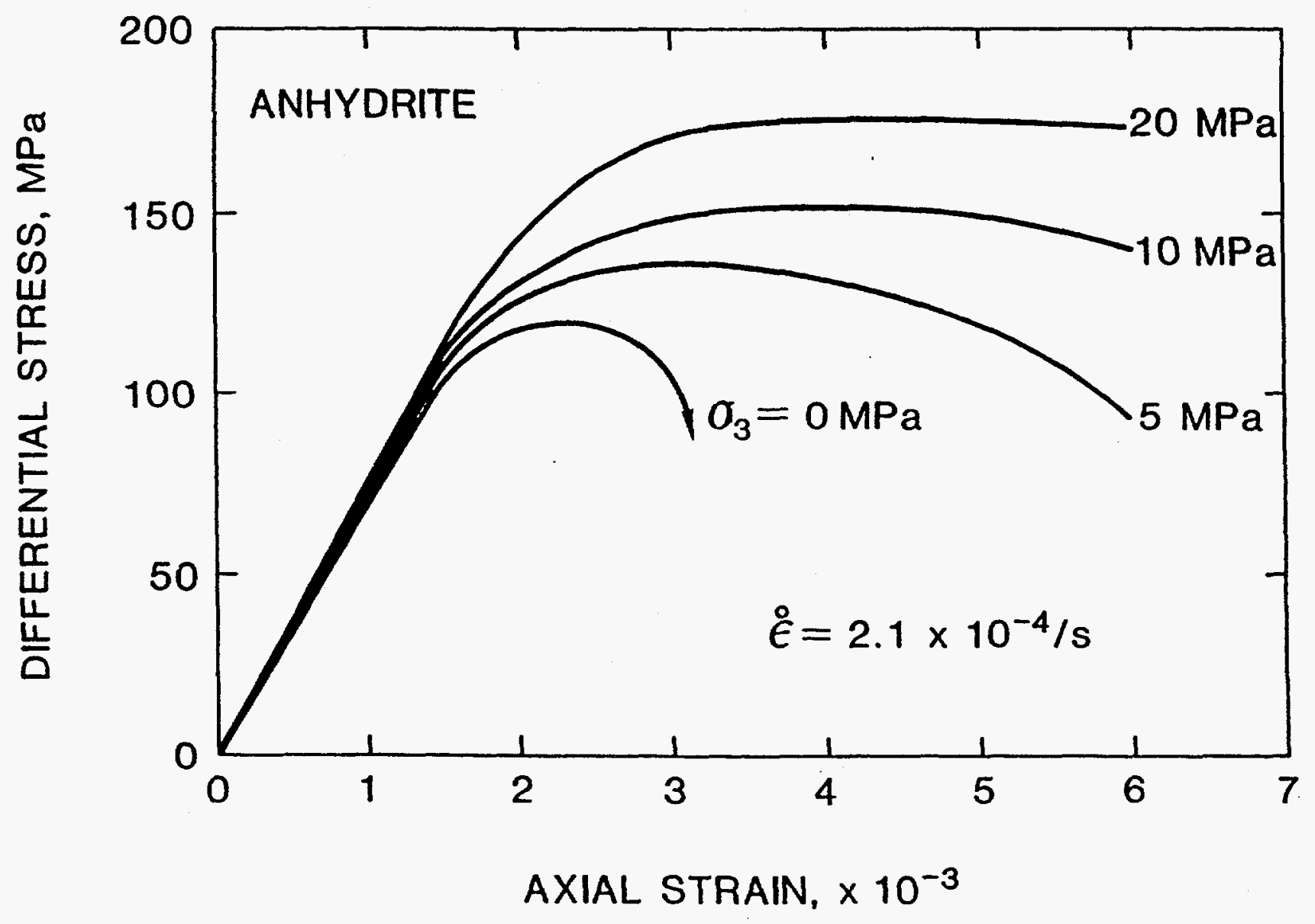

Figure B-1. Typical Stress Difference Versus Axial Strain for Triaxial Compression Tests on WIPP Anhydrite (After Teufel [1981]). 


\section{APPENDIX C}

SUPPORTING INFORMATION FOR

PFEIFLE AND SENSENY, 1981

STRESS-STRAIN CURVES FOR TRIAXIAL COMPRESSIVE STRENGTH TESTS

OF WIPP ANHYDRITE 


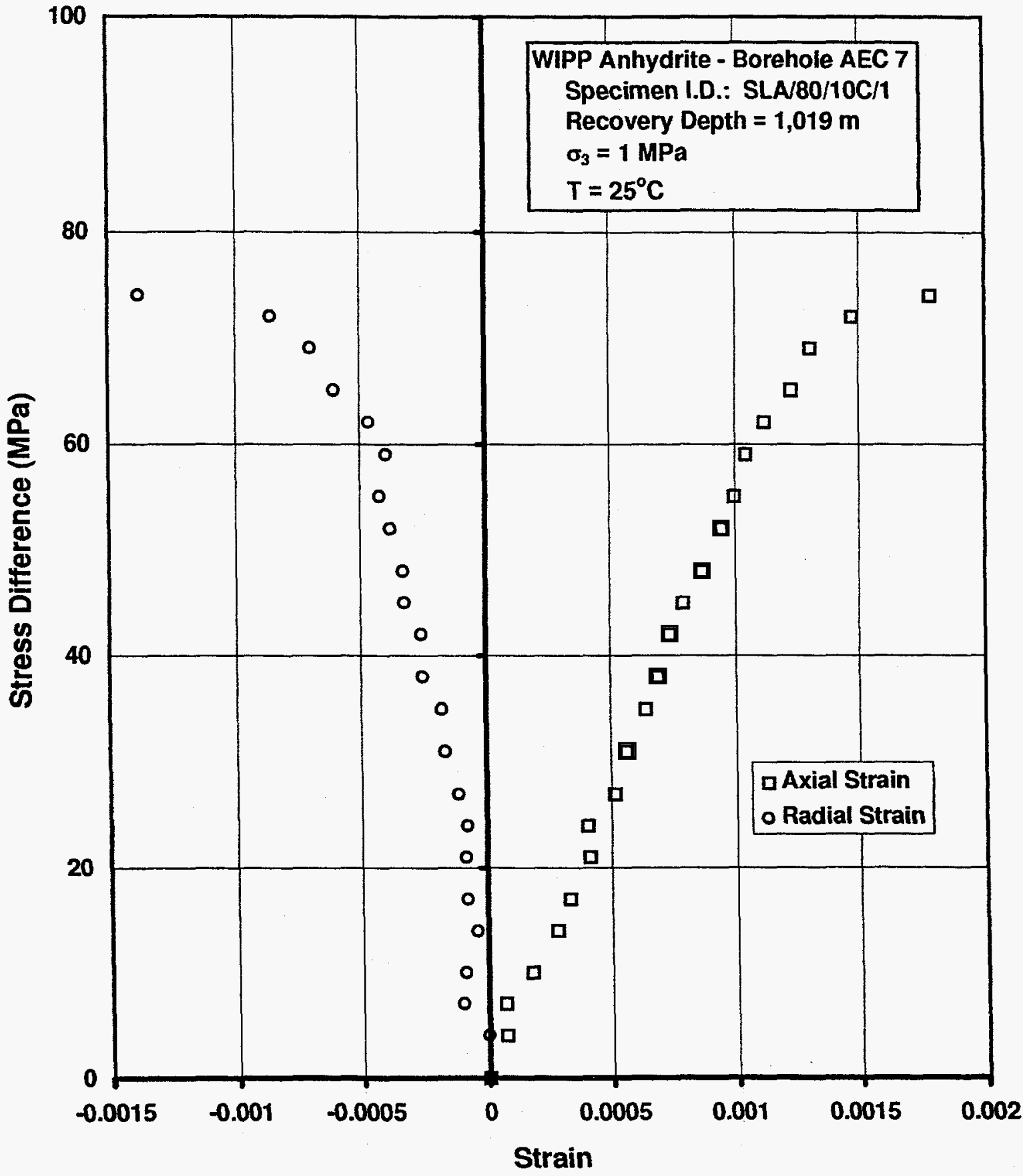

Figure C-1. Stress Difference Versus Axial and Radial Strain for a Triaxial Compression Test on WIPP Anhydrite at a Temperature of $25^{\circ} \mathrm{C}$ and a Confining Pressure of $1 \mathrm{MPa}$, Specimen SLA/80/10C/1. 


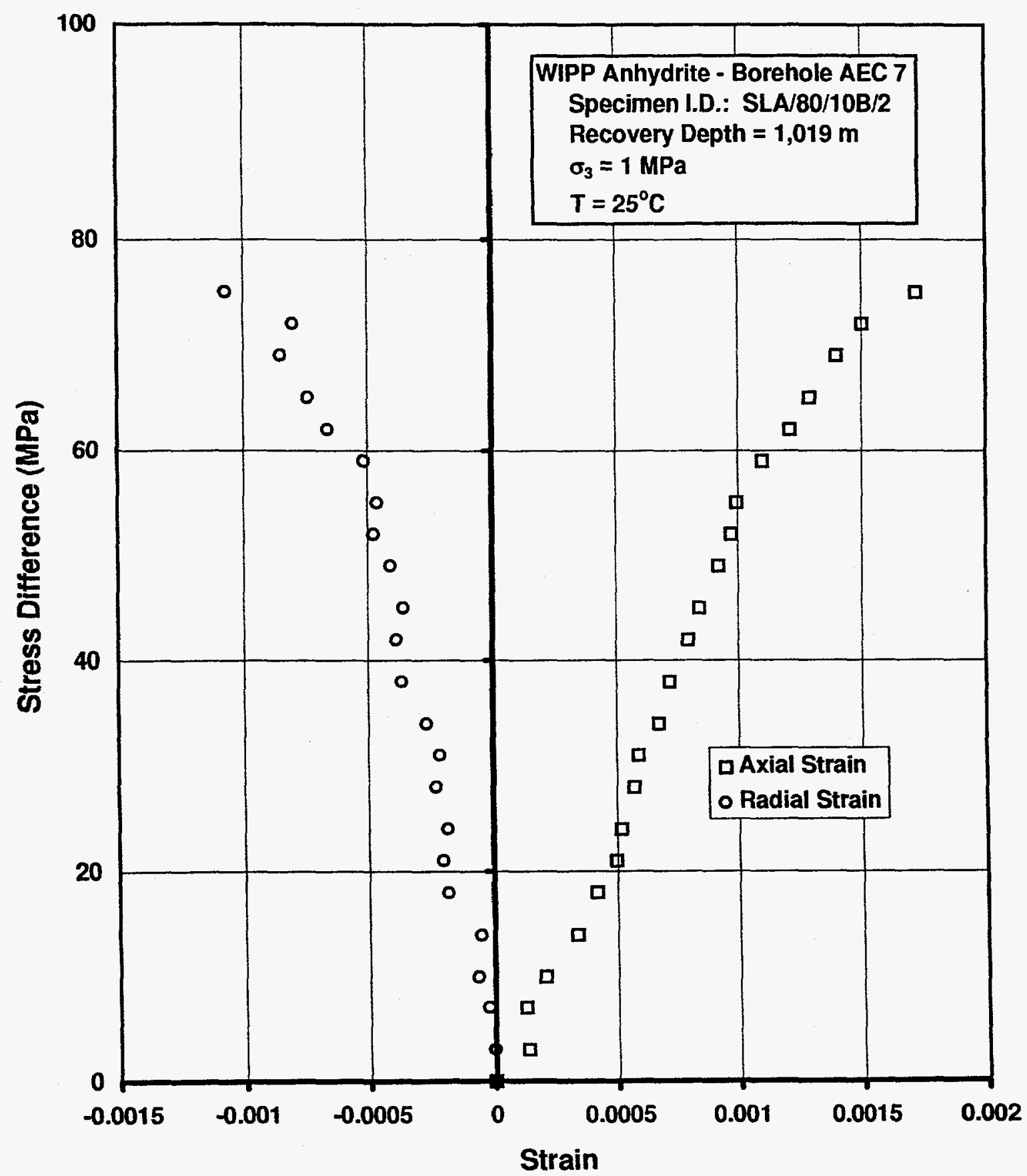

Figure C-2 Stress Difference Versus Axial and Radial Strain for a Triaxial Compression Test on WIPP Anhydrite at a Temperature of $25^{\circ} \mathrm{C}$ and a Confining Pressure of $1 \mathrm{MPa}$, Specimen SLA/80/10B/2. 


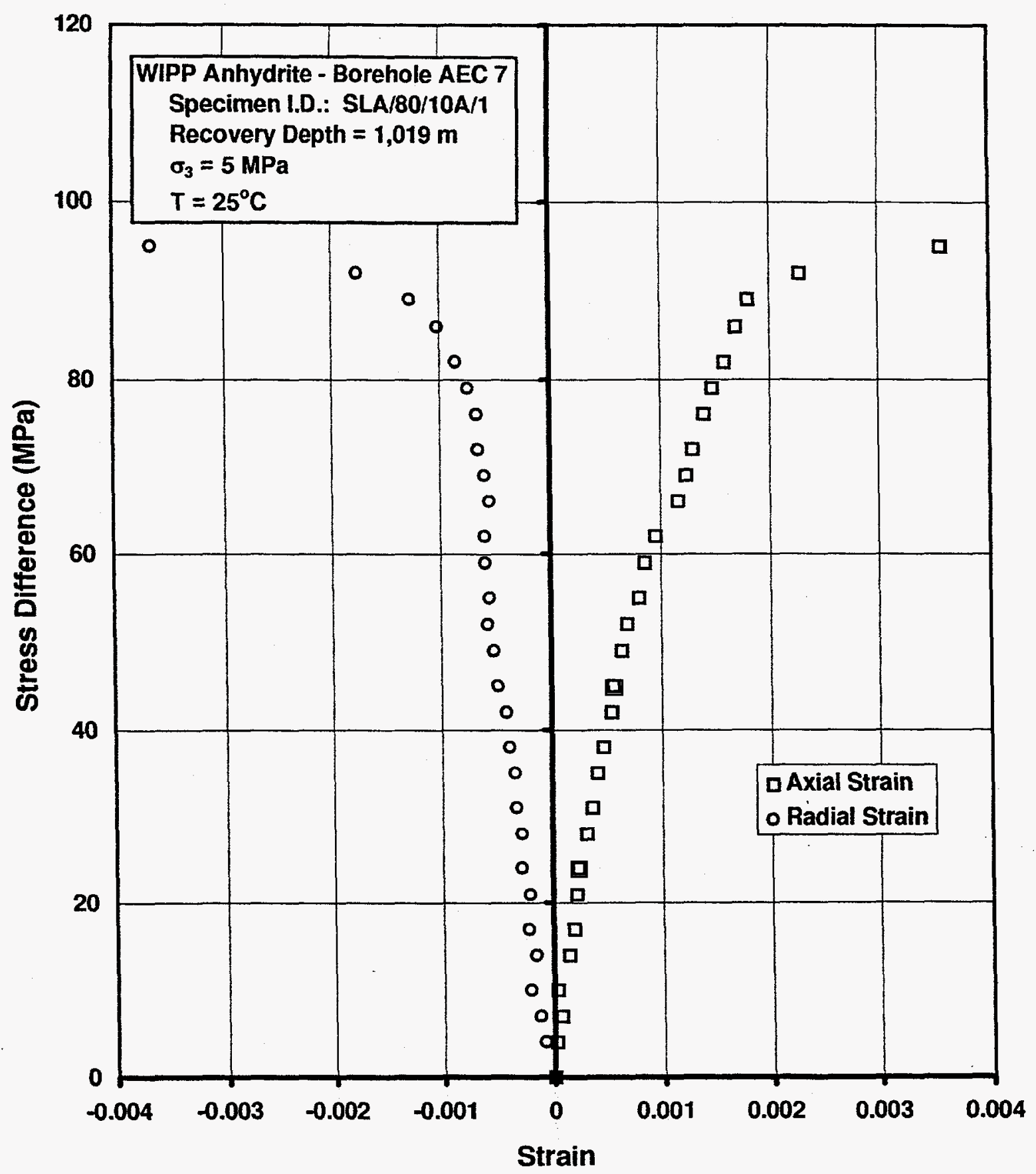

Figure C-3. Stress Difference Versus Axial and Radial Strain for a Triaxial Compression Test on WIPP Anhydrite at a Temperature of $25^{\circ} \mathrm{C}$ and a Confining Pressure of $5 \mathrm{MPa}$, Specimen SLA/80/10A/1. 


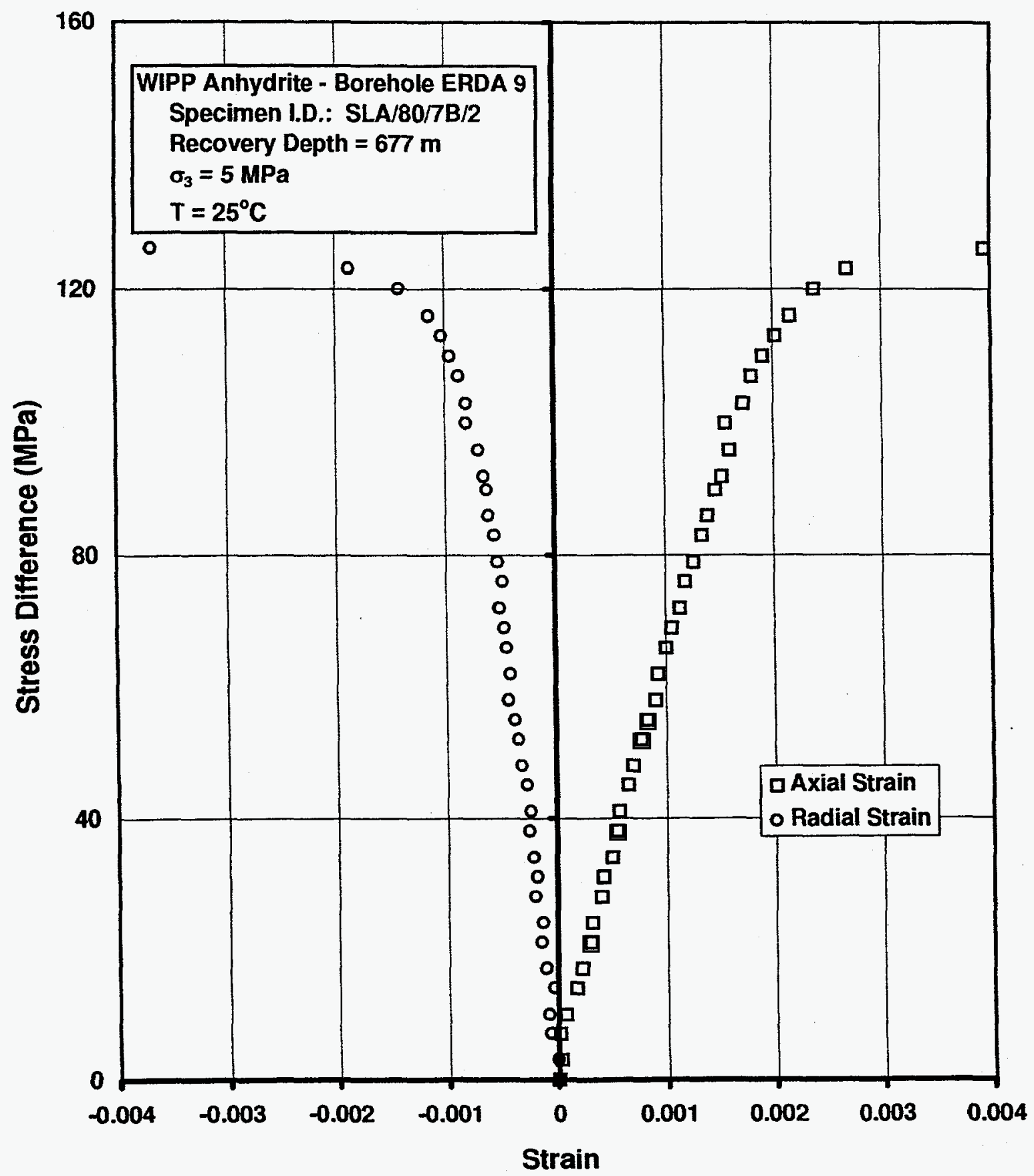

Figure C-4. Stress Difference Versus Axial and Radial Strain for a Triaxial Compression Test on WIPP Anhydrite at a Temperature of $25^{\circ} \mathrm{C}$ and a Confining Pressure of $5 \mathrm{MPa}$, Specimen SLA/80/7B/2. 
RSI-325-98-016

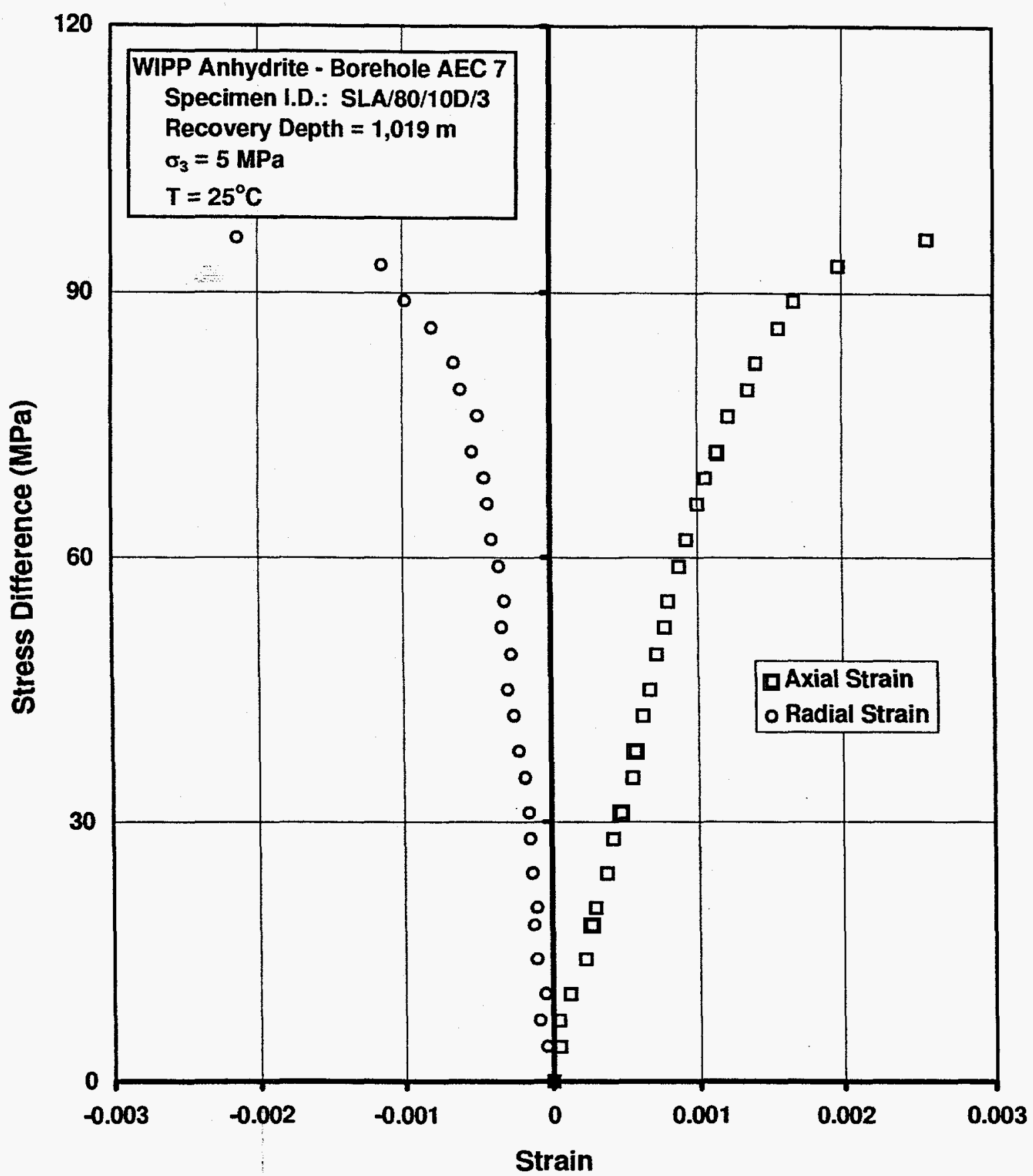

Figure C-5. Stress Difference Versus Axial and Radial Strain for a Triaxial Compression Test on WIPP Anhydrite at a Temperature of $25^{\circ} \mathrm{C}$ and a Confining Pressure of $5 \mathrm{MPa}$, Specimen SLA/80/10D/3. 


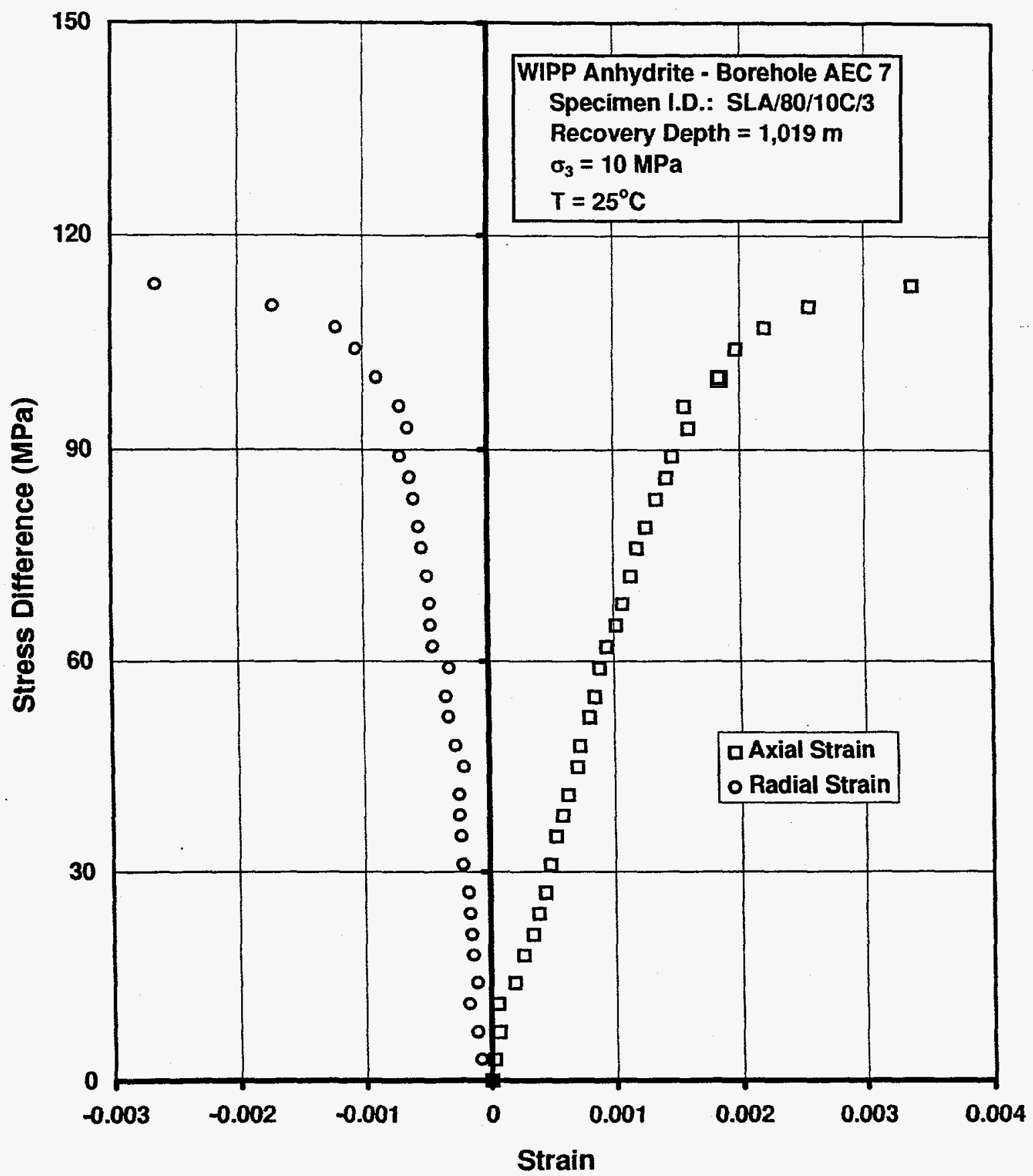

Figure C-6. Stress Difference Versus Axial and Radial Strain for a Triaxial Compression Test on WIPP Anhydrite at a Temperature of $25^{\circ} \mathrm{C}$ and a Confining Pressure of $10 \mathrm{MPa}$, Specimen SLA/80/10C/3. 


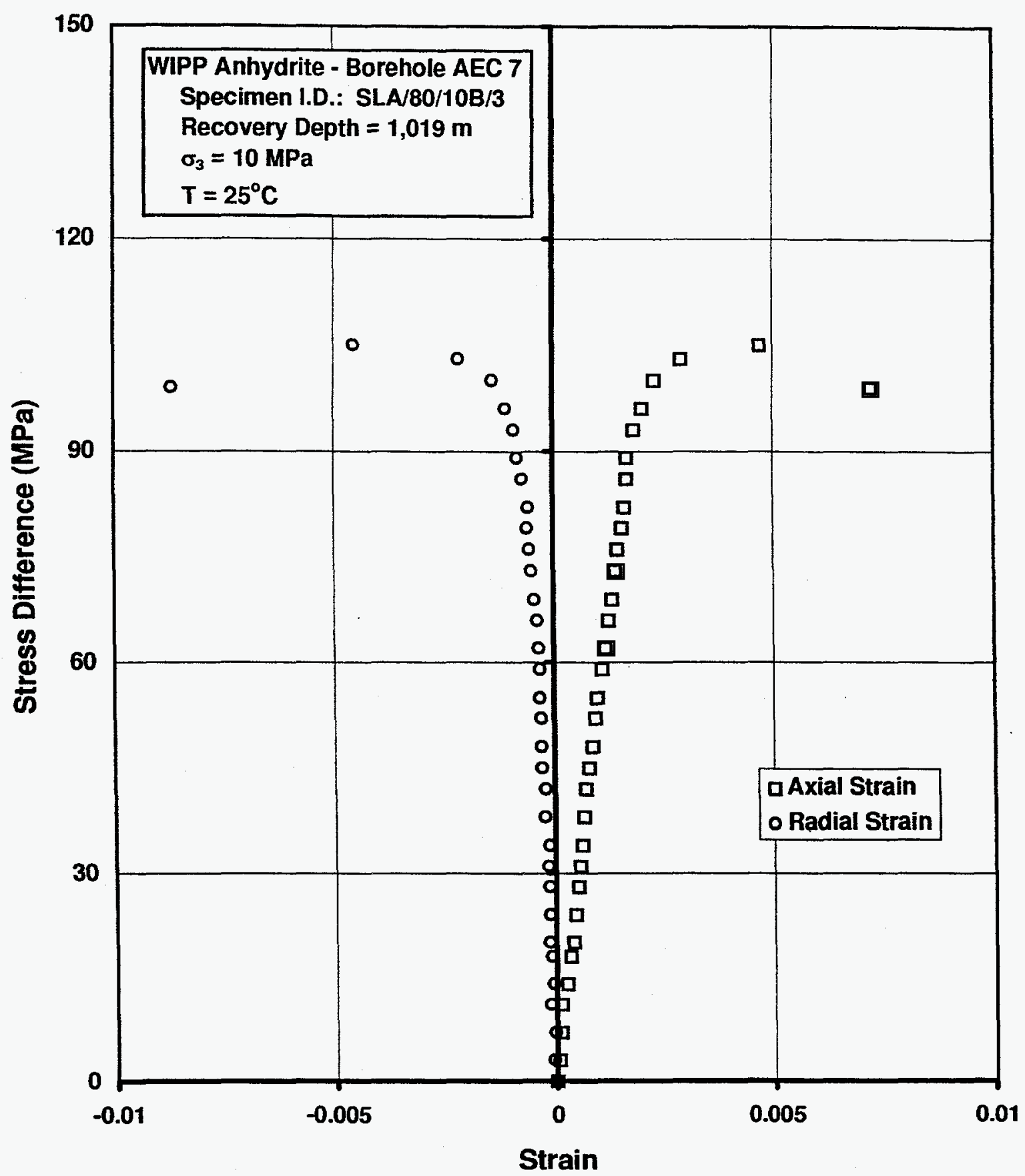

Figure C-7. Stress Difference Versus Axial and Radial Strain for a Triaxial Compression Test on WIPP Anhydrite at a Temperature of $25^{\circ} \mathrm{C}$ and a Confining Pressure of $10 \mathrm{MPa}$, Specimen SLA/80/10B/3. 
RS1-325-98-019

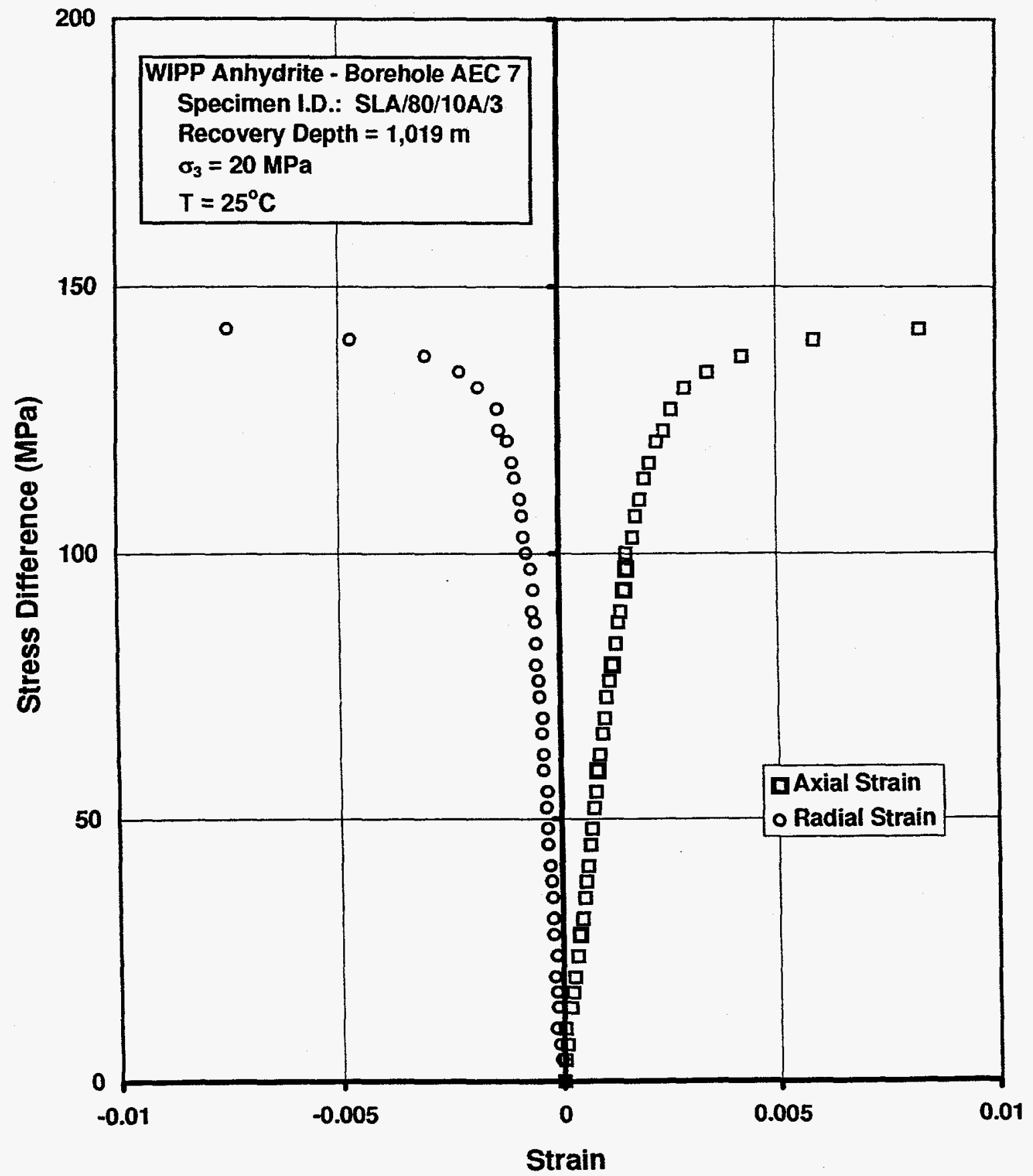

Figure C-8. Stress Difference Versus Axial and Radial Strain for a Triaxial Compression Test on WIPP Anhydrite at a Temperature of $25^{\circ} \mathrm{C}$ and a Confining Pressure of $20 \mathrm{MPa}$, Specimen SLA/80/10A/3. 


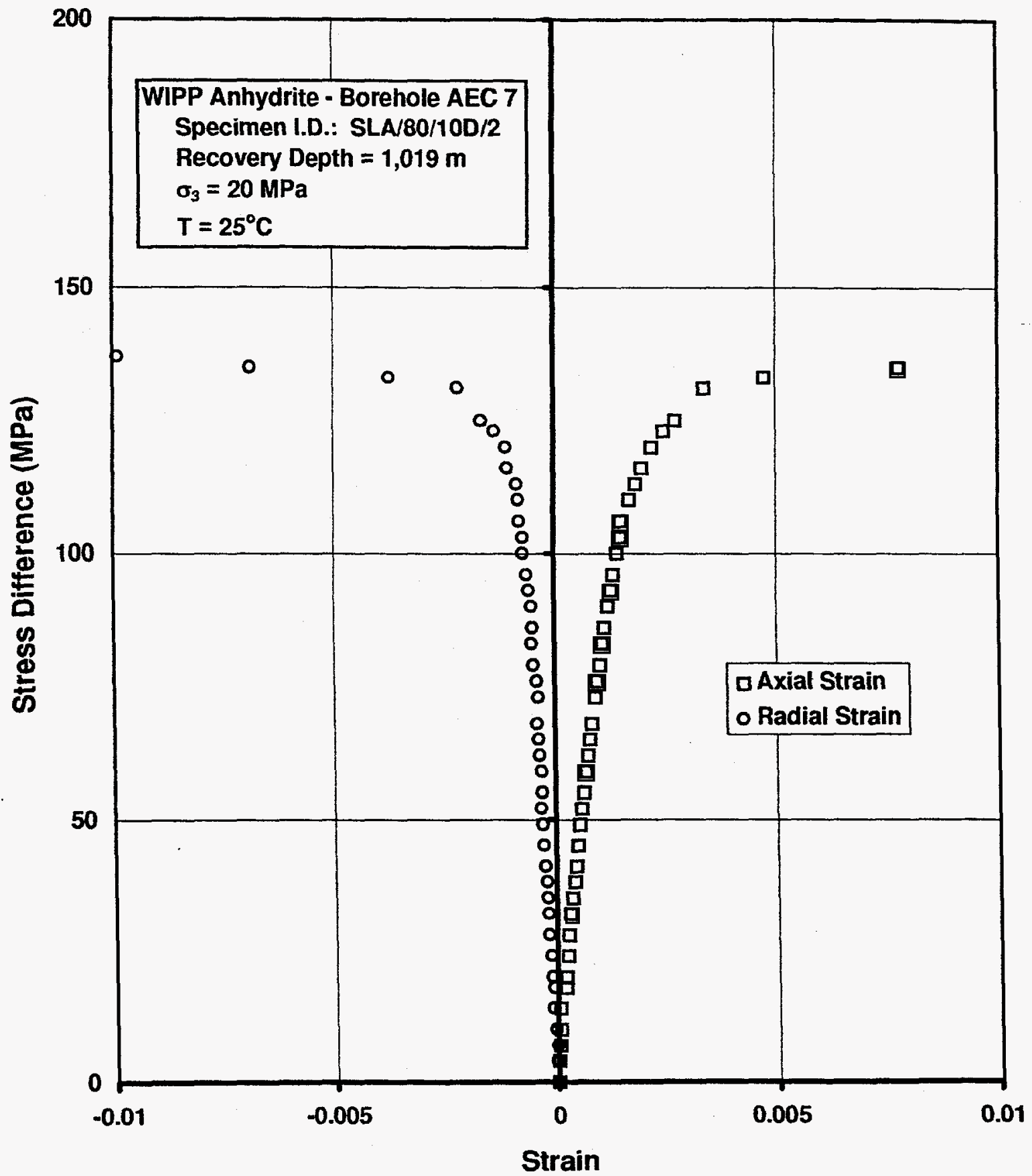

Figure C-9. Stress Difference Versus Axial and Radial Strain for a Triaxial Compression Test on WIPP Anhydrite at a Temperature of $25^{\circ} \mathrm{C}$ and a Confining Pressure of $20 \mathrm{MPa}$, Specimen SLA/80/10D/2. 
RSI-325-98-021

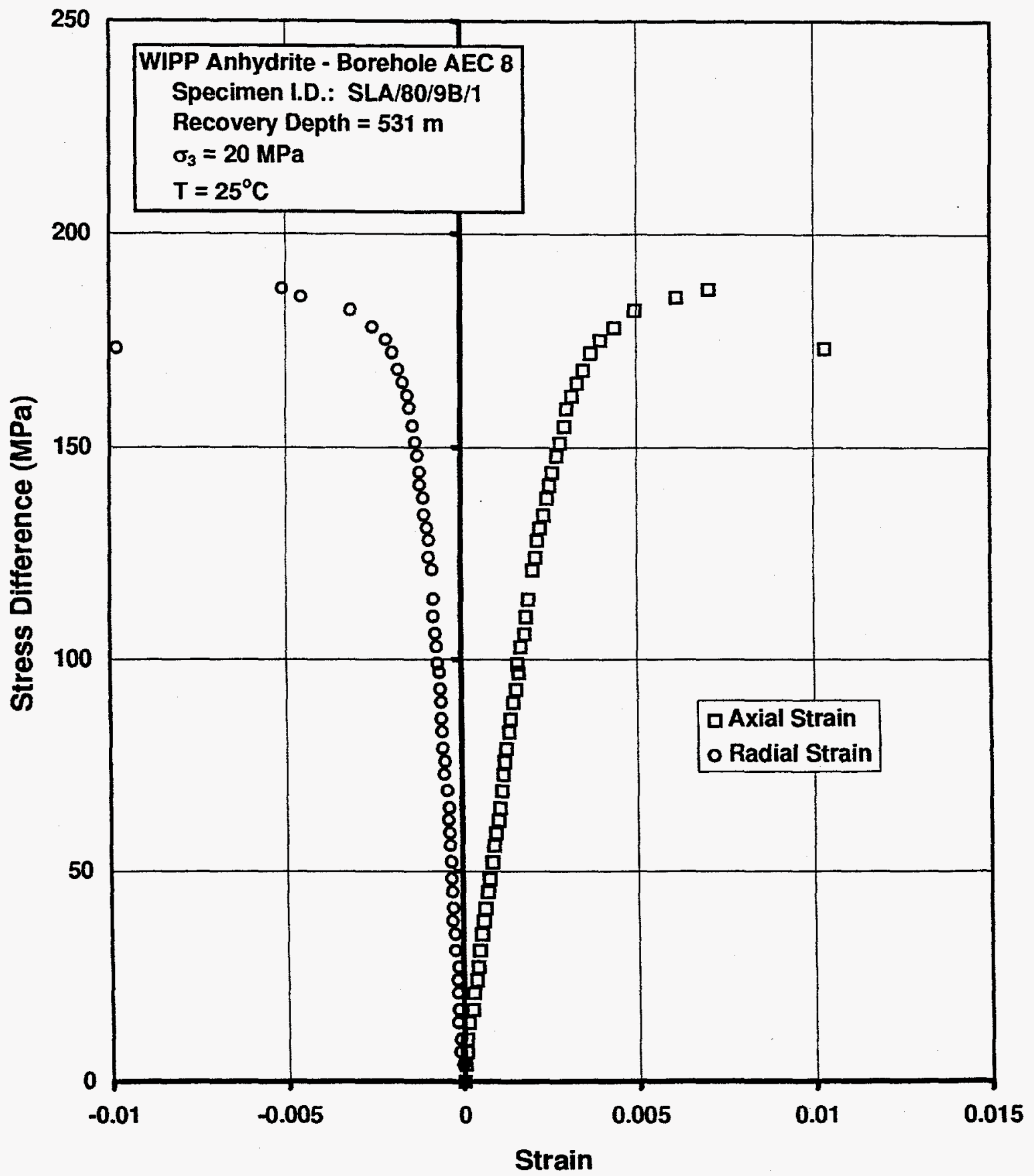

Figure C-10. Stress Difference Versus Axial and Radial Strain for a Triaxial Compression Test on WIPP Anhydrite at a Temperature of $25^{\circ} \mathrm{C}$ and a Confining Pressure of $20 \mathrm{MPa}$, Specimen SLA/80/9B/1. 


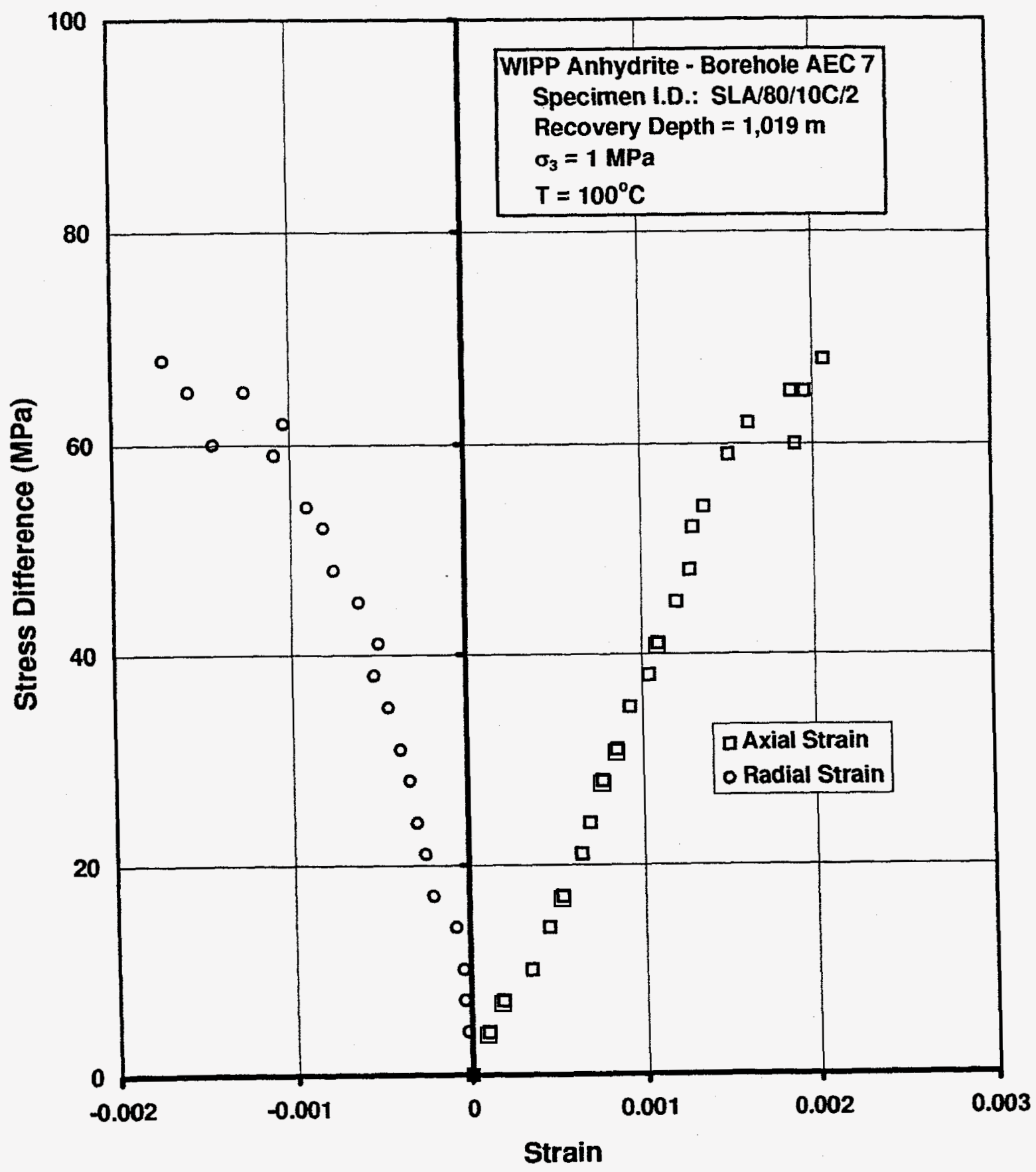

Figure C-11. Stress Difference Versus Axial and Radial Strain for a Triaxial Compression Test on WIPP Anhydrite at a Temperature of $100^{\circ} \mathrm{C}$ and a Confining Pressure of $1 \mathrm{MPa}$, Specimen SLA/80/10C/2. 


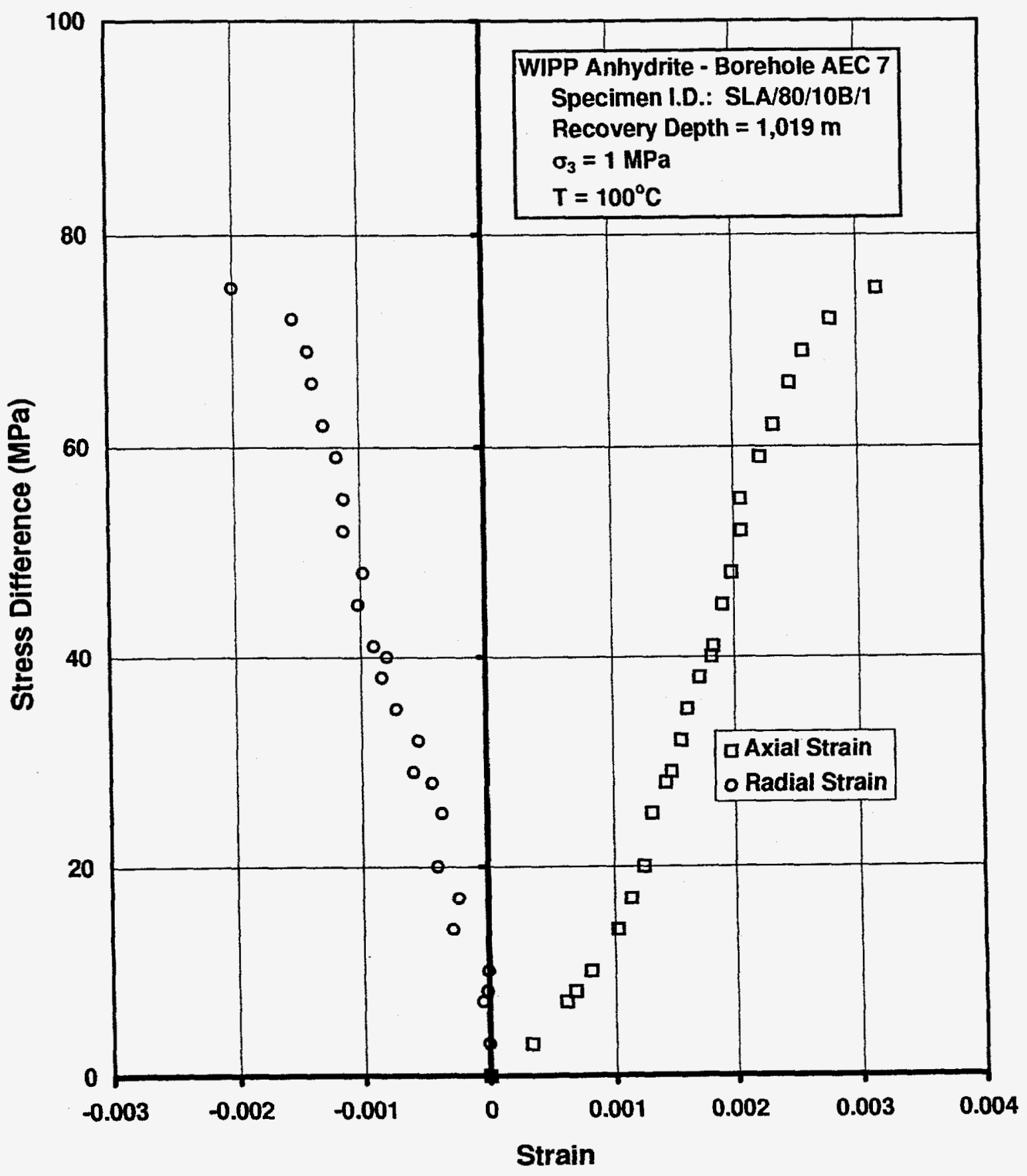

Figure C-12. Stress Difference Versus Axial and Radial Strain for a Triaxial Compression Test on WIPP Anhydrite at a Temperature of $100^{\circ} \mathrm{C}$ and a Confining Pressure of $1 \mathrm{MPa}$, Specimen SLA/80/10B/1. 


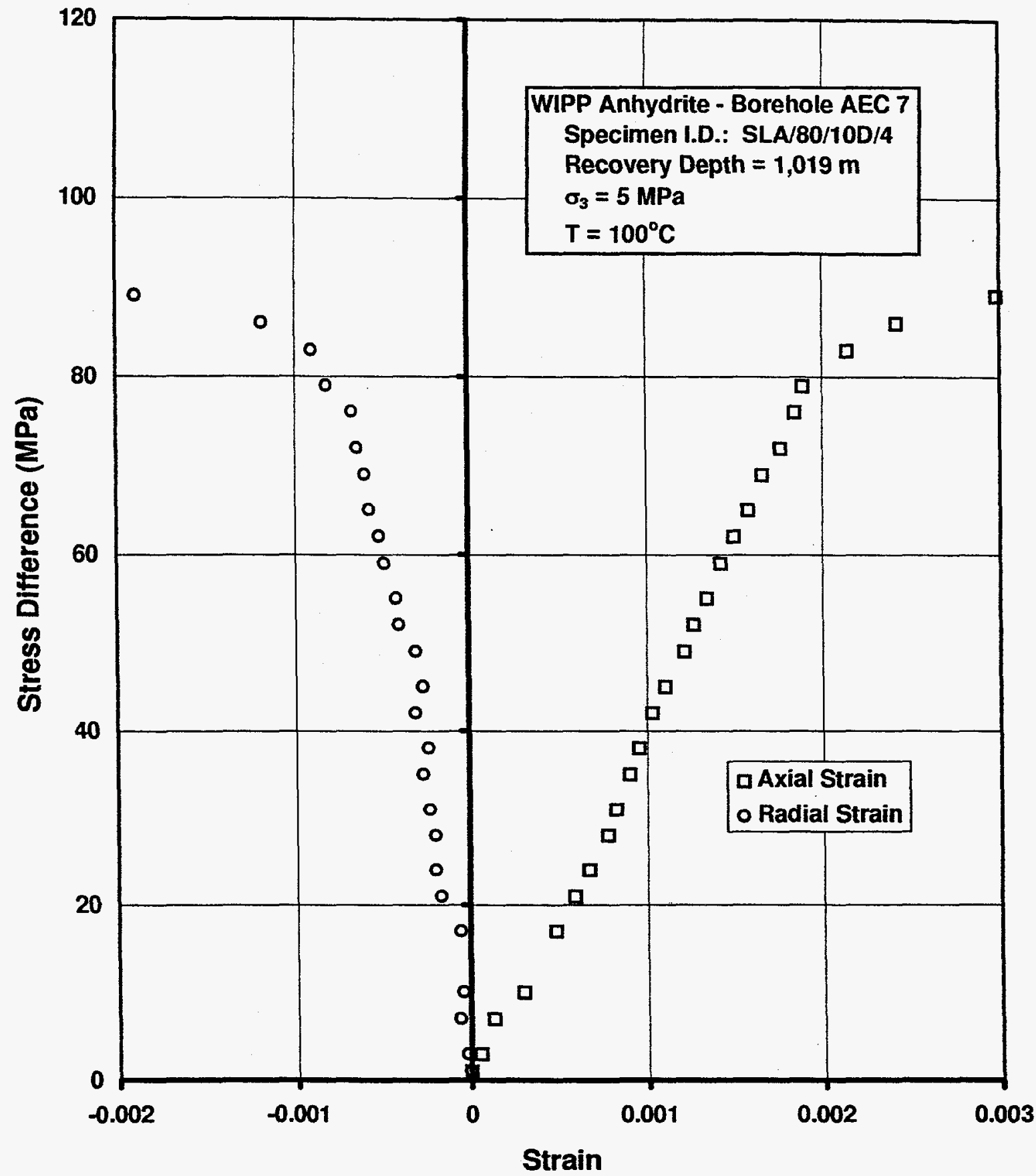

Figure C-13. Stress Difference Versus Axial and Radial Strain for a Triaxial Compression Test on WIPP Anhydrite at a Temperature of $100^{\circ} \mathrm{C}$ and a Confining Pressure of $5 \mathrm{MPa}$, Specimen SLA/80/10D/4. 


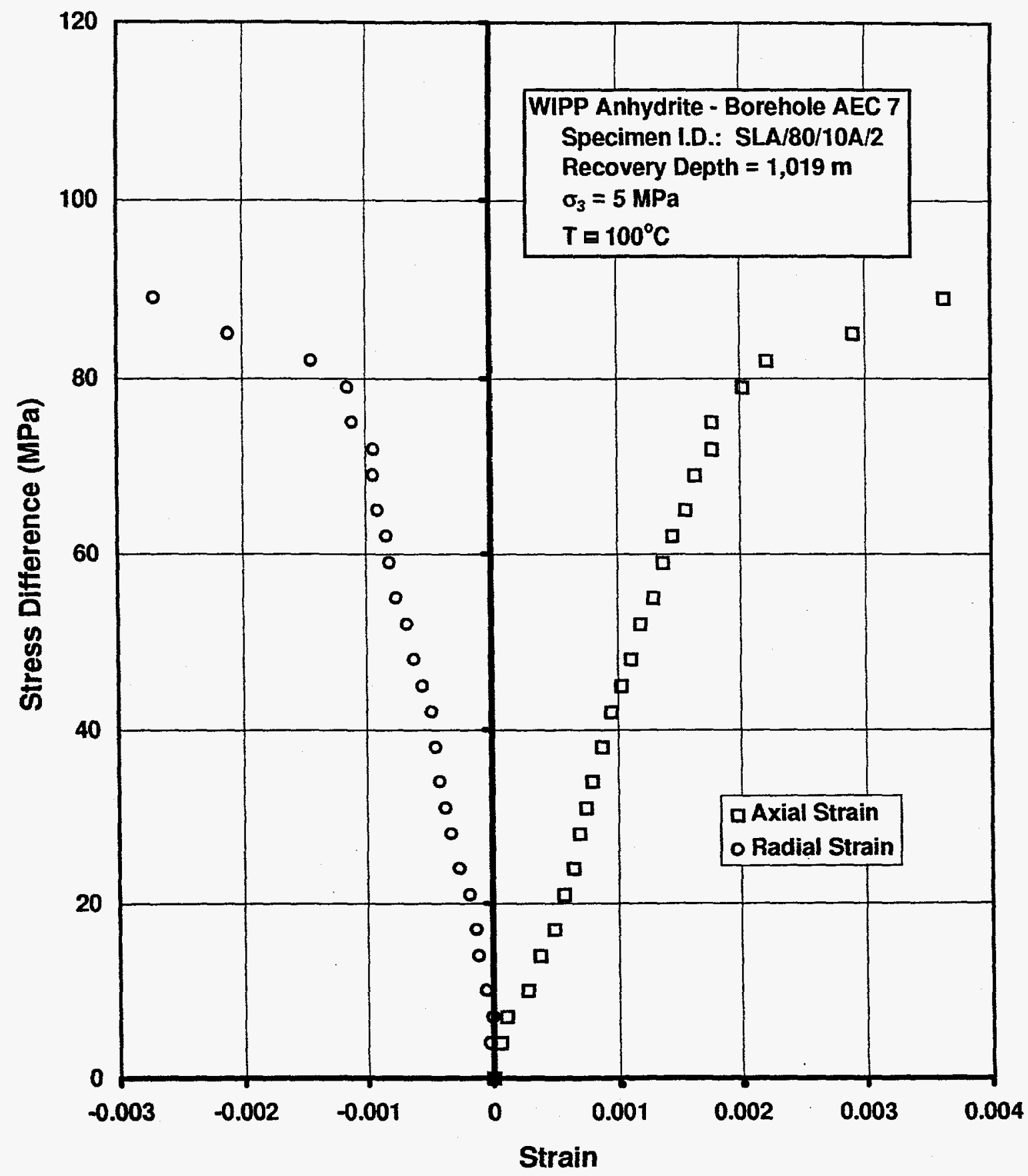

Figure C-14. Stress Difference Versus Axial and Radial Strain for a Triaxial Compression Test on WIPP Anhydrite at a Temperature of $100^{\circ} \mathrm{C}$ and a Confining Pressure of $5 \mathrm{MPa}$, Specimen SLA/80/10A/2. 


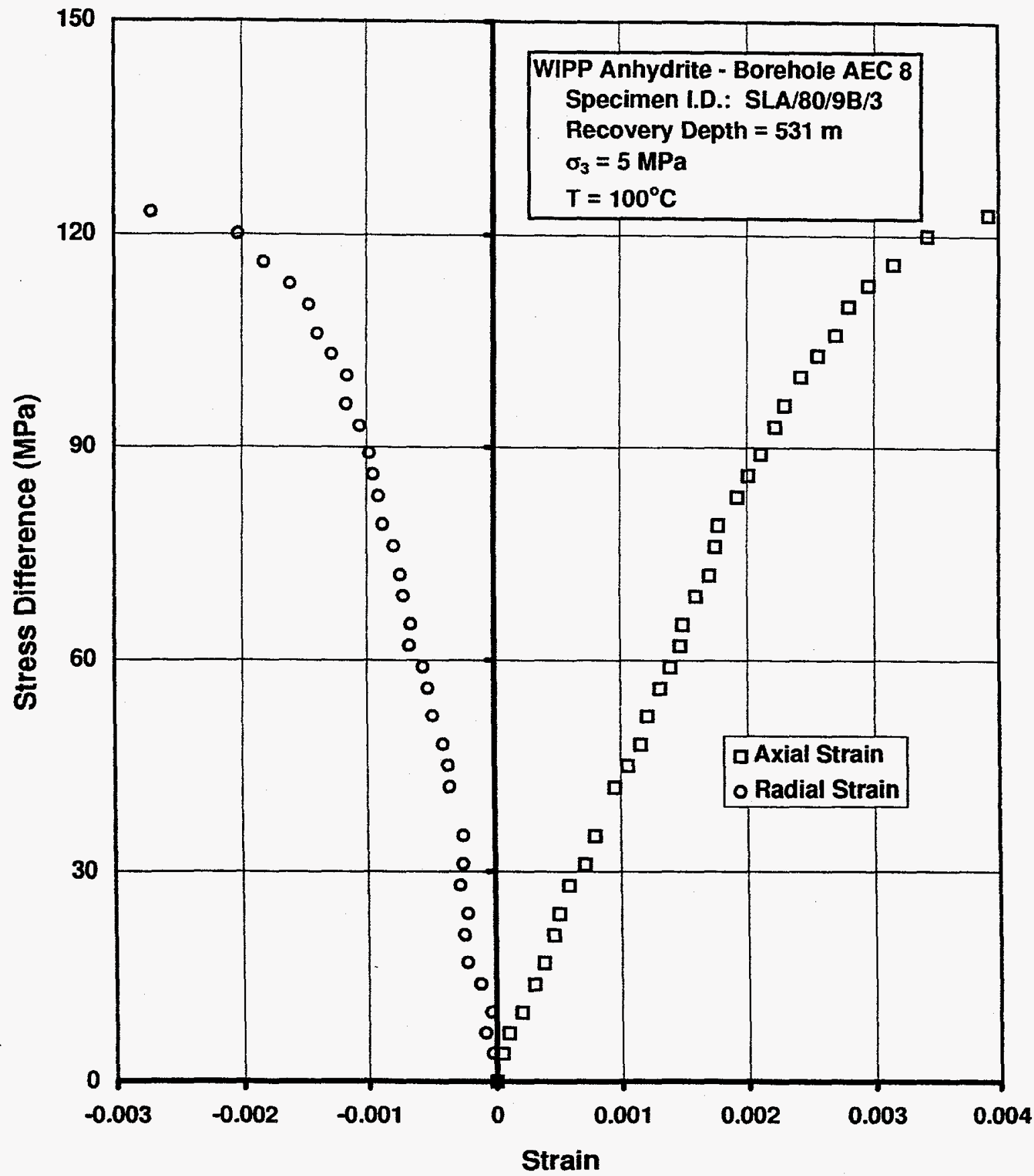

Figure C-15. Stress Difference Versus Axial and Radial Strain for a Triaxial Compression Test on WIPP Anhydrite at a Temperature of $100^{\circ} \mathrm{C}$ and a Confining Pressure of $5 \mathrm{MPa}$, Specimen SLA/80/9B/3. 


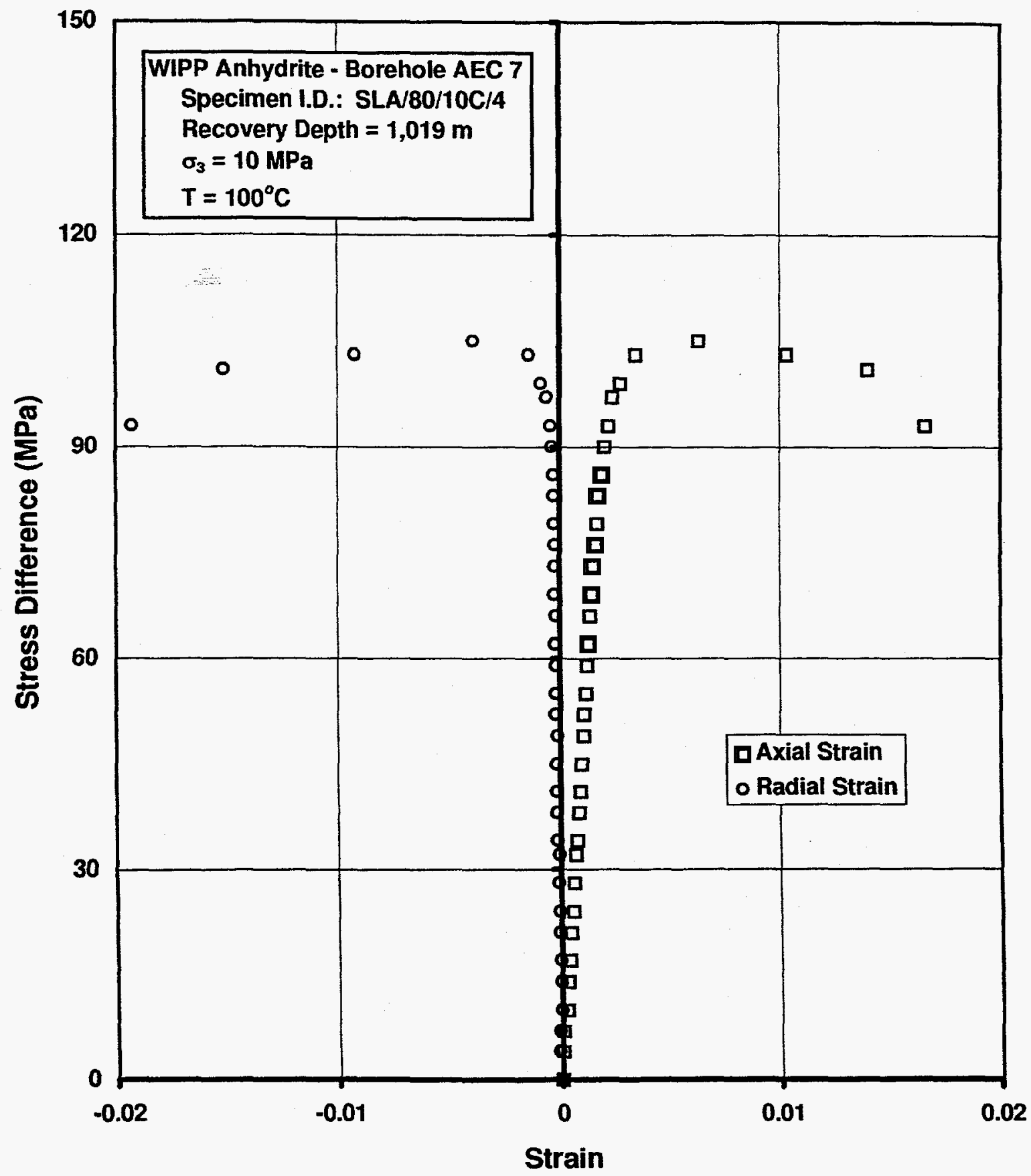

Figure C-16. Stress Difference Versus Axial and Radial Strain for a Triaxial Compression Test on WIPP Anhydrite at a Temperature of $100^{\circ} \mathrm{C}$ and a Confining Pressure of $10 \mathrm{MPa}$, Specimen SLA/80/10C/4. 


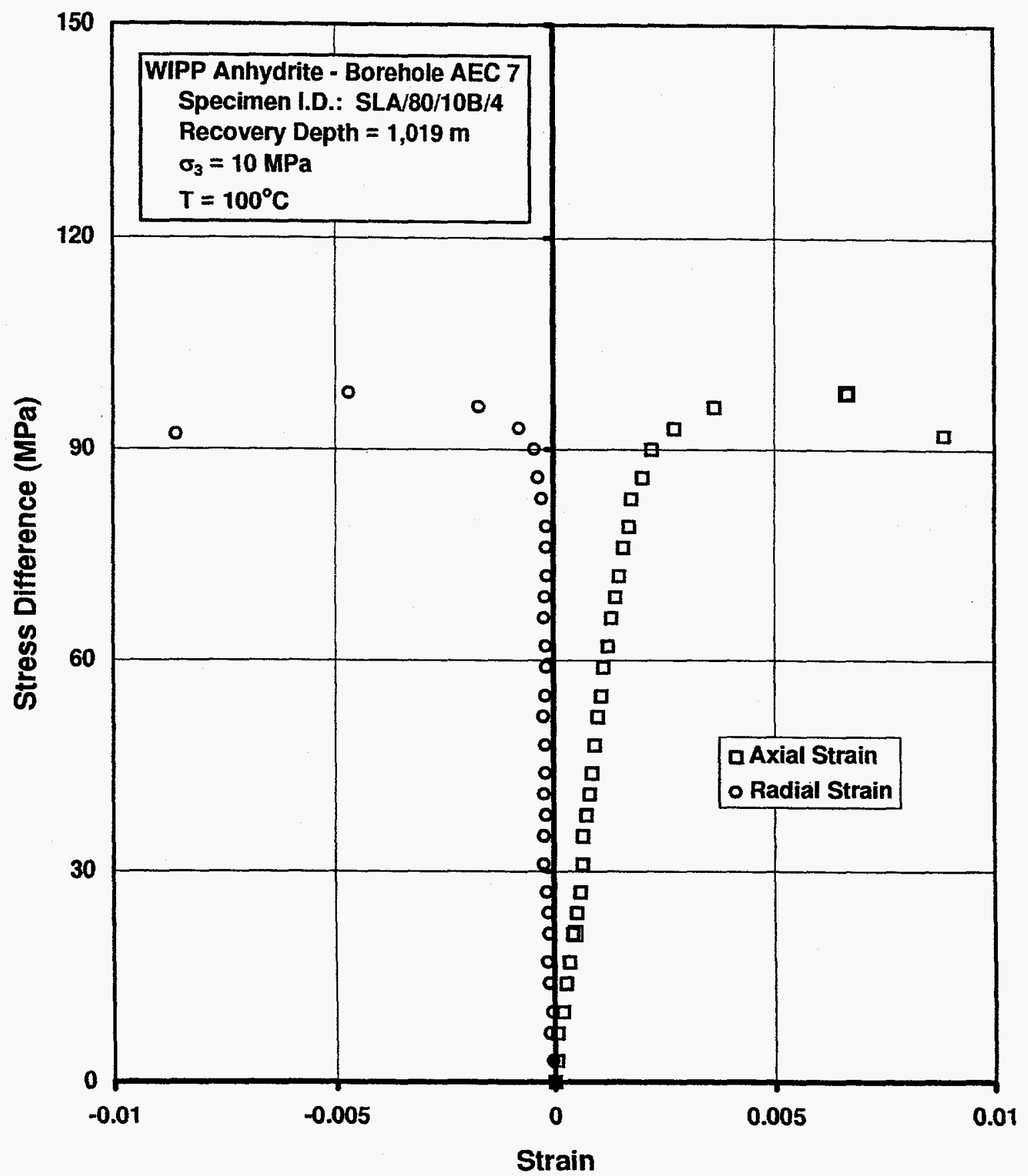

Figure C-17. Stress Difference Versus Axial and Radial Strain for a Triaxial Compression Test on WIPP Anhydrite at a Temperature of $100^{\circ} \mathrm{C}$ and a Confining Pressure of $10 \mathrm{MPa}$, Specimen SLA/80/10B/4. 


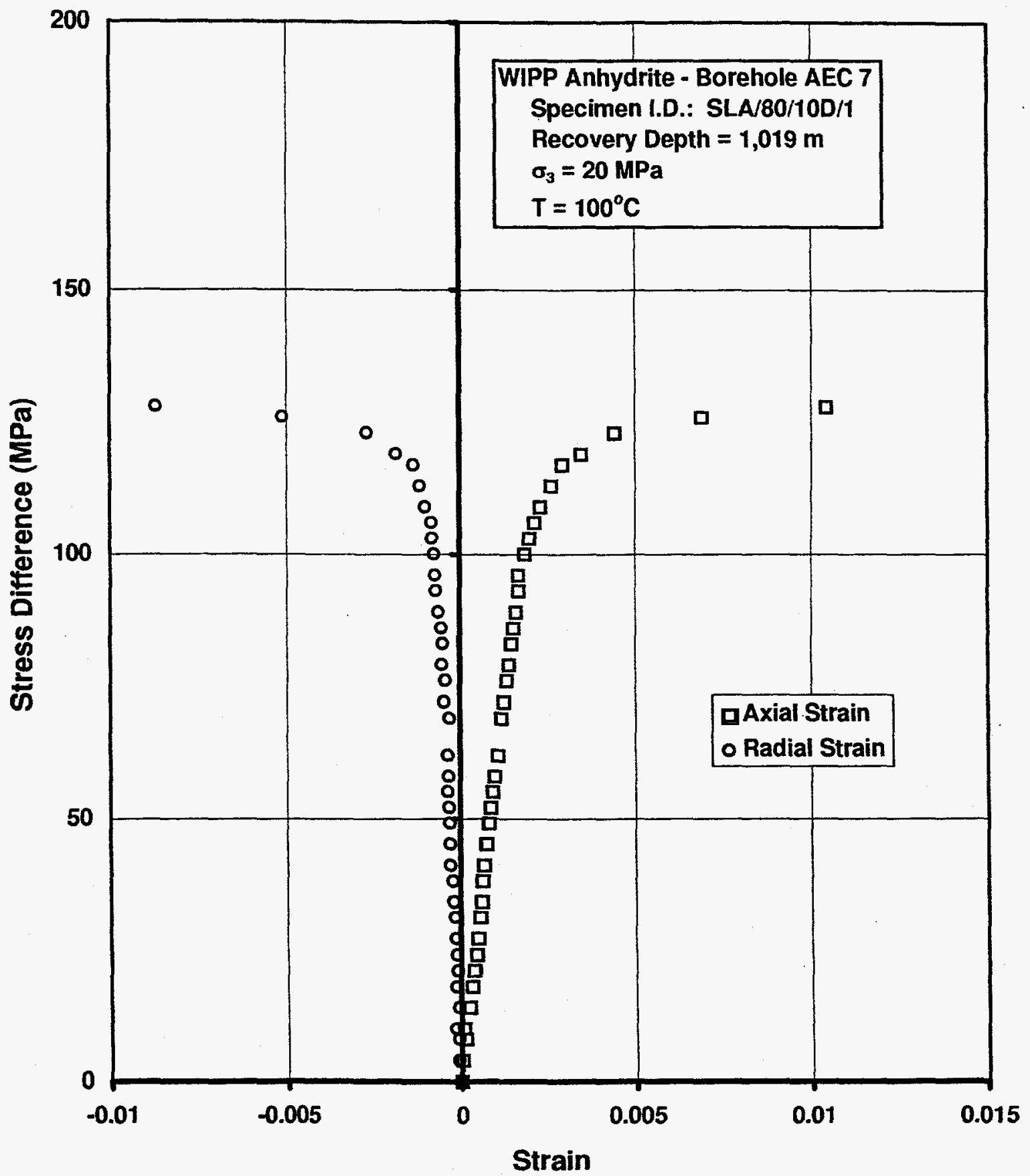

Figure C-18. Stress Difference Versus Axial and Radial Strain for a Triaxial Compression Test on WIPP Anhydrite at a Temperature of $100^{\circ} \mathrm{C}$ and a Confining Pressure of $20 \mathrm{MPa}$, Specimen SLA/80/10D/1. 


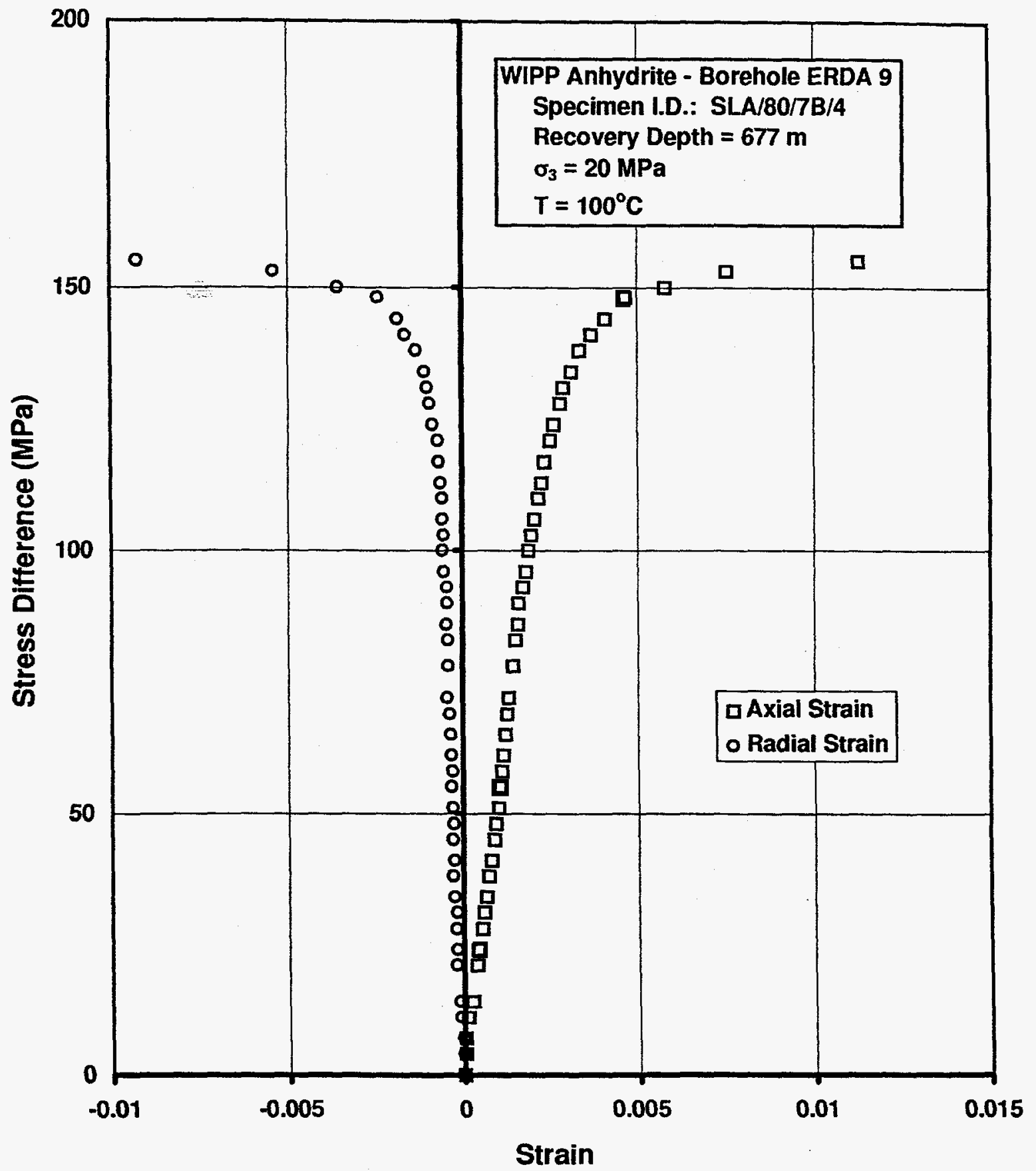

Figure C-19. Stress Difference Versus Axial and Radial Strain for a Triaxial Compression Test on WIPP Anhydrite at a Temperature of $100^{\circ} \mathrm{C}$ and a Confining Pressure of $20 \mathrm{MPa}$, Specimen SLA/80/7B/4. 


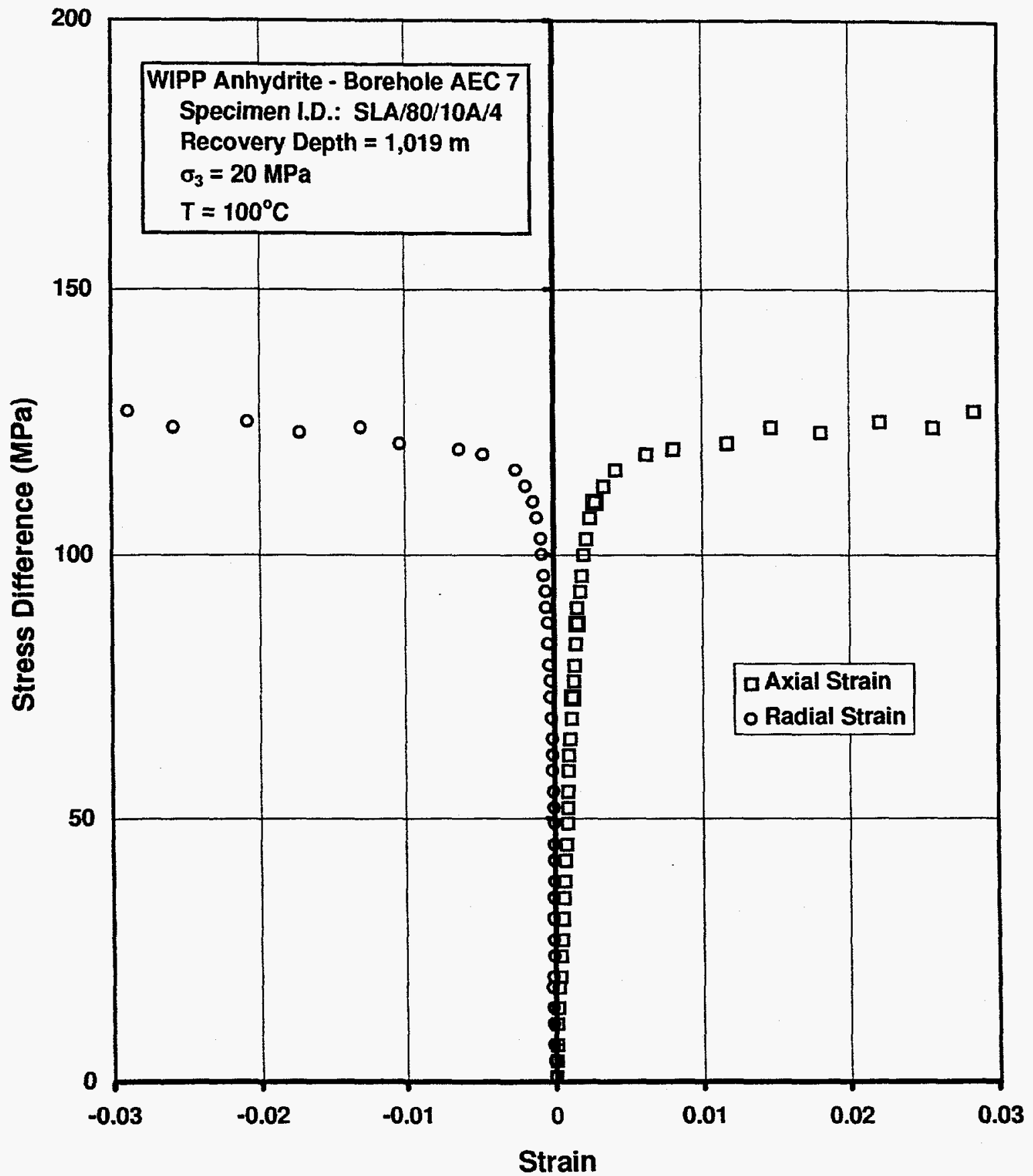

Figure C-20. Stress Difference Versus Axial and Radial Strain for a Triaxial Compression Test on WIPP Anhydrite at a Temperature of $100^{\circ} \mathrm{C}$ and a Confining Pressure of $20 \mathrm{MPa}$, Specimen SLA/80/10A/4. 
This page intentionally left blank 
APPENDIX D
SUPPORTING INFORMATION FOR
SANDIA CONTRACT AA-2020, 1992 THROUGH 1995

STRESS-STRAIN CURVES FOR TRIAXIAL COMPRESSIVE STRENGTH TESTS OF WIPP ANHYDRITE

STRAIN-TIME CURVES FOR CONFINED CREEP TESTS OF WIPP ANHYDRITE 


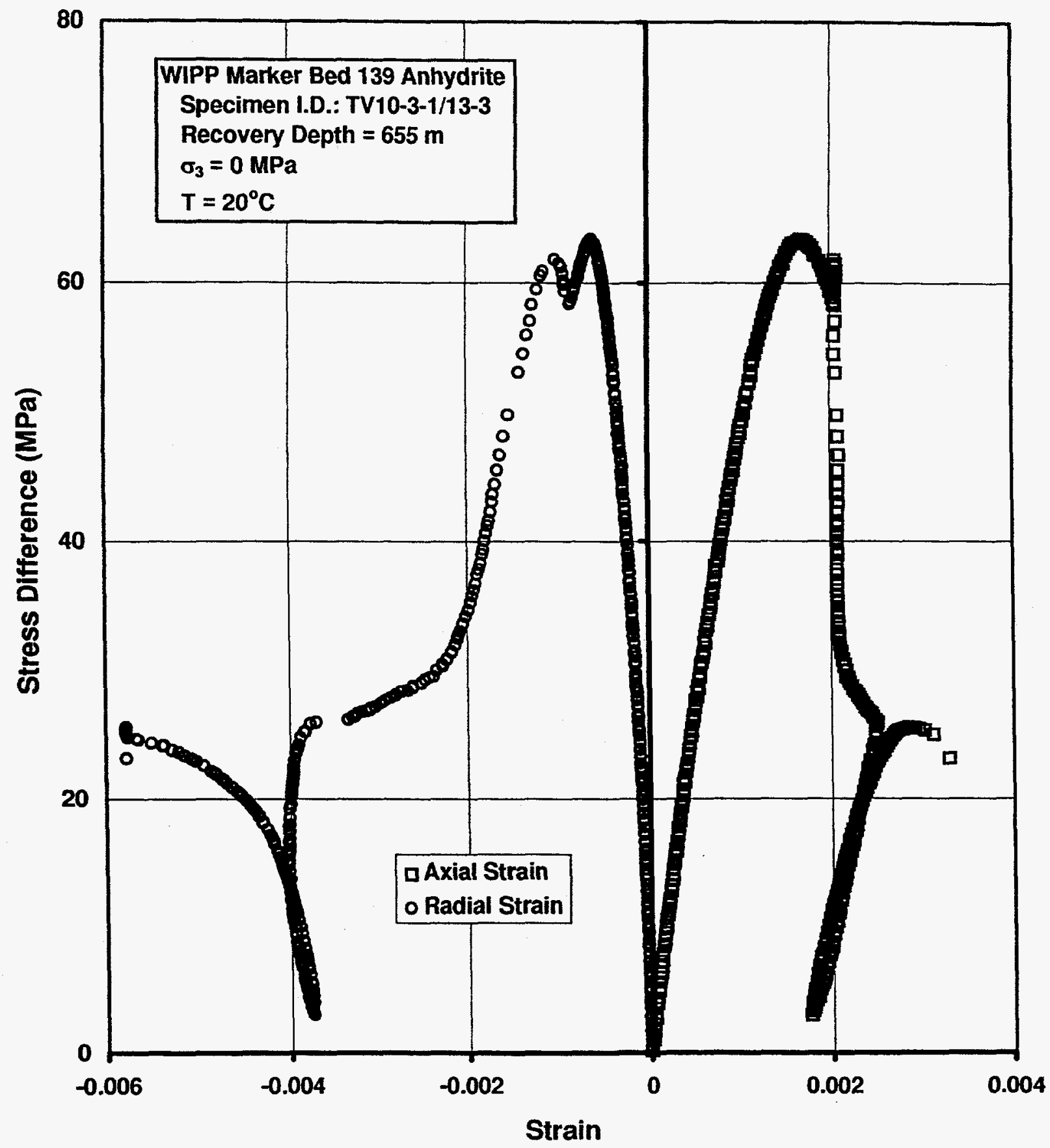

Figure D-1. Stress Difference Versus Axial and Radial Strain for a Triaxial Compression Test on WIPP Anhydrite at a Confining Pressure of $0 \mathrm{MPa}$, Specimen TV10-3-1/13-3. 


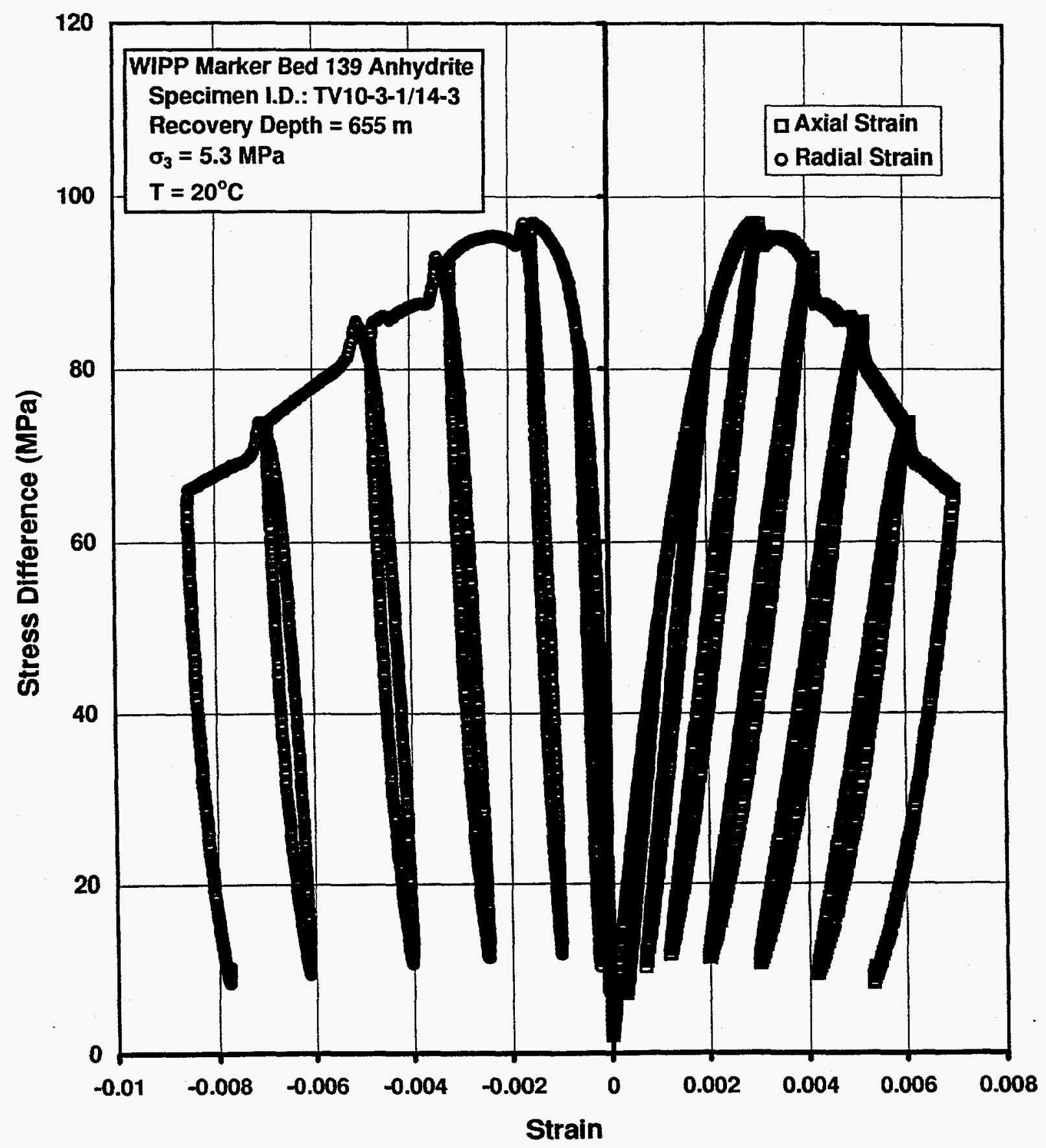

Figure D-2. Stress Difference Versus Axial and Radial Strain for a Triaxial Compression Test on WIPP Anhydrite at a Confining Pressure of 5.3 MPa, Specimen TV10-3-1/14-3. 


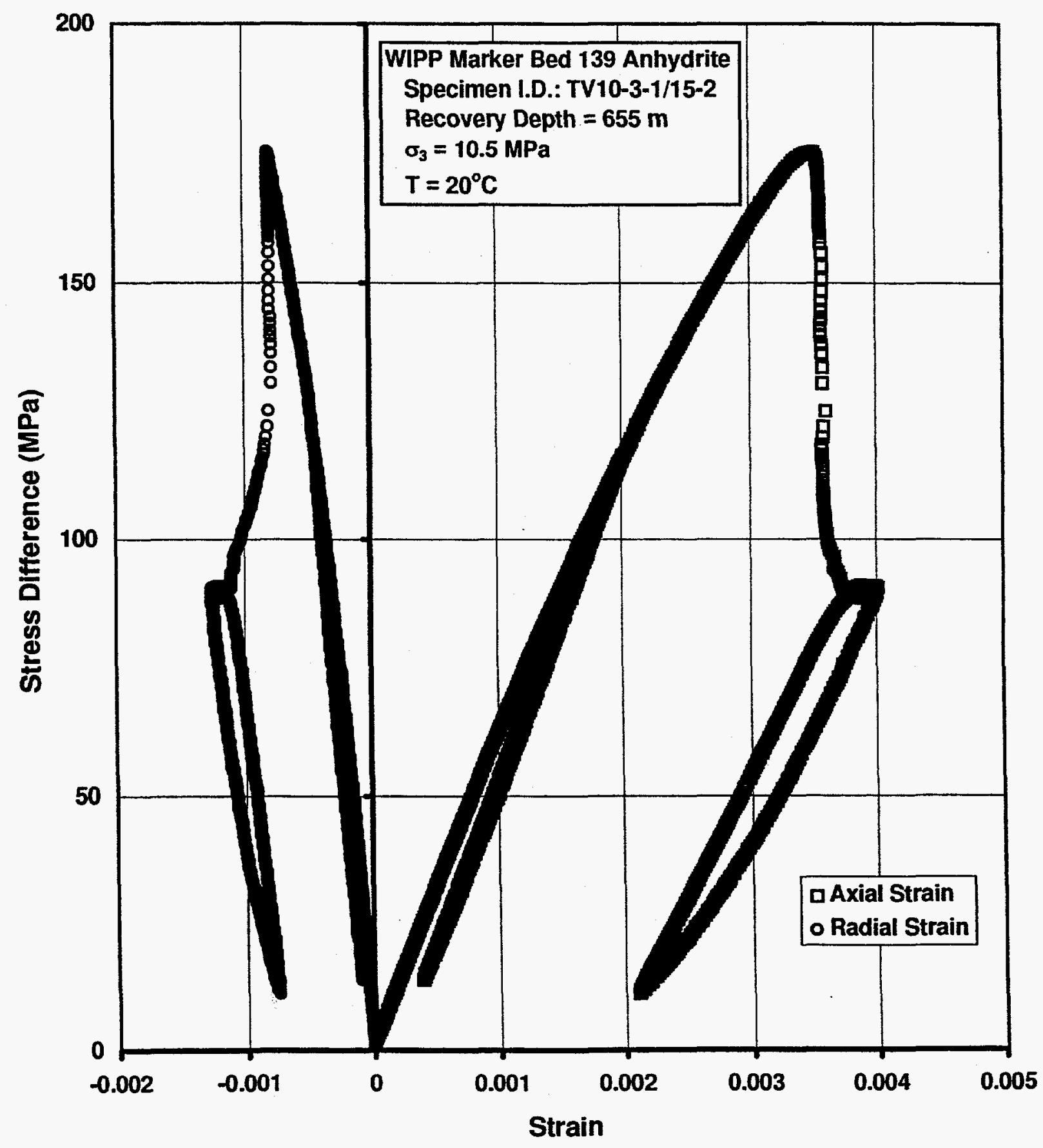

Figure D-3. Stress Difference Versus Axial and Radial Strain for a Triaxial Compression Test on WIPP Anhydrite at a Confining Pressure of $10.5 \mathrm{MPa}$, Specimen TV10-3-1/152. 


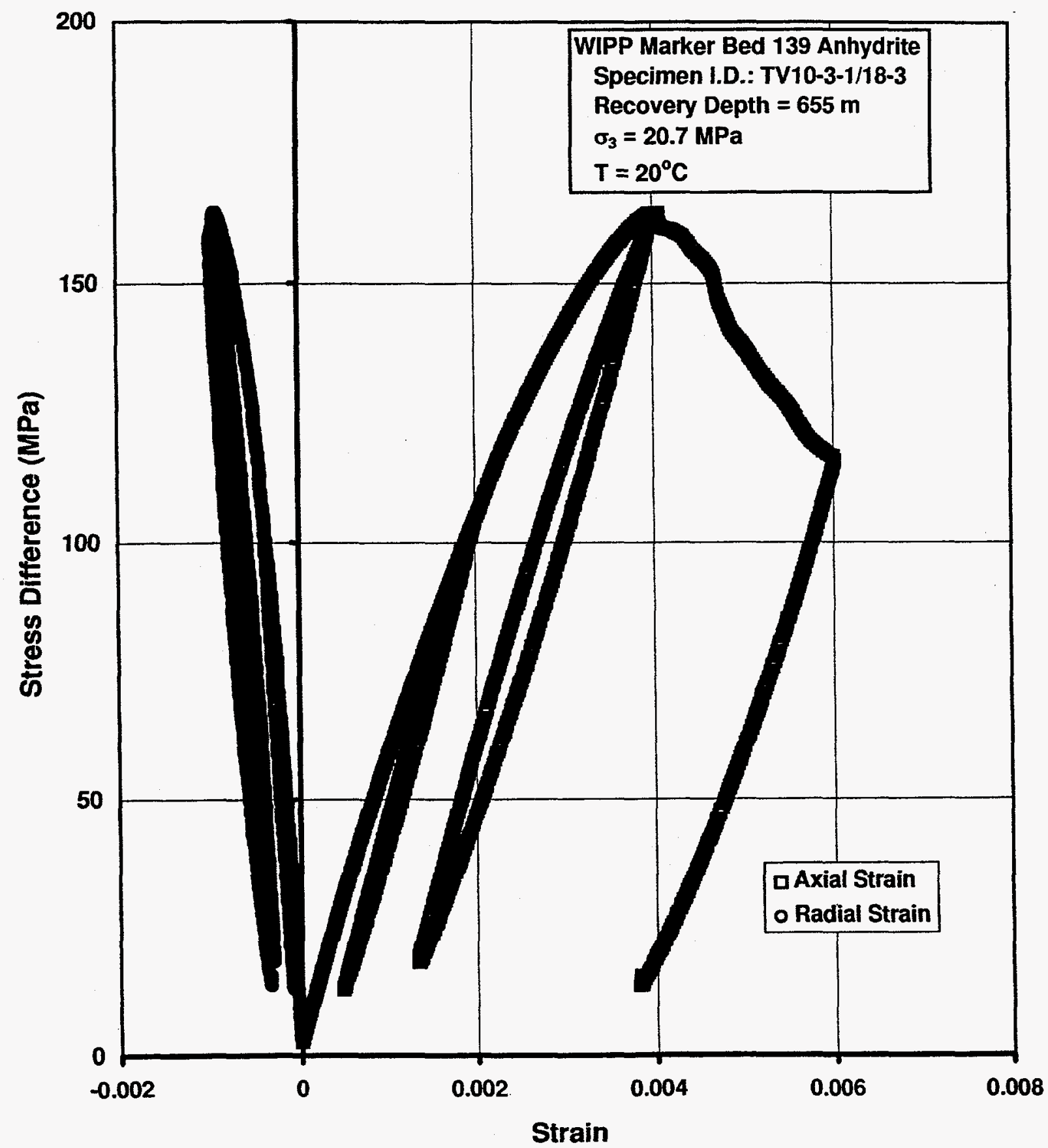

Figure D-4. Stress Difference Versus Axial and Radial Strain for a Triaxial Compression Test on WIPP Anhydrite at a Confining Pressure of $20.7 \mathrm{MPa}$, Specimen TV10-3-1/183. 


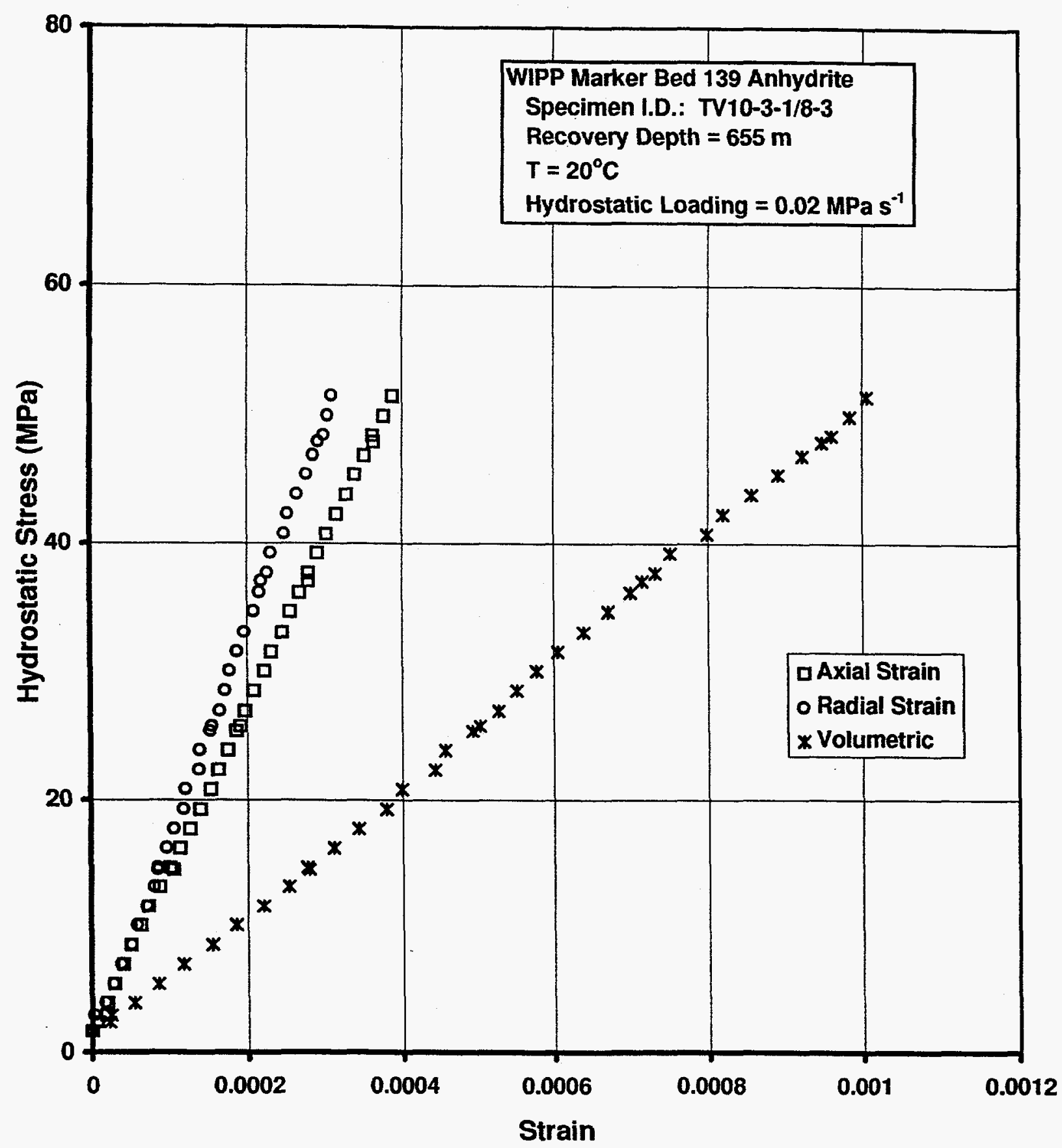

Figure D-5. Hydrostatic Stress Versus Axial, Radial, and Volumetric Strain For a Hydrostatic Compression Test on WIPP Anhydrite, Specimen TV10-3-1/8-3.

D-6 


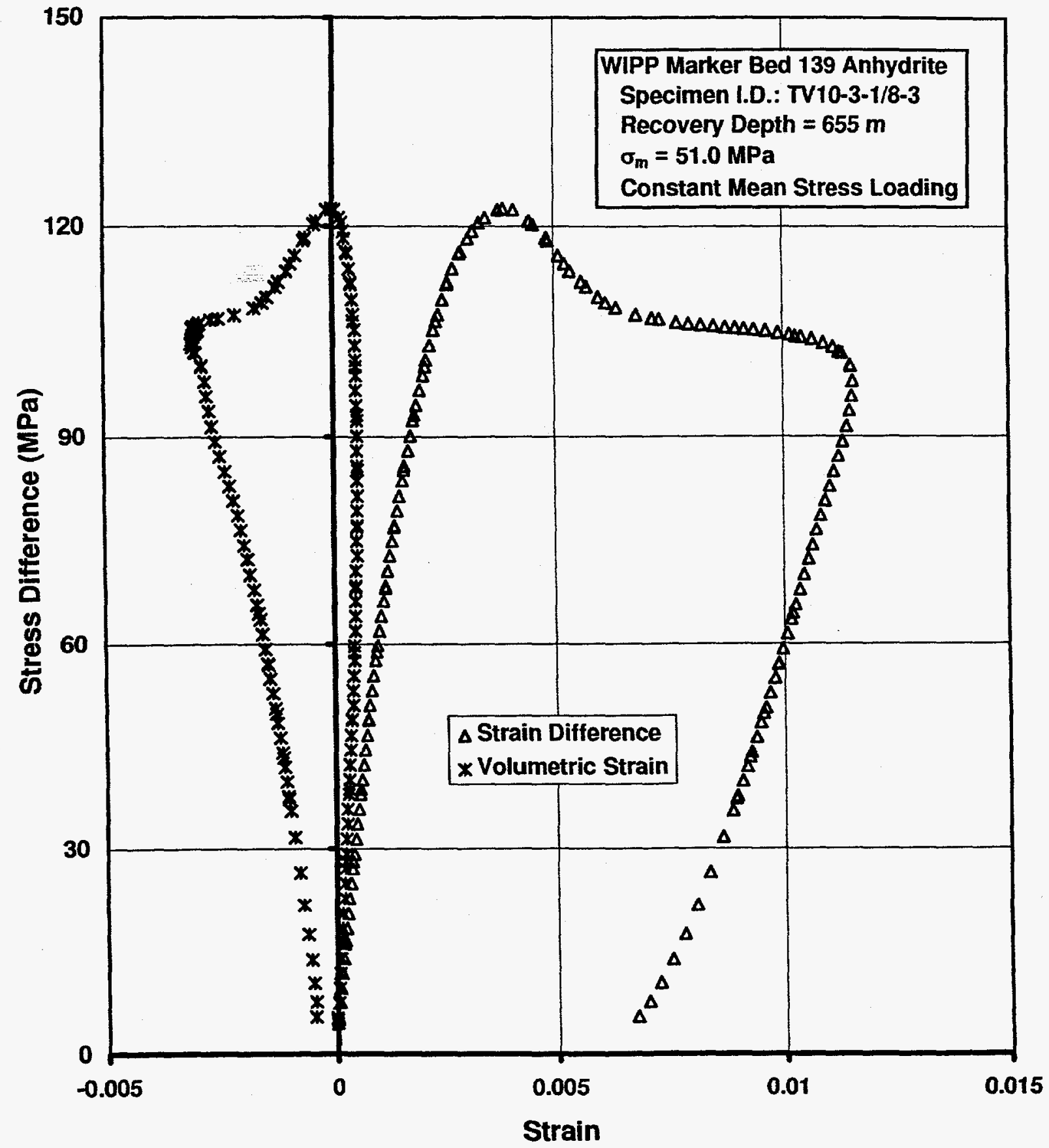

Figure D-6. Stress Difference Versus Axial and Radial Strain for a Triaxial Compression Test on WIPP Anhydrite at a Constant Mean Stress of 51.0 MPa, Specimen TV10-3$1 / 8-3$. 


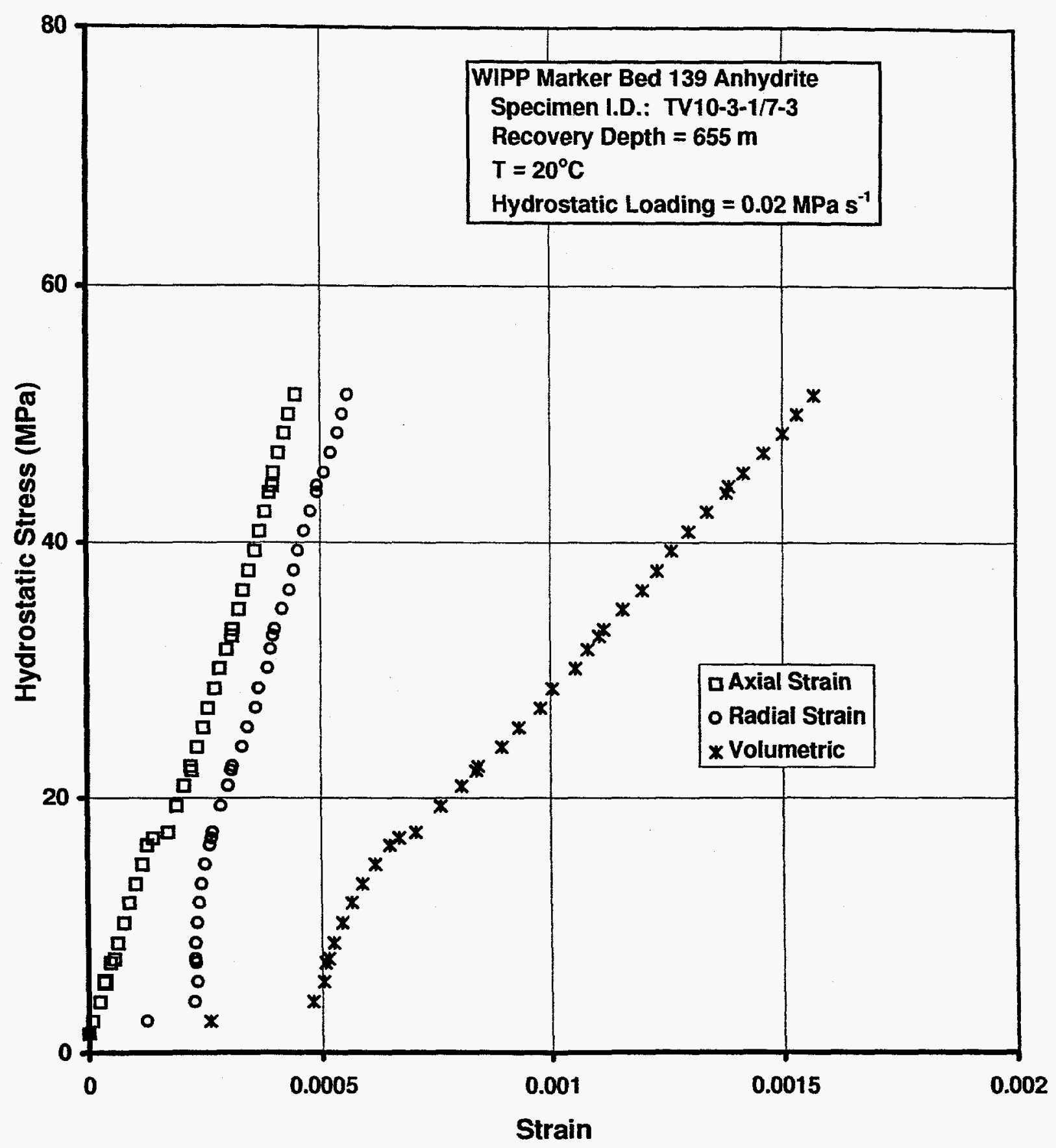

Figure D-7. Hydrostatic Stress Versus Axial, Radial, and Volumetric Strain for a Hydrostatic Compression Test on WIPP Anhydrite, Specimen TV10-3-1/7-3. 
RSI-325-98-039

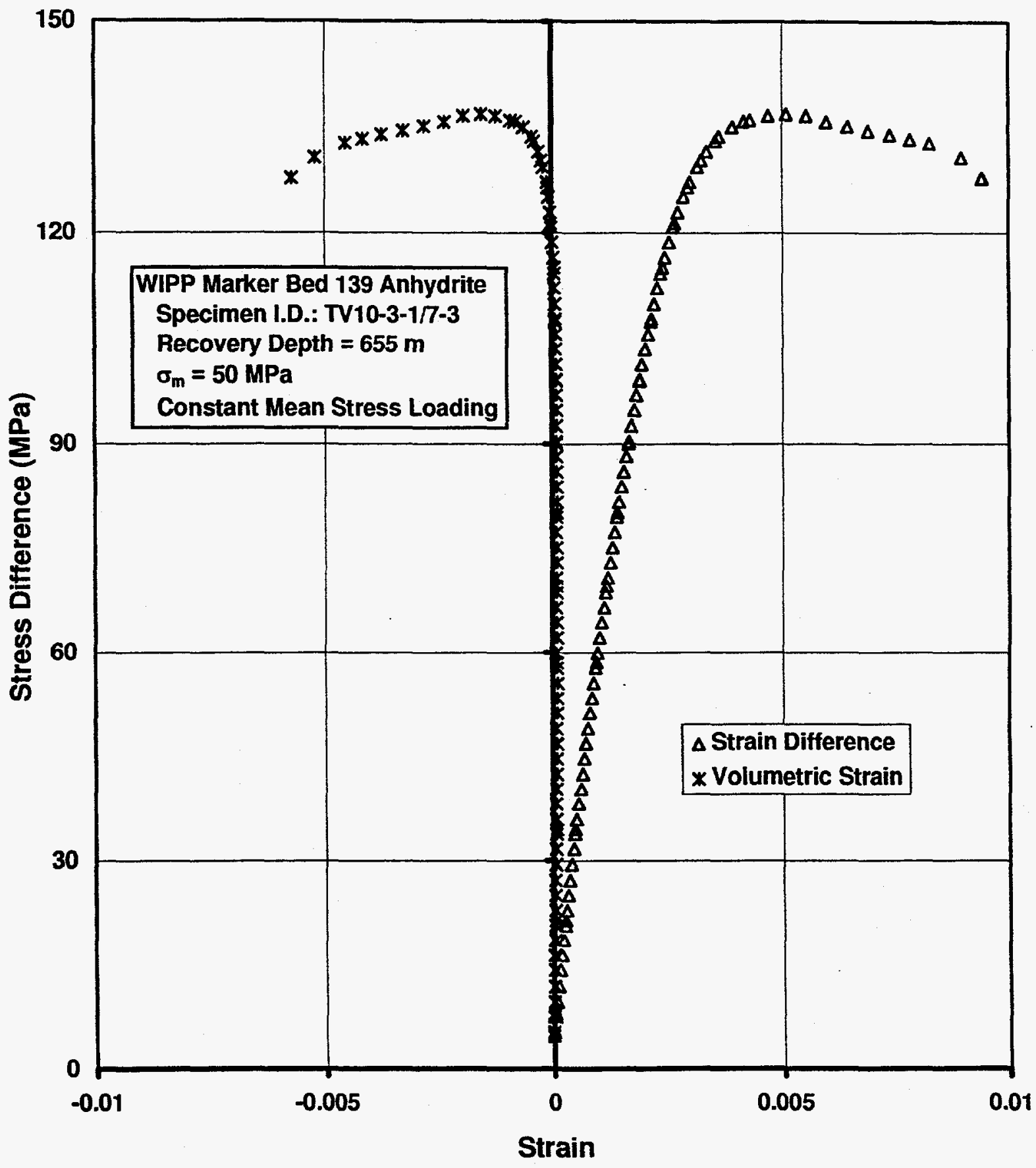

Figure D-8. Stress Difference Versus Axial and Radial Strain for a Triaxial Compression Test on WIPP Anhydrite at a Constant Mean Stress of $50 \mathrm{MPa}$, Specimen TV10-3-1/73. 


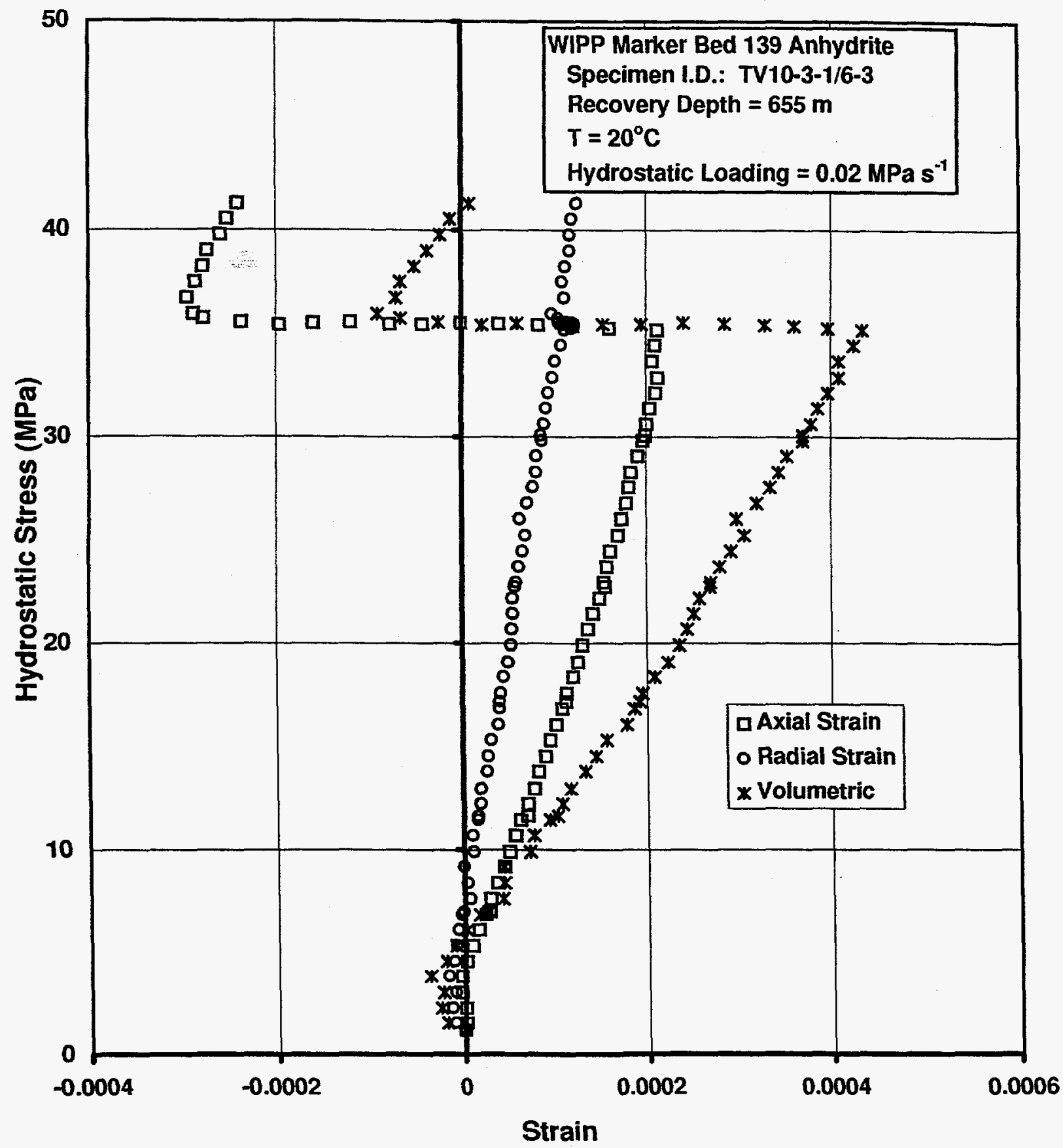

Figure D-8. Hydrostatic Stress Versus Axial, Radial, and Volumetric Strain for a Hydrostatic Compression Test on WIPP Anhydrite, Specimen TV10-3-1/6-3. 


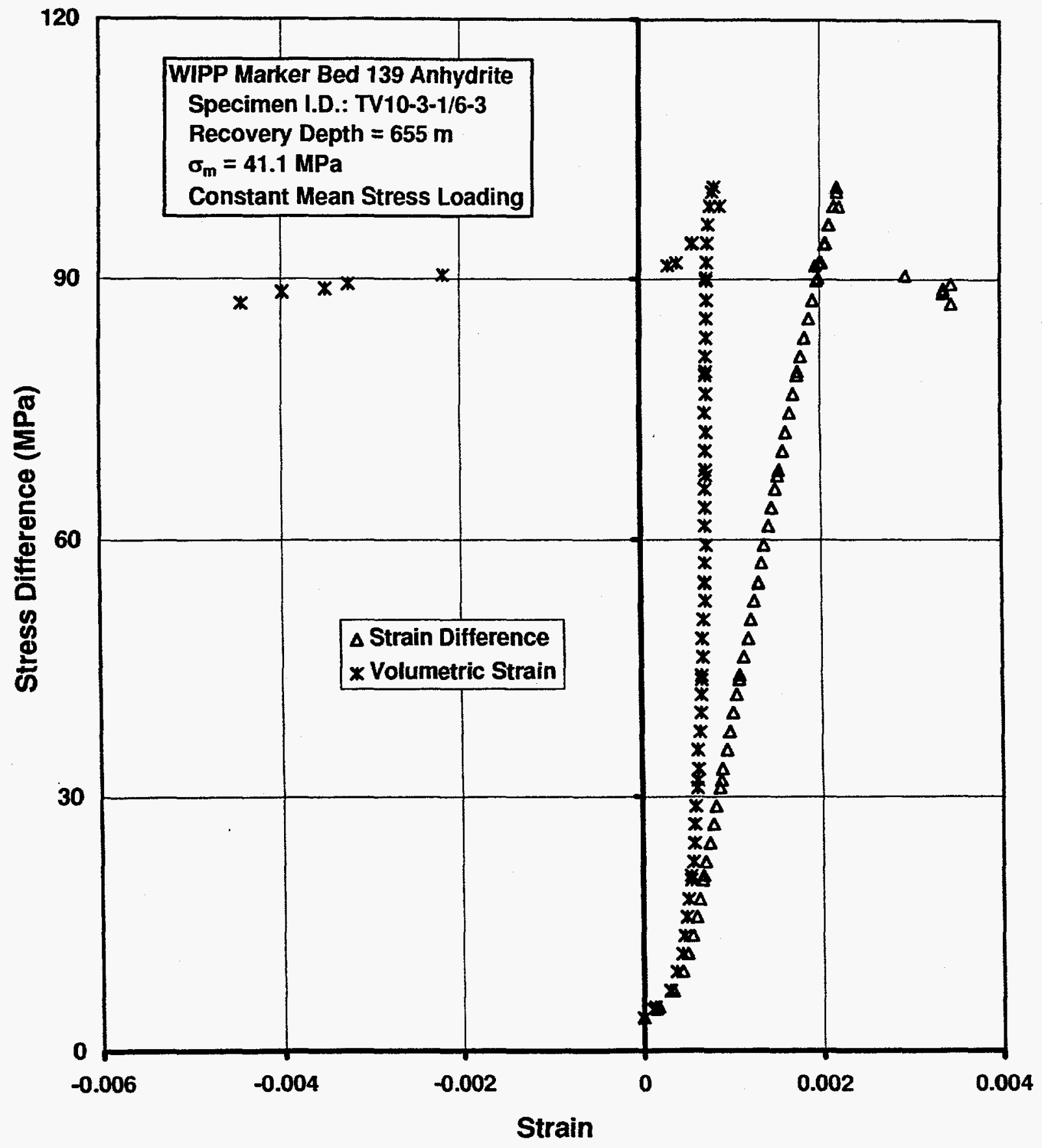

Figure D-10. Stress Difference Versus Axial and Radial Strain for a Triaxial Compression Test on WIPP Anhydrite at a Constant Mean Stress of $41.1 \mathrm{MPa}$, Specimen TV10-3-1/6-3. 


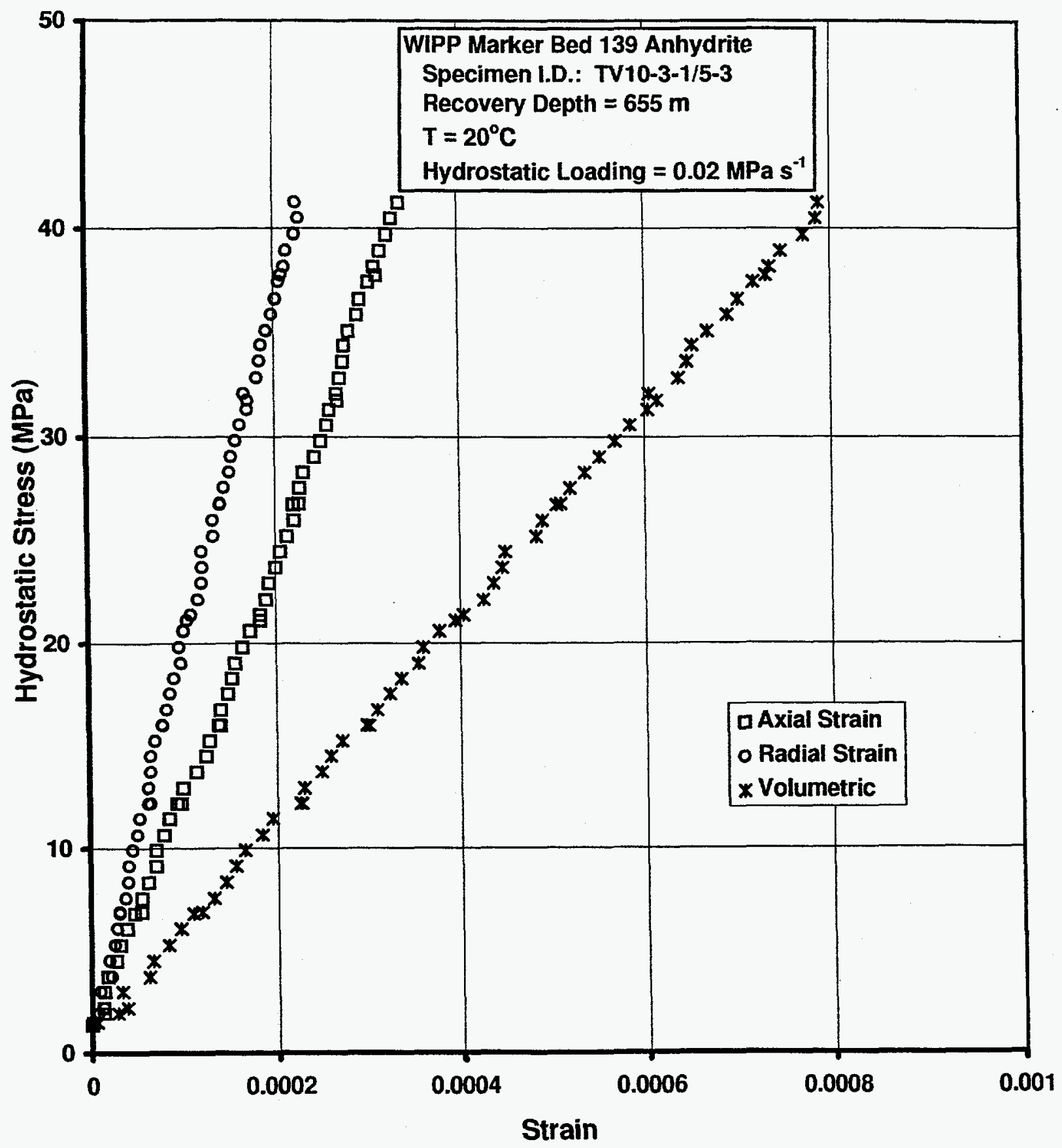

Figure D-11. Hydrostatic Versus Axial, Radial, and Volumetric Strain for a Hydrostatic Compression Test on WIPP Anhydrite, Specimen TV10-3-1/5-3. 


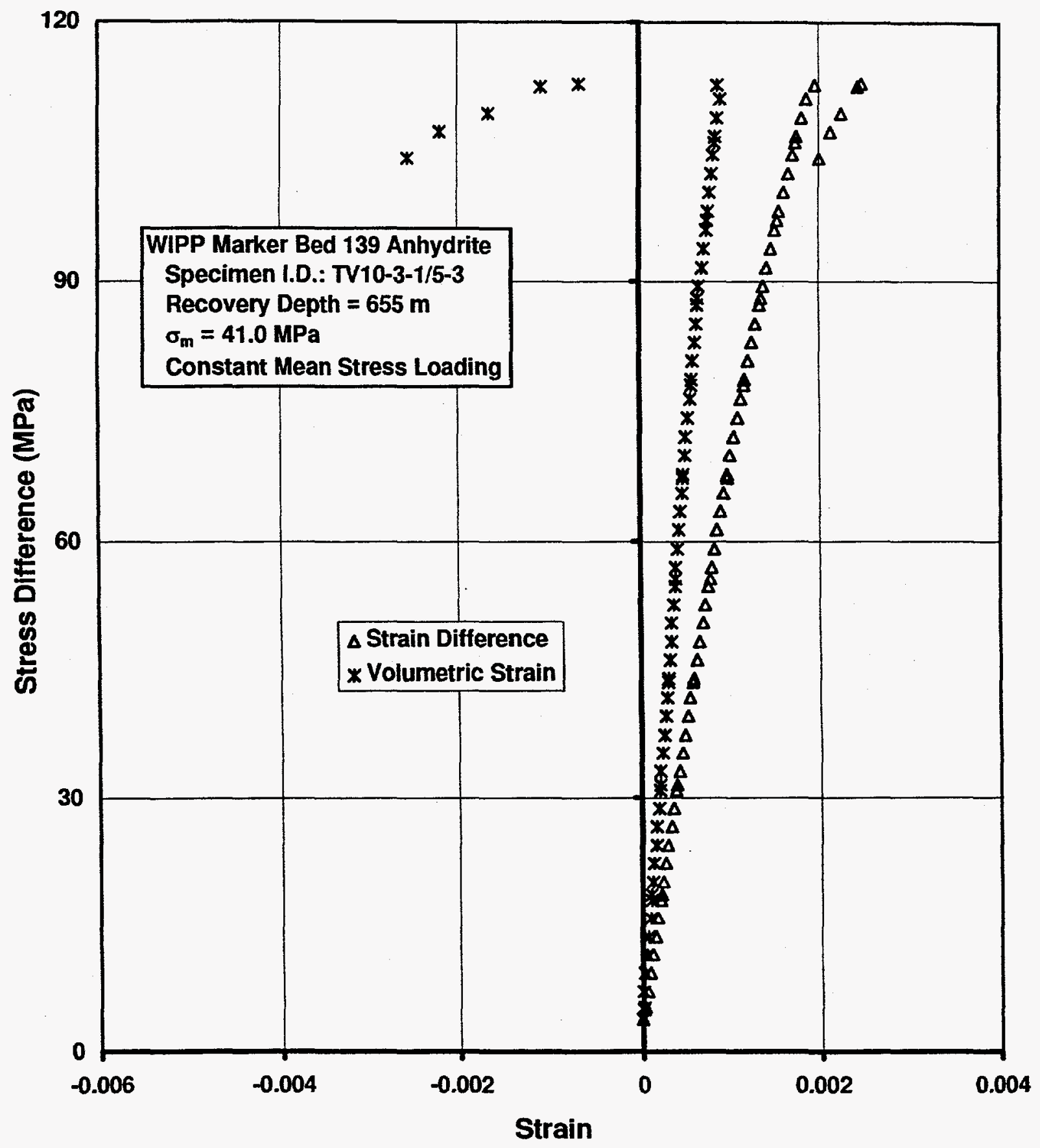

Figure D-12. Stress Difference Versus Axial and Radial Strain for a Triaxial Compression Test on WIPP Anhydrite at a Constant Mean Stress of $41.0 \mathrm{MPa}$, Specimen TV10-3-1/5-3. 


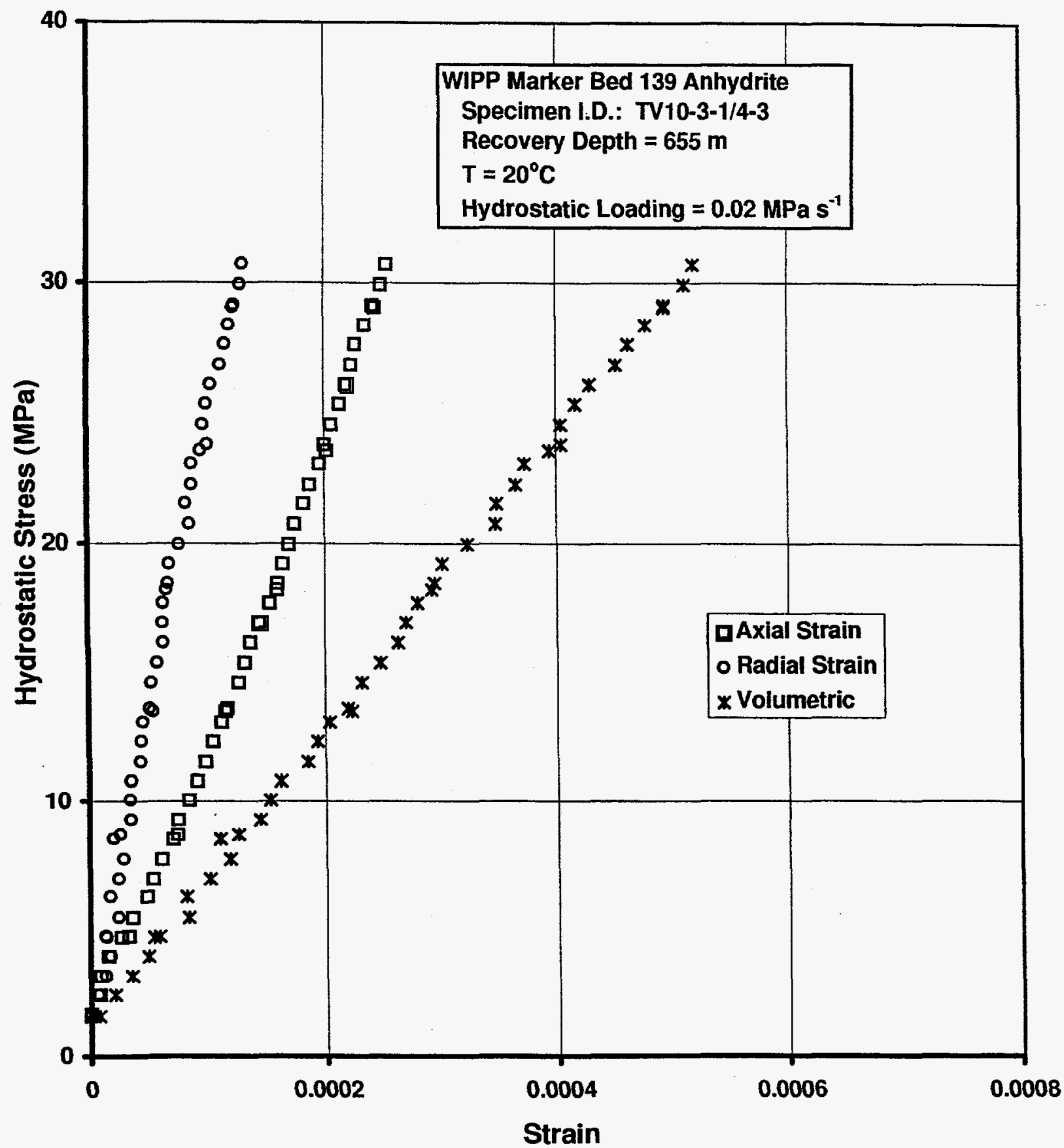

Figure D-13. Hydrostatic Stress Versus Axial, Radial, and Volumetric Strain for a Hydrostatic Compression Test on WIPP Anhydrite, Specimen TV10-3-1/4-3. 


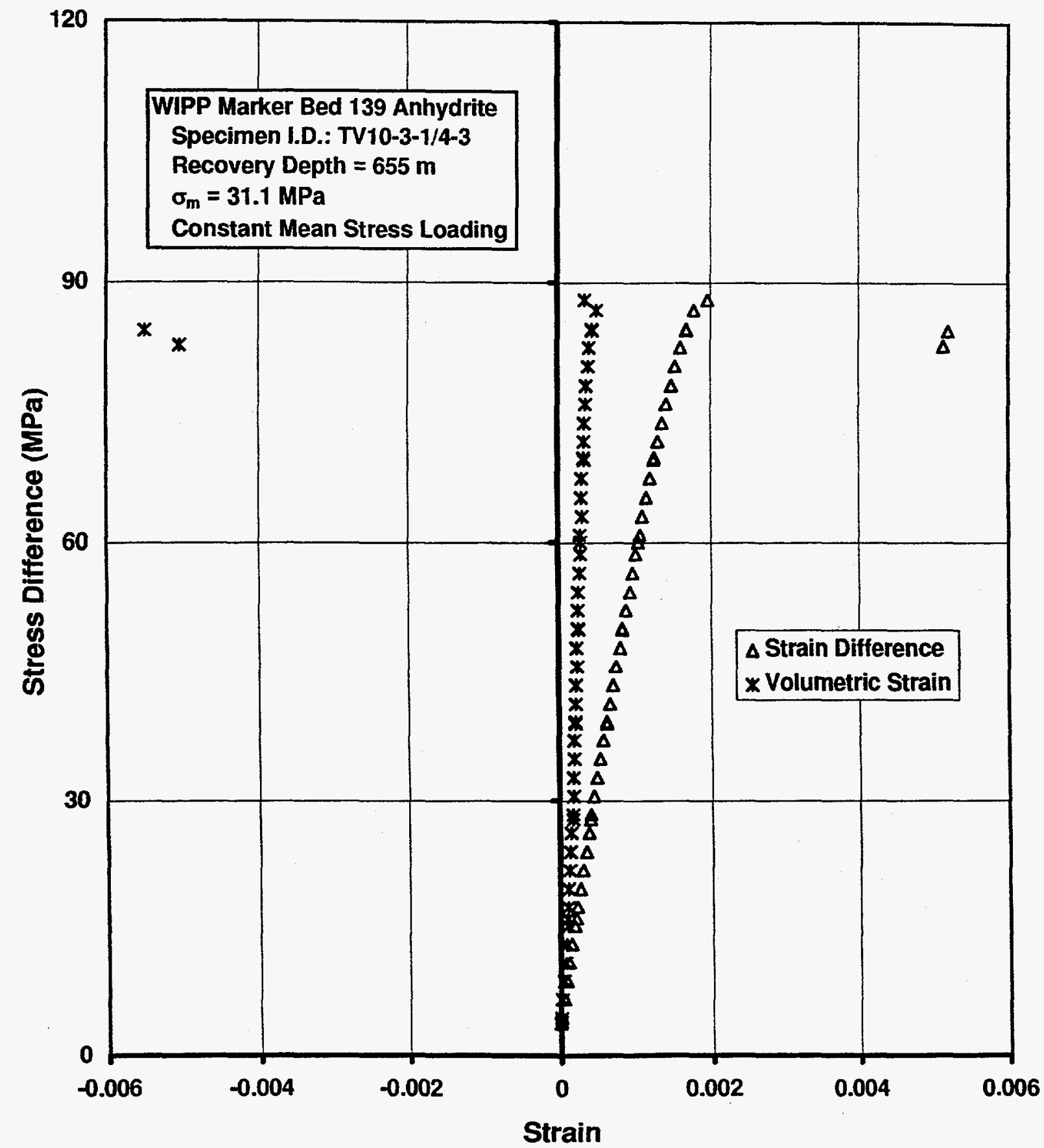

Figure D-14. Stress Difference Versus Axial and Radial Strain for a Triaxial Compression Test on WIPP Anhydrite at a Constant Mean Stress of 31.1 MPa, Specimen TV10-3-1/4-3. 


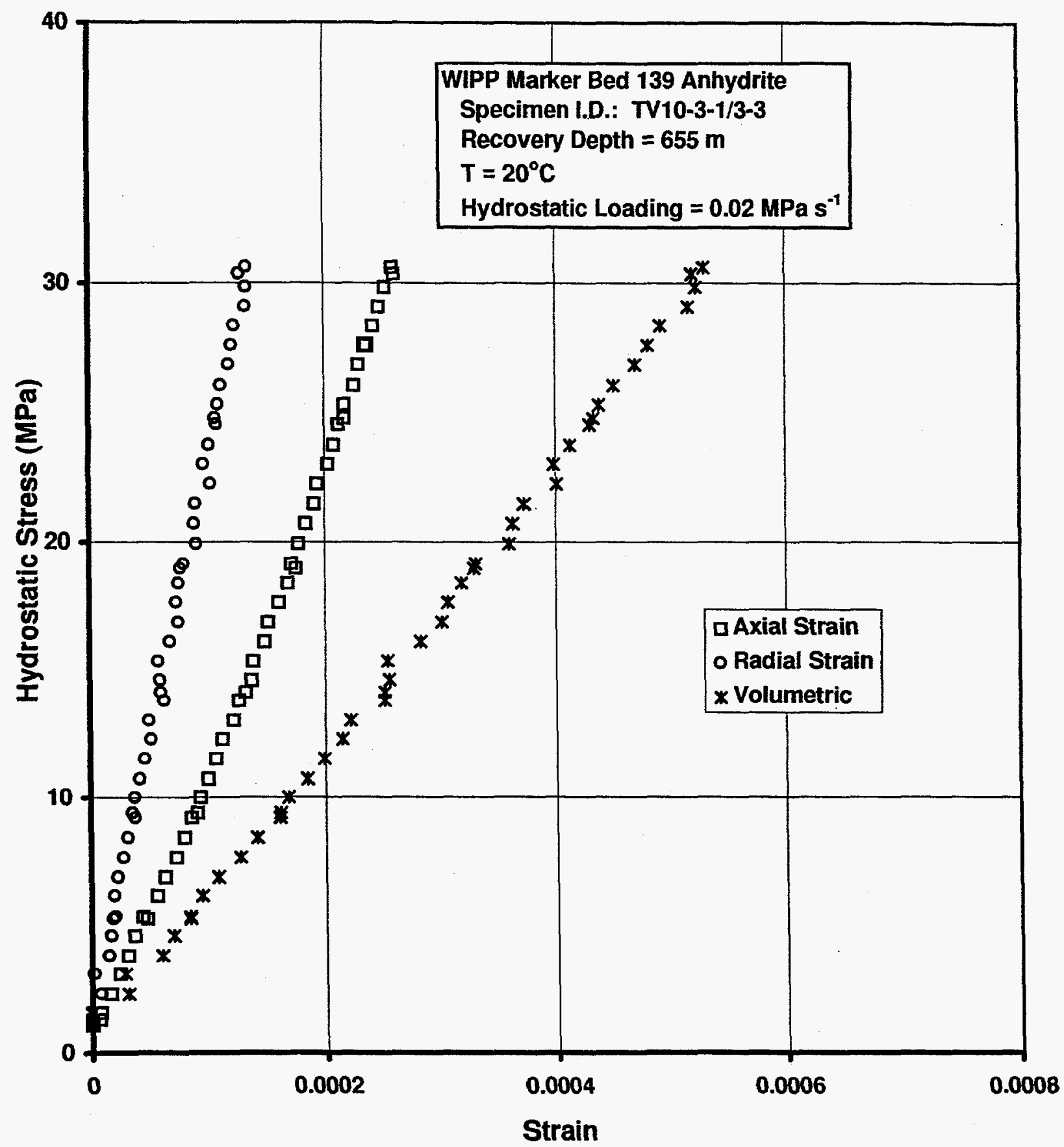

Figure D-15. Hydrostatic Stress Versus Axial, Radial, and Volumetric Strain for a Hydrostatic Compression Test on WIPP Anhydrite, Specimen TV10-3-1/3-3. 


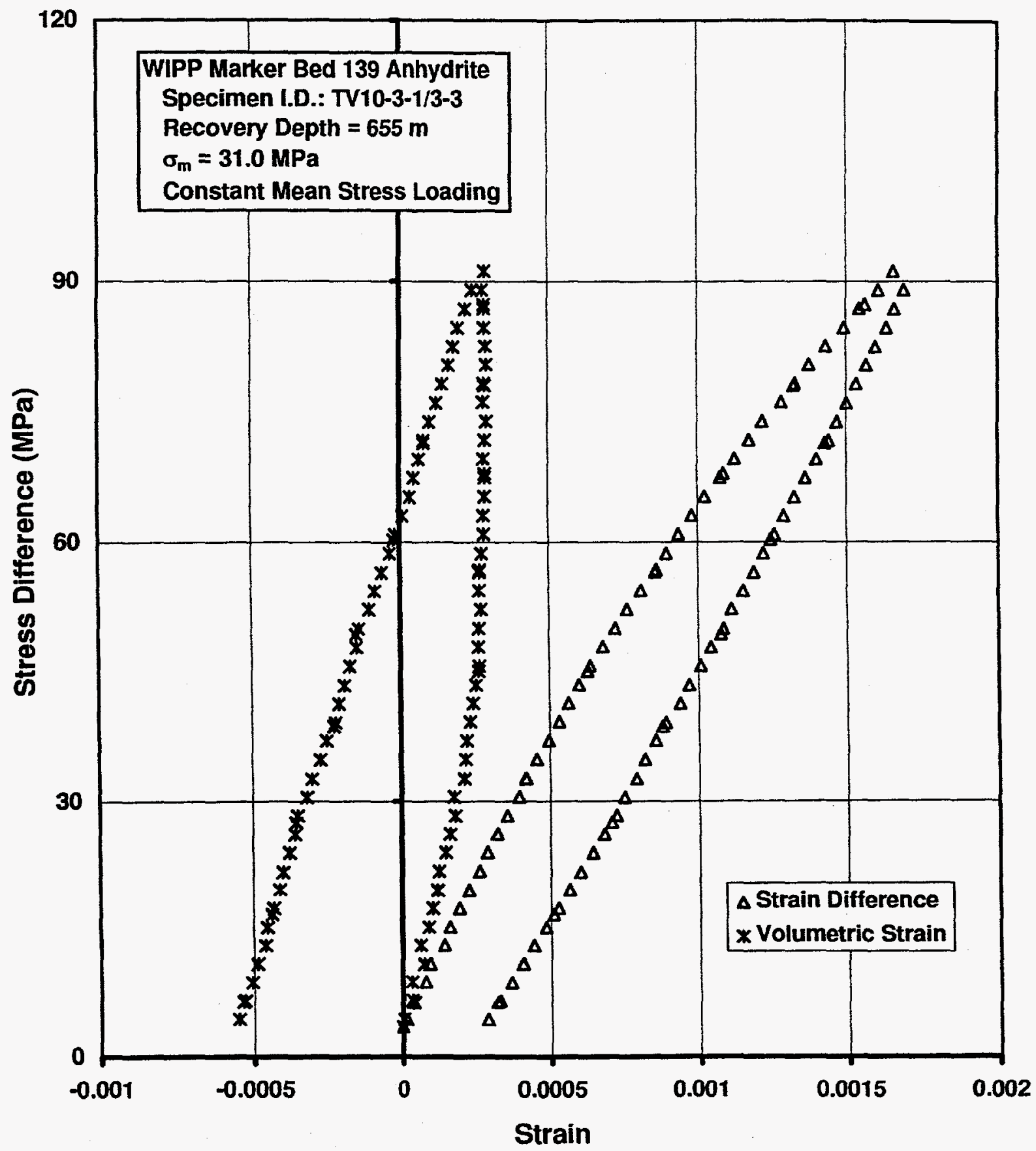

Figure D-16. Stress Difference Versus Axial and Radial Strain for a Triaxial Compression Test on WIPP Anhydrite at a Constant Mean Stress of 31.0 MPa, Specimen TV10-3-1/3-3. 
RSI-325-98-048

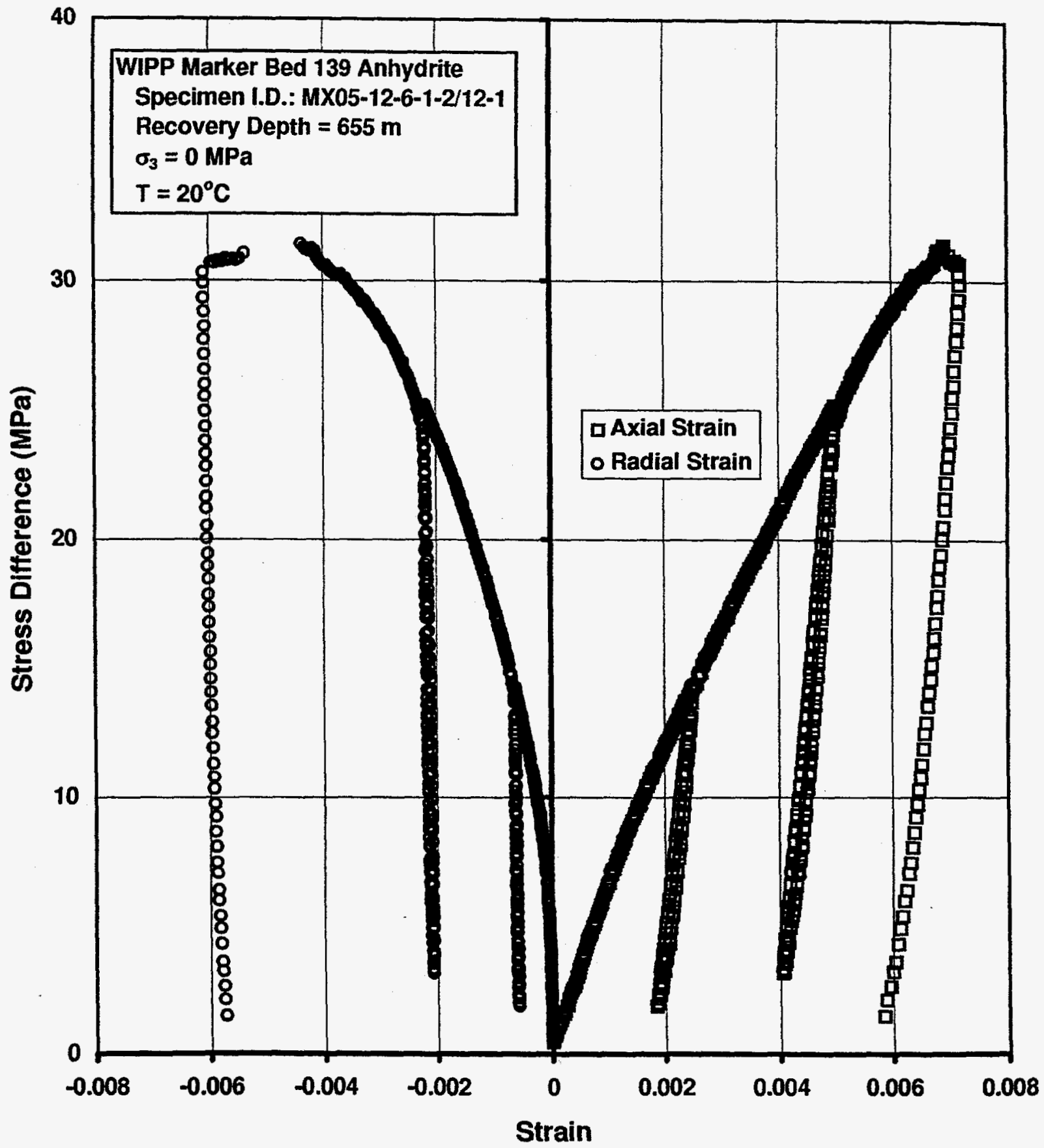

Figure D-17. Stress Difference Versus Axial and Radial Strain for a Triaxial Compression Test on WIPP Anhydrite at a Confining Pressure of $0 \mathrm{MPa}$, Specimen MX05-126-1-2/12-1. 


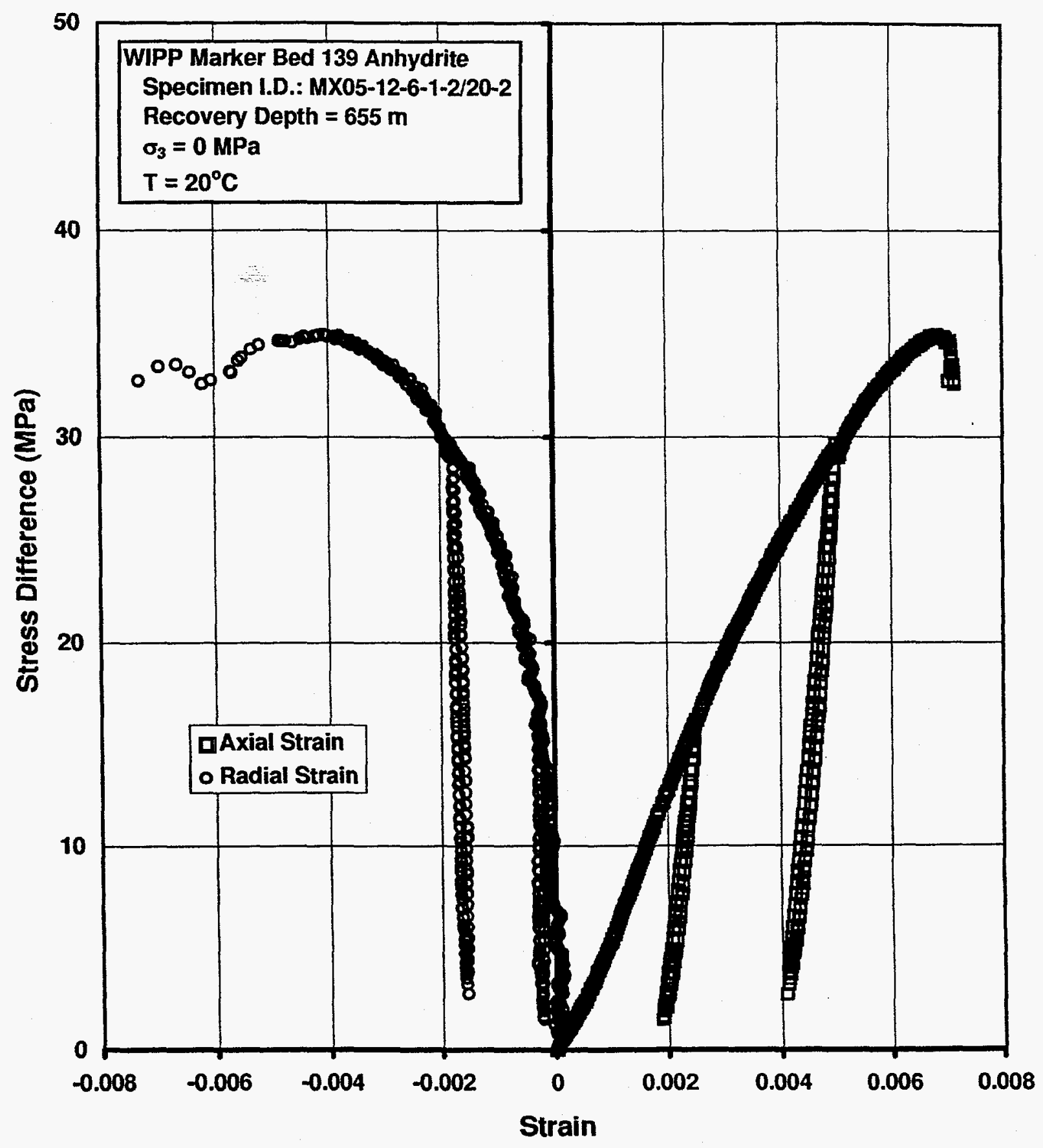

Figure D-18. Stress Difference Versus Axial and Radial Strain for a Triaxial Compression Test on WIPP Anhydrite at a Confining Pressure of $0 \mathrm{MPa}$, Specimen MX05-126-1-2/20-2. 


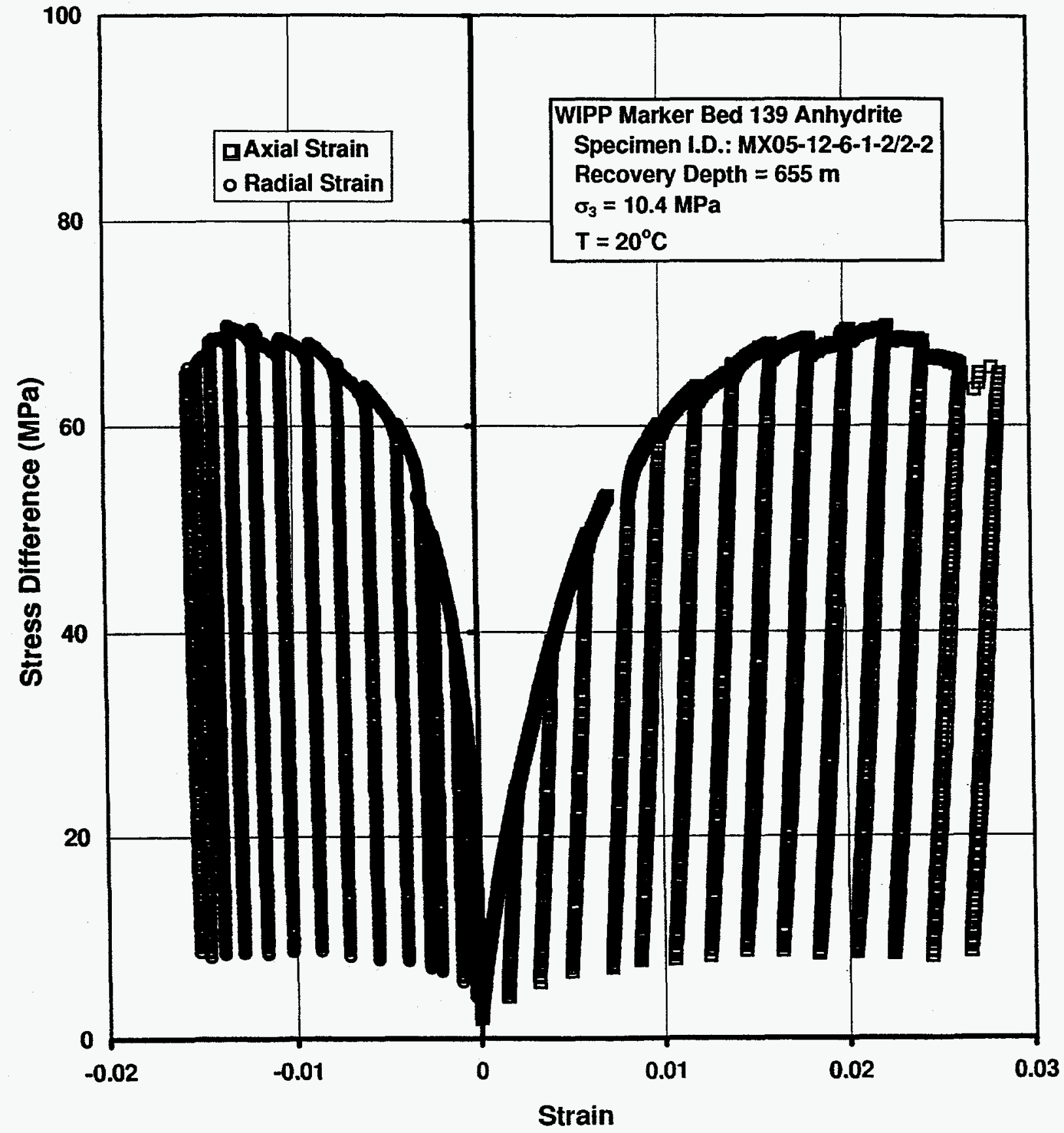

Figure D-19. Stress Difference Versus Axial and Radial Strain for a Triaxial Compression Test on WIPP Anhydrite at a Confining Pressure of 10.4 MPa, Specimen MX05$12-6-1-2 / 2-2$. 


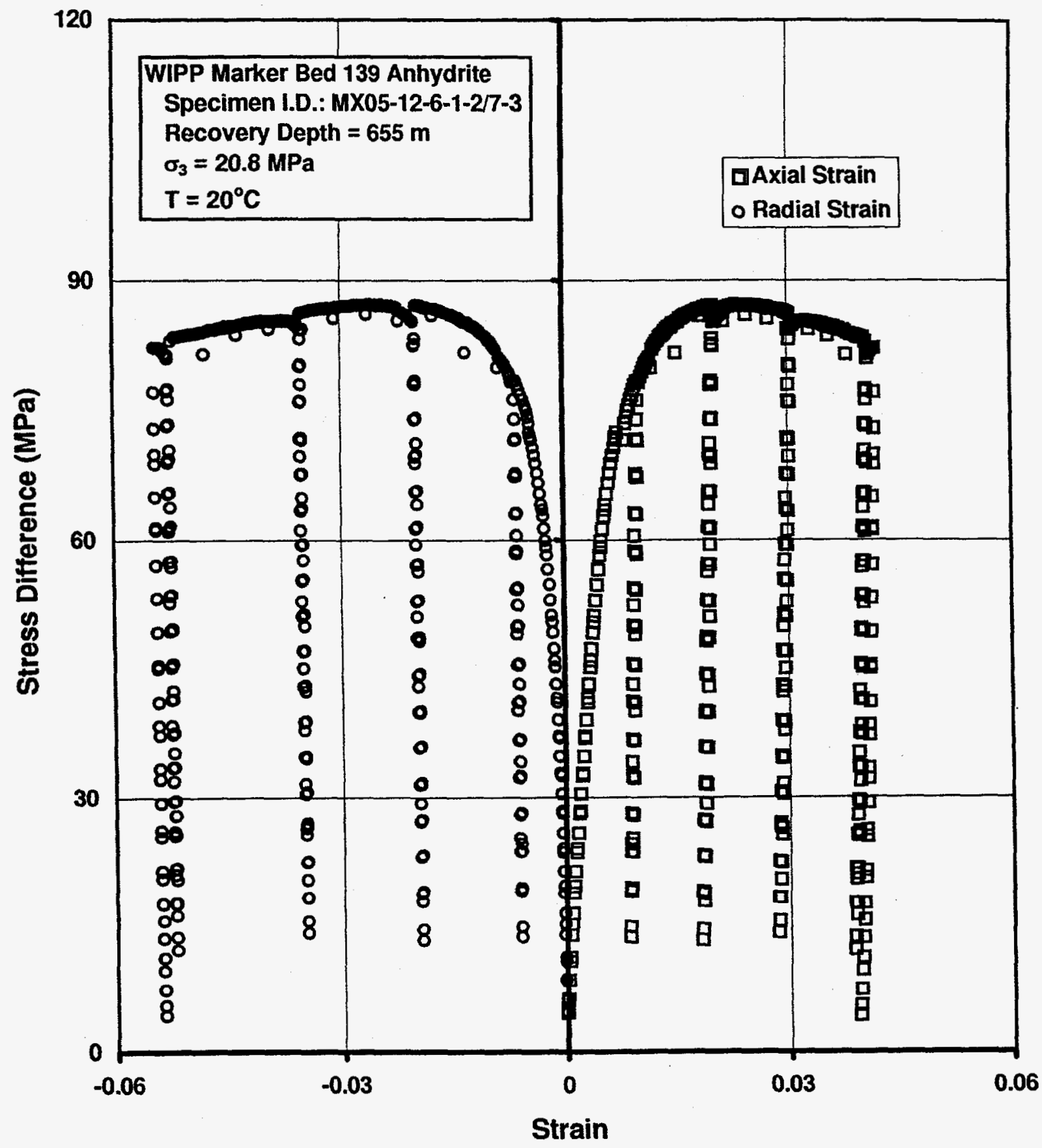

Figure D-20. Stress Difference Versus Axial and Radial Strain for a Triaxial Compression Test on WIPP Anhydrite at a Confining Pressure of $20.8 \mathrm{MPa}$, Specimen MX0512-6-1-2/7-3. 


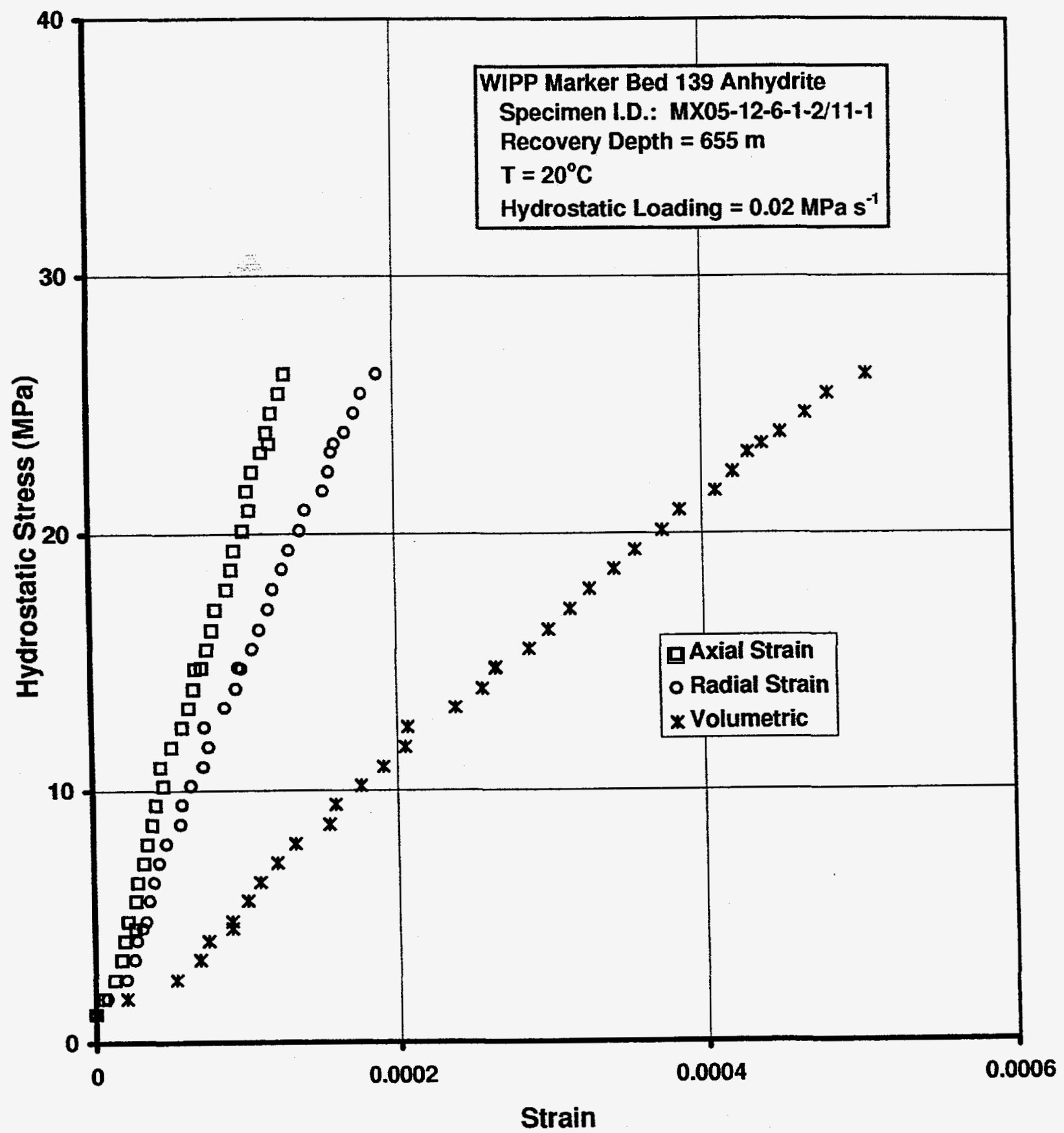

Figure D-21. Hydrostatic Stress Versus Axial, Radial, and Volumetric Strain for a Hydrostatic Compression Test on WIPP Anhydrite, Specimen MX05-12-6-12/11-1. 


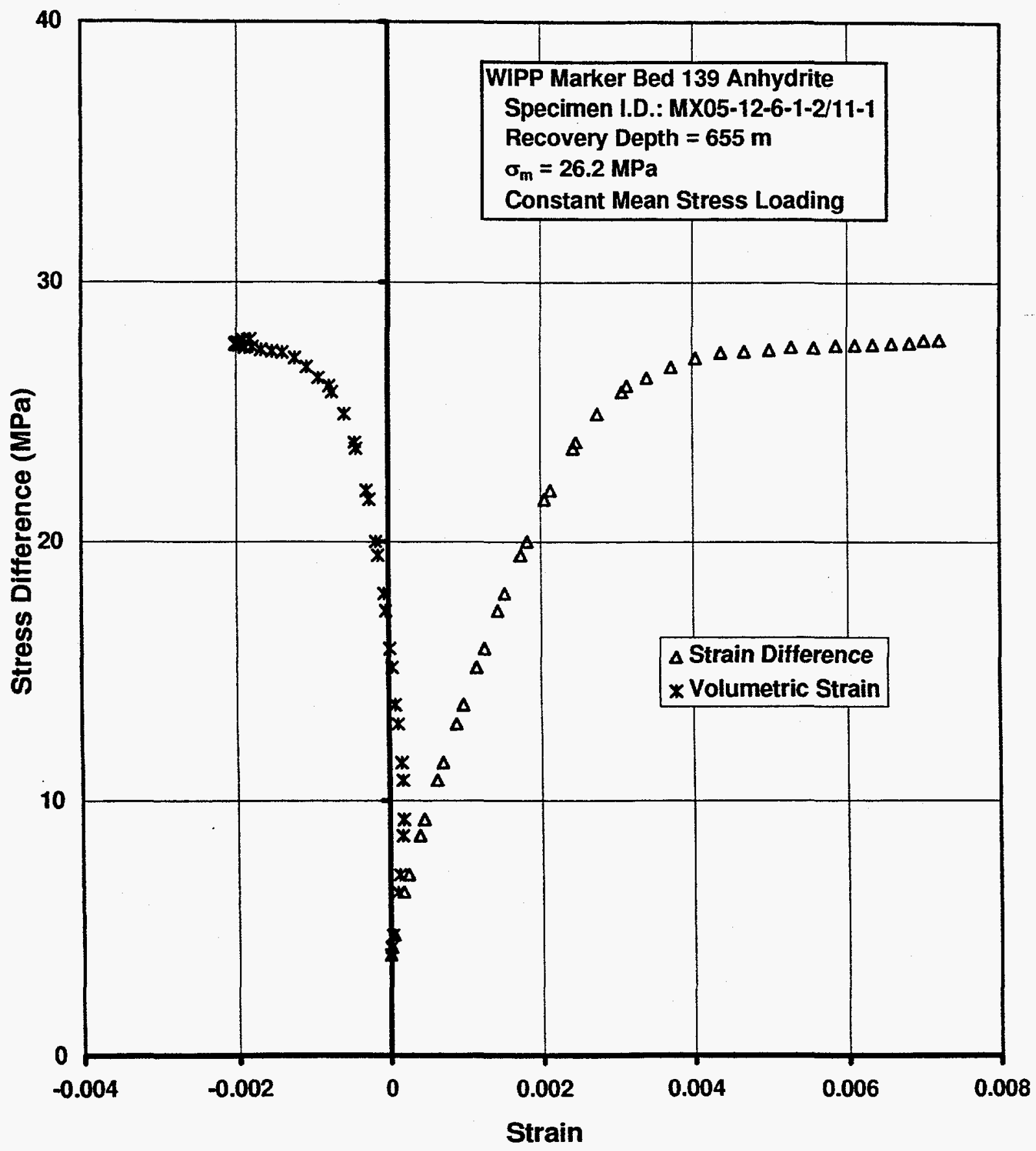

Figure D-22. Stress Difference Versus Axial and Radial Strain for a Triaxial Compression Test on WIPP Anhydrite at a Constant Mean Stress of $26.2 \mathrm{MPa}$, Specimen MX05-12-6-1-2/11-1. 


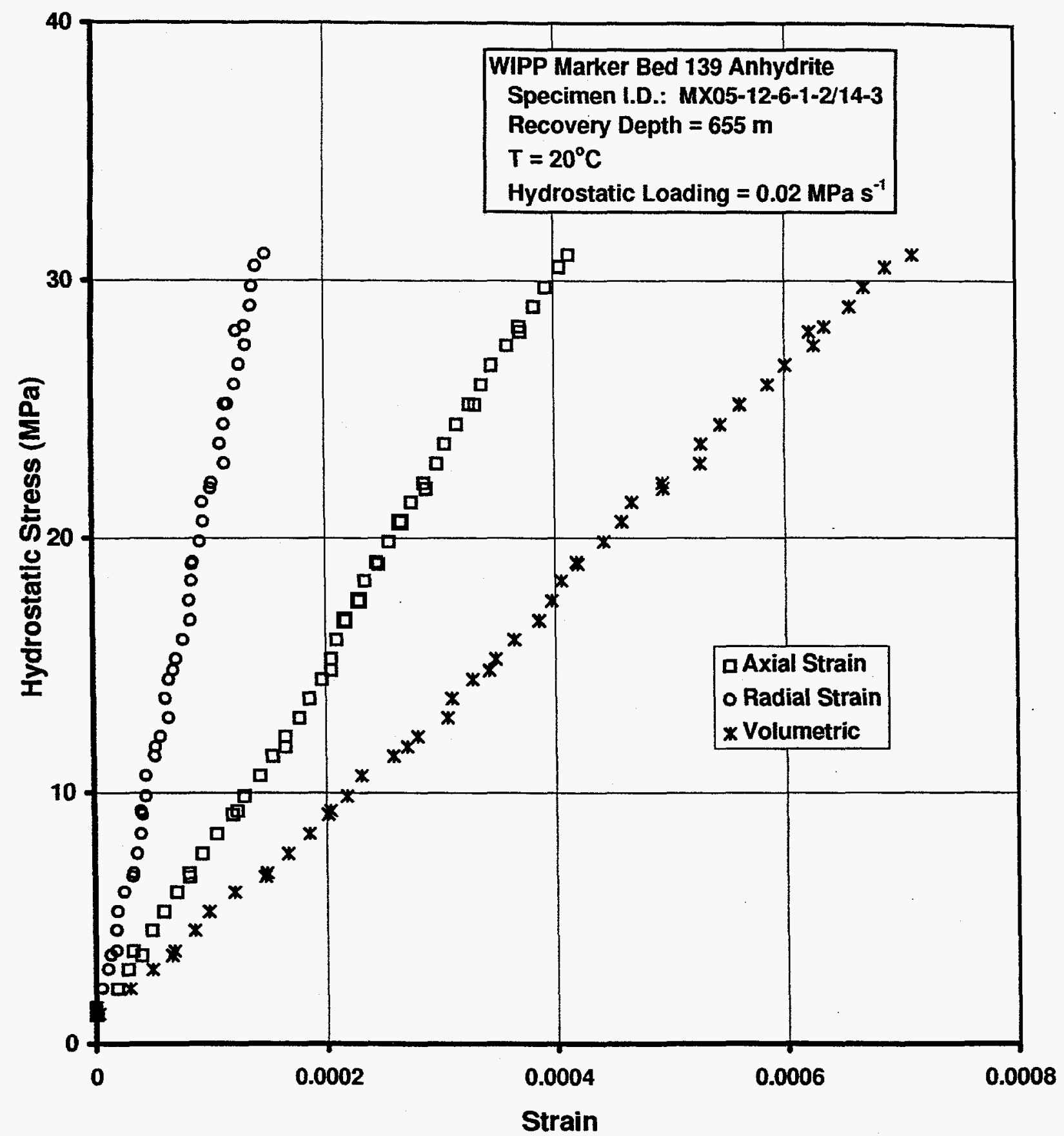

Figure D-23. Hydrostatic Stress Versus Axial, Radial, and Volumetric Strain for a Hydrostatic Compression Test on WIPP Anhydrite, Specimen MX05-12-6-12/14-3. 


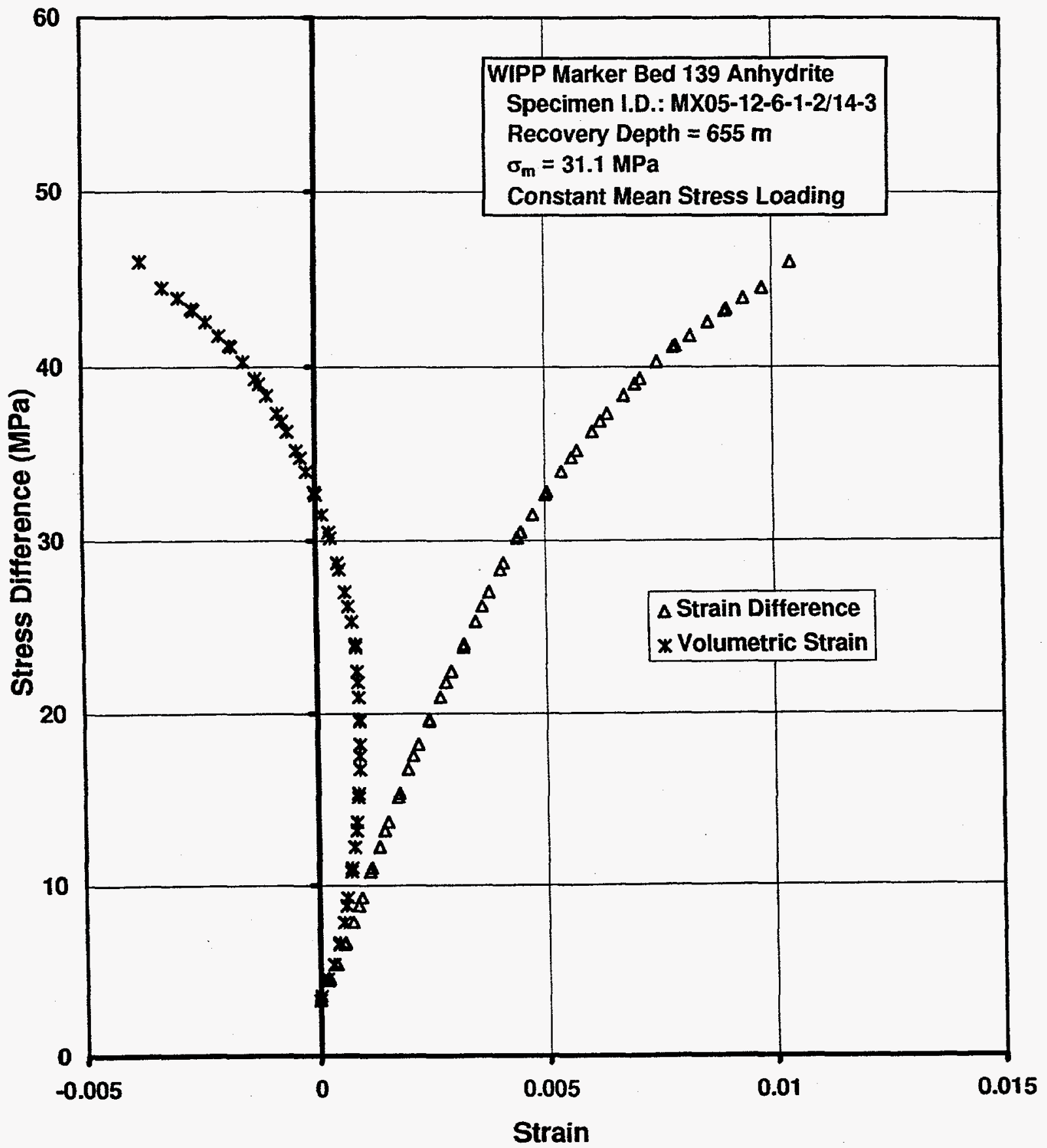

Figure D-24. Stress Difference Versus Axial and Radial Strain for a Triaxial Compression Test on WIPP Anhydrite at a Constant Mean Stress of $31.1 \mathrm{MPa}$, Specimen MX05-12-6-1-2/14-3. 


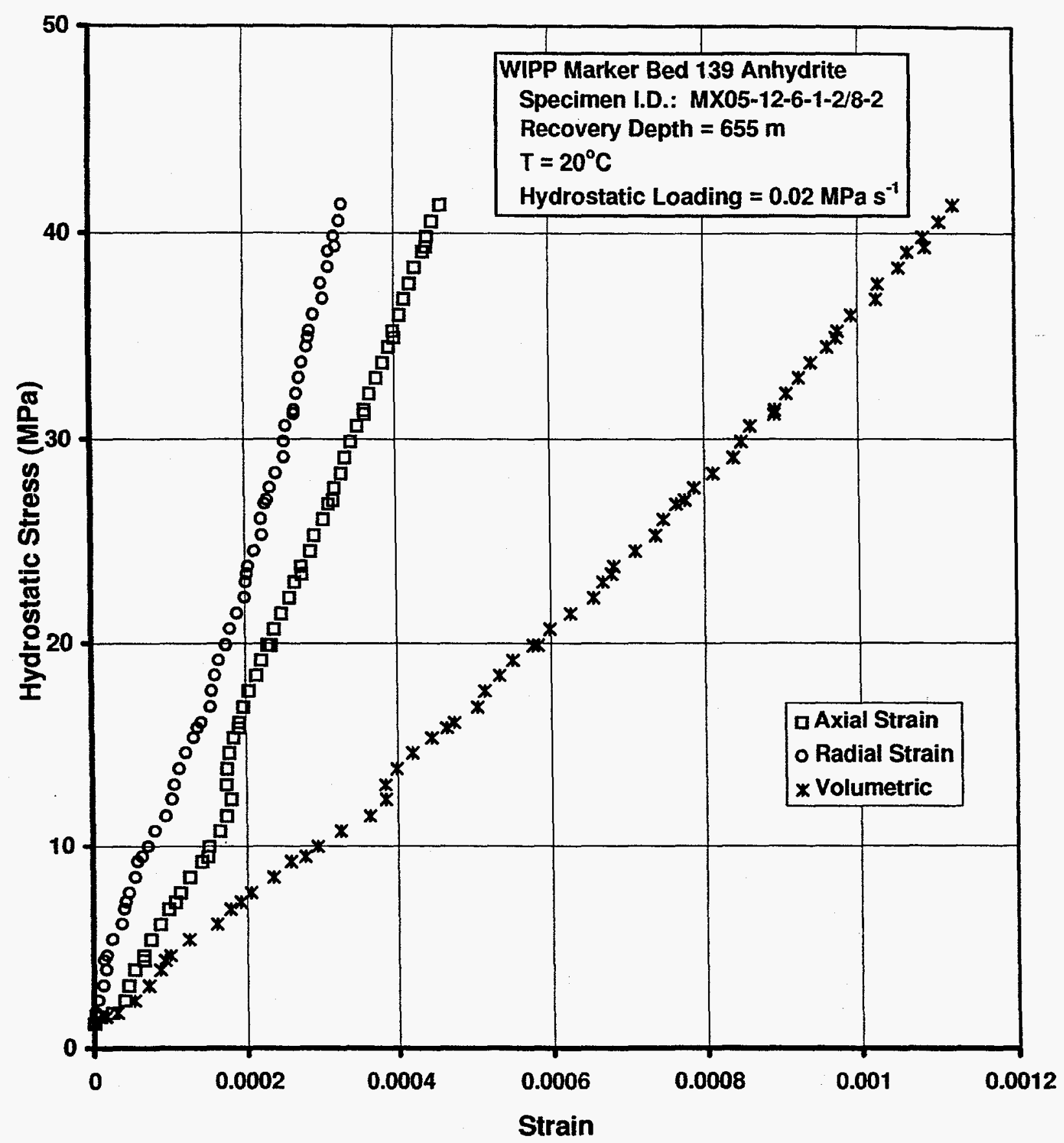

Figure D-25. Hydrostatic Stress Versus Axial, Radial, and Volumetric Strain for a Hydrostatic Compression Test on WIPP Anhydrite, Specimen MX05-12-6-12/8-2. 


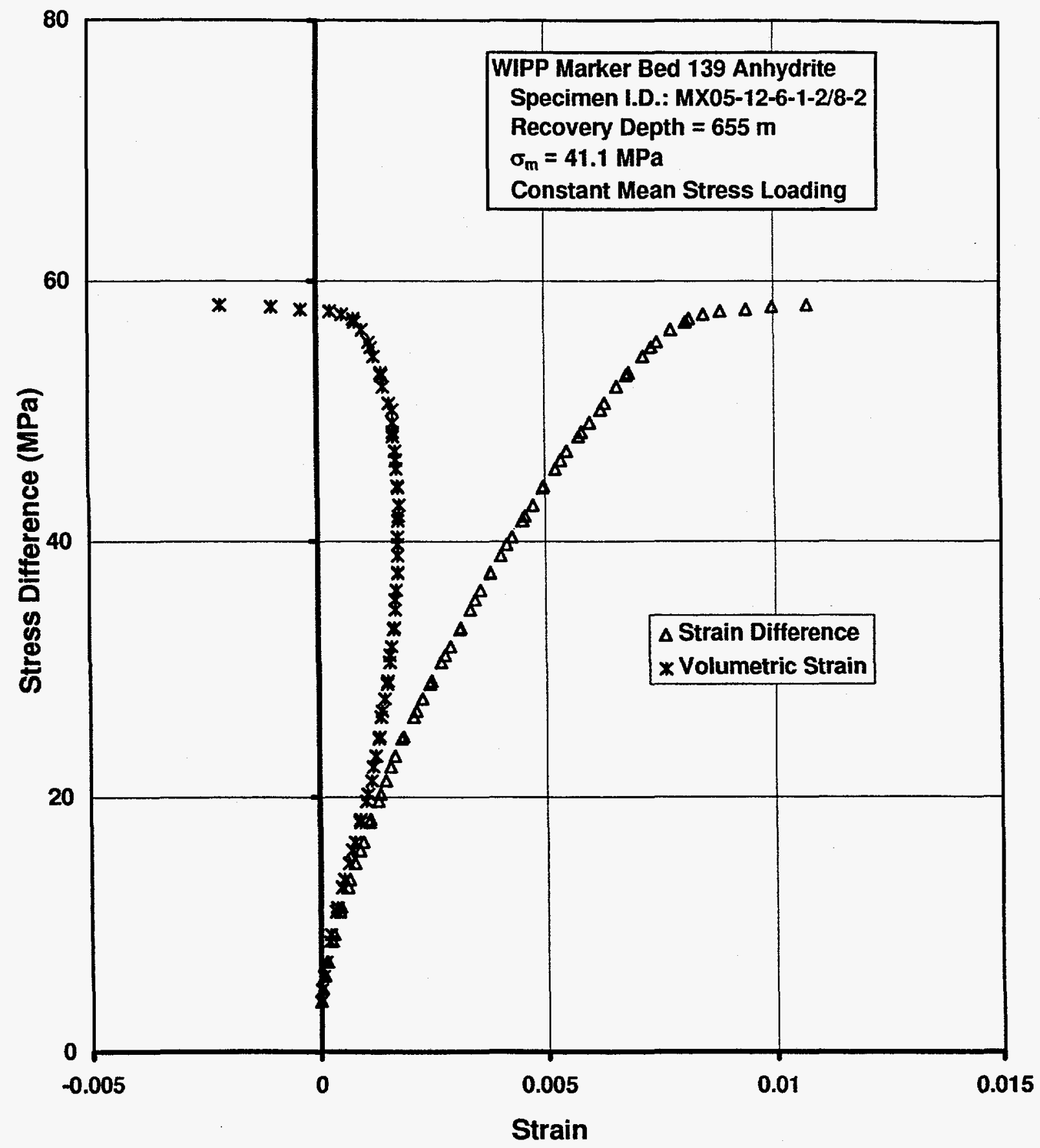

Figure D-26. Stress Difference Versus Axial and Radial Strain for a Triaxial Compression Test on WIPP Anhydrite at a Constant Mean Stress of $41.1 \mathrm{MPa}$, Specimen MX05-12-6-1-2/8-2. 


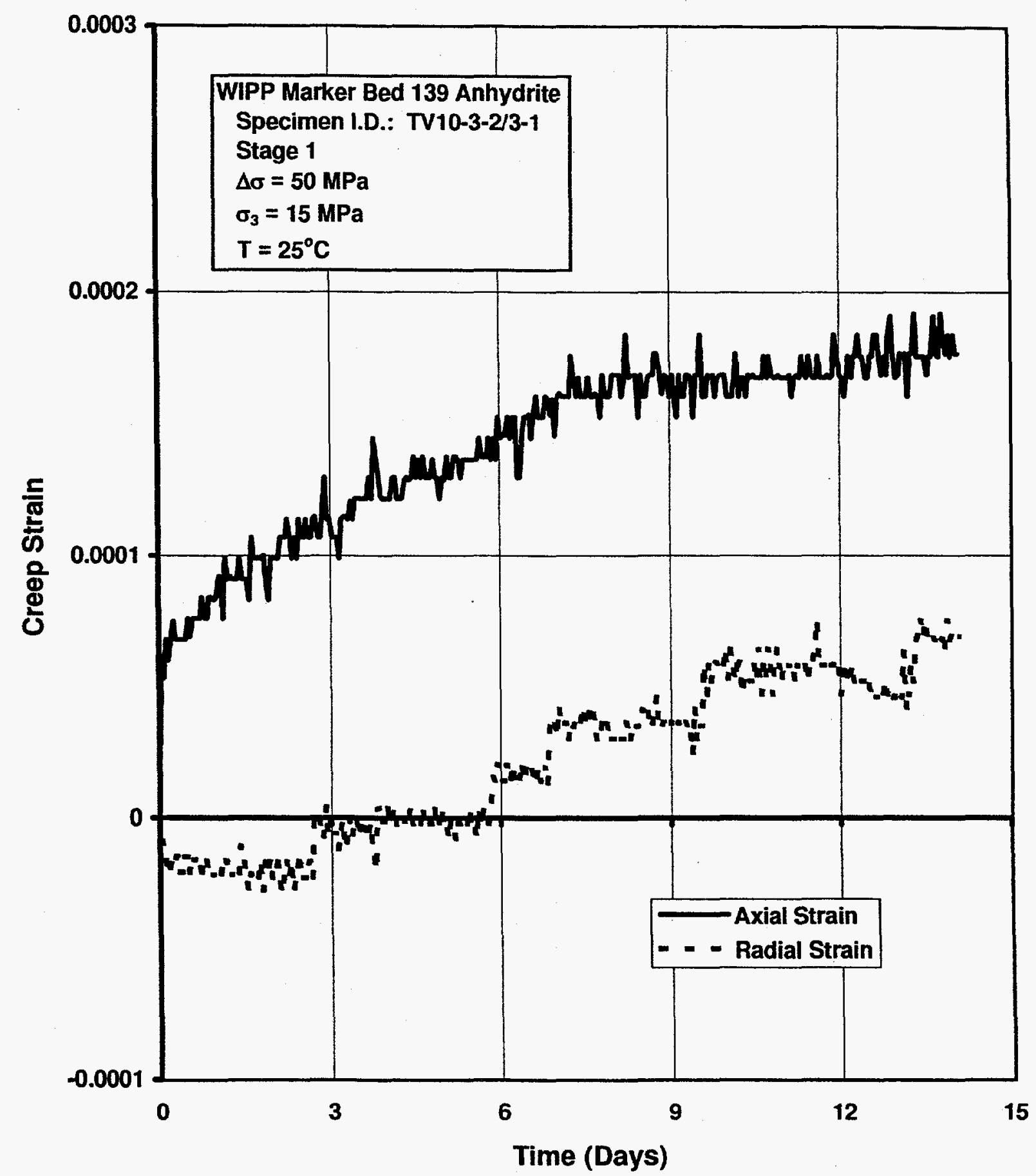

Figure D-27. Axial and Radial Creep Strain for WIPP Anhydrite at a Temperature of $25^{\circ} \mathrm{C}$, a Stress Difference of $50 \mathrm{MPa}$, and a Confining Pressure of $15 \mathrm{MPa}$, Specimen TV10-3-2/3-1, Stage 1. 
RSI-325-98-059

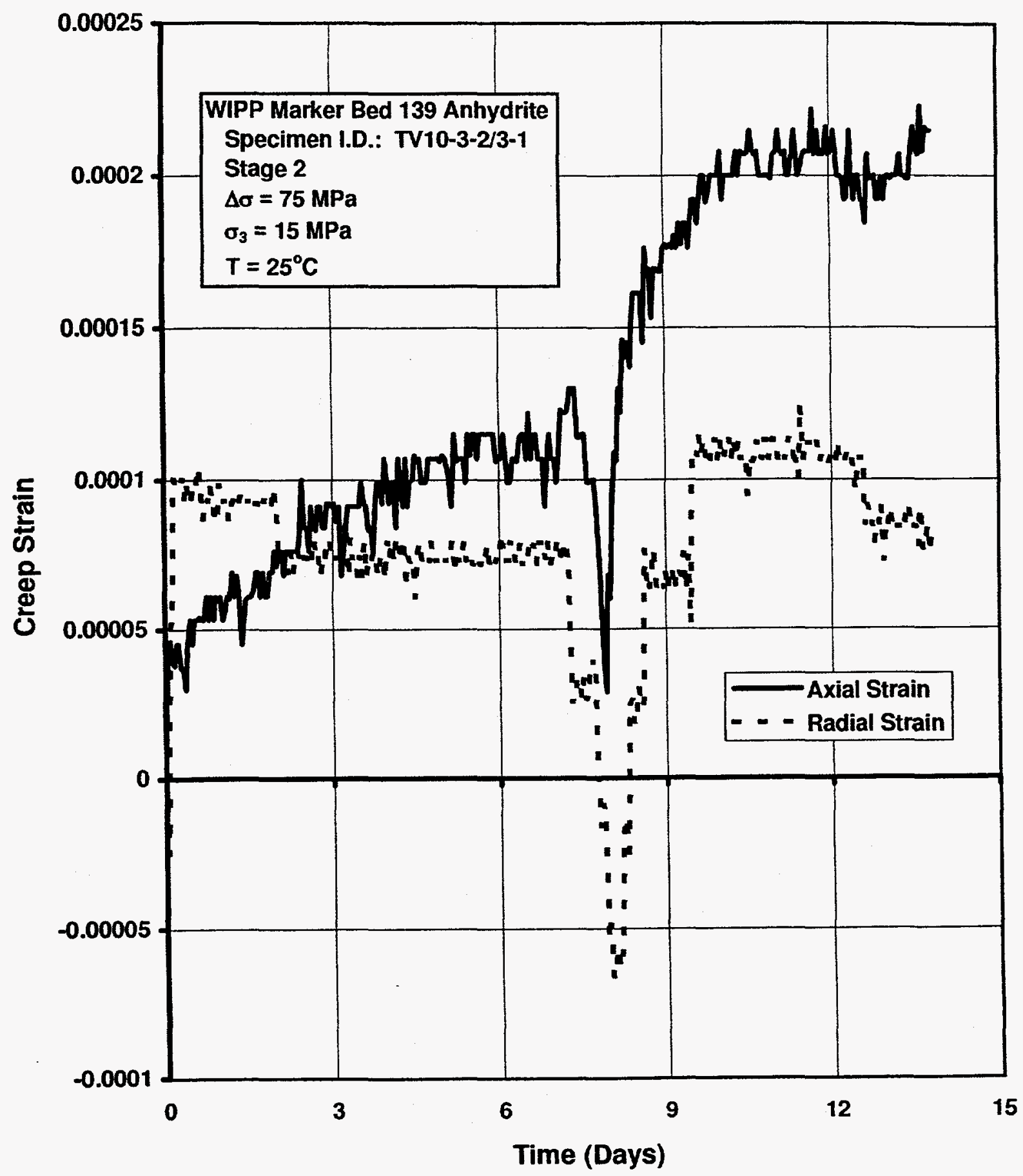

Figure D-28. Axial and Radial Creep Strain for WIPP Anhydrite at a Temperature of $25^{\circ} \mathrm{C}$, a Stress Difference of $75 \mathrm{MPa}$, and a Confining Pressure of $15 \mathrm{MPa}$, Specimen TV10-3-2/3-1, Stage 2. 


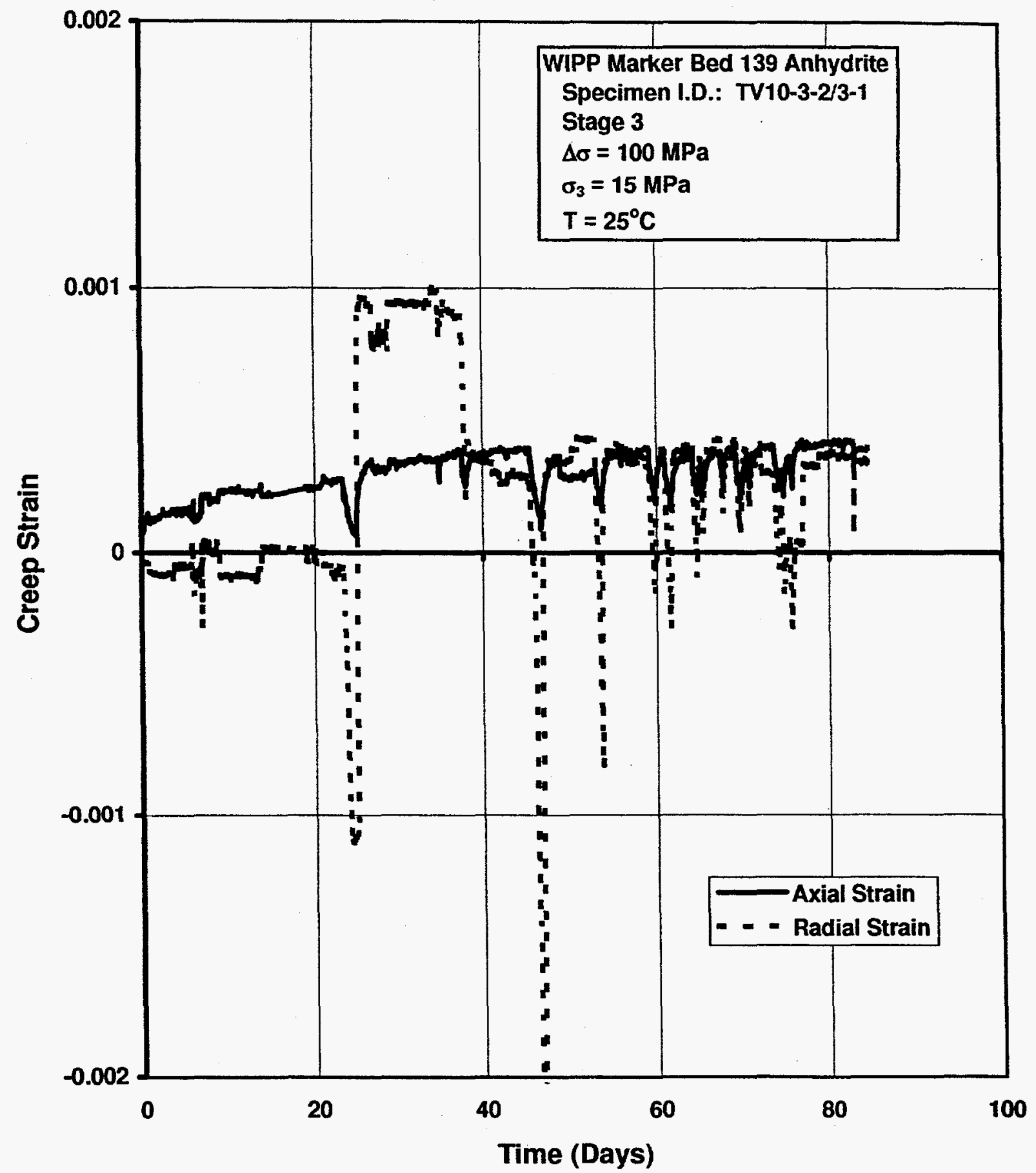

Figure D-29. Axial and Radial Creep Strain for WIPP Anhydrite at a Temperature of $25^{\circ} \mathrm{C}$, a Stress Difference of $100 \mathrm{MPa}$, and a Confining Pressure of $15 \mathrm{MPa}$, Specimen TV10-3-2/3-1, Stage 3. 


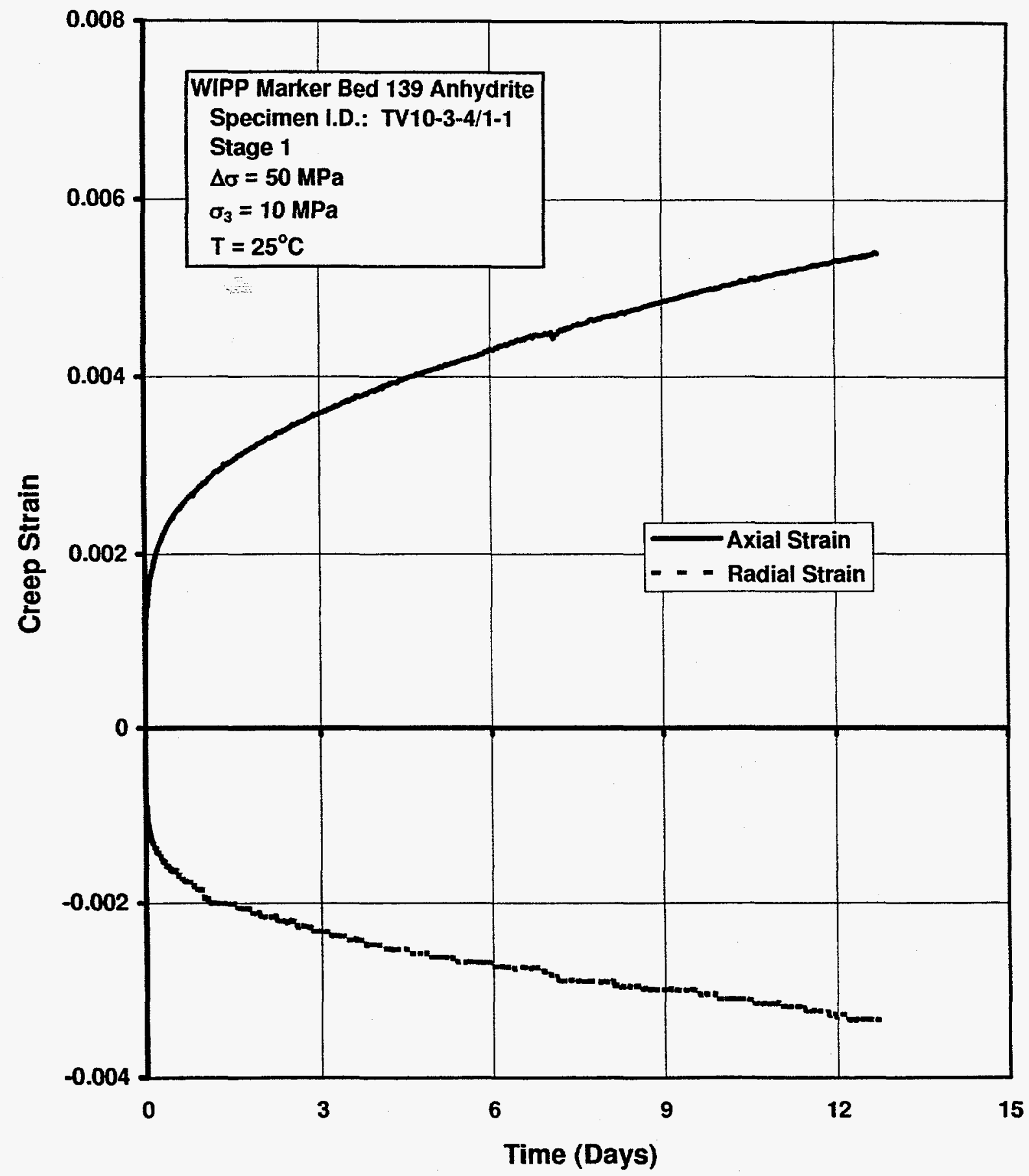

Figure D-30. Axial and Radial Creep Strain for WIPP Anhydrite at a Temperature of $25^{\circ} \mathrm{C}$, a Stress Difference of $50 \mathrm{MPa}$, and a Confining Pressure of $10 \mathrm{MPa}$, Specimen TV10-3-4/1-1, Stage 1. 


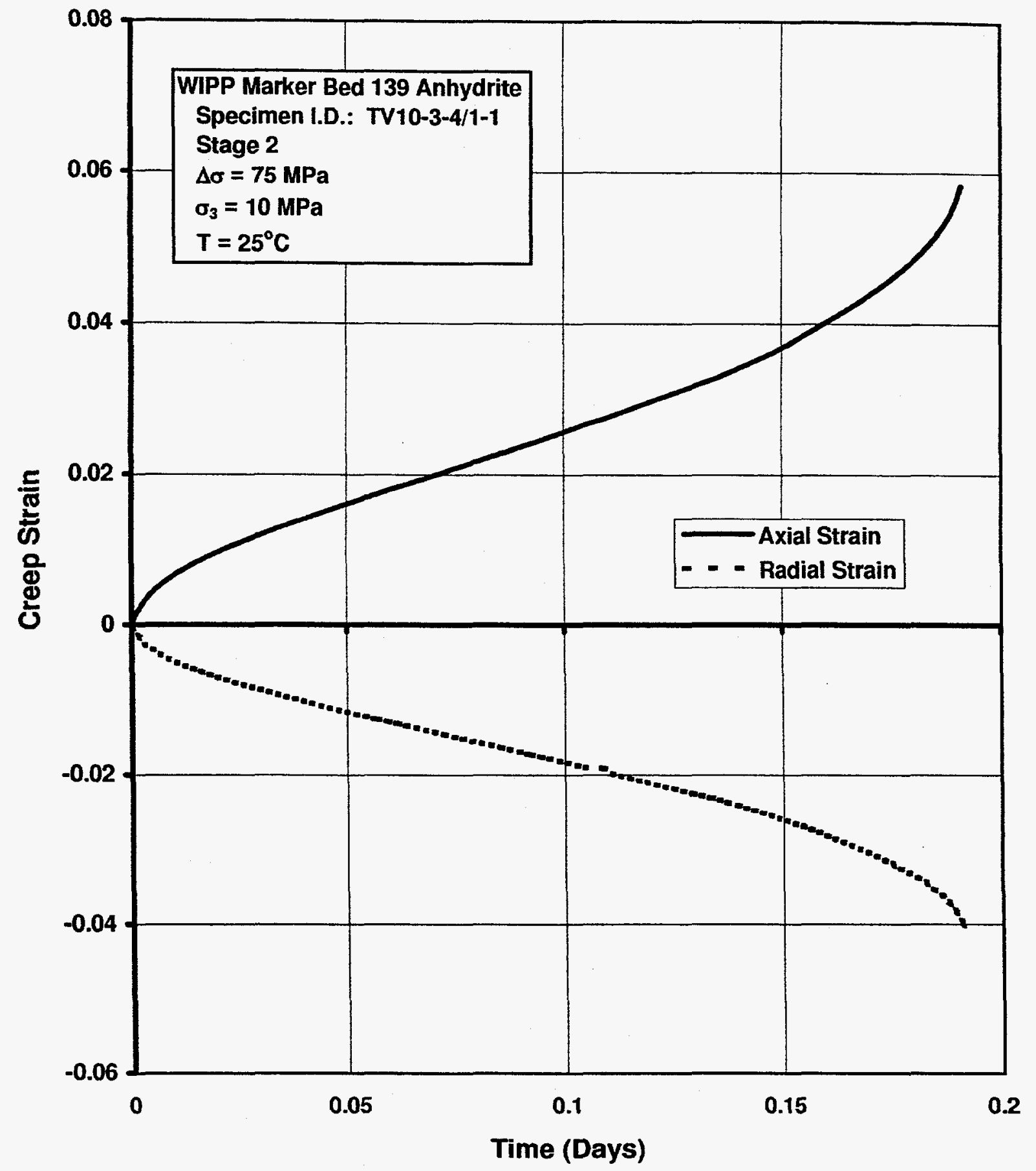

Figure D-31. Axial and Radial Creep Strain for WIPP Anhydrite at a Temperature of $25^{\circ} \mathrm{C}$, a Stress Difference of $75 \mathrm{MPa}$, and a Confining Pressure of $10 \mathrm{MPa}$, Specimen TV10-3-4/1-1, Stage 2. 


\section{APPENDIX E}

LOAD-DISPLACEMENT CURVES FOR BRAZILIAN INDIRECT TENSILE STRENGTH TESTS OF WIPP ANHYDRITE - SUPPLEMENTAL TESTING 


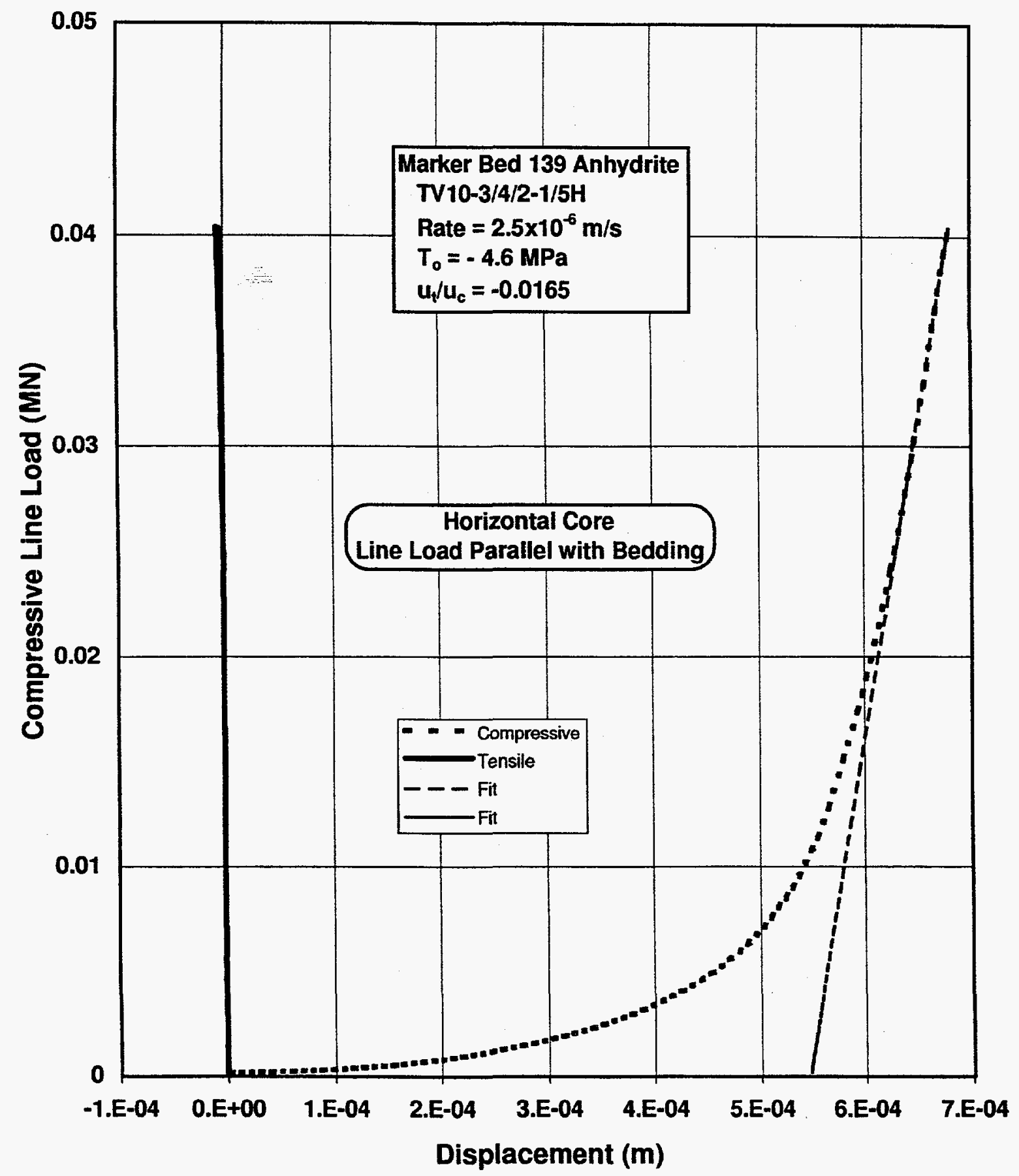

Figure E-1. Compressive and Tensile Displacements for Brazilian Indirect Tensile Strength Tests of WIPP Anhydrite, Specimen TV10-3/4/2-1/5H. 


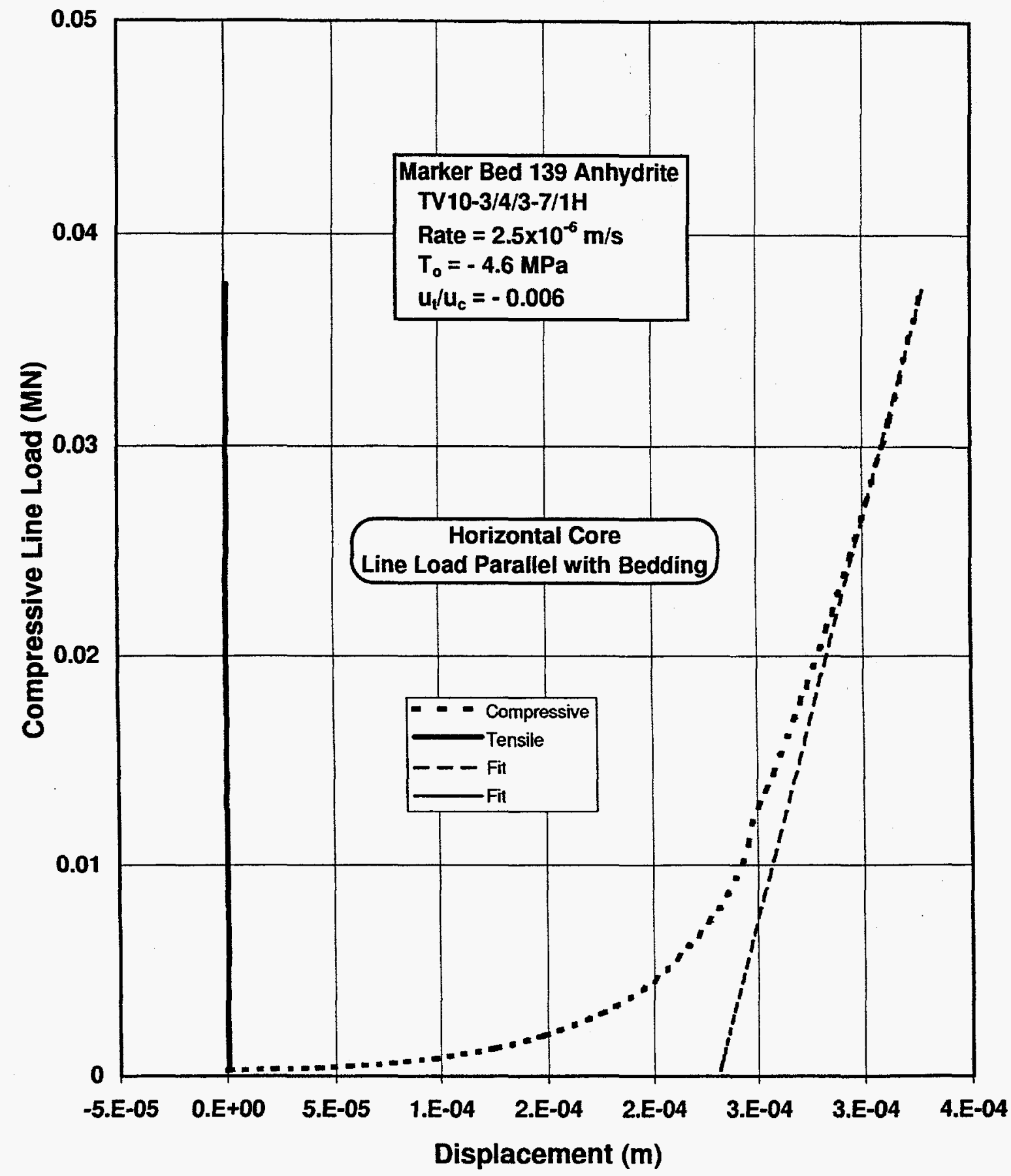

Figure E-2. Compressive and Tensile Displacements for Brazilian Indirect Tensile Strength Tests of WIPP Anhydrite, Specimen TV10-3/4/3-7/1H. 


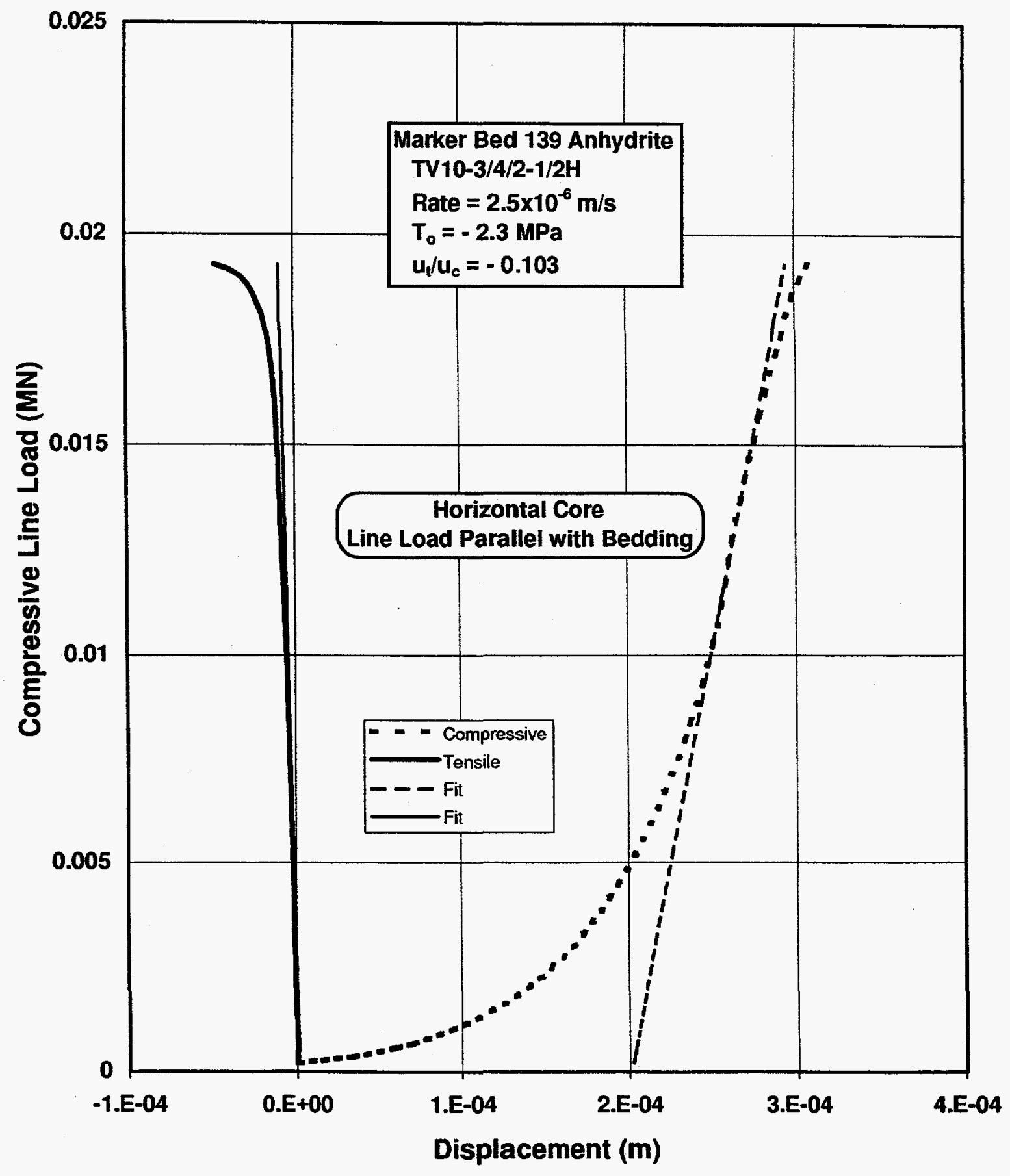

Figure E-3. Compressive and Tensile Displacements for Brazilian Indirect Tensile Strength Tests of WIPP Anhydrite, Specimen TV10-3/4/2-1/2H. 


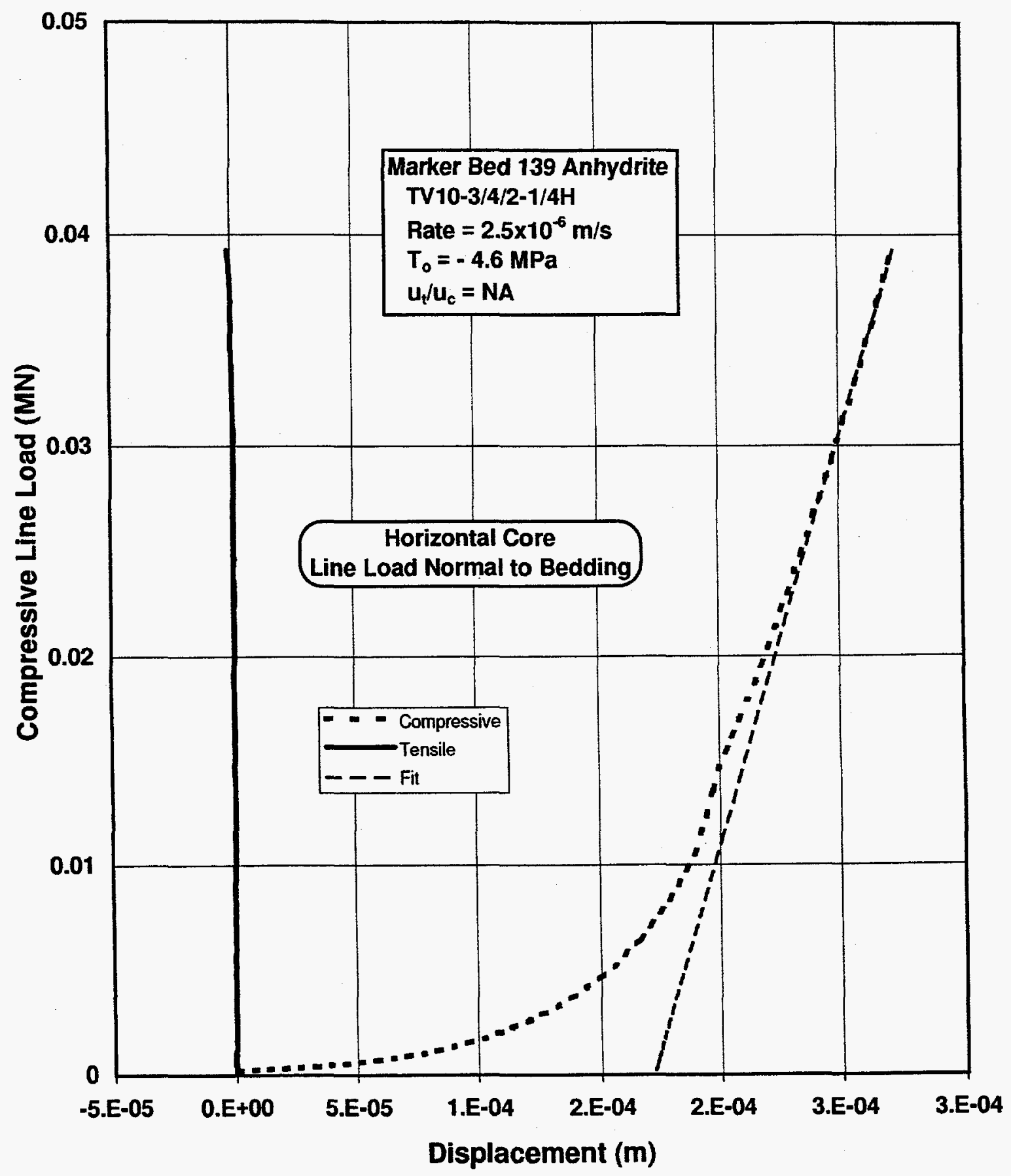

Figure E-4. Compressive and Tensile Displacements for Brazilian Indirect Tensile Strength Tests of WIPP Anhydrite, Specimen TV10-3/4/2-1/4H. 


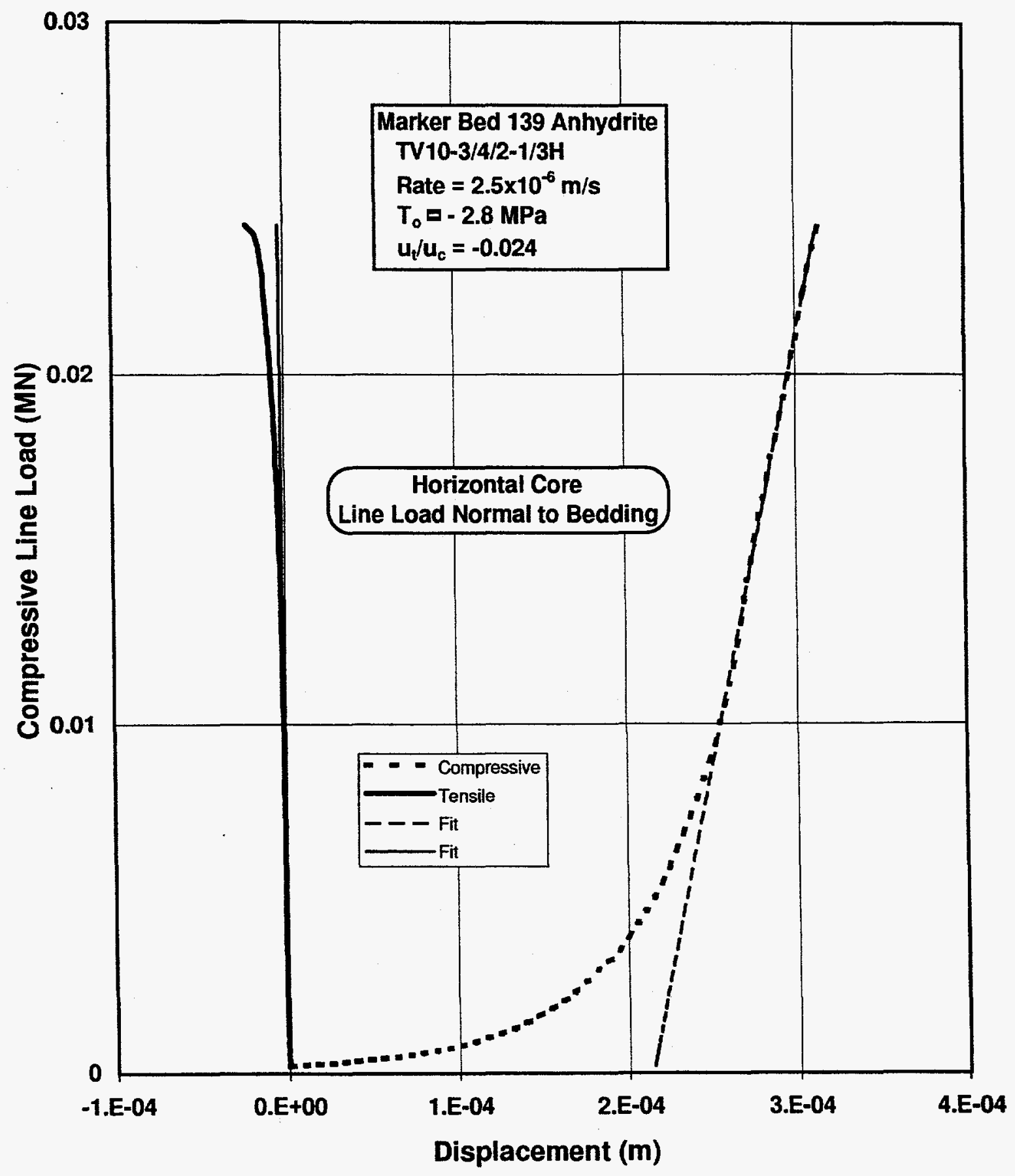

Figure E-5. Compressive and Tensile Displacements for Brazilian Indirect Tensile Strength Tests of WIPP Anhydrite, Specimen TV10-3/4/2-1/3H. 


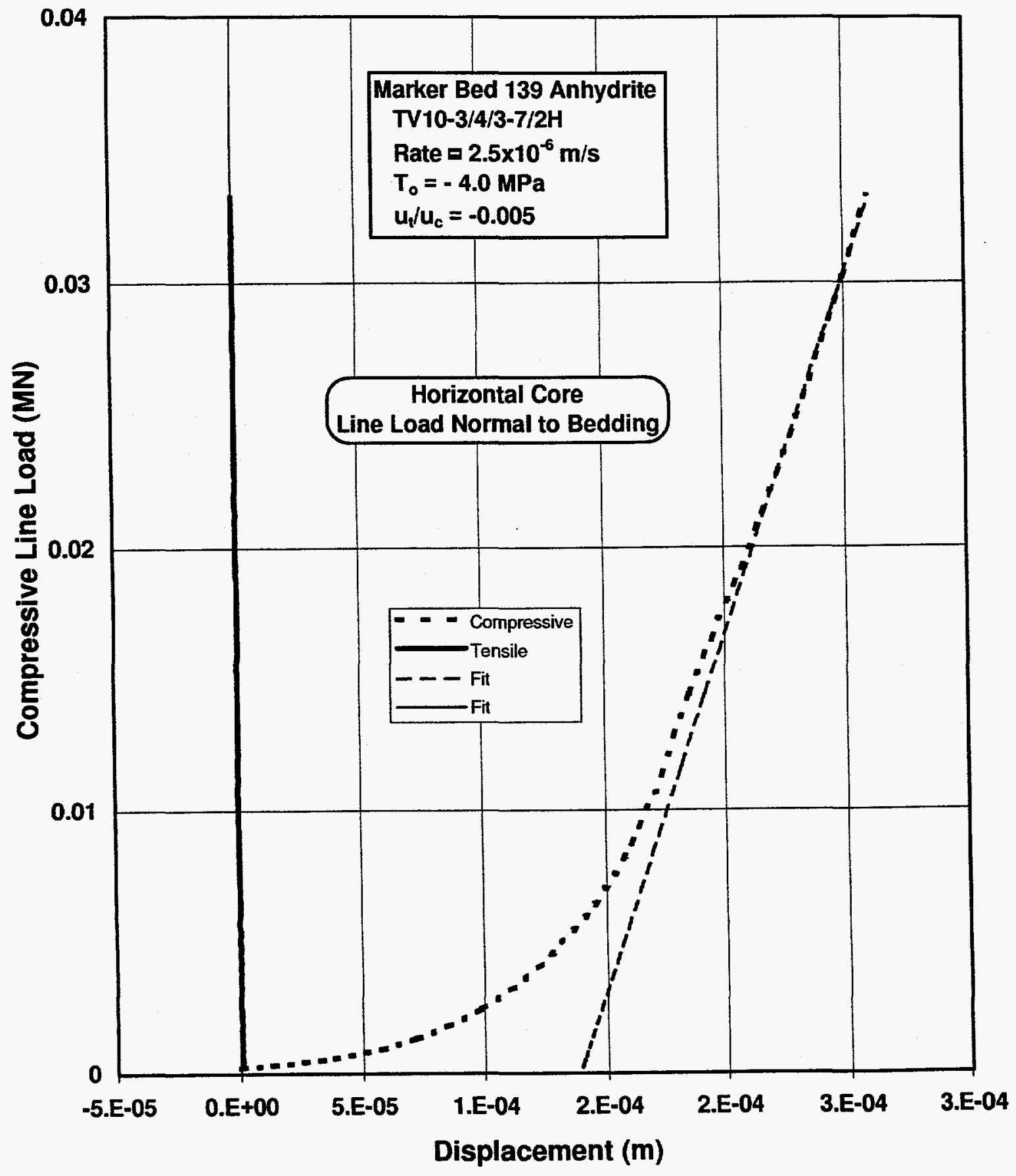

Figure E-6. Compressive and Tensile Displacements for Brazilian Indirect Tensile Strength Tests of WIPP Anhydrite, Specimen TV10-3/4/3-7/2H. 


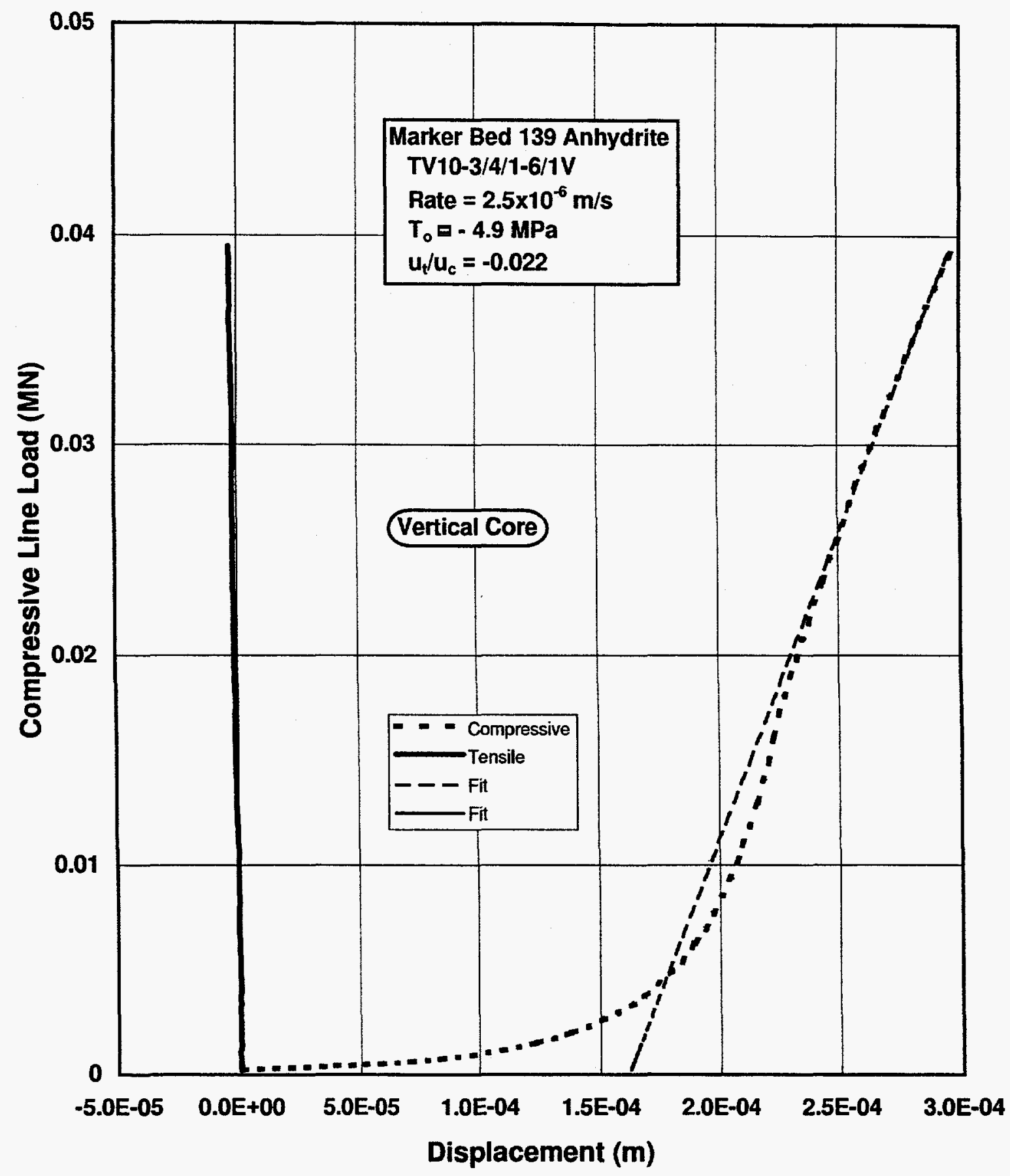

Figure E-7. Compressive and Tensile Displacements for Brazilian Indirect Tensile Strength Tests of WIPP Anhydrite, Specimen TV10-3/4/1-6/1V. 


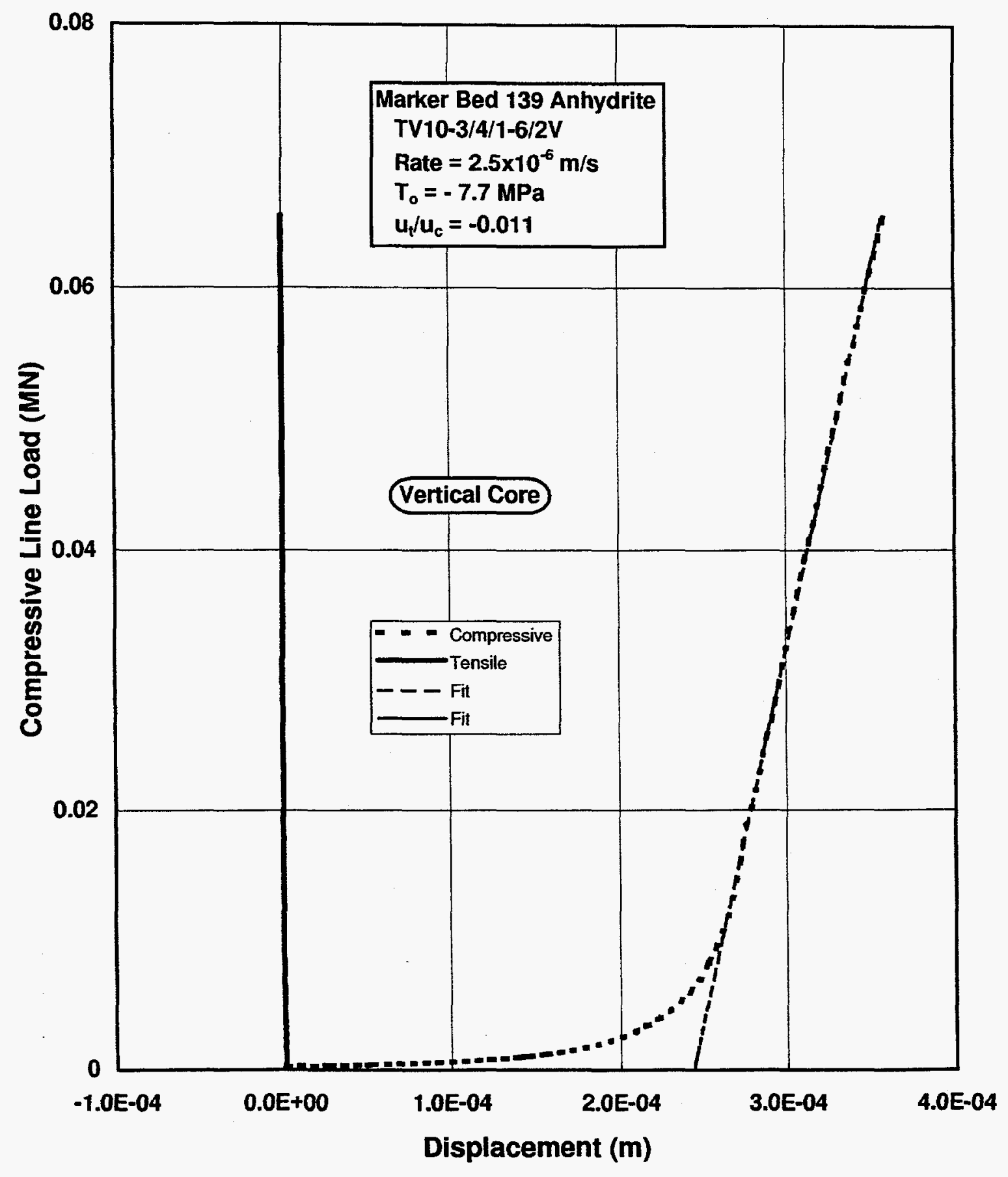

Figure E-8. Compressive and Tensile Displacements for Brazilian Indirect Tensile Strength Tests of WIPP Anhydrite, Specimen TV10-3/4/1-6/2V. 


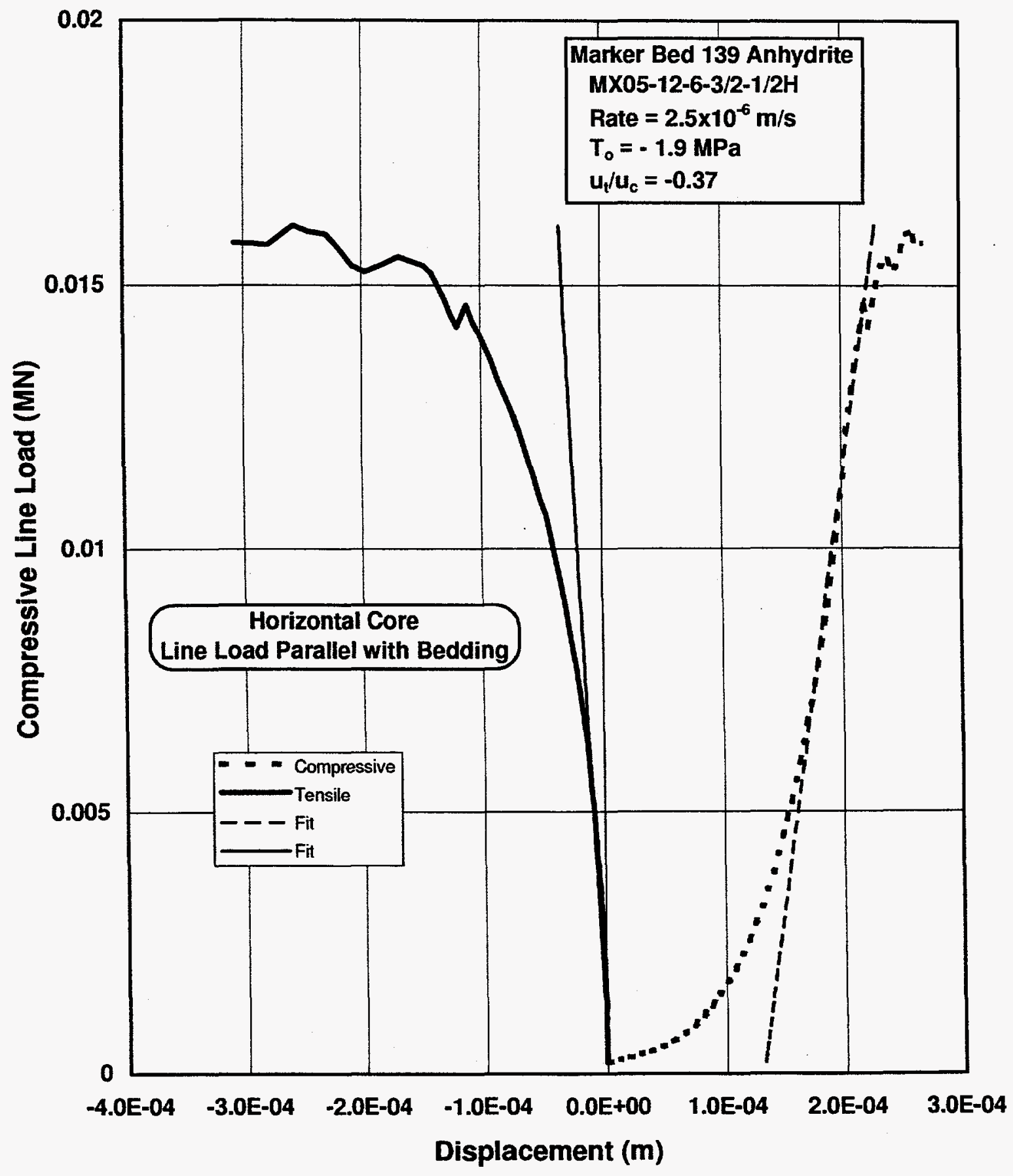

Figure E-9. Compressive and Tensile Displacements for Brazilian Indirect Tensile Strength Tests of WIPP Anhydrite, Specimen MX05-12-6-3/2-1/2H. 


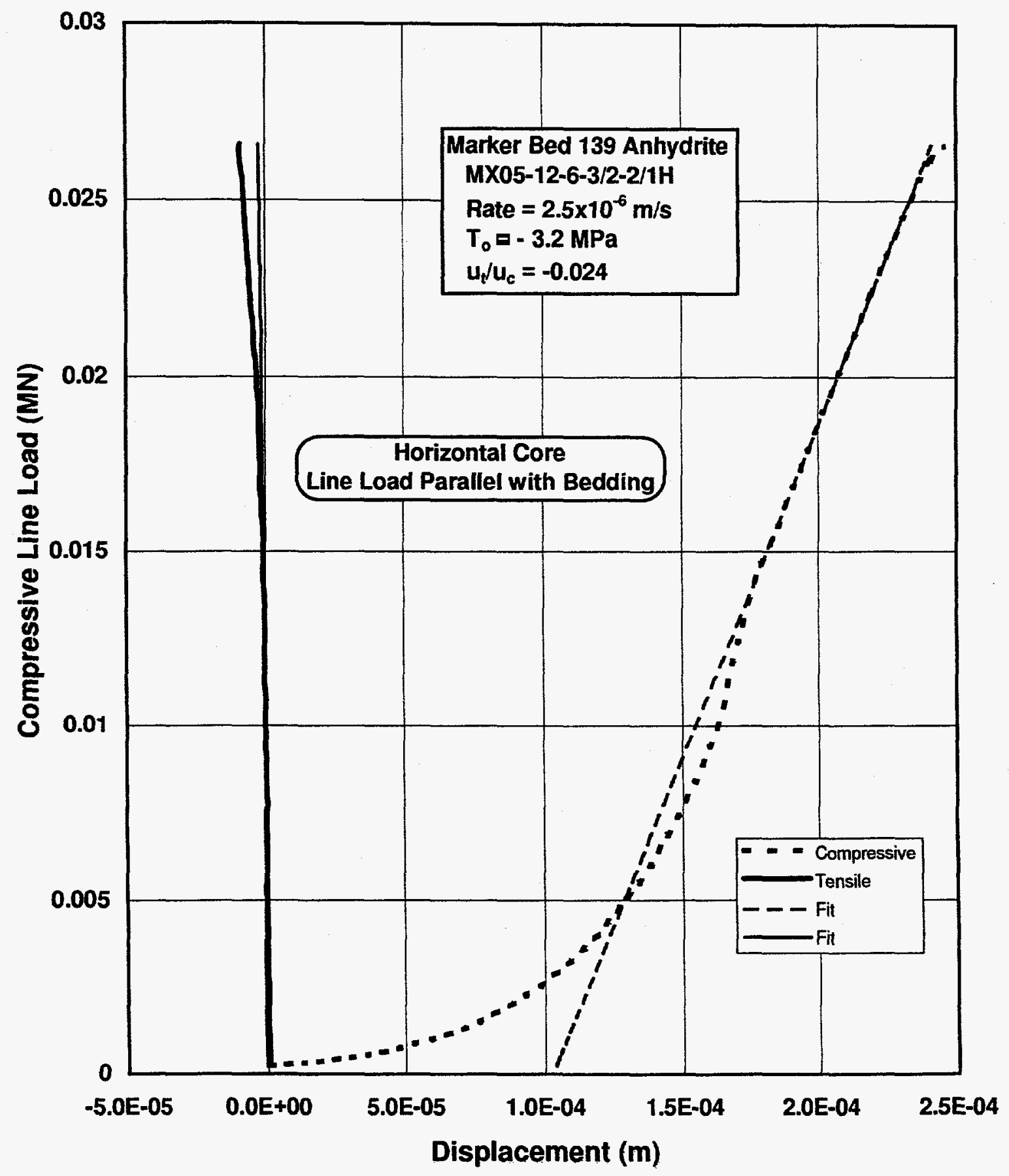

Figure E-10. Compressive and Tensile Displacements for Brazilian Indirect Tensile Strength Tests of WIPP Anhydrite, Specimen MX05-12-6-3/2-2/1H. 


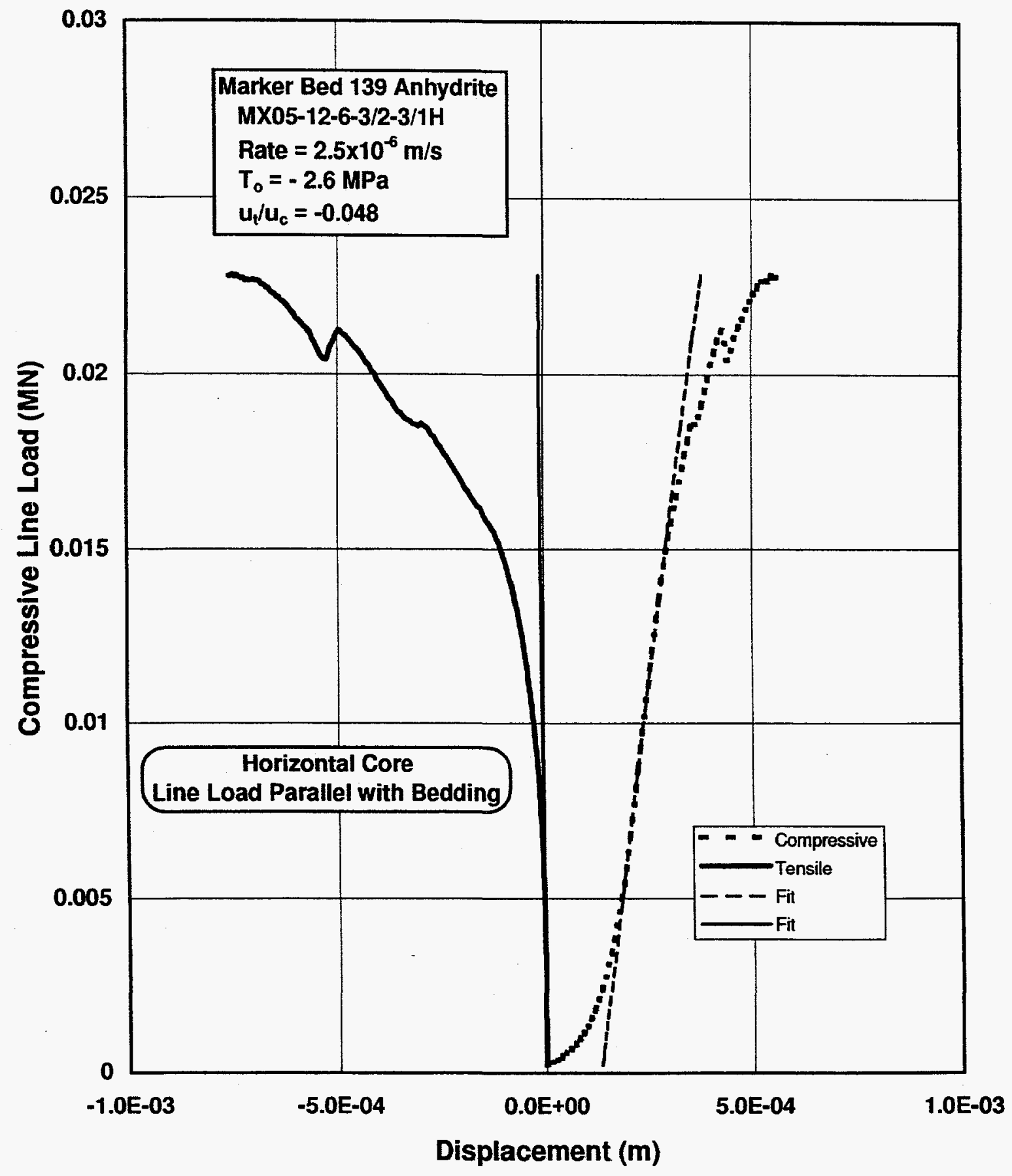

Figure E-11. Compressive and Tensile Displacements for Brazilian Indirect Tensile Strength Tests of WIPP Anhydrite, Specimen MX05-12-6-3/2-3/1H. 


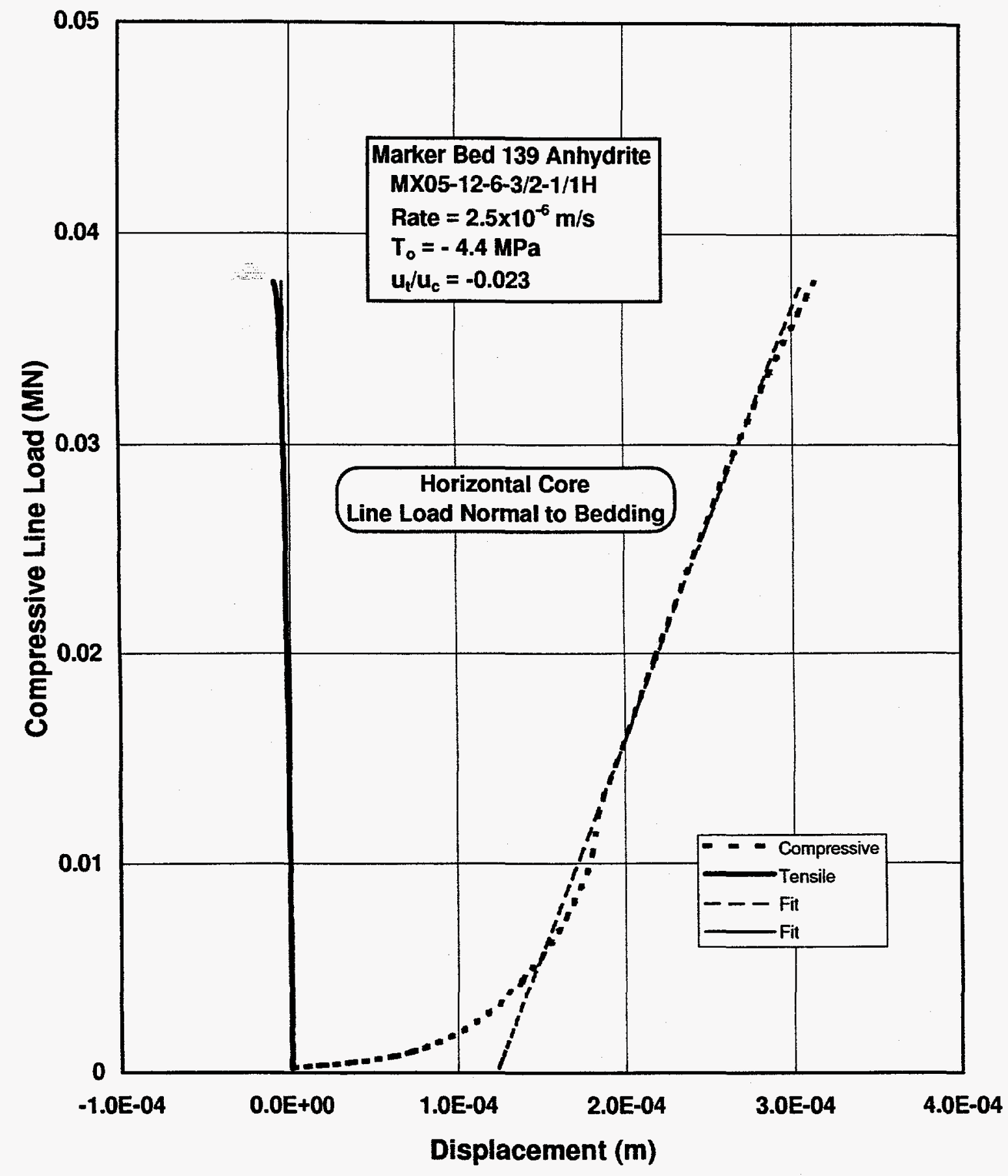

Figure E-12. Compressive and Tensile Displacements for Brazilian Indirect Tensile Strength Tests of WIPP Anhydrite, Specimen MX05-12-6-3/2-1/1H. 


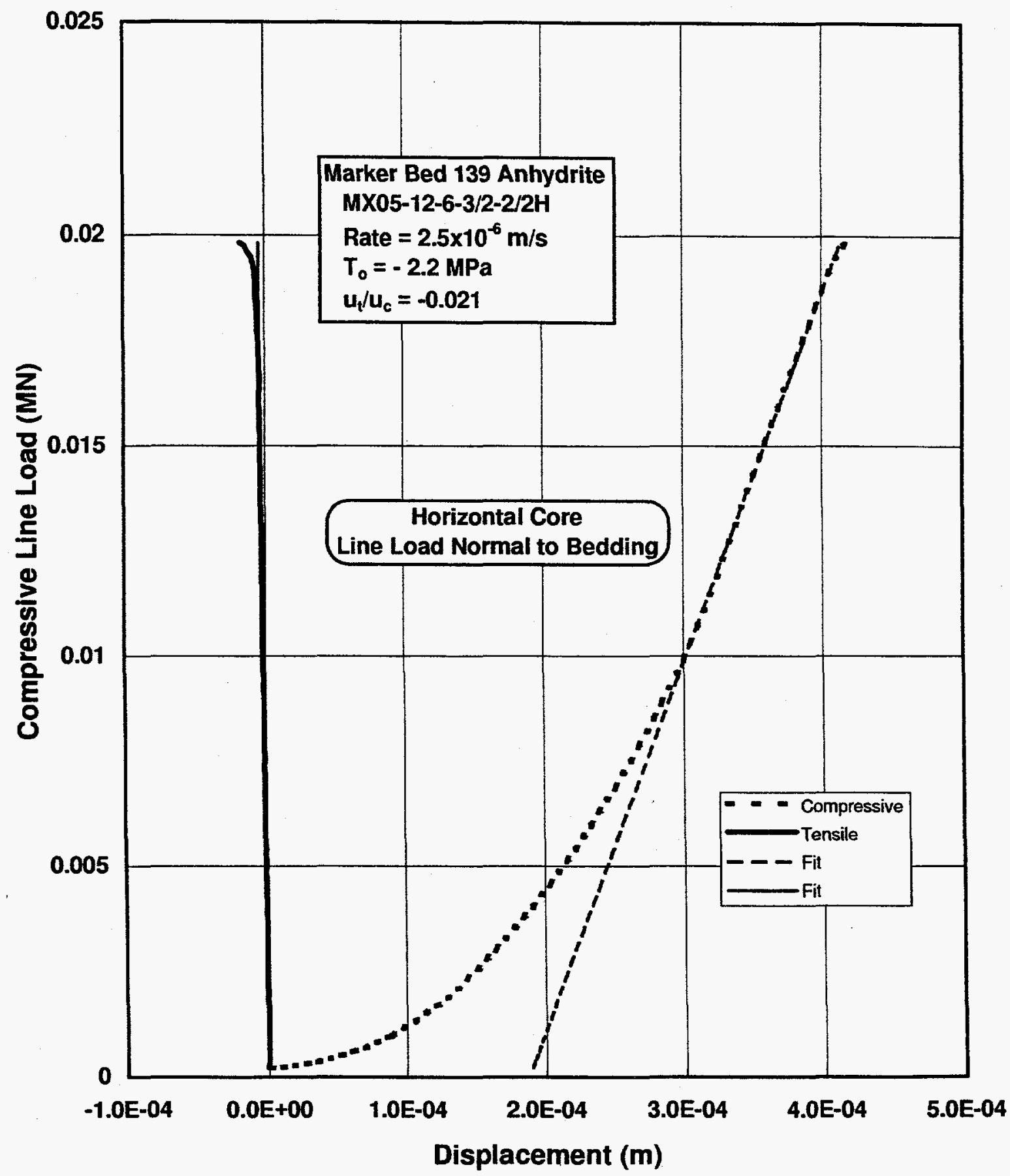

Figure E-13. Compressive and Tensile Displacements for Brazilian Indirect Tensile Strength Tests of WIPP Anhydrite, Specimen MX05-12-6-3/2-2/2H. 


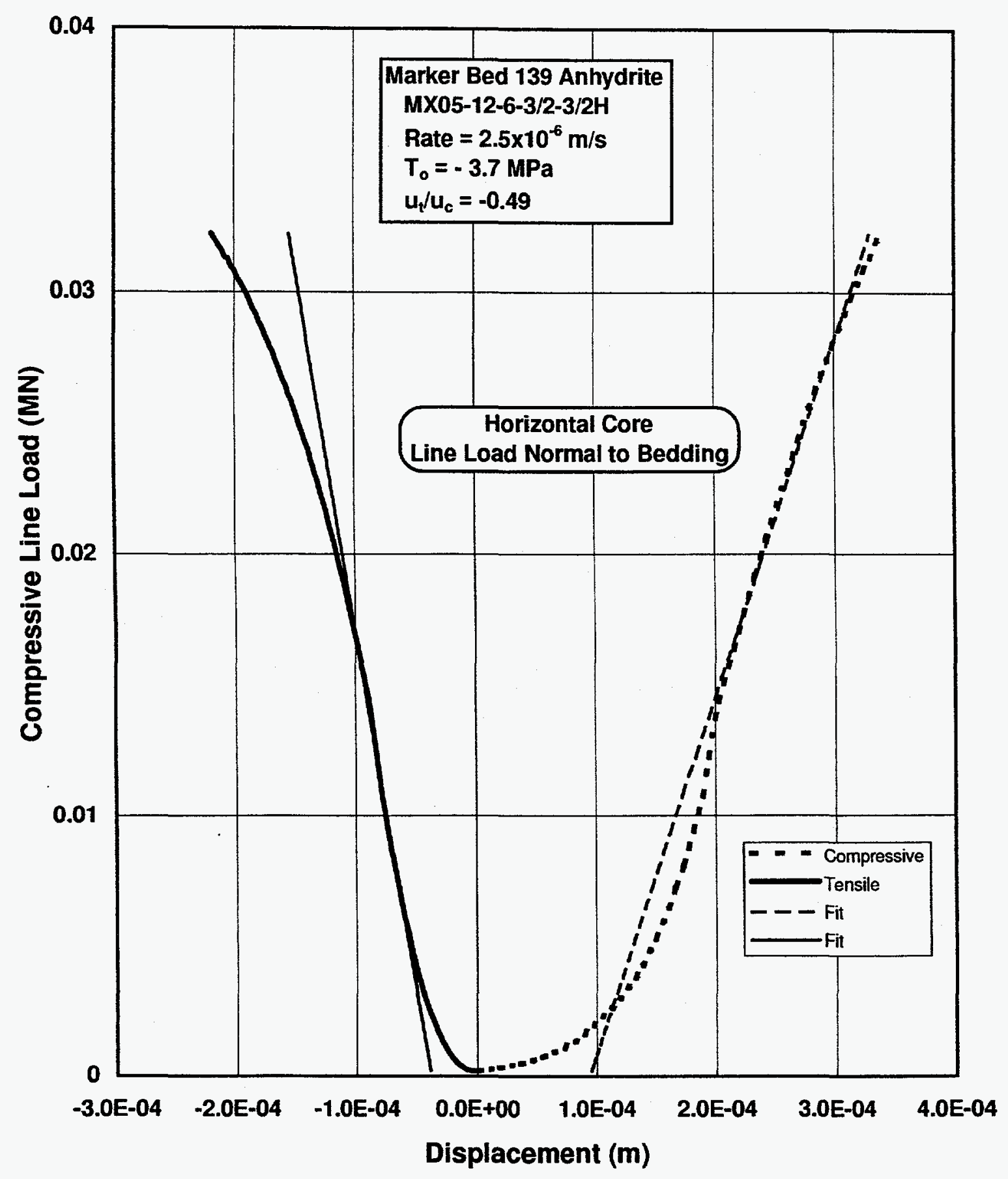

Figure E-14. Compressive and Tensile Displacements for Brazilian Indirect Tensile Strength Tests of WIPP Anhydrite, Specimen MX05-12-6-3/2-3/2H. 


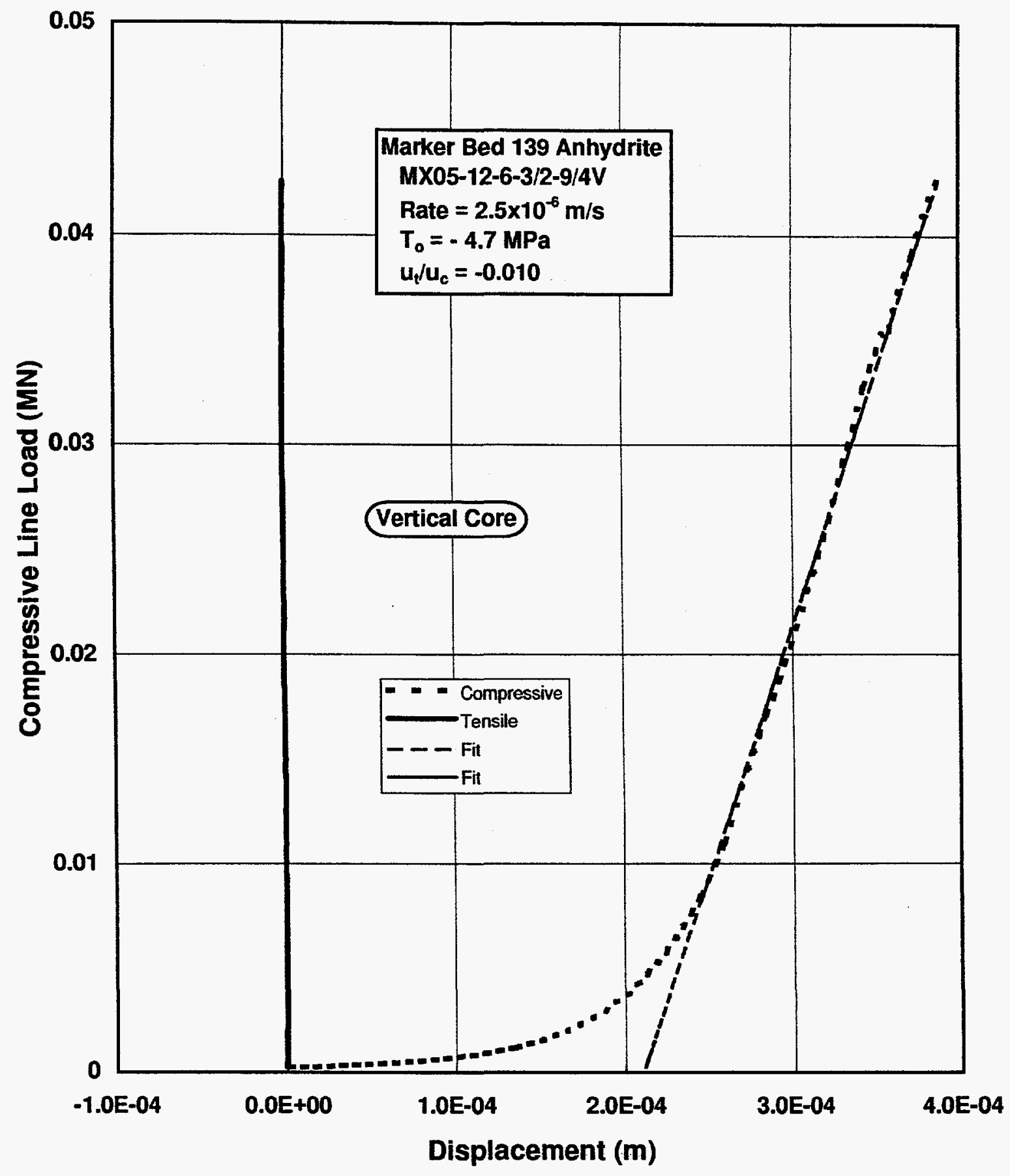

Figure E-15. Compressive and Tensile Displacements for Brazilian Indirect Tensile Strength Tests of WIPP Anhydrite, Specimen MX05-12-6-3/2-9/4V. 


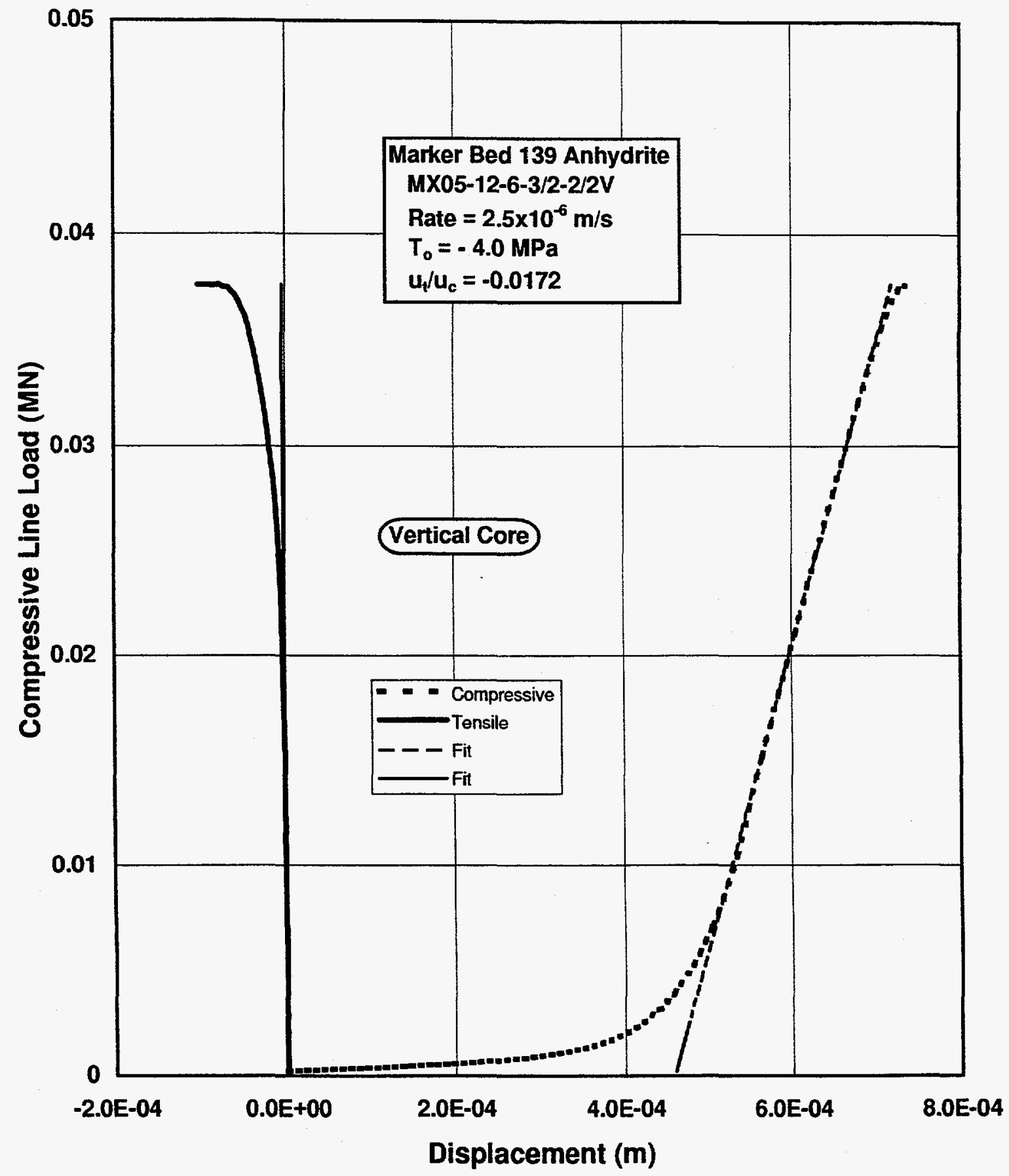

Figure E-16. Compressive and Tensile Displacements for Brazilian Indirect Tensile Strength Tests of WIPP Anhydrite, Specimen MX05-12-6-3/2-2/2V. 
This page intentionally left blank

E-18 


\section{APPENDIX F}

STRESS-STRAIN CURVES FOR TRIAXIAL COMPRESSIVE STRENGTH TESTS OF WIPP ANHYDRITE - SUPPLEMENTAL TESTING 


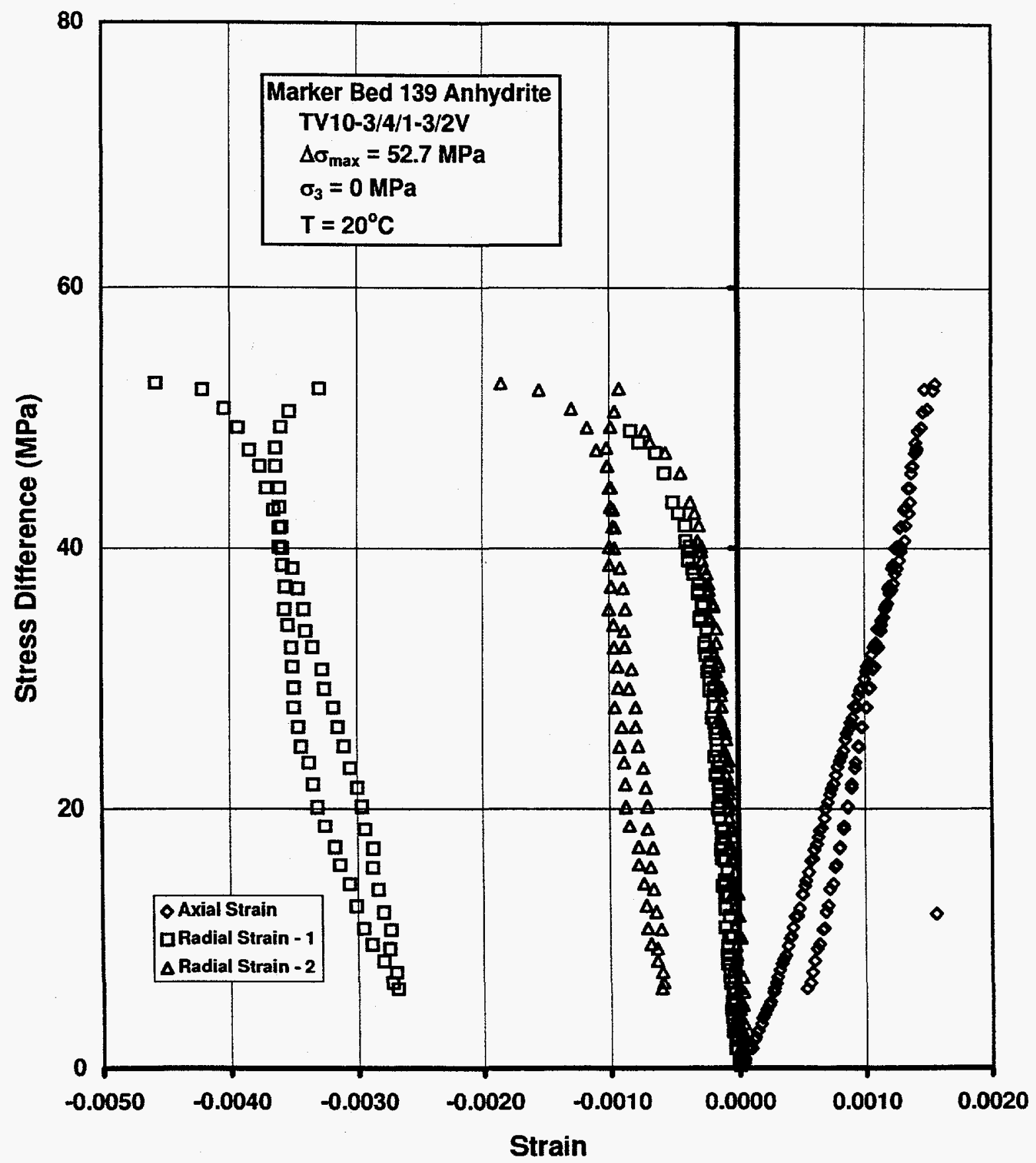

Figure F-1. Stress Difference Versus Axial and Radial Strain for a Triaxial Compression Test on WIPP Anhydrite at a Confining Pressure of $0 \mathrm{MPa}$, Specimen TV10-3/4/1-3/2V. 


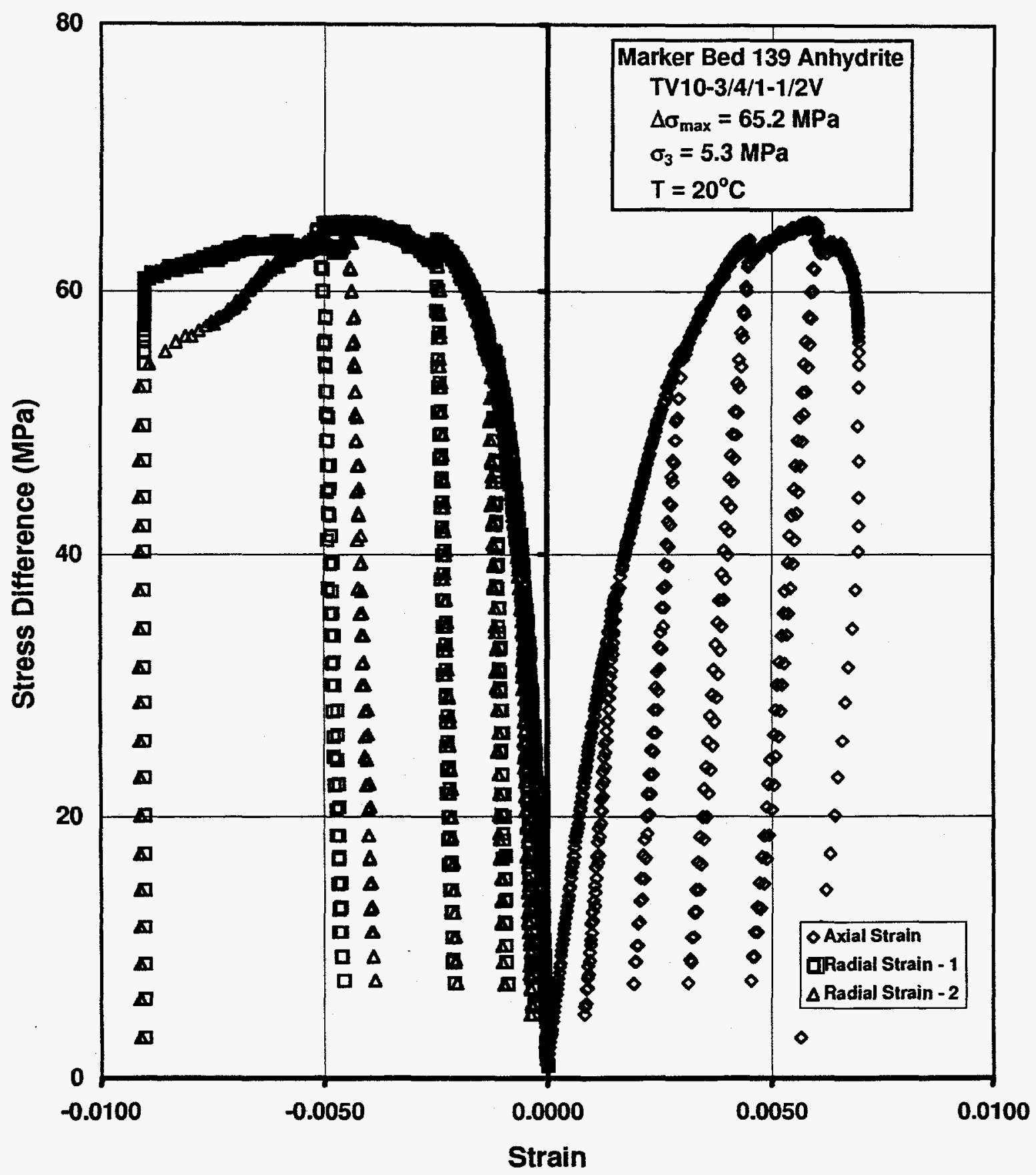

Figure F-2. Stress Difference Versus Axial and Radial Strain for a Triaxial Compression Test on WIPP Anhydrite at a Confining Pressure of 5.3 MPa, Specimen TV10-3/4/1$1 / 2 \mathrm{~V}$. 


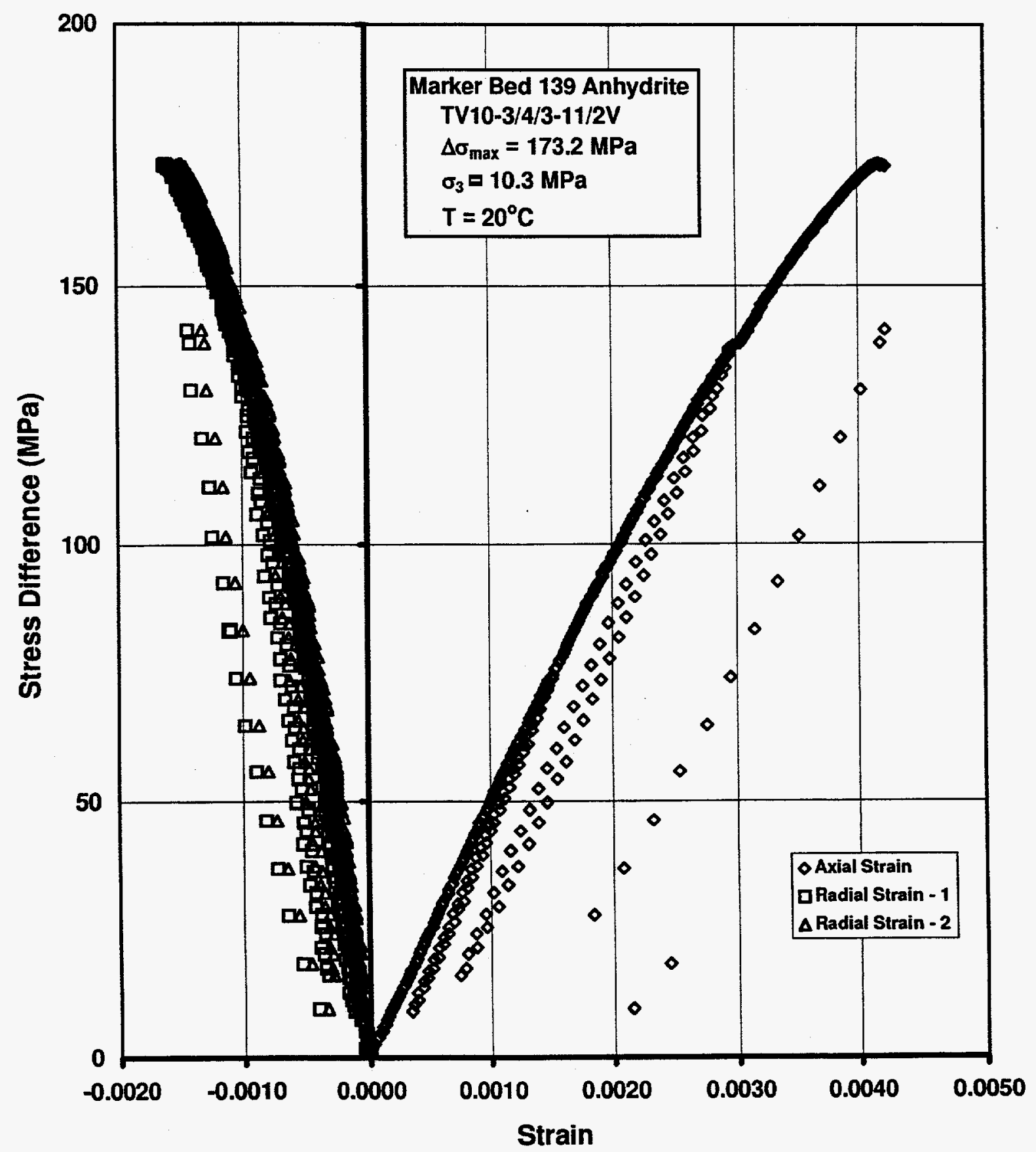

Figure F-3. Stress Difference Versus Axial and Radial Strain for a Triaxial Compression Test on WIPP Anhydrite at a Confining Pressure of $10.3 \mathrm{MPa}$, Specimen TV10-3/4/3$11 / 2 \mathrm{~V}$. 


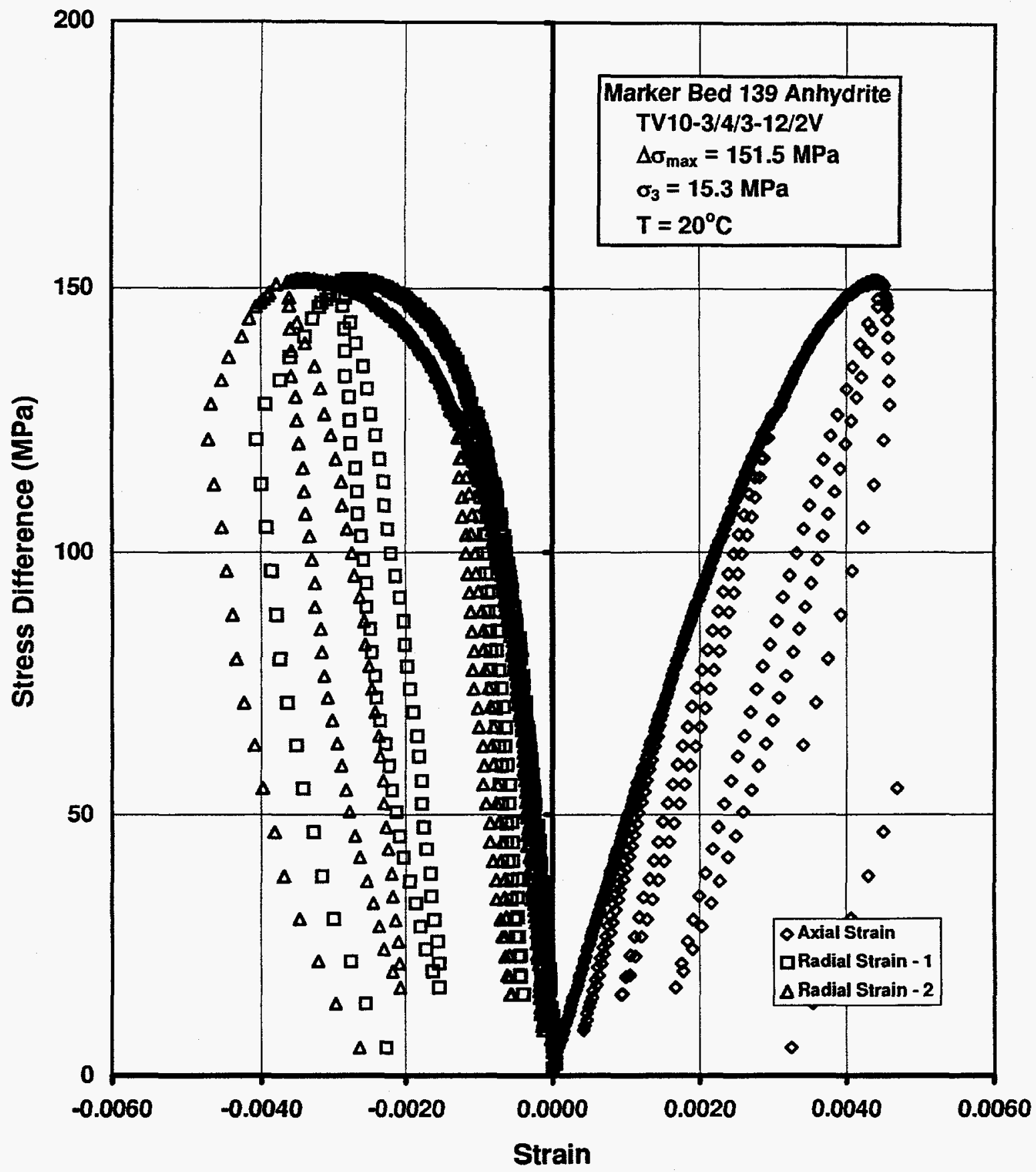

Figure F-4 Stress Difference Versus Axial and Radial Strain for a Triaxial Compression Test on WIPP Anhydrite at a Confining Pressure of 15.3 MPa, Specimen TV10-3/4/3$12 / 2 \mathrm{~V}$. 


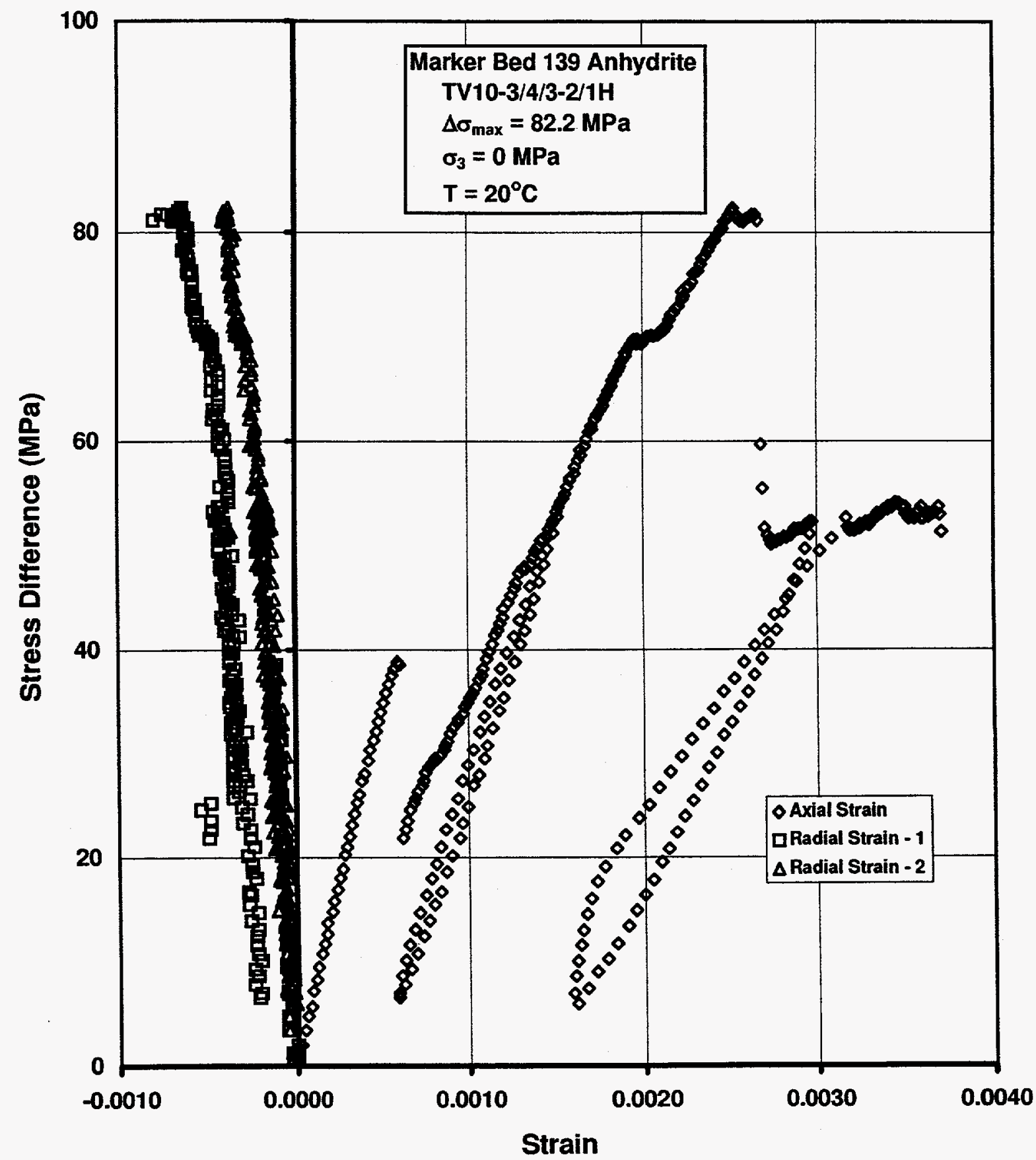

Figure F-5. Stress Difference Versus Axial and Radial Strain for a Triaxial Compression Test on WIPP Anhydrite at a Confining Pressure of $0 \mathrm{MPa}$, Specimen TV10-3/4/3-2/1H. 


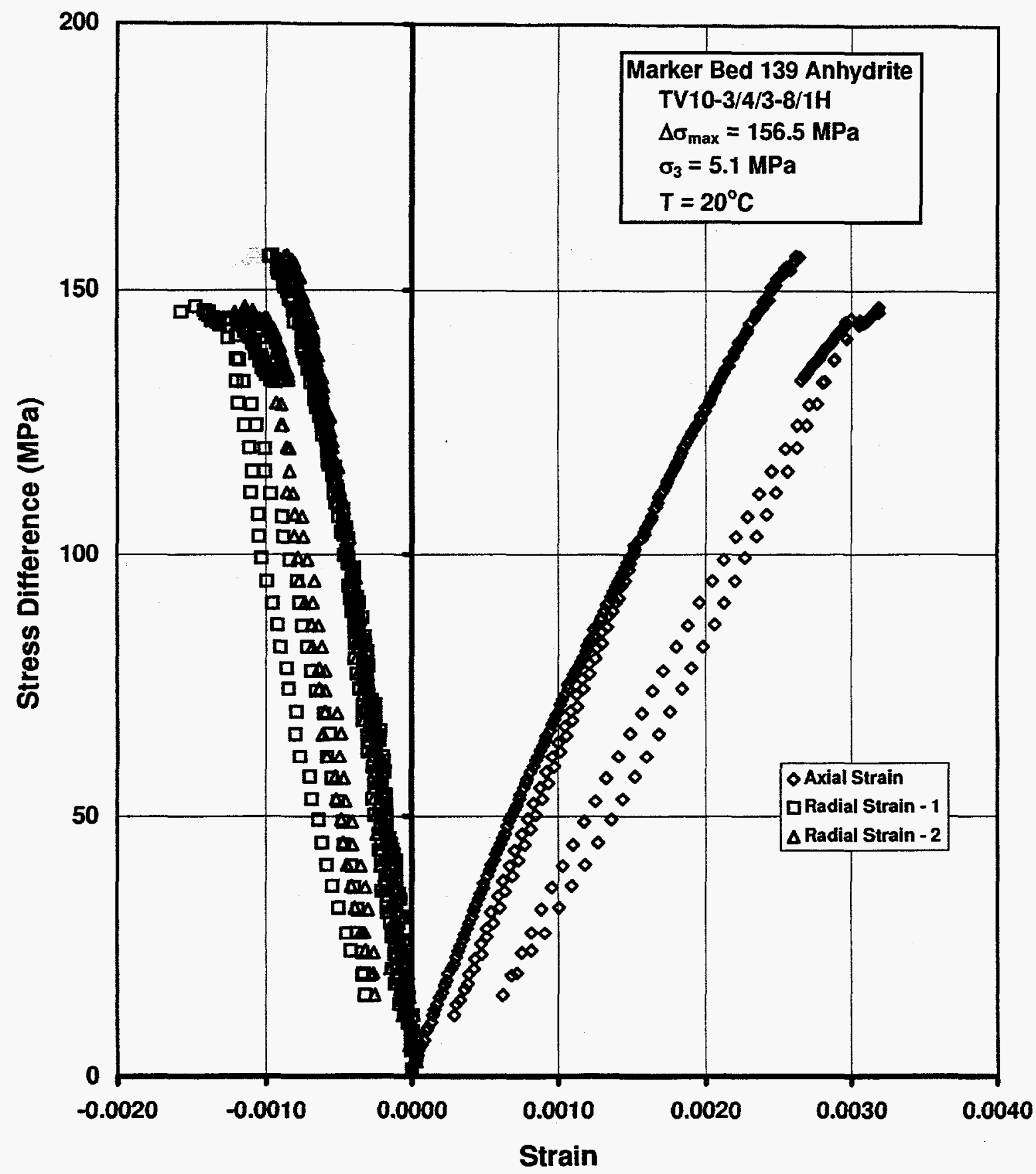

Figure F-6. Stress Difference Versus Axial and Radial Strain for a Triaxial Compression Test on WIPP Anhydrite at a Confining Pressure of 5.1 MPa, Specimen TV10-3/4/3$8 / 1 \mathrm{H}$. 


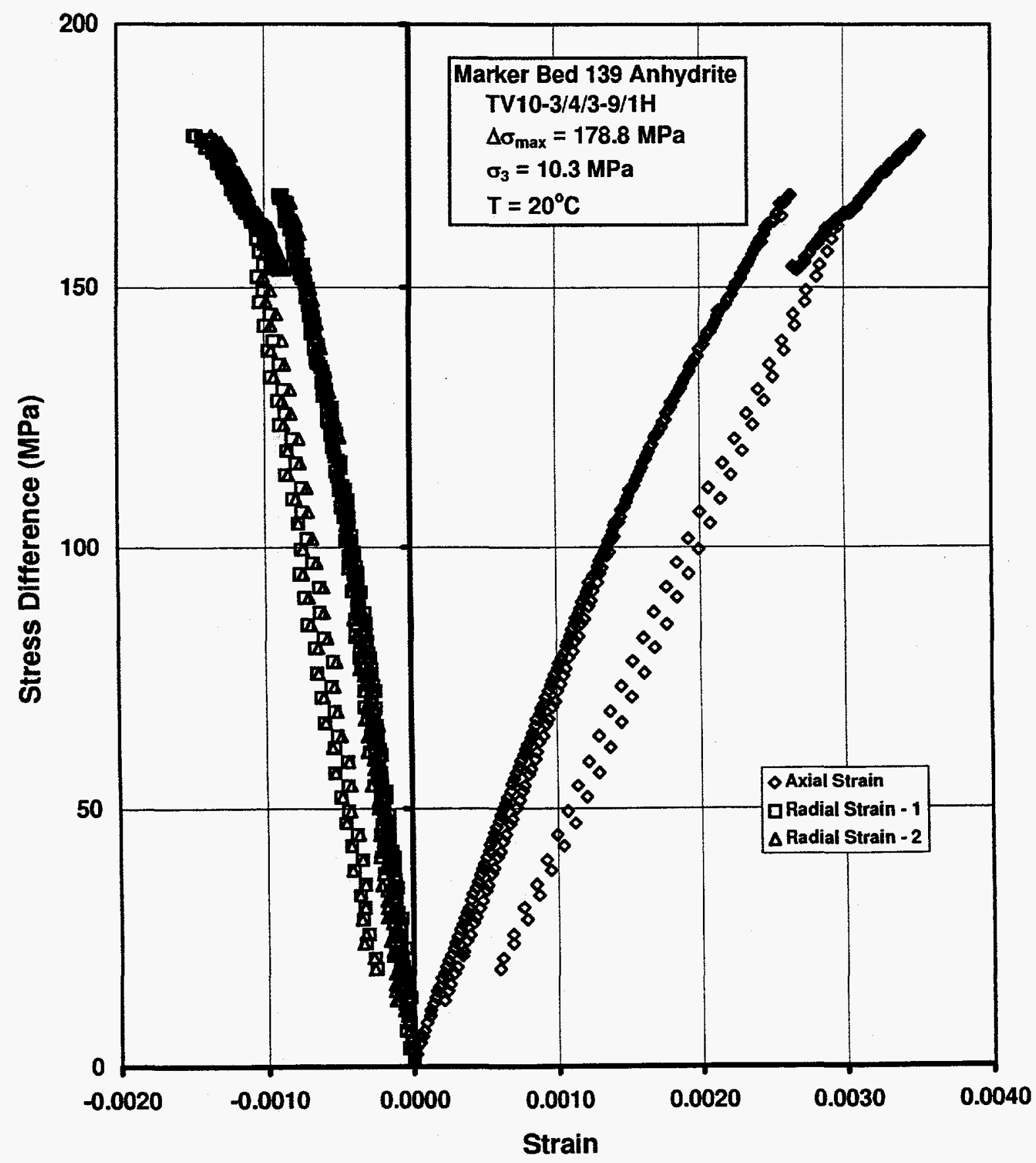

Figure F-7. Stress Difference Versus Axial and Radial Strain for a Triaxial Compression Test on WIPP Anhydrite at a Confining Pressure of $10.3 \mathrm{MPa}$, Specimen TV10-3/4/3$9 / 1 \mathrm{H}$. 


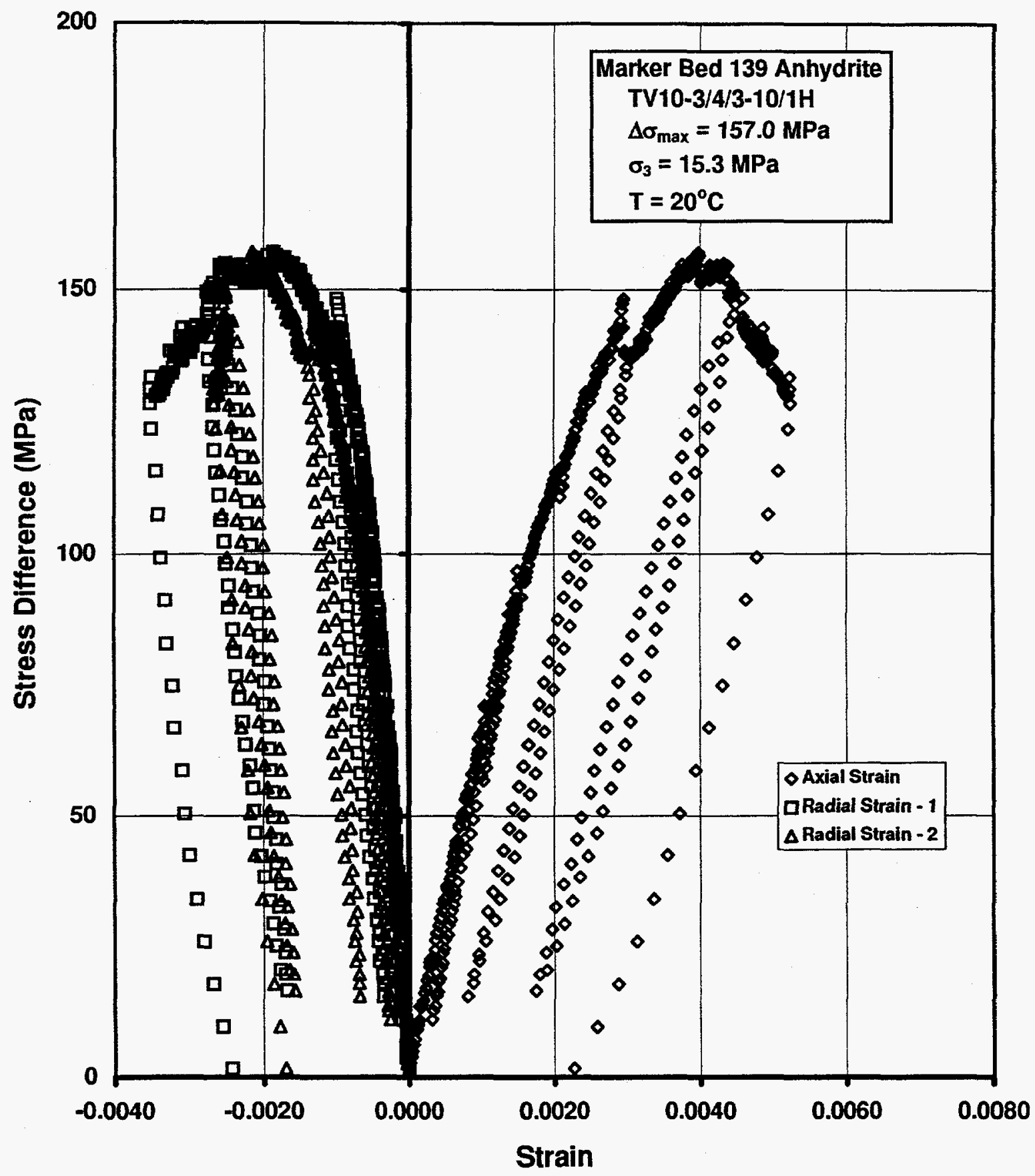

Figure F-8. Stress Difference Versus Axial and Radial Strain for a Triaxial Compression Test on WIPP Anhydrite at a Confining Pressure of $15.3 \mathrm{MPa}$, Specimen TV10-3/4/3$10 / 1 \mathrm{H}$. 


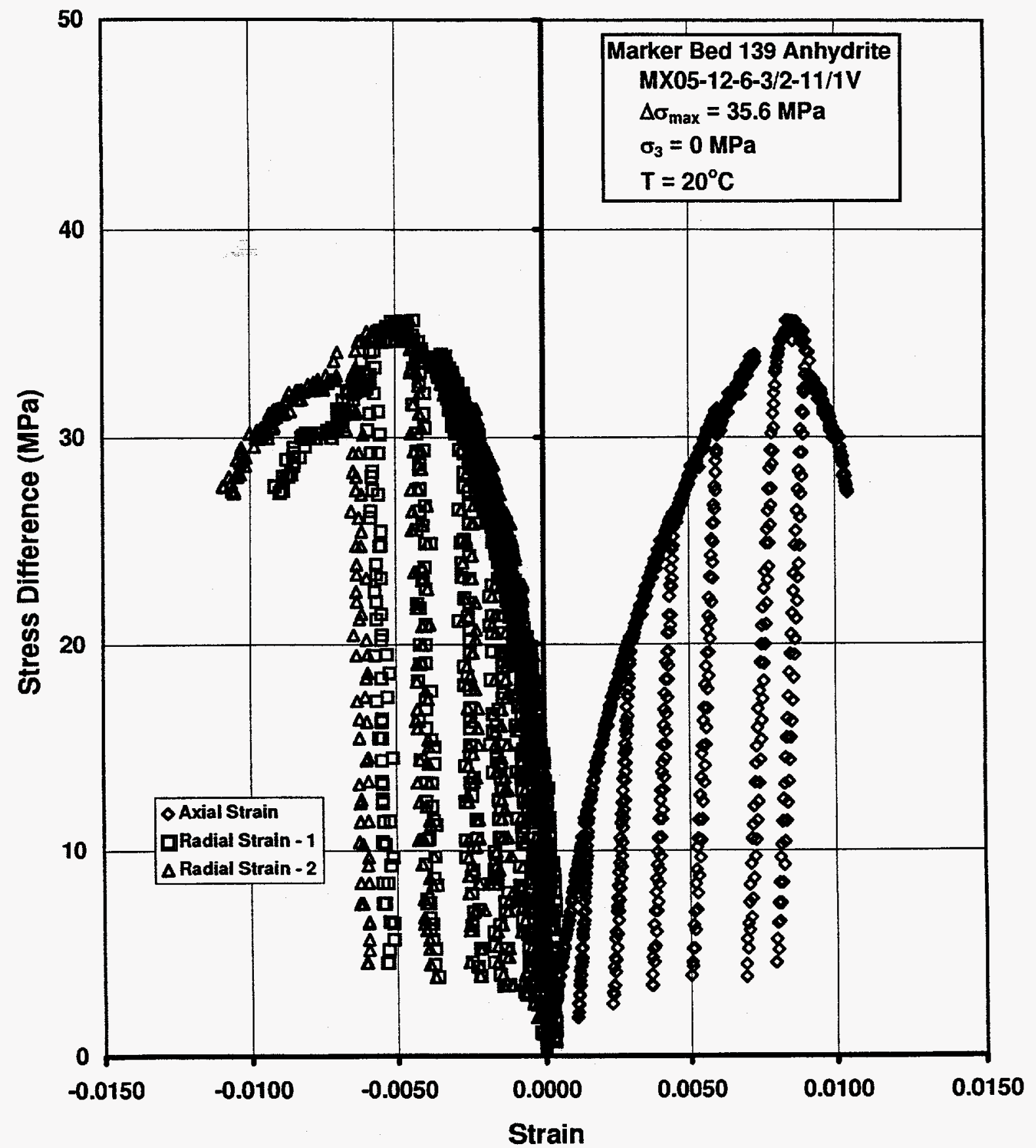

Figure F-9. Stress Difference Versus Axial and Radial Strain for a Triaxial Compression Test on WIPP Anhydrite at a Confining Pressure of 0 MPa, Specimen MX05-12-6-3/2$11 / 1 \mathrm{~V}$. 


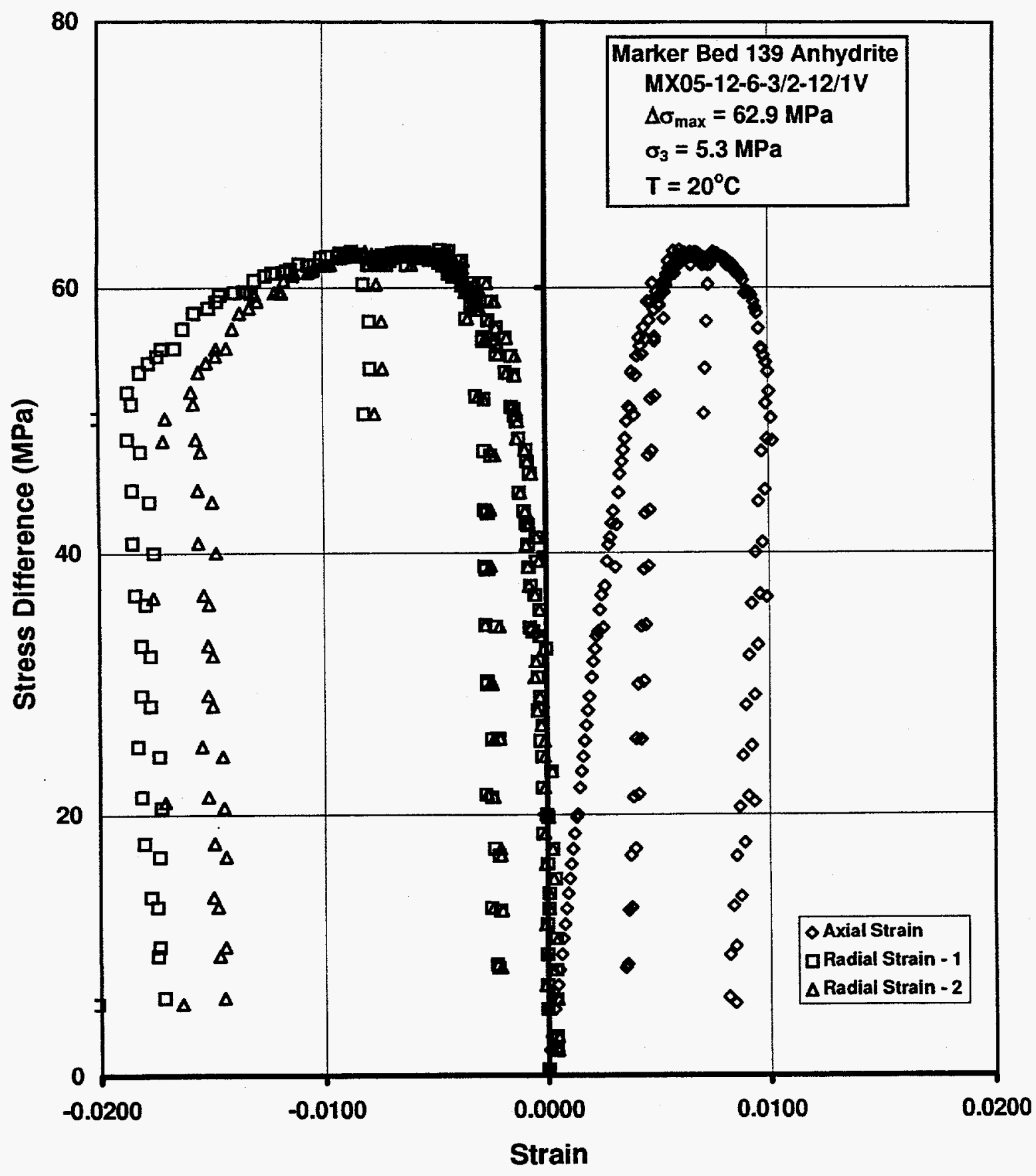

Figure F-10. Stress Difference Versus Axial and Radial Strain for a Triaxial Compression Test on WIPP Anhydrite at a Confining Pressure of 5.3 MPa, Specimen MX0512-6-3/2-12/1V. 


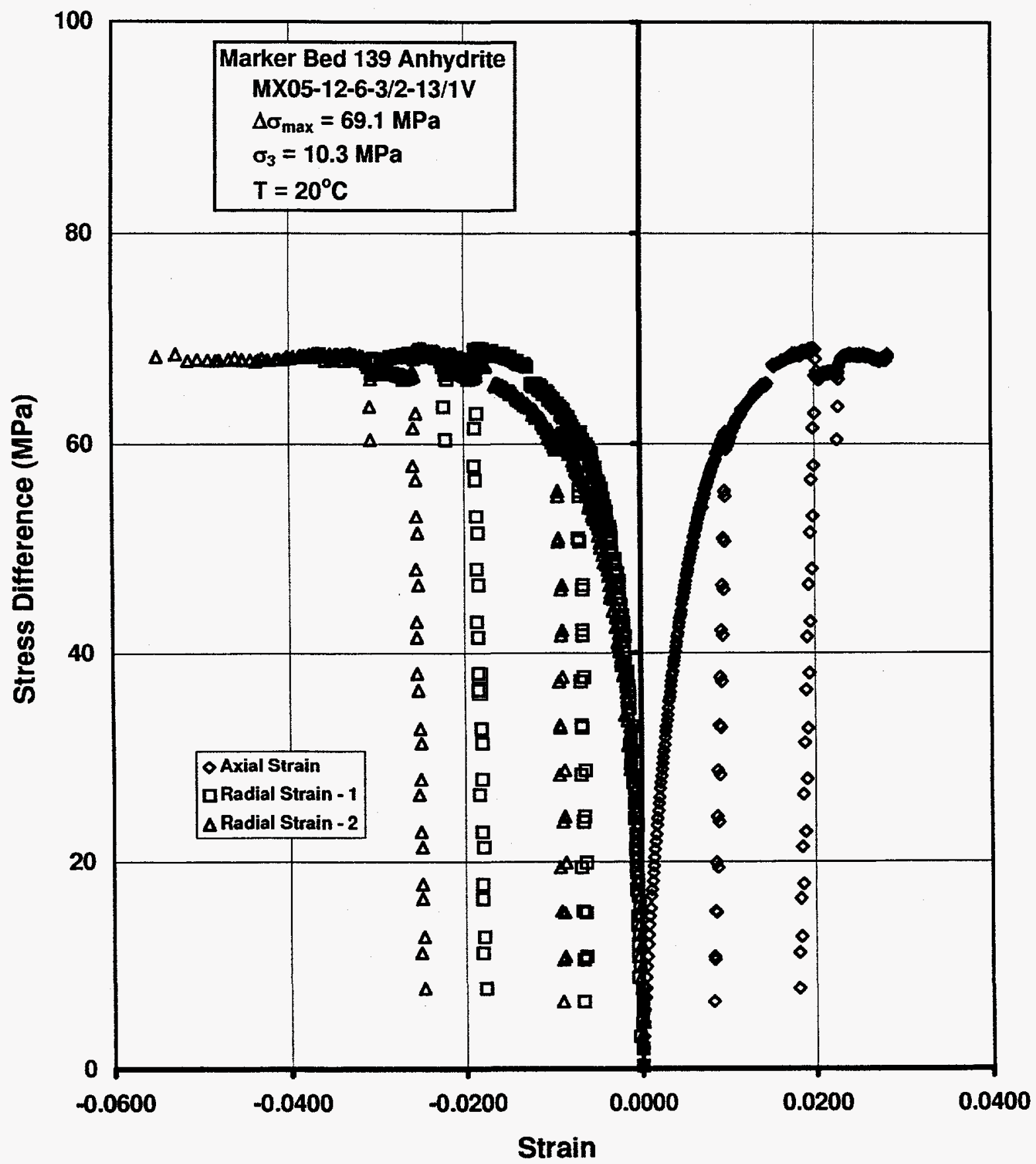

Figure F-11. Stress Difference Versus Axial and Radial Strain for a Triaxial Compression Test on WIPP Anhydrite at a Confining Pressure of $10.3 \mathrm{MPa}$, Specimen MX0512-6-3/2-13/1V. 


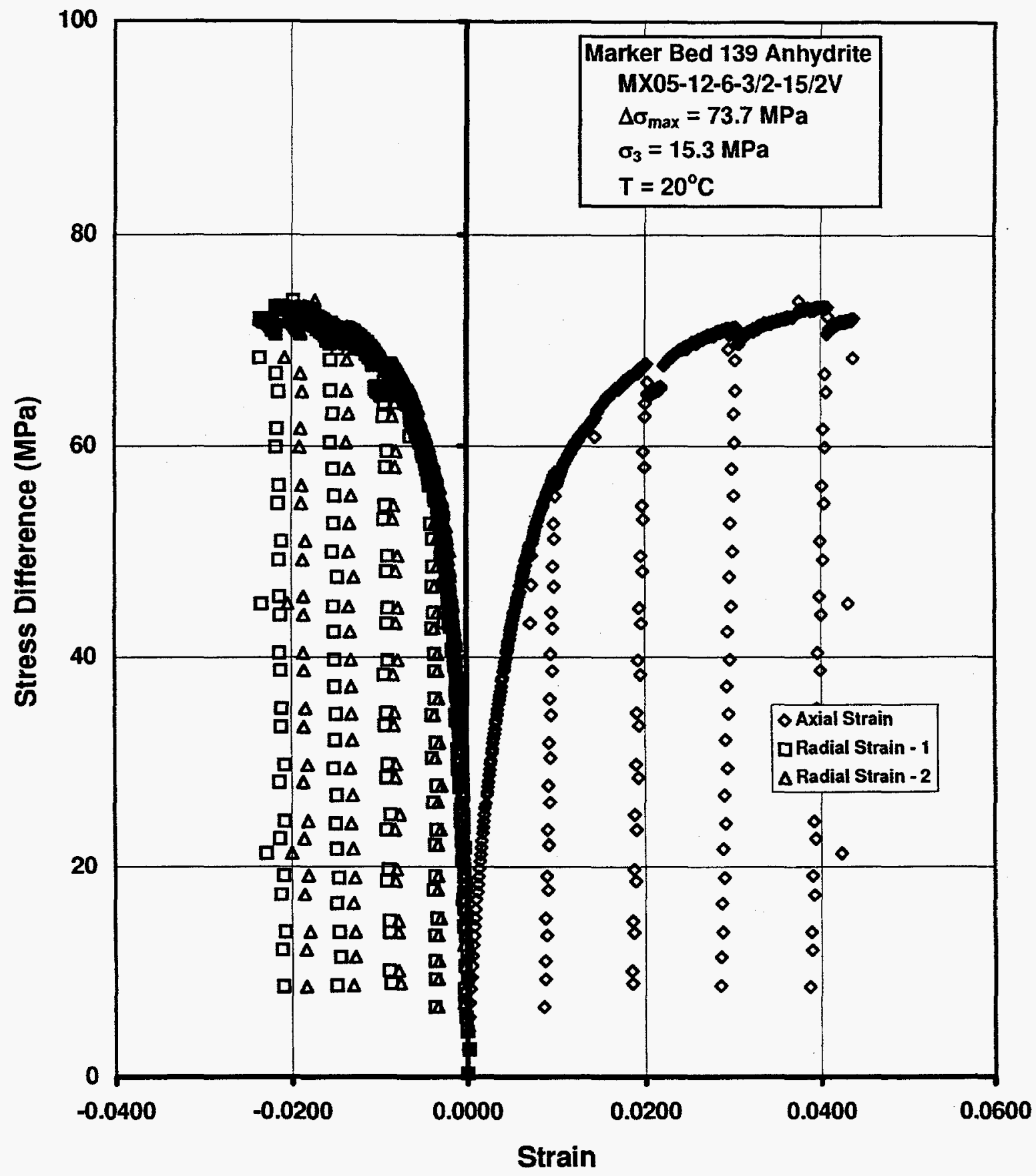

Figure F-12. Stress Difference Versus Axial and Radial Strain for a Triaxial Compression Test on WIPP Anhydrite at a Confining Pressure of $15.3 \mathrm{MPa}$, Specimen MX05$12-6-3 / 2-15 / 2 \mathrm{~V}$. 


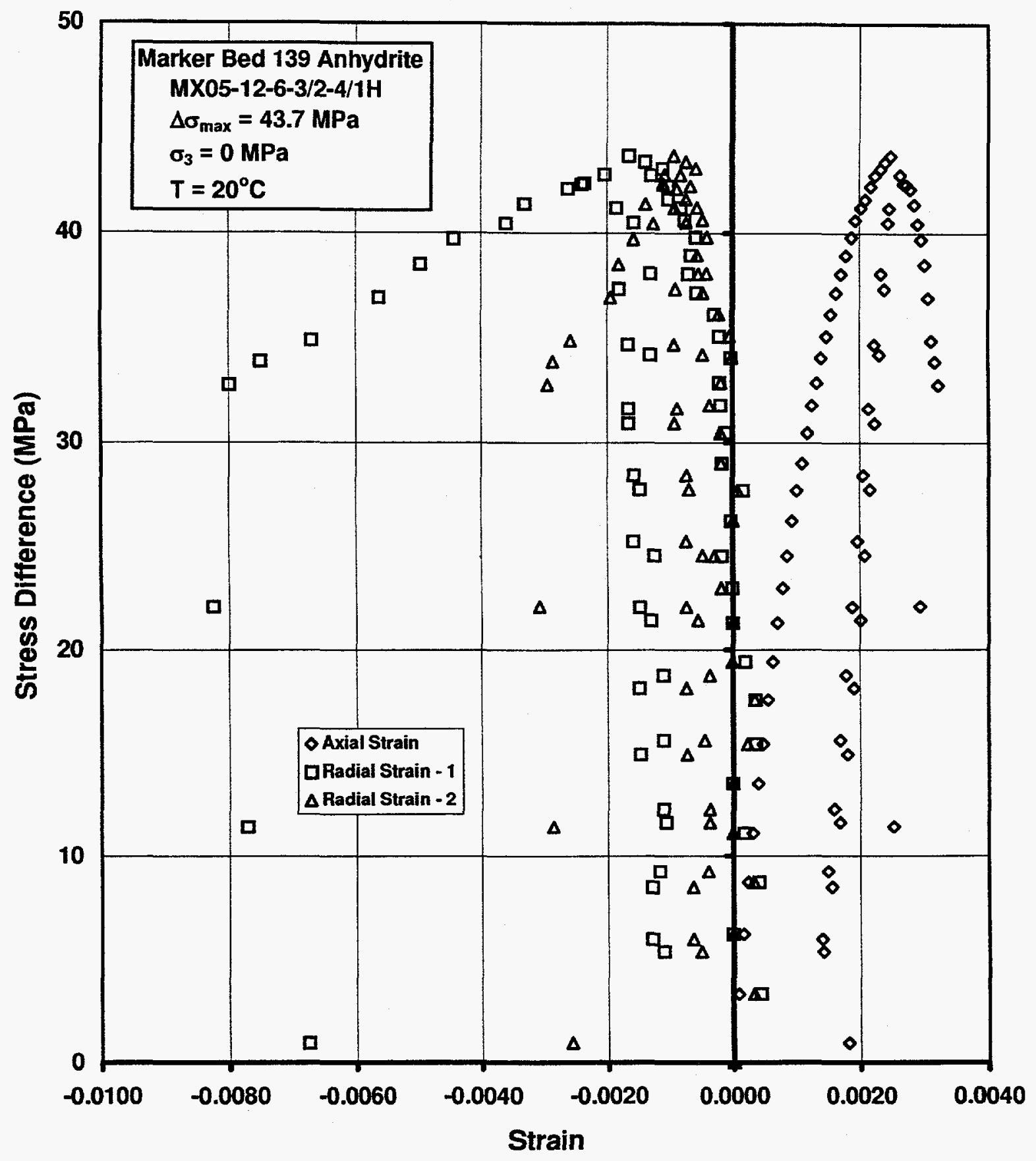

Figure F-13. Stress Difference Versus Axial and Radial Strain for a Triaxial Compression Test on WIPP Anhydrite at a Confining Pressure of $0 \mathrm{MPa}$, Specimen MX05-12$6-3 / 2-4 / 1 \mathrm{H}$. 


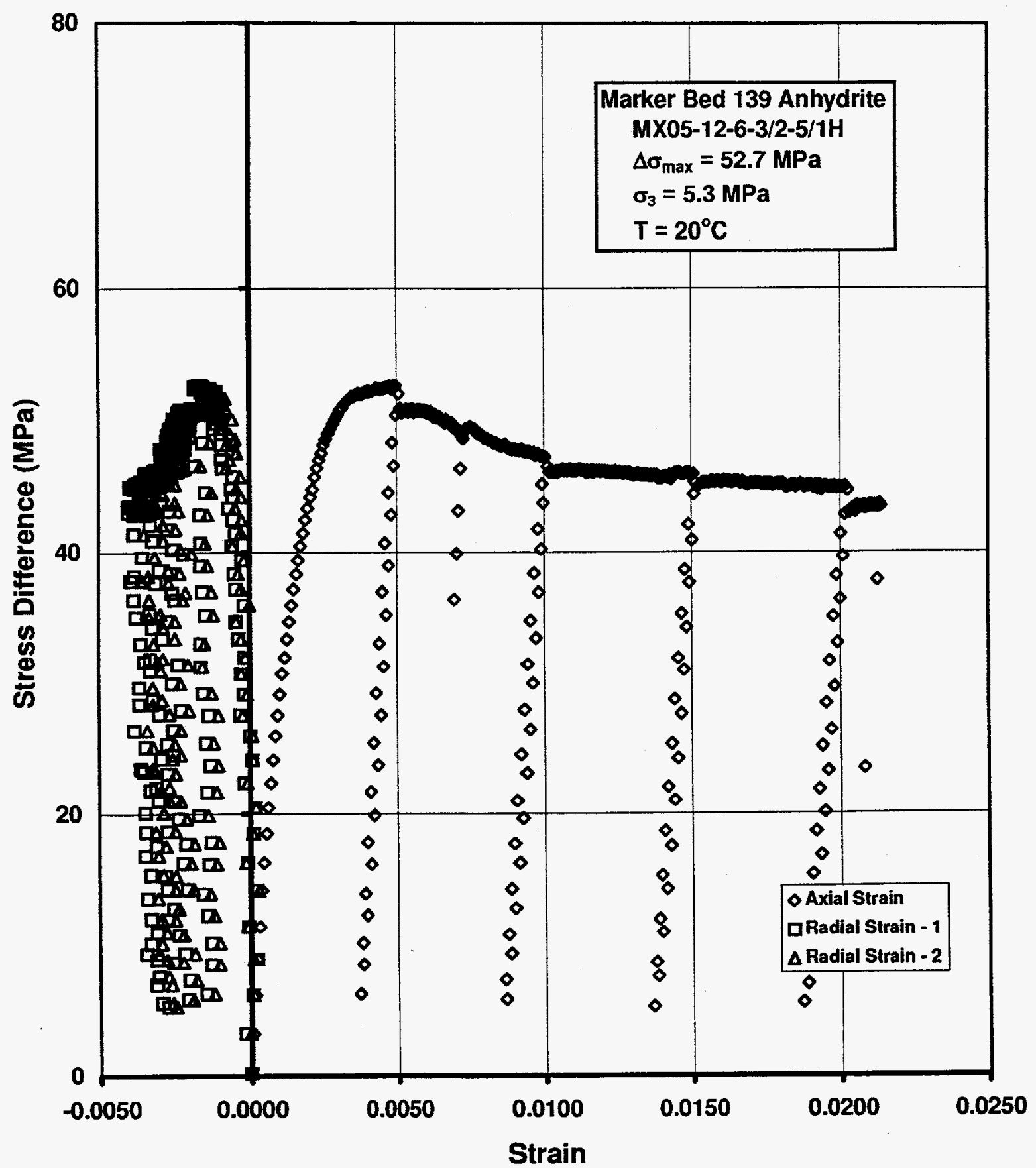

Figure F-14. Stress Difference Versus Axial and Radial Strain for a Triaxial Compression Test on WIPP Anhydrite at a Confining Pressure of 5.3 MPa, Specimen MX05$12-6-3 / 2-5 / 1 H$. 


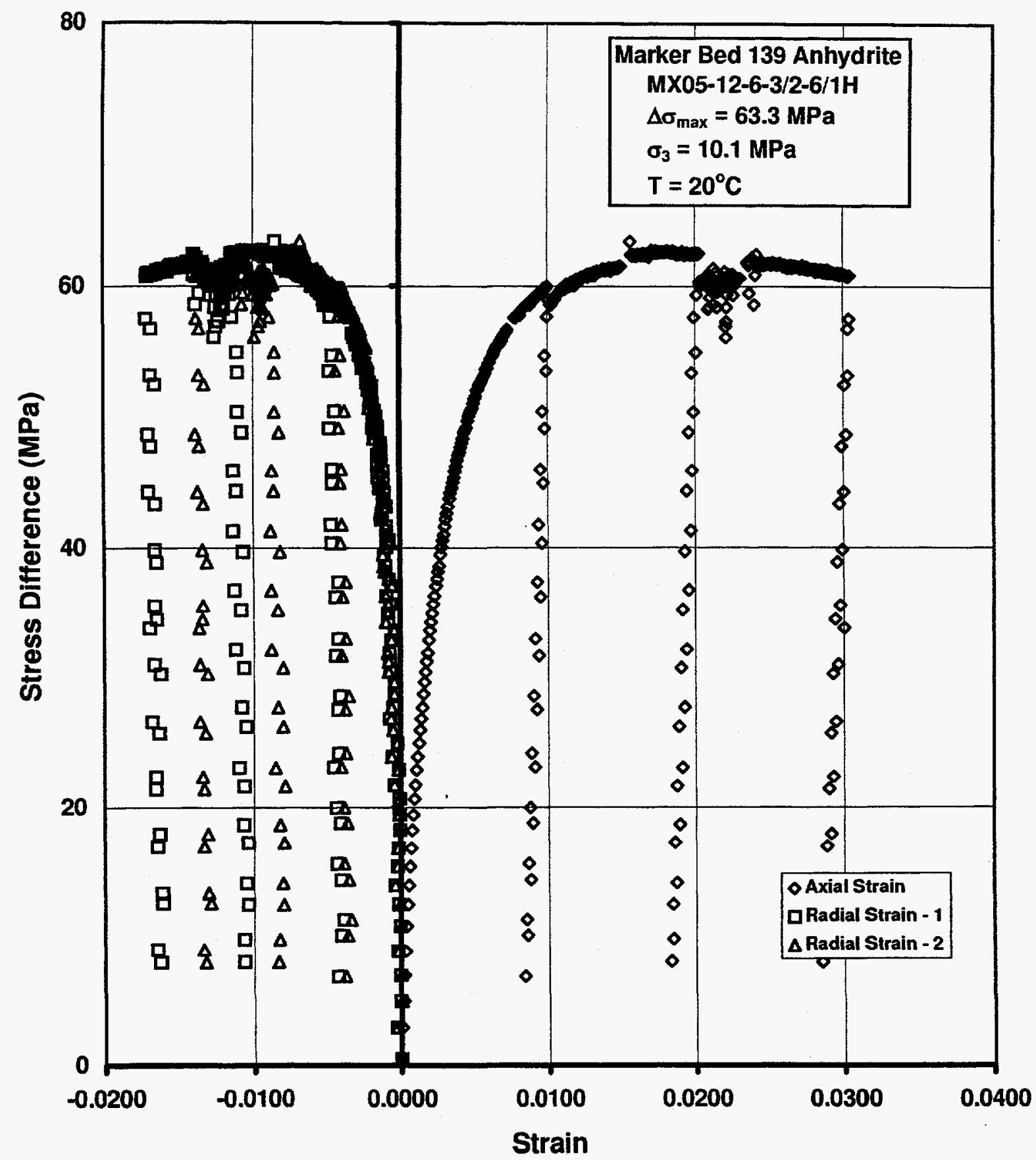

Figure F-15. Stress Difference Versus Axial and Radial Strain for a Triaxial Compression Test on WIPP Anhydrite at a Confining Pressure of $10.1 \mathrm{MPa}$, Specimen MX05$12-6-3 / 2-6 / 1 \mathrm{H}$. 


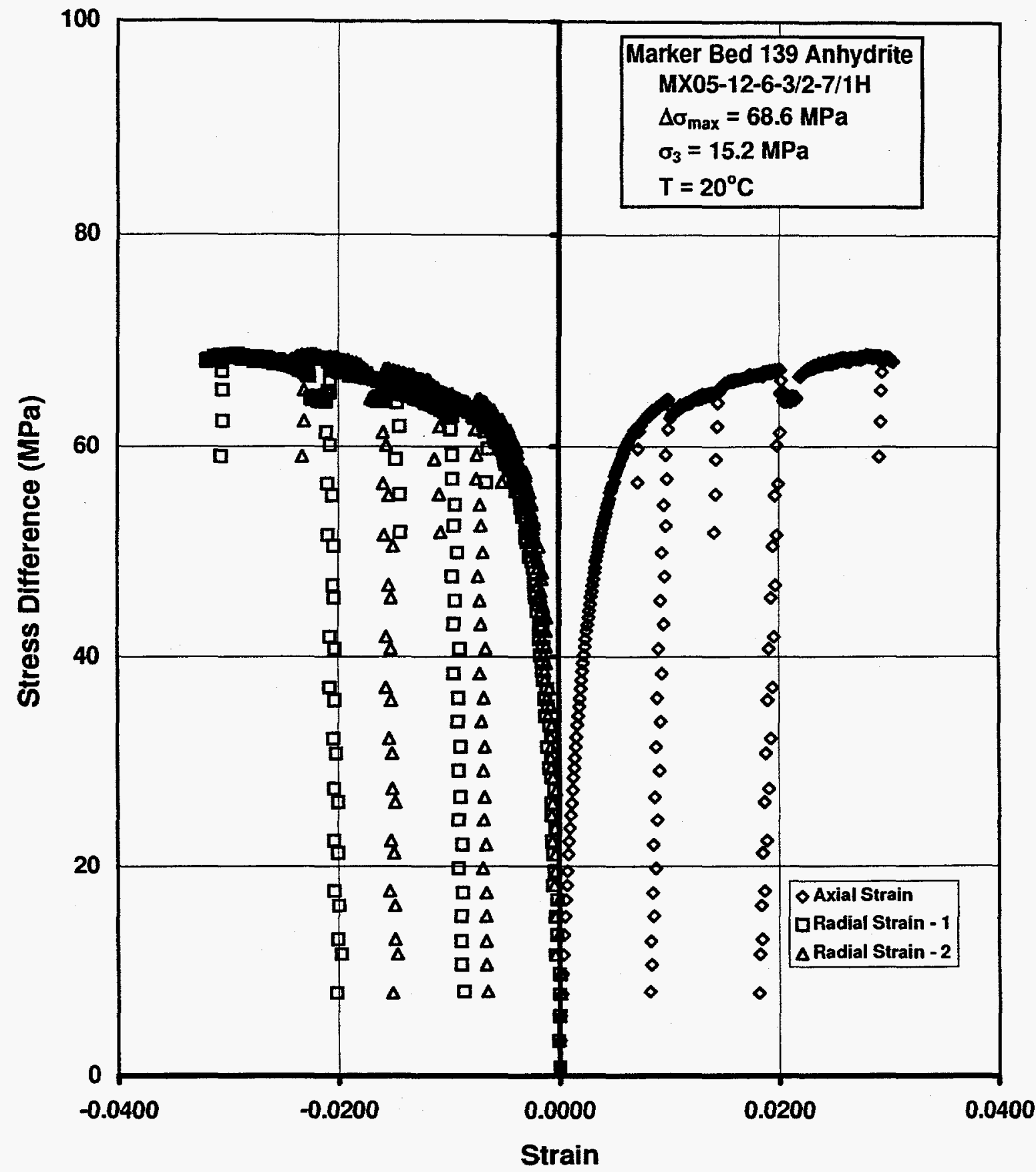

Figure F-16. Stress Difference Versus Axial and Radial Strain for a Triaxial Compression Test on WIPP Anhydrite at a Confining Pressure of $15.2 \mathrm{MPa}$, Specimen MX05$12-6-3 / 2-7 / 1 \mathrm{H}$. 
This page intentionally left blank

$$
\text { F-18 }
$$

